\title{
Chicken eggshell powder in nutritional intervention of age related bone loss
}

Citation for published version (APA):

Schaafsma, A. (2000). Chicken eggshell powder in nutritional intervention of age related bone loss. [Doctoral Thesis, Maastricht University]. Universitaire Pers Maastricht. https://doi.org/10.26481/dis.20000629as

Document status and date:

Published: 01/01/2000

DOI:

10.26481/dis.20000629as

Document Version:

Publisher's PDF, also known as Version of record

\section{Please check the document version of this publication:}

- A submitted manuscript is the version of the article upon submission and before peer-review. There can be important differences between the submitted version and the official published version of record.

People interested in the research are advised to contact the author for the final version of the publication, or visit the DOI to the publisher's website.

- The final author version and the galley proof are versions of the publication after peer review.

- The final published version features the final layout of the paper including the volume, issue and page numbers.

Link to publication

\footnotetext{
General rights rights.

- You may freely distribute the URL identifying the publication in the public portal. please follow below link for the End User Agreement:

www.umlib.nl/taverne-license

Take down policy

If you believe that this document breaches copyright please contact us at:

repository@maastrichtuniversity.nl

providing details and we will investigate your claim.
}

Copyright and moral rights for the publications made accessible in the public portal are retained by the authors and/or other copyright owners and it is a condition of accessing publications that users recognise and abide by the legal requirements associated with these

- Users may download and print one copy of any publication from the public portal for the purpose of private study or research.

- You may not further distribute the material or use it for any profit-making activity or commercial gain

If the publication is distributed under the terms of Article $25 \mathrm{fa}$ of the Dutch Copyright Act, indicated by the "Taverne" license above, 
Chicken Eggshell Powder in Nutritional Intervention of Age Related Bone Loss

(.) Anne Schaafsma, Leeuwarden 2000

ISBN 905278.2601

Vormgeving:

Anne Schaafsma \& Anneke Boringa-Heins.

Omslagidee:

Rieteke Tigchelaar-Schaafsma, Iwan Pakan \& Anne Schaafsma

Omslagrealisatie:

Rieteke Tigchelaar-Schaafsma

Druk:

Datawyse I Universitaire Pers Maastricht 


\title{
Chicken Eggshell Powder in Nutritional Intervention of Age Related Bone Loss
}

\author{
PROEFSCHRIFT \\ ter verkrijging van de graad van doctor \\ aan de Universiteit Maastricht \\ op gezag van de Rector Magnificus, \\ Prof.dr. A.C. Nieuwenhuijzen Kruseman \\ volgens het besluit van het College van Decanen, \\ in het openbaar te verdedigen \\ op donderdag 29 juni 2000 om 14.00 uur \\ door
}

\section{Anne Schaafsma}




\section{Promotor}

Prof.dr. W.H.M. Saris

Co-promotor

dr. F.A.A. Muskiet (Academisch Ziekenhuis Groningen)

\section{Beoordelingscommissie}

Prof. dr. G. Hornstra (voorzitter)

Prof. dr. G.J. Dinant

Prof. dr. J.G.A.J. Hautvast (Wageningen Universiteit)

dr. C.J. Netelenbos (Academisch Ziekenhuis van de Vrije Universiteit Amsterdam)

$d r$. C. Vermeer 


\section{Contents}

\section{Abbreviations}

1. Bone metabolism, role of nutrition and outline of this thesis

2. Delay of natural bone loss by higher intakes of specific minerals and vitamins

3. Mineral, amino acid and hormonal composition of chicken eggshell powder to evaluate its use in human nutrition

4. Eggshell powder, a comparable or better source of calcium than purified calcium carbonate: piglet studies

5. Short term effects of a chicken eggshell powder enriched dairy-based product on bone mineral density in persons with osteoporosis or osteopenia; a pilot study.

6. Supplementation of healthy, Dutch postmenopausall women with minerals and vitamins; positive effects of enriched chicken eggshell powder on bone mineral density of the femoral neck

7. Effects of an eggshell powder enriched dairy-based supplement on bone mineral density of postmenopausal women with low bone mass.

8. Vitamin $\mathrm{D}_{3}$ and vitamin $\mathrm{K}_{1}$ supplementation of Dutch postmenopausal women with normal and low bone mineral densities: effects on serum 25-hydroxyvitamin $D$ and carboxylated osteocalcin

9. General discussion

References

Summary

Samenvatting

Dankwoord

Curriculum vitae

Publications 


\section{Abbreviations}

AP:

anteroposterior

b-ALP: $\quad$ bone specific alkaline phosphatase

BMD: $\quad$ bone mineral density $\left(\mathrm{g} / \mathrm{cm}^{2}\right)$

\%carbOC: percent carboxylated osteocalcin of total osteocalcin

CPLX:

CPPS:

complexed acidic phospholipids

DEXA:

caseinophosphopeptides

D-Pyr:

dual energy $X$-ray absorptiometry

ESP or ES:

deoxypyridonoline

HRT:

IU:

Octot:

P1NP:

PTH:

eggshell powder

hormone replacement therapy

international units

osteocalcin total

amino-terminal propeptide extension of type I collagen

parathyroid hormone

25(OH)D: $\quad$ 25-hydroxyvitamin $\mathrm{D}$ or calcidiol

$1,25(\mathrm{OH})_{2} \mathrm{D}: \quad 1,25$-dihydroxy vitamin $\mathrm{D}$ or calcitriol

TGF $\beta$ :

$\mathrm{u}-\mathrm{Ca} / \mathrm{Cr}$ :

IL:

$\mathrm{PGE}_{2}$ :

PUFA:

DBP:

VDR:

IGF:

ECF:

transforming growth factor $-\beta$

urinary calcium/creatinine ratio

interleukin

prostaglandin $\mathrm{E}_{2}$

polyunsaturated fatty acids

vitamin $\mathrm{D}$ binding protein

vitamin $D$ receptor

insulin-like growth factor

Erratum page 6:

Humerus $=$ Femur

extra cellular fluid

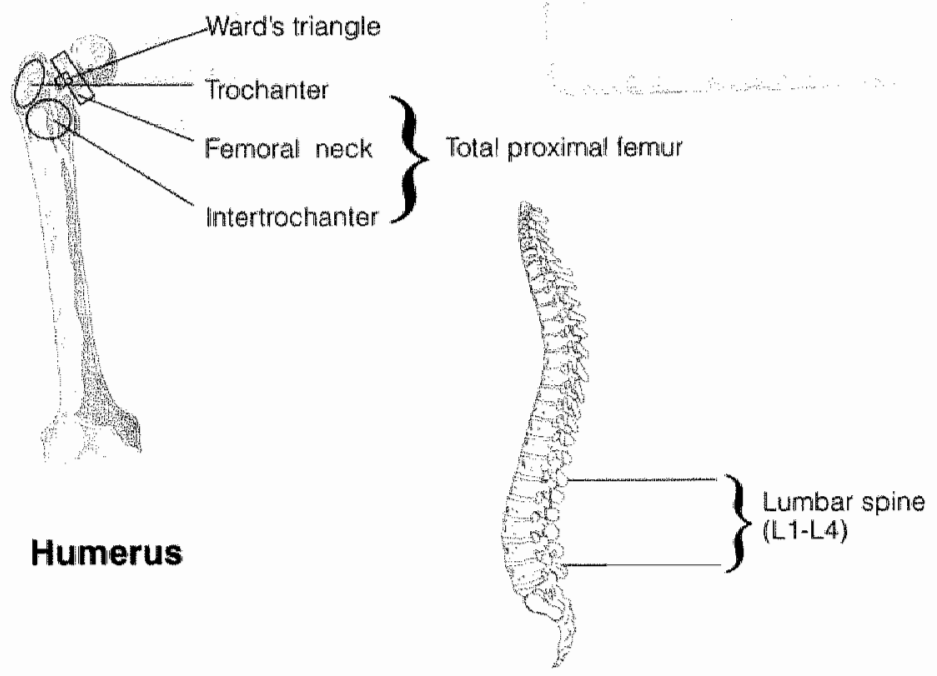

Vertebral column

Rough indication of sides at the humerus and spine where BMD measurements took place 


\section{Bone metabolism, role of nutrition and outline of this thesis}

\section{Introduction}

Nutrition is a strong determinant in the evolution of the human species, the socalled substrate-driven change (Crawford and Marsh 1989). The typically dietary patterns restricted to certain locations and populations have resulted in a strong genetic selection. Changes in those nutritional patterns because of increasing world-wide mobility and exchangeability, and increased life expectancy result in disclosure of age-related diseases and the genetic influences linvolved (Eastwood 1997). Osteoporosis is such an age-related disease. Bone is a large nutrient reserve for elements such as calcium, phosphorus, and magnesium. Keeping the plasma calcium concentration within narrow limits, therefore, is a process, which may be at the expense of bone. Furthermore, bone minerals are lost because of a decreased synthesis of gonadal hormones, a decreased intestinal absorption of nutrients, loss of kidney function and reduced physical activity at older age. Prevention of this bone loss, however, is likely to be a more effective strategy than treating osteoporosis. In ancient times, daily calcium intake of stone-age adults possibly was considerably higher than current Western intakes (Eaton 1997; Eaton 1996; Barger-Lux and Heaney 1994) and serum 25-hydroxyvitamin D [25(OH)D] levels probably were much higher than nowadays (Vieth 1999; Heaney 1996). These conditions at least did not stimulate the human species to develop an economical calcium metabolism. In contrast, calcium is easily lost and absorption is limited to protect against high intakes (Barger-Lux and Heaney 1994). The increasing incidence of osteoporotic fractures as a result of the increasing number of elderly with about $150 \%$ in Europe and over $200 \%$ in all other regions (World Health Organization 1998), makes insight in the nutritional possibilities of correction and prevention of osteoporosis very important.

\section{Bone metabolism}

\section{Osteoblasts, osteoclasts and osteocytes}

Bone cells are the regulators of bone metabolism in response to various environmental signals. The three cell types involved are osteoblasts, osteoclasts and osteocytes. The mononucleated osteoblasts (bone forming cells) synthesize osteoid (unmineralised collagen and other non-collagenous proteins), which calcifies to form bone (Puzas 1993; Reeve 1988; Lian and Stein 1995; Manten 1996).

The plasma membrane of the osteoblast is characteristically rich in alkaline phosphatase (Baron 1993).

The giant multinucleated osteoclasts (bone resorbing cells) are formed by fusion of mononuclear precursors, a process stimulated by calcitriol (1,25-dihydroxyvitamin $\mathrm{D}_{3}$ ) and parathyriod hormone (PTH) (Manten 1996; Mundy 1993; Reichel 1989).

The maturation of the precursor cells is probably stimulated by caicitriol anid by neuro-hormones (catecholamines) (Frediani 1996; Reichel 1989), Osteoblasts can activate osteoclasts in the presence of PTH (Dempster and Lindsay 1993) and transforming growth factor $\beta$ (TGF 3 ), possibly by the active production of fibronectin (Robey and Boskey 1995). A strong inhibitor of osteoclasts is 
calcitonim (Dempster and Lindsay 1993). Osteocyles are osteoblasts, which are trapped in bone during bone formation (Calvo 1996). Due to the encasement and lack of nutrient supply; the metabolic activity of the cell decreases dramatically. Gas and nutrients exchange through small canals known as canaliculi (Puzas 1993). In concert with calciotropic hormones, osteocytes regulate the balance of minerals between bone and blood, and participate in bone growth, modeling and remodeling (Calvo 1996). Lining cells, which cover bone surfaces, are also derived from the osteoblasts. The initiation of bone resorption depends on retraction of these lining cells, a process, which is probably stimulated by PTH (Baron 1993; Bronner 1994; Dempster and Lindsay 1993).

\section{Bone formation}

Bone has multiple functions among which mechanical support, attachment of muscles, weightbearing, protection and participation in calcium homeostasis are the most important (Boskey 1988). Adult bone consists of $60 \%$ (by weight) calcium salts, $30 \%$ collagen fibrils and $10 \%$ water and other compounds (Groot and Vermeer 1988). A thick and dense layer (the cortex) of cortical (compact) bone forms the external part of bones. Towards the metaphysis and the epiphysis, the cortex becomes progressively thinner and the internal space is filled with trabecular (spongy) bone (Wood and Fleet 1998; Baron 1993). Cortical rich parts of the hip, femoral neck and trochanter also contain some trabecular bone (Wood and Fleet 1998; Baron 1993). Most of trabecular bone is found in the axial skeleton (Fallon 1994; Peel and Eastell 1995).

The main trabeculae line up along the major axes of force to which the bone is subjected during development (Heaney 1993). About $20 \%$ of mature skeleton mass consist of trabecular bone and $80 \%$ is cortical bone (Fallon 1994).

Cortical and trabecular bone constitutes of the same cells and matrix elements, but have structural and functional differences: $80-90 \%$ of the volume of compact bone is calcified versus $15-25 \%$ in trabecular bone (Baron 1993). The cavities in the trabecular network contain the bone marrow, connective tissue, and blood vessels (Spiers 1988; Baron 1993). In adults, bone marrow adipocytes are able to express aromatase, a cytochrome P450 enzyme, which converts circulating androgens into estrone or oestradiol (Gimble 1996). This is important under pathological conditions, such as fractures, to counteract the osteoclast stimulating cytokines [such as interleukin (IL) -1, IL-6, and IL-8] which increase as a result of the fracture (Lea 1997).

The growth in length of long bones takes place in the epiphyseal growth plate (Krefting 1993). After epiphyseal closure of the bones, additional mineral deposits during a period of consolidation (Calvo 1996). Cessation of bone growth, but also the onset of bone loss, seems to occur at an earlier age at the hip than at the spine (Hui 1999). At older age, bone structure changes (Cuijpers 1997): crystals increase in size and/or perfection, the number and location of extraneous ions (e.g. $\mathrm{CO}_{3}, \mathrm{Mg}$, $\mathrm{Na}$ ) changes, and the ratio $\mathrm{Ca} / \mathrm{P}$ increases from a value 1.3 to a value close to 1.7. Size and chemistry of hydroxyapatite crystals, their changes in orientation and solubility, and the way they pack with the collagen and noncollagenous proteins to create a composite material, influence static properties of bone and the dynamics of change induced by bone cells in this tissue (Grynpas 1993).

Apart from calcium, vitamin D and other vitamins and minerals, essential polyunsaturated fatty acids (especially $\alpha$ linolenic acid) and arginine may be important in bone formation. Essential fatty acids are necessary for an appropriate 
biosynthesis of acidic phospholipids present in the membrane of matrix vesicles. These vesicles are involved in the initiation of mineralization in all calcifying tissues, supplying hydroxyapatite crystals and specific enzymes such as alkaline phosphatase (Seifert and Watkins 1997; Termine 1993; Boskey 1988). Furthermore, it is presumed that especially $n-3$ fatty acids and conjugated linoleic acid lower the amounts of linoleic and arachidonic acid in bone and as a consequence also the amounts of prostaglandin $E_{2}\left(P G E_{2}\right)$ The latter is involved in bone formation in low concentrations but in bone resorption in higher concentrations (Seifert and Watkins 1997; Chapuy 1997; Ralston and Grabowski 1996; Mundy 1993). Arginine, a potent nitric oxide provider, was found to have a direct inhibitory effect on osteoclast-mediated bone resorption in rats (Wimalawansa 1997; 1996).

\section{Major bone proteins}

Collagen is required for the deposition of calcium phosphate (hydroxyapatite) crystals $\left[\mathrm{Ca}_{10}\left(\mathrm{PO}_{4}\right)_{6}(\mathrm{OH})_{2}\right]$ to form bone (Stryer 1995). Some $85-90 \%$ of total bone protein consists of type-l collagen fibers (Termine 1993), which are synthesized in the form of prepeptides in the osteoblast (Calvo 1996). During fibrillogenesis and fibril maturation, $\mathrm{N}$ - and $\mathrm{C}$-terminal propeptides extensions are removed and enter the circulation or become entrapped in the final matrix of bone (Calvo 1996; Termine 1993). In serum especially the $\mathrm{N}$ extension is a useful marker of bone formation (Termine 1993). Pyridinium ring structures, pyridinoline (or hydroxylysylpyridinoline) and deoxypyridinoline (or lysylpyridi-noline), tie several collagen monomer molecules together within the formed collagen fiber (Termine 1993). Because deoxypyridinoline (D-Pyr) has only been found in significant amounts in the type I collagen of bone the excreted amounts in urine serve as a marker of bone resorption (Seibel 1993). In addition to collagen there are a large number of highly charged anionic noncollagenous proteins comprising about 10 . $15 \%$ of total bone protein (Termine 1993; Boskey 1988). These proteins are involved in the control of hydroxyapatite formation (e.g. asteocalcin, osteonectin) and are possible candidates (e.g. osteopontin, bone sialoprotein) to anchor osteoclasts to the bone extracellular matrix receptors called clear zones (Robey and Boskey 1995; Hruska 1995; Termine 1993).

Not only osteocalcin but also matrix-glaprotein, protein $S$ and nephrocalcin, need a vitamin $\mathrm{K}$ dependent post-translational $\gamma$-carboxylation (Booth 1997; Termine 1993).

\section{Bone remodeling}

Bone modeling is the process of bone growth during skeletal maturation, a process that lacks local coupling of bone resorption with bone formation (Seifert and Watkins 1997). Bone remodeling is a continuous process in which normally bone resorption is followed by bone formation (Dempster and Lindsay 1993; Groot and Vermeer 1988). This process takes place in discrete units on the surface of trabecular bone and in the Haversian canals of cortical bone (Einhorn 1996; Dempster and Lindsay 1993). It is the only mechanism by which new bone is formed in adults (Kanis 1999; Dempster and Lindsay 1993). Modeling and remodeling are importantly controlled by signals derived from bone strains, with muscles causing the largest strains (Frost 1999). The renewal of bone, by the co-operative action of osteoclasts and osteoblasts, is necessary to maintain viability of the cells (especially the osteocytes) and for the self-repair of skeletal tissue in order to maintain biomechanical competence (Boskey 1988; Groot and Vermeer 1988).

Bone remodelling (Figure 1.1) starts (resting phase) with the activation of 
osteoclasts (Mundy 1999). PTH probably indirectly stimulates osteoclast recruitment via osteoblasts or other surface cells and lymphocytes. The transformation of mononucleated cells to multinucleated osteoclasts is stimulated by calcitriol. Following activation, a group of osteoclasts start bone resorption during about 8 days (resorption phase). After this period osteoclasts are replaced by mononuccleated cells with resorptive capacity which make the cavities deeper in about 1 month. When resorption at a site is completed (reversal phase), the resorption cells leave or die (possibly enhanced by TGF $\beta$ ) and osteoblasts start osteoid formation which is mineralized after an initial 15-25 days lag time (osteoid maturation period) (Mundy 1999; Melsen and Mosekilde 1988).

Probably a primary quick mineralization up to $65 \%$ of the final status (formation \& mineralization phase) is followed by a period of slow mineralization (maturation) over several months (Grynpas 1993). The osteoblasts function at the same site for about 5 months after which they have been converted into flat, inactive-looking lining cells or osteocytes. The complete process of deformation followed by formation of bone takes a period of about 6 months (Melsen and Mosekilde 1988; Boskey 1988).

Peri and postmenopausal remodeling inbalance is caused by the strongly decreased production of oestrogens. As a consequence, activity of osteoclasts is less inhibited, and their apoptosis is less stimulated. Furthermore, differentiation of osteoblasts is less stimulated (McCarthy 1996; Tobias and Compston 1999; Qu 1998; Manten 1996). During this period, up to 2-3 years following menopause, bone turnover rate is high, and as a

Figure 1.1: Simplified and schematic representation of bone remodeling

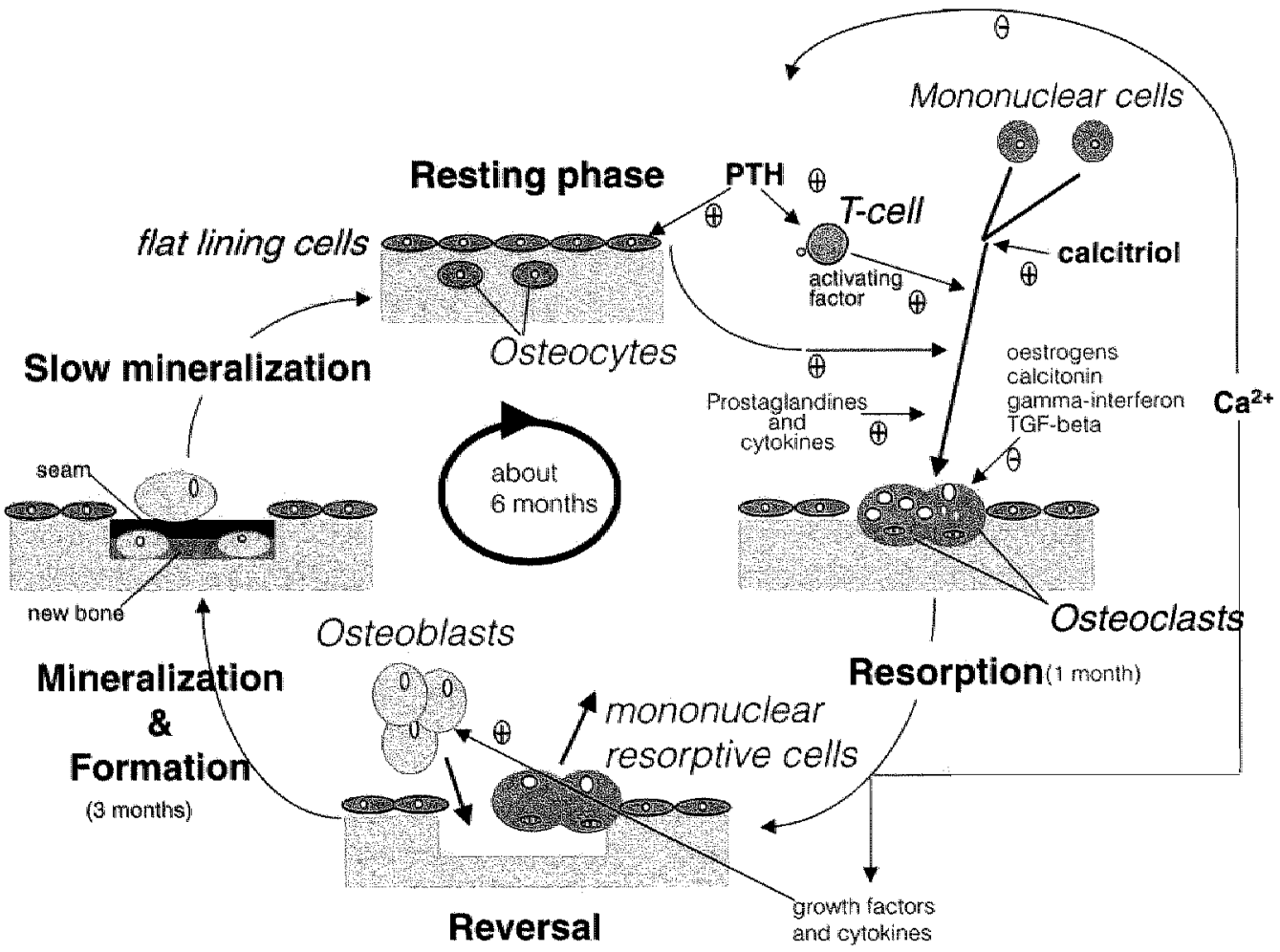


consequence, bone loss is high (Elders 1994; Delmas 1997; Manten 1996).

It is suggested that if PTH is the principal driving force for bone remodeling, it predicts the rise in remodeling rate after menopause (Recker 1977). However, an increased remodeling might also be caused by a decreased renal calcium reabsorption as a result of oestrogen deficiency (Nordin 1991). In that case an increased PTH is a secondary event. Based on the time schedule of remodeling it can be predicted that if resorption is stopped or slowed down and formation continues apace, bone mass will increase for several months. This is called the remodeling transient (Riggs 1998;

Mackerras and Lumley 1997). Indeed, the largest increase in bone mass produced by inhibitors of bone resorption is seen during the first 6 months of treatment (Rodan 1997). This also explains why the increase in bone mineral density (BMD) following treatment with an antiresorptive agent will be greater when turnover is higher and when duration of the remodeling cycle is longer (Seeman 1995). The acquired gain in BMD after such a treatment can remain if bone turnover stays reduced (Kanis 1999; Fleisch 1996).

\section{Osteoporosis}

Age-related bone loss finally leads to osteoporosis, a multifactorial, chronic skeletal disease with an increased risk for fractures after minimal trauma because of a reduced skeletal mass and microarchitectural deterioration (Kanis 1997; Kleerekoper 1995). Postmenopausal osteoporosis and senile osteoporosis are both called primary osteoporoses (Marcus 1996). Menopausal bone loss is followed by senile osteoporosis, which is primarily an effect of defective bone resorption and defective bone formation (Kung 1998).

Secondary osteoporosis results from specific, defined clinical disorders (Marcus 1996). Osteoporotic fractures are especially common in the spine, hip and forearm (European Community 1998): Based on BMD, bone status can be defined and expressed as a T-score (Table 1.1) of the particular skeletal site.

Table 1.1: Diagnostic guidelines as proposed by the World Health Organization 1994 (World Health Organization 1994):

\begin{tabular}{ll}
\hline Classification & Toscore \\
\hline Severe osteoporosis & $<-2.5$, and the presence of \\
& fractures \\
Osteoporosis & $<-2.5$ \\
Osteopenia & $>-2.5$ and $<-1$ \\
Normal & $\geq-1$ \\
\hline
\end{tabular}

"Difference in BMD compared with the mean value of peak bone mass in young nomal women expressed as standard dewiation:

This is important information as BMD is a strong determinant of bone strength (Peacock 1995; Hodgskinson 1997; Netelenbos and Lips 1996; Cooper and Ainie 1994).

\section{Peak bone mass}

Prevention of osteoporosis already starts during puberty when about $90 \%$ of the maximum skeleton mass is reached (Figure 1.2). More than two thirds of peak bone mass is genetically determined (Puntila 1997; Murray 1997). However, to

Figure 1.2: Schematic course of BMD from birth onwards with indication (*) of important moments of intervention

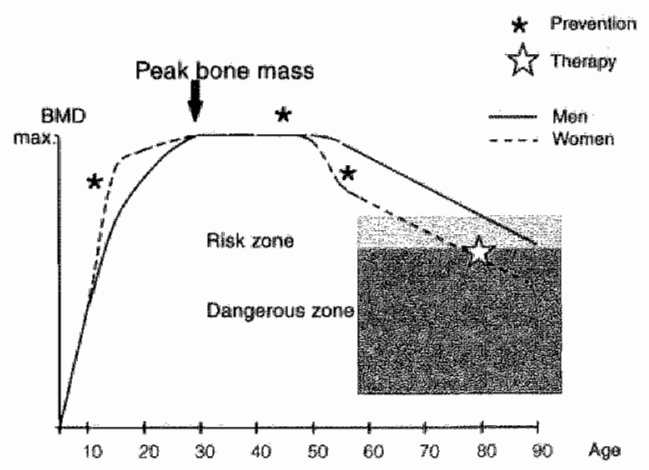


achieve one's genetic potential, adequate nutrition and physical activity during growth is necessary for optimum skeletal development (Rosenberg and Rosenberg 1998; Dempster and Lindsay 1993).

Of great influence are the various polymorphisms identified (e.g. of vitamin D receptor, oestrogen receptor, type I collagen, apolipoprotein E genotype, and interleukin-6) (Wood and Fleet 1998; Murray 1997). Although additional calcium supplementation and physical activity in prepubertal children increase BMD, to maintain this extra gain continuation through life seems to be necessary (Kanis 1999; Puntila 1997). Muscle contractions are of importance for fine-tuning of microarchitecture to provide maximum strength with minimum of bone mass (Frost 1997; Burger 1995), Oestrogens might play an important role in this process by decreasing the threshold of bone modeling and by stimulating the remodeling conservation-mode of bone next to marrow. In this way girls at puberty can make more bone than boys with similar muscle strength. The model also explains the postmenopausal bone loss (increased thresholds). As well in puberty as after menopause, bone gain or loss plateaus as soon as the bone has become strong or weak enough to balance the bone strains (Frost 1999; Schiessl 1998).

\section{Life-style factors}

Apart from low physical activity (Bérard 1997) and medicines [antibiotics, anticonvulsants, anti-acid medication, glucocorticoids and some diuretics (Breslau 1994; Nordin 1997; Mück and Lippert 1994)] at least the following lifestyle and nutrition-related factors have been reported to promote the development of osteoporosis: alcohol abuse, smoking excessive intakes of protein, sodium, caffeine and fiber, and chronic low-llevel exposure to cadmium. Alcohol may have direct toxic effects on osteoblasts (Heaney 1996a) and may lead to poor nutrition, altered vitamin D metabolism (Nevitt 1994) and an increased risk of falls (Lindsay 1993). Small amounts of alcohol (3-4 glasses of wine per week), however, have been associated with an increased bone mass. A suggested mechanism for this effect was the induction of adrenal production of androstenedione and its adrenal conversion to estrone (New 1997). Tobacco smake may directly be toxic to bone and may increase the hepatic metabolism of oestrogen (Kiel 1996; Heaney 1996). It has been reported from a prospective study (Feskanich 1997) that high intakes of milk and other calcium-rich foods during adult years do not decrease the risk of hip or forearm fracture but even may increase bone loss. Earlier, a metaanalysis revealed a small but significant positive relation between calcium intake and bone mass in females aged 18 through 50 years (Welten 1995).

Although there is no reason to think badly about milk, it is a protein-rich food. High intakes of protein, not only sulfurcontaining amino acids as thought before, may lower the blood $\mathrm{pH}$ which is in part corrected by the release of alkaline calcium salts from bone and which results in a higher calcium excretion. Buffering of the low blood $\mathrm{pH}$ also seems to be possible through additional potassium bicarbonate (Weaver and Plawecki 1994; Wood 1994). Every gram of protein metabolized causes an increment in urine calcium of about 1 $\mathrm{mg}$ (Heaney 1996a). Low intakes of protein $(0.7 \mathrm{~g} / \mathrm{kg} /$ day), however, are not preferable either as those intakes have shown to cause a depressed intestinal calcium absorption leading to a secondary hyperparathyroidism in healthy, young women (Kerstetter 1998). High urinary sodium excretion has been shown to be associated with larger decreases in BMD of the intertrochanteric and total hip sites. An increased filtered sodium load reduces 
tubular reabsorption of calcium because they share the same transport system (Devine 1995). Every $100 \mathrm{mmol}$ sodium excreted by the kidney pulls $0.5-1.5 \mathrm{mmol}$ of calcium out with it (Nordin 1993; Visser and Hoekman 1994; Heaney 1996). Based on multiple regression analysis it has been suggested that halving daily sodium excretion (from 3.5 to $1.7 \mathrm{~g}$ ) may reduce bone loss equivalent to an additional daily intake of $890 \mathrm{mg}$ of callcium (Devine 1995). In young healthy women however an increased sodium intake (from $80 \mathrm{mmol} / \mathrm{d}$ to $180 \mathrm{mmol} / \mathrm{d}$ ) increased urinary sodium and calcium excretion but did not affect markers of bone resorption (deoxypyridinoline) and bone formation (osteocalcin and bone alkaline phosphatase) (Ginty 1998). Fiber and caffeine decrease intestinal calcium absorption but these are relatively minor effects. A single cup of coffee (containing 60 to $180 \mathrm{mg}$ of caffeine per $180 \mathrm{ml}$ ) increases calcium excretion with 2-3 $\mathrm{mg}$, which is more than adequately offset by a tablespoon or two of milk (Heaney 1996a; Lloyd 1997a). It was also suggested that coffee intake in excess of $1,000 \mathrm{ml}$ could induce an extra calcium loss of $1.6 \mathrm{mmol}$ of calcium per day (Hasling 1992). However, even intakes up to $1,400 \mathrm{mg}$ of caffeine per day do not seem to influence total body or hip BMD of healthy postmenopausal women (Lloyd 1997). Although high fiber diets increase gastric $\mathrm{pH}$ this does not influence calcium absorption. Binding of calcium to the fiber complex seems to be of more importance but in general the effects are small (Heaney 1996b; Knox 1991b). Chronic exposure to low-levels of cadmium derived from contaminated food, tobacco smoke or polluted air was recently found (Staessen 1999) to correlate with a higher fracture rate in older men and women. Cadmium is thought to disturb the reabsorption of urinary calcium, may reduce the synthesis of renal calcitriol, may interact directly with bone cells diminishing their ability to mineralize, and inhibits procollagen $\mathrm{C}$ proteinases and collagen production.

\section{Past menopause and at older age} The decreased production of oestrogen at menopause seems to change the bending set point of bone and gives the signal that the skeleton has more bone than it needs. This loss is often not due to nutrient deficiency and cannot substantially be influenced by the diet (Heaney 1996b). The high bone losses in early postmenopausal women, up to $4 \%$ per year, are predominantly at the expense of trabecular bone (Abraham 1991; Riis 1987). Although the rate of bone loss is especially high during menopause and the first 3-5 years after menopause, an accelerated loss of BMD may persists for 10 years (Elders 1994; Ohta 1996). During this period about $15 \%$ of bone mass is lost (Heaney 1996b). In the following years, the annual decrease in BMD drops to about $1 \%$ with mainly cortical bone being affected. Age-related changes in calcium and vitamin $D$. metabolism may increase bone turnover and as a consequence bone loss (Nevitt 1994). Because bone turnover can be reduced by food components, the role of nutrition may become more and more important under these circumstances. Past menopause and at older age, loading of the skeleton by exercise is important to maintain a BMD as high as possible and to increase muscle strength or reduce muscular losses (Lord 1996; Sinaki 1996; Bulstra 1997). Perhaps the most important goal of an increase in physical activity of the elderly is reduction of falls by improving co-ordination, balance and flexibility (Nelson 1994; The National Osteoporosis Society 1995).

\section{Fractures}

Prevention or delay of osteoporotic fractures is the hard clinical endpoint of treatment and prevention strategies. BMD of a particular skeletal site can be used as 
a predictor for fracture risk of that site. Therefore it has been suggested that a higher BMD of the total population might prevent more fractures than treatment of only high-risk women and men (BarretConnor 1998).

Most fractures result from a combination of axial compression, bending, and torsion (Einhorn 1996). The most serious fractures are those of the hip, which contribute substantially to morbidity, mortality and health care costs. Vertebral and wrist fractures cause pain, deformity and disability, all are reducing quality of life (Kanis 1997). The risk of hip fractures increases with age. A reduction of $1 \mathrm{SD}(Z$ score -1$)$ of femoral BMD increases the risk of hip fracture by two- to threefold

(Table 1.2). The same reduction in BMD of the lumbar spine doubles the risk of vertebral fracture (Devogelear 1996). It has been reported (Cummings 1993) that an increase in BMD of approximately $1 \%$ reduces fracture risk with $6-8 \%$ at the particular skeletal site. Postponing bone loss with 7.5 years would reduce the number of hip fractures with about $15 \%$ (Reichelt 1996). Any reduction or arrest of loss is therefore thought to contribute to a reduced incidence of hip fractures (Lindsay 1997).

Trabecular bone geometry plays an important role in fracture etiology. By the loss of horizontal trabeculae, vertical trabeculae begin to behave like columns and, as such, are subjected to loads they are not prepared for (Einhorn 1996), Loss of trabeculae therefore has a greater impact on bone strength than lass of thickness of trabeculae. In a model it was found that a reduction in BMD with $10 \%$ accompanied by a loss of trabeculae reduced strength with about $70 \%$, whereas without loss of trabeculae the reduction in strength was only $20 \%$. This means that an effective treatment strategy should primarily prevent the loss of trabeculae (Silva and Gibson 1997) or in other words should start early.

\section{Nutritional intervention}

As mentioned before, prevention can be achieved by improving nutrition and physical activity, adapting life-style and the realization of a high peak bone mass. Some nutrients have a negative influence on bone when they are consumed in large amounts. Other nutrients have a negative impact on bone when they are consumed in low amounts. The term 'low' in this respect is difficult to explain. Sometimes intakes are in accordance with current recommendations but still may be considered as low when new parameters are used to measure the bodily status of that particular nutrient.

\section{Minerals and vitamins}

Well-known nutrients in bone metabolism are calcium and vitamin D. Especially calcium is part of almost every treatment or preventive strategy of osteoporosis (Kanis 1999; Nelson 1996). High calcium intakes (2,000-3,000 $\mathrm{mg} /$ day), prevented bone loss

Table 1.2: Relative risk of a hip fracture calculated for several classes of BMD (Reichelt 1996).

\begin{tabular}{llll}
\hline BMD Class & $\begin{array}{l}\text { Mean BMD } \\
\left(9 / \mathrm{cm}^{2}\right)\end{array}$ & $\begin{array}{l}\text { Relative decrease } \\
\left(\mathrm{SD}^{\prime}\right)\end{array}$ & $\begin{array}{l}\text { Relative fracture risk and } \\
95 \% \text {-confidentiality inierval }\end{array}$ \\
\hline 1 & 0.98 & 0 & 12 \\
2 & 0.85 & 1.1 & $2.7(2.0-3.9)$ \\
3 & 0.77 & 1.7 & $5.1(3.0-8.8)$ \\
4 & 0.65 & 2.6 & $11.8(5.2-27.2)$ \\
\hline
\end{tabular}

$1 \mathrm{SD}=0.13 \mathrm{~g} / \mathrm{cm}^{2},{ }^{2}$ BMD class 1 is the reference class 
of the lumbar spine in premenopausal and early perimenopausal women (Elders 1994). Of interest is the outcome of the analysis of Nieves et al (1998) who found that additional calcium improves the outcome of treatment with oestrogen and calcitonin in early postmenopausal women. Also treatments with bisphosphonates and fluoride are accompanied by additional calcium (Libanati 1996; Meunier 1997; Hansson and Roos 1987). Vitamin D is more and more recognized as an essential part of prevention strategies also for the apparently healthy postmenopausal women. To decrease an increased postmenopausal and age related bone turnover, a reduction of PTH levels is the primary goal which can be achieved by higher intakes of calcium and vitamin $\mathrm{D}$ (Wilkin 1999; Vieth 1999; Meunier 1994). An overview of calcium supplementation studies, with or without vitamin D, studying effects on BMD of the spine and temoral neck is presented in Table 1.3. The overall conclusion from this table is that calcium supplementation inhibits BMD loss of the lumbar spine and femoral neck in postmenopausal women. Vitamin D may enhance the effect especially when calcium dosage is low (500 mg/day). Higher doses (about 1,000 mg/day) seem to be more effective than lower doses and possibly more effective in late $>5$ years past menopause) than in early ( $<5$ years) postmenopausal women. Calcium and vitamin $D$ as well as magnesium, strontium, boron, fluorine, vitamin $K$ and

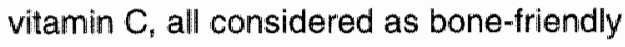
nutrients, are discussed in Chapter 2 of this thesis.

Beside the above mentioned minerals and vitamins, zinc, silicon, vanadium and vitamin $E$ may play a role in the preservation of bone. Zinc is important for bone accretion (Anderson 1992) and is a co-factor of metalloproteinases, such as collagenase and alkaline phosphatase, which play a role in the process of bone modeling and remodeling (Oomez $1999^{\circ}$ Makal and Chudacek 1991). It is assumed that silicon has a role in the cross-linking of connective tissue (Nielsen 1991) stimulating the activity of prolyl-4hydroxylase (Birchall and Esple 1986; Carlisle 1986). Silicon is a major uon of osteogenic cells especially during the metabolically active state of the cell (Dempster and Lindsay 1993). Vanadium deficiency in animal studies increased skeletal deformations and affected the thyroid function. Many actions of vanadium suggest that it acts like or enhances growth factors such as epidermal growth factor, fibroblast growth factor and insulin. In vitro, vanadium stimulates bone cell proliferation and collagen synthesis (Nielsen 1991). Vitamin $E$ might maintain normal bone development by protecting against free radicals, which are produced by osteoclasts, by oxidation of unsaturated fatty acids, or because of PGE, activity (Seifert and Watkins 1997).

\section{Phyto-oestrogens, PUFA and caseinophosphopeptides}

Apart from the minerals and vitamins at least three other food components are of interest, phyto-oestrogens, polyunsaturated fatty acids (PUFA) and caseinophosphopeptides. Phyto-oestrogens are plant phenolics of which some structurally resemble human oestrogens (Messina 1995; Barrett 1996). As a consequence they have weak oestrogenic effects. In rats, however, also anti-oestrogenic effects have been found (Bingham 1998). The two major classes of phyto-oestrogens for humans are lignans and isoflawonies (Knight and Eden 1996). Lignans are present in high concentrations in flaxseeds, but are also found in small amounts in cow's milk.

Soyfoods in particular are rich in isoflavones. Since phyto-oestrogens may bind to the oestrogen receptors (Messina 1995; Knight and Eden 1996; Barrett 1996), they are thought to increase BMD, 
to relieve menopausal symptoms, and may protect against coronary heart disease.

The evidence for these events, however is weak. Furthermore, it seems that the effects of phyto-oestrogens are dosedependent. Based on the intake of soy products by Asian women, about $40 \mathrm{mg}$ of isoflavones are suggestedl to be necessary for a positive effect on bone.

In postmenopausal women, $90 \mathrm{mg}$ of isoflavones per day increased BMD of the lumbar spine significantly after 6 months, whereas a lower dose (56 mg per day) tended to do so. Several animal studies confirm beneficial effects on bone. In premenopausal women, however, higher intakes of isoflavones possibly exert antioestrogenic effects and may reduce normal oestrogen synthesis. As a consequence, this may lead to lower BMD (Messina 1999; Anderson and Garner 1997). It also is not clear whether isoflavones may be involved in the development of breast cancer or not (Messina 1999; Bingham 1998).

The role of PUFA has been discussed before. In short, higher amounts of fatty acids from the $\alpha$-linolenic acid family prevent an overproduction of $\mathrm{PGE}_{2}$ from arachidonic acid (linoleic acid family). It is of interest to know that conjugated linoleic acid, which occurs predominantly in milk fat and meat from ruminants (Kim and Liu 1999), also might be able to control $\mathrm{PGE}_{2}$ production. $\mathrm{PGE}_{2}$ is known to stimulate bone formation but possibly only at lower levels (Kim and Liu 1999; Seifert and Watkins 1997; Chapuy 1997). Since aspirin and other nonsteroidal antiinflammatory drugs (NSAIDs) inhibit $\mathrm{PGE}_{2}$ synthesis, it was suggested that they might prevent bone resorption. Although this was confirmed in short-term studies, significant long-term benefits were not found (Lane 1997). NSAIDs, however, are biphasic and may increase $\mathrm{PGE}_{2}$ production in low concentrations, which will be achieved regularly when they are administered intermittently (Kawaguchi 1995). Caseinophosphopeptides (CPPs) are bioactive peptides derived from the tryptic digestion of casein, which is the major protein in milk. The CPP fraction is about $10 \%$ of the total amount of peptides after pancreatic digestion of casein. Because CPPs appear to be resistant to extensive proteolytic degradation they accumulate in the small intestine. By binding of calcium they are thought to increase calcium solubility and by that calcium absorbability. However, this is confirmed in only a few human studies whereas not all animal studies showed an effect (FitzGerald 1998; Kitts and Yuan 1992).

\section{Outline of this thesis}

For an additional supply of calcium, a wide range of calcium sources is available for the use in pure form or for the enrichment of food. Of interest are more complex calcium sources such as milk calcium, ground oyster shells, bone meal, dolomite and ground chicken eggshells because they supply more than calcium alone. Some of the accompanying components are thought to have a positive influence on bone metabolism. However, these natural complexes may also contain unacceptable levels of unwanted elements such as lead, cadmium or mercury, which may cause unnecessary chronic loading with potential toxic metals (Whiting 1994).

Chicken egg-shell powder is a rather unknown calcium source for humans. From a Slovakian study (Makai and Chudacek 1991) it can be suggested that chicken eggshell powder, in the way it was prepared (Biomin a.s. 1995) and in combination with other bone-friendly minerals and vitamins, might be of particular interest for postmenopausal women and older men.

Before application can take place, however, a number of questions have to be answered: 
Which minerals and vitamins are of major interest for bone preservation in postmenopausal women?

Chapter 2 is a review of the literature describing the influence of calcium, magnesium, boron, strontium, fluoride, and the vitamins $C, D$ and $K$ on bone metabolism. This search was necessary to substantiate the possibilities of nutritional intervention and was used for the composition of the supplements as tested in human studies.

Does chicken eggshell powder have acceptable levels of impurities, and does it contain minerals or proteins that possibly explain its reported effects on bone metabolism?

Chapter 3 reports about the mineral and hormonal composition of Slovakian chicken eggshell powder. Mineral composition of several production batches was studied to get an impression about the normal variability. The influence of feed or way of housing was scouted by taking three samples of Dutch consumption eggs differing in these aspects. The mean mineral composition of Slovakian eggshell powder was compared with commercially available purified, food grade calcium carbonate, oyster shell tablets and a Japanese eggshell powder. Furthermore, the mineral composition was compared with the recommended or acceptable daily intake for adults. Based on the effects reported in poorly documented case studies and the study of Makai et al (1991), we analyzed Slovakian eggshell powder for the presence of calcitonin, TGF $\beta_{1}$, calcitriol, oestradiol and progesterone.

Is chicken eggshell powder a source of bioavailable calcium?

In Chapter 4 two piglet studies are described in which the apparent digestibility of chicken eggshell powder is compared with purified calcium carbonate. The latter is generally accepted as a good calcium source. The piglet can be considered as a predictive model for humans. In the first piglet study both calcium sources were tested in combination with casein as the major protein source and supplier of CPPS. In the second piglet study soy protein was used because on the one hand it may disturb calcium absorption but on the other hand the use of soy protein is of interest because it provides phyto-oestrogens.

Could the effects as reported from the Slovakian study with a high dosage of eggshell powder be confirmed in a Dutch study with a lower dosage? In Chapter 5 a small pilot study is discussed which aimed to repeat the effects as reported by Slovakian researchers (Makai and Chudacek 1991) but with only half the amount of eggshell powder. The study should last for only 6 months and had to focus on BMDs of the lumbar spine and hip. During that period 10 participants with osteoporosis or osteopenia, selected by the Medical Centre of Leeuwarden, took twice daily a milk drink derived from a powdered supplement, which was diluted with water. The supplement not only supplied $3 \mathrm{gram}$ of chicken eggshell powder per day but also other minerals and vitamins including magnesium, vitamin $D_{3}$ and vitamin $K_{1}$. At baseline and after about 6 months, BMDs were measured as were some routine parameters in blood and urine. After the first 6 months, 6 of the participants continued to use the supplement up to 2 years but only once daily and with some questions about compliance.

\section{Could the eggshell powder enriched} supplement be of benefit for healthy Dutch postmenopausal women?

In a preventive strategy, healthy postmenopausal women are the primary target group. In The Netherlands, the intake of calcium generally is in line with the 
recommendations. Therefore it was of interest to study whether an additional calcium supplementation would show any effects, in particular when given as chicken eggshell powder. Chapter 6 describes a one-year, prospective, randomized and controlled study with healthy postmenopausal women with a relatively high calcium intake at baseline. To our opinion a one-year study is long enough as effects of calcium supplementation are especially an effect of the first year and may remain for at least 4 years as long as bone turnover stays reduced (Devine 1997; Reid 1995). Two supplements enriched with minerals and vitamins including magnesium, vitamin $\mathrm{D}_{3}$ and vitamin $\mathrm{K}_{1}$ and only differing in calcium source (chicken eggshell powder versus purified calcium carbonate) were compared with a placebo product. The study focussed on changes in BMD but also biochemical markers of bone resorption and bone formation were analyzed.

Could the results as obtained from the pilot study be confirmed in a larger number of apparently healthy women with a low BMD of the lumbar spine?

As only small effects were expected in the study with the healthy postmenopausal women (Chapter 6) a comparable study was started at the same time with apparently healthy postmenopausal women but this time with a low BMD of the lumbar spine (Chapter 7). Women were included when the T-score of the lumbar spine was $\leq-1$ SD. Randomly the women were allocated to a standard treatment with calcium and vitamin $\mathrm{D}_{3}$ or to a chicken eggshell powder enriched supplement. Composition of the eggshell powder supplement and study length and parameters were comparable with the study described in Chapter 6.

\section{Can necessity of additional vitamin} $D_{3}$ and vitamin $K_{1}$ for Dutch healthy postmenopausal women be notified? The Dutch Food Nutrition Council (1992) recommends $0-100 \mathrm{IU}$ vitamin $\mathrm{D}$ for women $50-65$ years of age and $100-200 \mathrm{IU}$ vitamin $\mathrm{D}$ for women 65 years and oider. There is no Dutch recommendation for vitamin K. Studies (Schurgers 1999; Dutch National Food Consumption Survey 1998) indicate that current recommendations are achieved (USA recommendation for vitamin K) in The Netherlands. However, optimal amounts for both vitamins may be higher than recommended and additional information is urged. Chapter 8 describes the effects of additional vitamin $D_{3}$, vitamin $K_{1}$ or a combination of vitamins $D_{3}$ and $K_{1}$, in postmenopausal women with a normal or low BMD of the lumbar spine, during one year.

\section{Finally}

The liesults of the before mentioned studies are summarized and discussed in Chapter 9. 
요용ㅇㅇ요용

品品

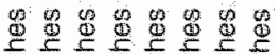

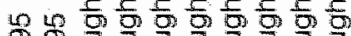

g.

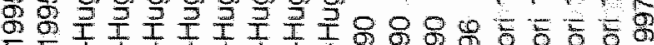

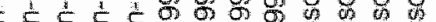

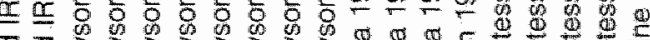

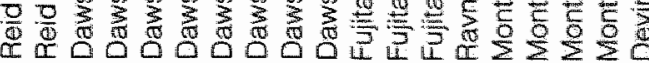

ז

客

$\frac{1}{6} \frac{0}{0}$

(2) E

a.

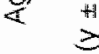

$\sum_{\mathrm{m}}^{\infty} \frac{\mathrm{v}}{\mathrm{O}}$

离离命

क.

E

o $\frac{\mathbb{2}}{0}$

密

$80 \frac{5}{5}+1$

$\sum_{0}^{\infty} \sum_{0}^{\infty}$

过 $\subseteq \frac{0}{\text { E }}$

5

$\stackrel{\omega}{\circ}$

$\stackrel{\circ}{5}$

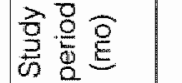

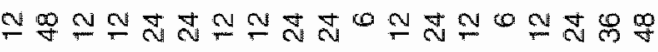

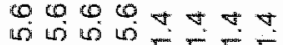

$0.00 \%$

H H H

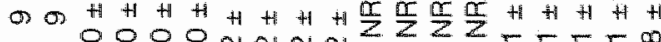

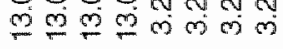

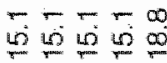

オ

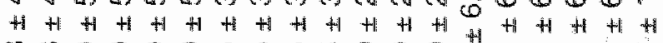

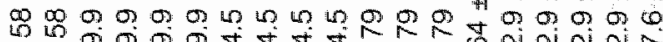

का

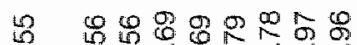

क

0 \%

o

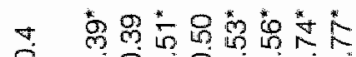

+1 $9000000000 \%$

mb

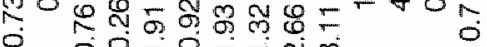

क

돌 $\frac{2}{2} \frac{2}{2}$

它

os

0

30

8.

$E \stackrel{9}{0}$

$\frac{2}{0}$

ธิ

듬

$\frac{\Phi}{6}$

w $\bar{c}$

Q)

Lis

$\therefore 8$

$\frac{1}{\frac{0}{0}}$

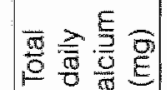

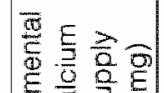

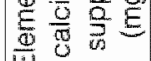

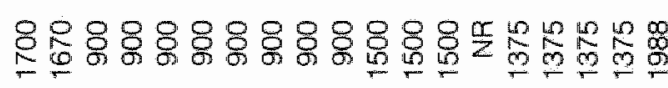

o. 901 989

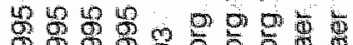
욘 (0) ES

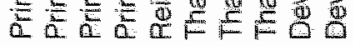

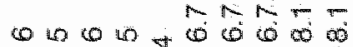

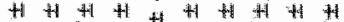

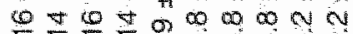

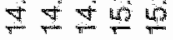

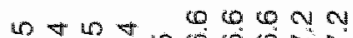

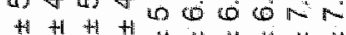
$0000^{4}$ H 4 w 4 स

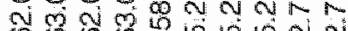
แ० 40 \%

8 क क

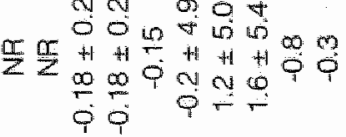

in $N{ }^{*}$

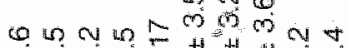
$-0000 \%$ H min

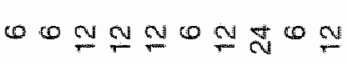

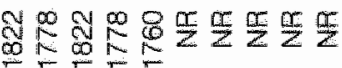

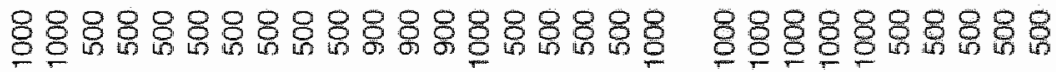

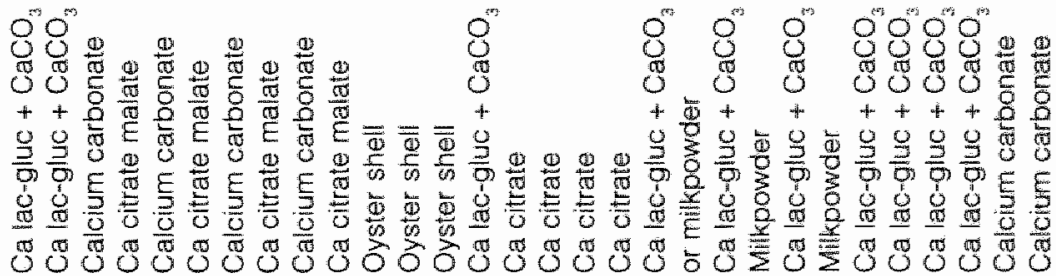


$8: 8 \%$

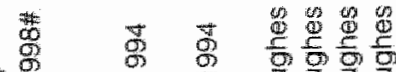

照

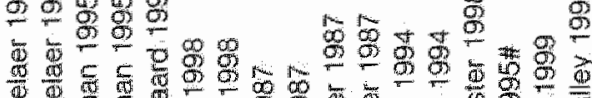

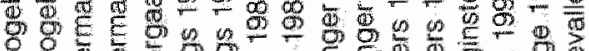

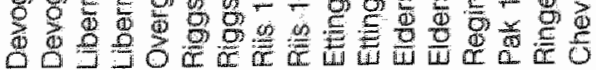

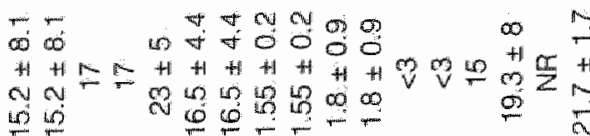

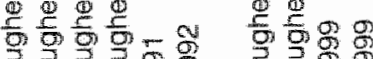

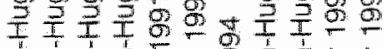

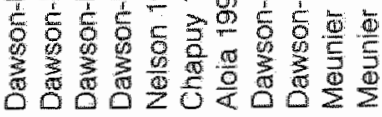
$010 \infty \mathrm{m}$

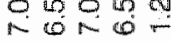

$+4+4+4$ a 4 a

$m+m+\infty \geq \div$

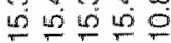

and in

-

C)

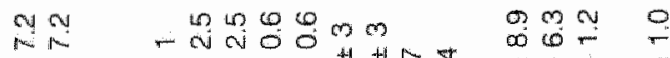

$\underset{1}{2}$

$m-m-m$

$\infty \propto$

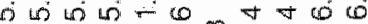

+ + स⿺

M.

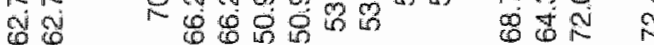

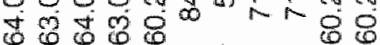

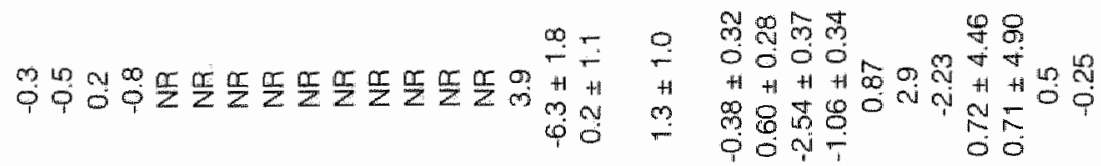

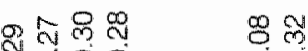

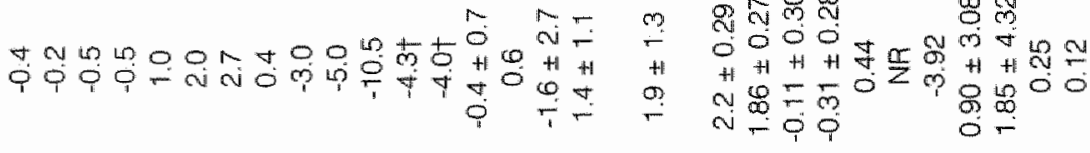

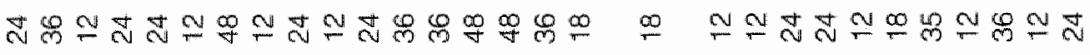

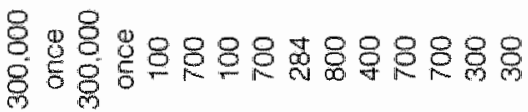

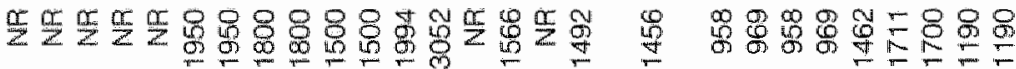

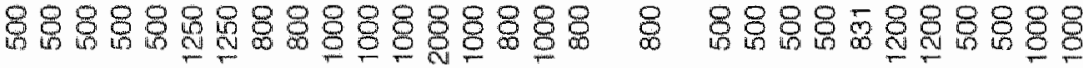

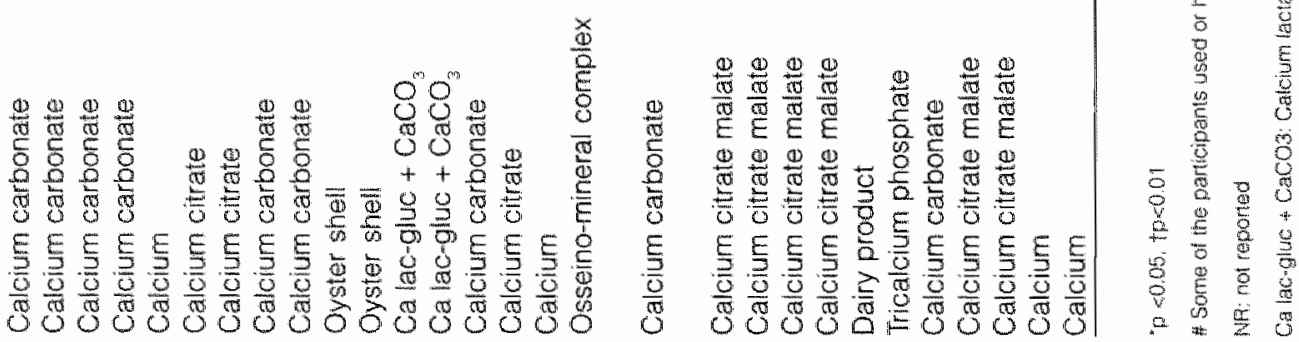




\title{
Delay of natural bone loss by higher intakes of specific minerals and vitamins
}

\author{
A. Schaafsma1 , P.J.F. de Vries ${ }^{1}$, W.H.M. Saris ${ }^{2}$
}

1 Friesland Coberco Dairy Foods, Department of Research \& Development Leeuwarden, Leeuwarden, The Netherlands.

2 University Maastricht, Department of Human Biology, Maastricht, The Netherlands.

\section{Resubmitted to Critical Reviews in Food Science and Nutrition}

\section{Abstract}

For early prevention or inhibition of postmenopausal and age related bone loss, nutritional interventions might be a first choice. For some vitamins and minerals an important role in bone metabolism is known or suggested. Calcium and vitamin D support bone mineral density and are basic components in most preventive strategies. Magnesium is involved in a number of activities supporting bone strength, preservation and remodeling. Fluorine and strontium have bone forming effects. However, high amounts of both elements may reduce bone strength. Boron is especially effective in case of vitamin $D_{n}$ magnesium and potassium deficiency. Vitamin $K$ is essential for the activation of osteocalcin. Vitamin $C$ is an important stimulus for osteoblast derived proteins. Increasing the recommended. amounts (US RDA 1989), adequate intakes (US DRI 1997) or assumed normal intakes of mentioned food components might lead to a considerable reduction or even prevention of bone loss especially in late postmenopausal women and the elderly.

Keywords: nutrition, bone mineral density, bone metabolism, postmenopausal wamen.

\section{Introduction}

Bone loss at an older age ( $>50$ years) will sooner or later lead to osteoporosis and fractures in millions of people associated with a decrease in general well-being and with high costs for health care, especially in the case of hip fractures. Bone mass, architecture and composition are largely under genetic control and strongly influenced by mechanical stress in an early stage of life. However, to achieve one's genetic potential, adequate nutrition during growth and maintenance is necessary for optimum skeletal development and health (Dempster and Lindsay 1993). A first step in the prevention of osteoporosis is a high bone mass during puberty and adolescence. Between peak bone mass and the age of about 50 , bone mass has to be preserved by a healthy life style and adequate nutrition. After that period, strategies to preserve bone strength should start as soon as possible (Silva and Gibson 1997). Although architecture plays an important role in bone strength, a valid and non-invasive predictor of fracture risk at an older age is bone mineral density (BMD) (Hodgskinson 1997). At an older age, bone mass will decrease as a result of aging (type 2 or senile osteoporosis), decreased synthesis of gonadal hormones (type 1 or postmenopausal osteoporosis), and often by malnutrition. Only during the early postmenopausal phase (less than 
5 years following menopause), nutritional intervention seems to be less effective (Marcus 1996a). Vitamin D and calcium return regularly in preventive strategies. However, other food ingredients also play important roles, assisting calcium and vitamin $\mathrm{D}$ or just by completing nutrition. Copper, manganese and zinc are cofactors for enzymes involved in bone metabolism (Eaton-Evans 1994). Premenopausal higher intakes of zinc, magnesium, potassium, fiber, and vitamin $C$ were associated with a higher BMD of the lumbar spine. Positive influences on BMD of lumbar spine and femoral neck were seen in early adulthood because of milk and fruit intakes (New 1997). Fluorine is known to stimulate bone formation (Marcus 1996a). Such a function has also been suggested for strontium (Canalis 1996). The role boron playes in maintaining bone mineral density is less clear (Beattie and Peace 1993). Silicon and aluminum are thought to increase thickness of trabeculae whereas aluminum also might increase connectivity of trabecular bone (Seeman 1995). However, aluminum is also mentioned as an inhibitor of hydroxyapatite growth (Birchall and Espie 1986). Vitamin K is known as a co-factor in the activation of a number of proteins involved in bone metabolism (Marcus 1996a). This article reviews the current knowledge about the role of calcium, magnesium, strontium, boron, fluorine, vitamin $\mathrm{D}$, vitamin $\mathrm{K}$ and vitamin $\mathrm{C}$ on bone metabolism in postmenopausal women.

\section{Calcium}

To secure vital activities, serum calcium concentration is maintained within narrow limits (range 2.1 to $2.6 \mathrm{mmo} / \mathrm{L}$ ), a process controlled by the hormones calcitriol $\left[1,25(\mathrm{OH})_{2} \mathrm{D}_{3}\right], \mathrm{PTH}$ and to a lesser extent calcitonin (Nordin 1988). It has been suggested that the calcium intake of postmenopausal women should be at least 1,500 $\mathrm{mg}$ per day (National Institutes of
Health Consensus Panel. 1994) which is higher than the US adequate daily intake of $1,200 \mathrm{mg}$ (Standing Committee on the Scientific Evaluation of Dietary Reference Intakes 1997). Important dietary calcium sources are dairy products (Renner 1994). Dark green vegetables are also rich in calcium but often with a lower bioavailability except for Brassica vegetables such as broccoli. Less wellknown calcium sources are fatty fish (the small fish-bones included), nuts, and subtropical fruits (School of Public Health 1992). To achieve high calcium intakes, calcium supplements may be necessary which differ in purity, percentage of elemental calcium and solubility. In subjects without health problems, calcium intakes up to $2,500 \mathrm{mg}$ are safe (Standing Committee on the Scientific Evaluation of Dietary Reference Intakes 1997). High intakes of calcium are not related to kidney stone formation and might even prevent this by binding dietary oxalate in the intestine (Whiting and Wood 1997; Liebman and Chai 1997). The absorption of dietary iron (including heme iron) is already limited by small amounts $(300 \mathrm{mg})$ of calcium (Whiting and Wood 1997). Inhibition of zinc absorption can be overcome by zinc supplementation (Wood and Zheng 1997) whereas reduced magnesium absorption might be compensated by reduced urinary losses (Martini 1999).

\section{Absorption and losses of calcium} Reported mean absorption percentages of calcium range from 24 to $35 \%$ (Standing Committee on the Scientific Evaluation of Dietary Reference Intakes 1997; Nordin 1988; Hansen 1996). Passive calcium absorption, which is determined by the consumed amount of calcium, is of major importance for elderly ( 65 years and older). Their active transport of calcium may be less efficient due to reduced serum calcitriol concentrations and a reduced 
gastrointestinal sensitivity to calcitriol (Marcus 1996a). Small differences in intestinal calcium absorbability seem to have a low impact on calcium balance in healthy middle-aged women. Differences in urinary calcium excretion are of major importance (Marcus 1996a; Bronner and Pansu 1999). Urinary calcium losses increase after the menopause apparently for a period of 15-20 years (Nordin 1988). It has been hypathesized (Nordin 1991) that the rise in bone resorption is secondary to a decreased reabsorption of renal calcium as a result of a lowered sensitivity of kidneys for PTH because of oestrogen deficiency.

\section{Effects of calcium supplementation in} elderly and postmenopausal women Increases in trabecular BMD after calcium supplementation which, result from closure of remodeling spaces (the so-called remodeling transient), can be considered as a short term effect (6 to 12 months) (Mackerras and Lumley 1997; Rilis 1987) but this effect may remain when supplementation is continued (Fleisch 1996; Riggs 1998).

Calcium supplementation reduces bone turnover, possibly by suppressing PTH secretion (Marcus 1996a) which takes place especially during the first hours after intake (Kärkkäinen 1997). Vitamin $D$ too is known to inhibit bone resorption by reducing the circulating amounts of PTH (Lukert 1992). Senile hyperparathyroidism was treated with a daily dosage of about $1,000 \mathrm{mg}$ of calcium in combination with 400 to 800 IU of vitamin D (Prestwood 1996; Chapuy 1992 "Meunier 1994). During the first 5 to 10 years after menopause bone comes into a new steady state at about a $15 \%$ lower bone mass (Heaney 1996a). This oestrogen-deficiency related bone loss cannot be prevented by calcium supplementation (500-1,200 mg) with (Aloia 1994) or without vitamin D. Only a moderate inhibition was reported in particular for compact bone (DawsonHughes 1990; Rilis 1987). No effect in early postinenopausal women probably can be explained by already reduced levels of PTH, and calcitriol as a consequence. because serum calcium levels are sufficient because of the increased bone resorption (Prentice 1997; Breslau 1994). This also might explain the reported prevention of bone loss from the lumbar spine in young women with oestrogen deficiency by PTH treatment (increased calcitriol synthesis and calcium absorption) (Finkelstein 1994). If bone resorption is inhibited (e.g. by hormone replacement therapy) calcium supplementation becomes more effective during this early postmenopausal period (Nieves 1998). Increased calcium intakes $(2,000-3,000$ $\mathrm{mg} /$ day) did prevent bone loss in premenopausal and early perimenopausal women (Elders 1994).

The greatest benefits of calcium supplementation are reported from studies in elderly (Chapuy 1992; Chevalley 1994) and late postmenopausal women (Riggs 1998; Dawson-Hughes 1990; Polley 1987; Nelson 1991; Reid 1995) who have moderate losses of trabecular and cortical bone of about $1 \%$ per year. In a study with Swedish postmenopausal women (Michaëlsson 1997), a positive relation with BMD was found at estimated calcium intakes above $1,400 \mathrm{mg}$ per day. Other studies (Riggs 1998; Ravn 1996; Prince 1995; Reid 1995; Reid 1993) indicate that supplementation with 800 to $1,250 \mathrm{mg}$ of calcium per day is beneficial for BMD of the lumbar spine especially during the early phase of supplementation (Figure 2.1). Effects on BMD of the femoral neck and total proximal femur are contradictory but might be positive in the long term. Lower amounts of supplemented calcium (500 $\mathrm{mg}$ per day) are not or less effective, especially in combination with low dietary calcium intakes (Liberman 1995; Montessori 1997; Devogelear 1996; Thamsborg 1996; 
Figure 2.1: Effects of calcium supplementation without additional vitamin D on BMD of the lumibar spine. Changes are presented as a percentage from baseline after $12,24,36$, or 48 months of intervention. Information presented includes: the calcium source, arnount of supplemented elemental calcium, the amount of dietary calcium, and the age of participants. No information about dietary calcium is presented as NR.

\begin{tabular}{|c|c|c|c|c|c|}
\hline Ca supplement & Dellta Lumbar spine & mg Ca suppl & mg Ca diet & Age & Reference \\
\hline Oyster shell & & 900 & 600 & 79 & Fulfita, 1990 \\
\hline Milkpowder & L & 1000 & 780 & 63 & Prince, 1995 \\
\hline Ca lact glue carb. & & 1000 & 990 & 67.6 & Devine, 1997 \\
\hline Ca lact gluc. carb. & 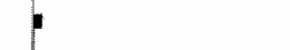 & 1000 & 760 & 58 & Reid, 1993 \\
\hline Ca lact. gluc. carb. & & 1000 & 820 & 62 & Prince, 1995 \\
\hline Ca lact. gluc. carb. & 5 & 1000 & WR & 64 & Ravn: 1996 \\
\hline Ca lact gluc carb. & $=$ & 1000 & 700 & 58 & Reid, 1995 \\
\hline Ca citrate & $=$ & 1250 & 700 & 66.2 & Riggs, 1998 \\
\hline Ca lact. gluc. carb. & 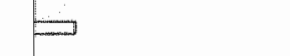 & 500 & NR & 70 & Overgaard. 1992 \\
\hline Ca lact. gluc. carb. & 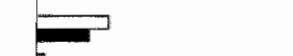 & 500 & NR & 65.2 & Thamsborg, 1996 \\
\hline Ca citrate & $48 \mathrm{mih}$ & 500 & 875 & 62.9 & Mantessori, 1997 \\
\hline Ca citrate malate & $36 \mathrm{mth}$ & 500 & 400 & 59.9 & Daw.Hug., 1990 \\
\hline Ca carbonate & $\begin{array}{l}\square 24 \text { mth } \\
\text { 12 mth }\end{array}$ & 500 & NR & 64 & Liberman, 1995 \\
\hline Ca carbonate & & 500 & NR & 62.7 & Devogelaer, 1996 \\
\hline Ca carbonate & $=$ & 500 & 400 & 59.9 & Daw.-Hug., 1990 \\
\hline
\end{tabular}

Dawson-Hughes 1990).

This suggests that a total daily calcium intake shoud be $\geq 1,500$ for a positieve influence on bone. In northern Europe, however, high calcium intakes go hand in hand with a high incidence of osteoporosis. Recently, it has been suggested that this is not related to the high calcium intake, but probably to excessive daily intakes $(>1,5 \mathrm{mg}$ ) of retinol (not provitamin A carotenoids) (Whiting 1999).

It has to be considered however, that comparison of the studies referred to is difficult as the contribution of dietary calcium intake differed from 400 to about $1,000 \mathrm{mg}$ per day. Beside that, different calcium preparations were used and supplements were sometimes given in divided doses during the day, which increases daily absorption.

The additional effect of vitamin $D$ is not clear but is likely especially in case of a marginal vitamin D status. In elderly, a reduced fracture incidence was reported after intakes of $700 \mathrm{IU}$ (Dawson-Hughes 1997) and $800 \mathrm{IU}$ (Chapuy 1992) of vitamin $D$ per day or a single dose of 300,000 IU of vitamin D (Chevalley 1994), in combination with a daily calcium supplementation of $500,1,200$ and 800 $\mathrm{mg}$, respectively. Postmenopausal women with osteoporosis formed less new vertebral fractures after 2 years of intervention with daily intakes of $1,000 \mathrm{mg}$ of calcium and $800 \mathrm{IU}$ of vitamin $\mathrm{D}_{2}$. These women however, still lost bone from the femoral neck (Meunier 1998).

Postmenopausal women, with a low daily calcium intake of $950 \mathrm{mg}$ including $500 \mathrm{mg}$ from supplementation, combined with 700 IU of vitamin $D$, only increased BMD of the lumbar spine and the femoral neck during the first year of the study. After the 2nd year, BMDs were below baseline 
values (Dawson-Hughes 1995). These above mentioned studies indicate that also in case of vitamin D supplementation at older age, a high total daily calcium intake $(\geq 1,500 \mathrm{mg}$ ) seems to be important for a positive effect.

\section{Vitamin D}

Vitamin D deficiency is associated with rickets, osteoporosis, muscle weakness; and decreased immune function (DeLuca and Zierold 1998; Machlin 1991). Based on the serum level of calcidiol $(25(\mathrm{OH}) \mathrm{D})$, vitamin D-status has been defined as lowered (<100 nmol/L), insufficient (25-50 $\mathrm{nmol} / \mathrm{L}$ ) or deficient ( $<25 \mathrm{nmol} / \mathrm{L}$ ) (McKenna and Freaney 1998).

For healthy subjects, no adverse effects have been seen with serum calcidiol concentrations $<140 \mathrm{nmol} / \mathrm{L}$. The highest 'natural' level obtained from sunshine was found to be even $225 \mathrm{nmol} / \mathrm{L}$ (Vieth 1999). It has to be mentioned, however, that the outcome of calcidiol analyses strongly depend on the method used (Lips 1999). Calcitriol $\left(1,25(\mathrm{OH})_{2} \mathrm{D}\right)$ is the most active metabolite of vitamin $D$ and specific receptors are found in many tissues (Machlin 1991).

The most well-known function is the support of active intestinal calcium absorption. Fatty fish, fish-liver oils (herring liver oil in particular), and liver are rich sources of vitamin $D_{3^{n}}$. Products like milk, yogurt, margarine, and breakfast cereals are important contributors if they are fortified with vitamin D. Vitamin $\mathrm{D}_{2}$ (of vegetable origin) plays a minor role in the overall vitamin D intake (Marcus 1996a; Shearer 1997). US Adequate intakes (Standing Committee on the Scientific Evaluation of Dietary Reference Intakes 1997) for ages 51-70, and over 70 , are 400 and $600 \mathrm{IU}$ per day, respectively.

However, higher dosages ( 800 to $1,000 \mathrm{IU} /$ day) might be preferable for the older age group (Vieth 1999; Utiger 1998).
The dietary intake of vitamin $\mathrm{D}$ should probably not exceed 2,400 14 per day (Utiger 1998). Extreme intakes of vitamin D $(>10,000$ U 4 per day) resulted in calcidiol serum levels with considerable biological activity which may lead to extra-osseous calcifications (Ooms 1994).

\section{Absorption and synthesis of vitamin} $D$ and its metabolites

Vitamin $D$ is absorbed in the small intestine in association with dietary fat or synthesized in the skin after exposure to UV light (Machlin 1991). Skin derived vitamin $\mathrm{D}_{3}$ may account for about $50 \%$ of circulating vitamin D (Kinyamu 1997) and $80 \%$ to $90 \%$ of the body stores (Shearer 1997; Ooms 1994). Latitude determines when an adequate synthesis of vitamin $D$ can take place. Above and below latitudes of approximately $40^{\circ} \mathrm{N}$ and $40^{\circ} \mathrm{S}$, respectively, synthesis of vitamin $D_{3}$ in the skin is absent during most of the winter months (Standing Committee on the Scientific Evaluation of Dietary Reference Intakes 1997; Lips 1996). As a consequence, serum calcidiol decreases during the winter and PTH levels increase when the amount of dietary vitamin $D$ is insufficient. This seasonal rhythm has not only been found in postmenopausal women but also in healthy adolescents (Guillemant 1999). Synthesis of vitamin D in the skin also markedly decreases because of aging (Holick 1998).

Especially in the liver, but also in many other tissues, vitamin $D$ can be converted into calcidiol (Bouillon 1998). Although, this synthesis depends primarily upon the amount of circulating vitamin D (Marcus 1996a), the calcidiol level is maintained within the range of about $75-220 \mathrm{mmol} / \mathrm{L}$ across vitamin D supplies from 800-10,000 or 20,000 IU per day (Vieth 1999).

The synthesis of calcidial is more effective from vitamin $D_{3}$ than from $D_{2}$, which is possibly because of a higher affinity of $D_{3}$ for vitamin D binding protein (DPB) (Trang 
1998). Circulating calcidiol concentrations are found to be higher in men than in women (Jacques 1997), higher in white women than in black women (Harris and Dawson-Hughes 1998), and seem to be inversely correlated with body mass index (Jacques 1997) and age (Shearer 1997). In the kidney, calcidiol can be converted into calcitriol by $1 \alpha$-hydroxylase. Minor amounts of calcitriol may be produced in other tissues such as bone cells, monocytes and macrophages. In circulation, the major part of calcitriol is bound to DBP. Only about $0.4 \%$ appears free or unbound in serum and is hormonally active. The synthesis of calcitriol is stimulated by PTH and phosphate, and is less influenced by the amount of circulating calcidiol (Marcus 1996a). Calcitriol and increased serum calcium lower serum PTH levels (Machlin 1991). Calcitriol also inhibits its own synthesis in the kidney by binding to the vitamin D receptor (VDR) which stimulates the enzyme 24-hydroxylase. This enzyme mediates the initial step in a cascade of oxidations, which ultimately results in calcitroic acid (Staal 1997). The major route of excretion of vitamin $\mathrm{D}$ and its metabolites is in the feces (Machlin 1991).

\section{Vitamin D receptor (VDR)}

Non-genomic actions of calcitriol involve the opening of voltage sensitive calcium channels and the activation of protein kinases, through which changes occur in intracellular calcium, phospholipid metabolism and phosphate transport, alkaline phosphatase and adenylate cyclase activities (Marcus 1996a), and membrane fluidity (Machlin 1991). Some of these rapid non-genomic actions of calcitriol might be mediated by a membrane-bound VDR (Fleet 1999). The genomic VDR mediated mechanism influences gene transcription (Ooms 1994). Hormones and growth factors can up and down regulate the expression of VDR. Subtle changes in the number or genotype of VDR are expected to play a major role in changes of bone metabolism. An age related decline in intestinal VDR, creates a relative calcitriol resistant state and impairs active calcium absorption (Marcus 1996a). It has been suggested that polymorphism of the VDR gene may account for a substantial proportion (as much as $20 \%$ (White 1994)) of the heritable component of BMD (Wishart 1997). However, this hypothesis remains controversial, is possibly more pronounced in younger subjects, and might be true only in case of low calcium intakes (Ferrari 1998). In Oriental ethnic groups with a traditionally low calcium intake, VDR genotypes associated with a low BMD have a lower frequency compared to the Western populations which points to a genetic selection. Aside from BMD, VDR polymorphisms might be linked to cellular proliferation, osteophyte formation, prostate cancer, hyperparathyroidism ${ }$ and perhaps diabetes (Wood and Fleet 1998).

\section{Classical actions of vitamin D}

The responses to calcitriol are tissue specific and depend on the state of cellular differentiation and concentration of calcitriol. This implies that effects may be opposite to each other, as has been reported for calcitonin and type 1 collagen (Marcus 1996a; Dambacher and Schacht 1996). In Table 2.1 a number of calcitriol regulated proteins are listed. The active uptake of calcium as well as the sodium dependent uptake of phosphate is controlled by calcitriol (Marcus 1996a). This control may be as high as $60 \%$ in case of low calcium intakes or as low as $20 \%$ at calcium intakes of about $1,500 \mathrm{mg}$ (Lips 1996). Oestrogens stimulate active callcium absorption by upregulation of gut VDR (Ooms 1994), and by increasing serum levels of DBP (Marcus 1996a). In bone, the principal target cells for calcitriol are believed to be the osteoblasts (Mee 1996) with effects being dependent on the 
stage of cell differentiation and calcitriol concentration. In rat and osteosarcoma cell cultures it was found that genes of osteocalcin, alkaline phosphatase and collagen are down-regulated in proliferating immature osteoblasts but up-regulated in mature osteoblasts (Shearer 1997; Marcus 1996a). With regard to osteoclasts, calcitriol stimulates the retraction of nodule associated osteoblasts to allow for osteoclast interaction, stimulates the differentiation of promonocytes finally into osteoclasts, and activates the synthesis of $\beta_{3}$ protein which is part of the osteoclast surtace marker $\alpha_{v} \beta_{3}$. Binding of this marker to the bone matrix protein osteopontin finally stimulates bone resorption (Marcus 1996a). Some of the bone resorption stimulating effects of calcitriol may be through the up-regulation of epidermal growth factor (EGF) receptors (Reichel 1989). It is thought that the osteoclastmediated effects are especially stimulated in case of high, pharmacological doses vitamine $D$ for long periods (Dambacher and Schacht 1996; Bikle 1994). In skeletal muscle tissue, calcitriol controls muscle contraction through a direct effect on calcium transport and may reduce instability and falls in the elderly (Machlin 1991; Stryer 1995).

In the kidney calcitriol regulates the $1 \alpha$ and 24-hydroxylases and the synthesis of calbindin D28k, a protein mediating the active calcium reabsorption (Marcus 1996a). With age, when renal mass and function falls including the capacity to synthesize calcitriol (Dempster and

Table 2.1: Important calcitriol-dependent proteins and their main physiologic function in bone metabolism.

\begin{tabular}{|c|c|c|c|c|}
\hline Protein & Origin & Function & Action of calcitriol & Reference \\
\hline PTH & parathyroid gland & $\begin{array}{l}\text { stimulation calcitrioll } \\
\text { synthesis } \\
\text { stimulation bone } \\
\text { resorption }\end{array}$ & inhibition & Nordin 1988 \\
\hline Calcitonin & thyroid gland & $\begin{array}{l}\text { inhibition osteoclast } \\
\text { inhibition PTH }\end{array}$ & inhibition/stimulation & $\begin{array}{l}\text { Chen 1997; } \\
\text { Nordin } 1988\end{array}$ \\
\hline 1 $\alpha$-hydroxylase & kidney & synthesis calcitriol & inhibition & Marcus 1996x \\
\hline 24-hydroxylase & a/o. kidney & $\begin{array}{l}\text { metabolisation of } \\
\text { calcitriol }\end{array}$ & stimulation & Marcus 1996a \\
\hline Type I collagen & osteoblast & bone formation & inhibition/stimulation & $\begin{array}{l}\text { Dambacher 1996; } \\
\text { Marcus 1996\% }\end{array}$ \\
\hline Osteocalcin & osteoblast & $\begin{array}{l}\text { coupling bone } \\
\text { formationiresorption }\end{array}$ & stimulation & Marcus 1996a \\
\hline Osteopontin & $\begin{array}{l}\text { osteoblast, } \\
\text { osteoclast. } \\
\text { osteocyte }\end{array}$ & $\begin{array}{l}\text { anchoring of } \\
\text { osteoclasts }\end{array}$ & stimulation & Marcus 1996a \\
\hline $\begin{array}{l}\text { Bone alkaline } \\
\text { phosphatase }\end{array}$ & osteobllast & $\begin{array}{l}\text { mediating bone } \\
\text { formation }\end{array}$ & stimulation & Marcus 1996a. \\
\hline |GF-I receptor & $\begin{array}{l}\text { osteoblast, } \\
\text { osteoclast }\end{array}$ & $\begin{array}{l}\text { mediating bone } \\
\text { formation and } \\
\text { resorption }\end{array}$ & stimulation & Dambacher 1996 \\
\hline $\begin{array}{l}\text { Calcium binding } \\
\text { proteins }\end{array}$ & $\begin{array}{l}\text { a/o. intestine, } \\
\text { kidney }\end{array}$ & transport of calcium & stimulation & Machilin 1991 \\
\hline
\end{tabular}


Figure 2.2: Schematic representation of the role of aging on vitamin D and PTH in bone metabolism

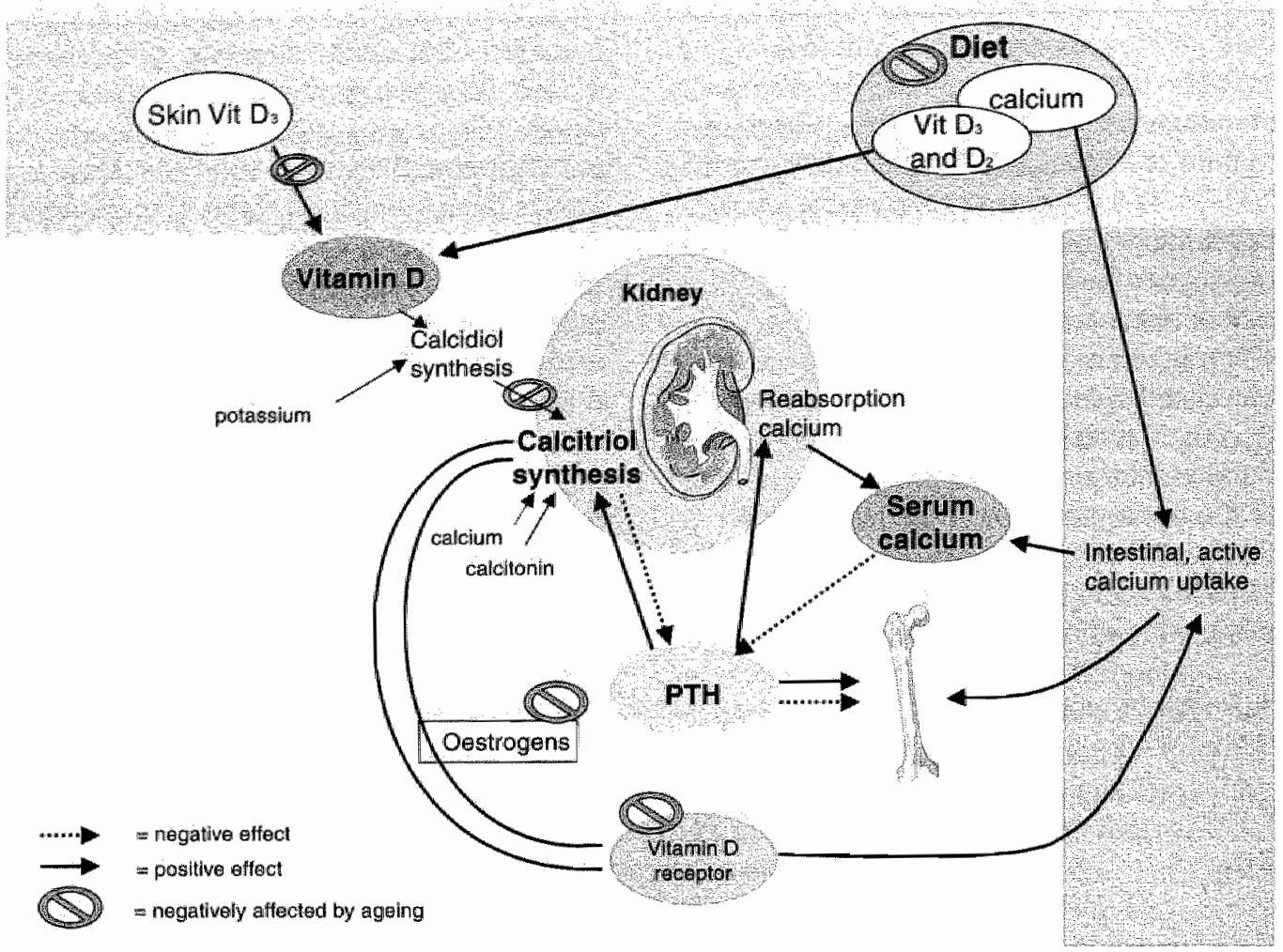

Lindsay 1993), a mild secondary hyperparathyroidism may deveiop to stimulate $1 \alpha$-hydroxylase (Figure 2.2) (Marcus 1996a; Bikle 1994). Vitamin D deficiency, a decreased number of VDR in the parathyroid gland and oestrogen deficiency can also cause hyperparathyroidism (Nordin 1988; Marcus 1996a). Hyperparathyroidism not only stimulates calcitriol synthesis and, hence, intestinal calcium absorption, but also bone turnover (Breslau 1994).

\section{Effects of vitamin D supplementation} Supplementation can take place by giving either vitamin $D$ or one of its metabolites (Dambacher and Schacht 1996). Major effects of vitamin $D$ treatment are a lowering of serum PTH levels and an increase in intestinal calcium absorption
(Kinyamu 1998; Lukert 1992). In early postmenopausal women therefore, vitamin D might be less effective since PTH levels are already reduced because of adequate serum calcium levels (Prentice 1997). However, these women may develop an increased sensitivity to normal serum levels of PTH, which stimulates bone turnover. Small or no effects were seen with 300 or $400 \mathrm{IU}$ of vitamin D per day on BMD or calcitriol synthesis in early postmenopausal women with a high calcium intake (Komulainen 1997; Aloia 1996). Treatment of early postmenopausa! Japanese women (Chen 1997) with an oral dose of $0.75 \mu \mathrm{g}$ of $1 \alpha$-hydroxyvitamin $D_{3}$, decreased serum PTH levels and bone resorption, and slightly but significantly increased BMD of the lumbar spine. This study supports the idea that vitamin $D$ 
treatment in early postmenopausal women is most effective when synthesis of calcitriol is not or less dependent on serum PTH (Tuppurainen 1998). In the elderly, additional dietary vitamin D (up to $800 \mathrm{IU}$ per day) possibly prevents an important number of fractures, particular in those on a marginal calcium and vitamin $D$ intake (Lips 1996; Torgerson and Kanis 1995; Chapuy 1992). In Finnish elderly (with a suggested adequate intake of calcium) a single injection of 150,000 to $300,000 \| \mathrm{U}$ vitamin $D$ significantly reduced all fractures (Heikinheino 1992). Contradictory results were found between a Dutch (Lips 1996) and French study (Chapuy 1992). The Dutch participants did not show a reduction in hip fractures. They differed from the French by being relative healthy and by having already that a lower incidence of hip fractures. Furthermore, the Dutch received no additional calcium, had a lower total daily calcium intake and a lower vitamin D supplementation ( 400 IU versus 800 (U). These lower intakes may have negatively "influenced fracture prevention. A dosage of 400 IU of vitamin D was reported to be ineffective in postmenopausal osteoporosis (Dambacher and Schacht 1996). In combination with oestrogen therapy, $300 \mathrm{IU}$ of vitamin $\mathbb{D}_{3}$ per day had an additional positive effect on femoral neck. BMD in osteoporotic women $(7.1$ years postmenopausal, $750 \mathrm{mg}$ calcium per day) (Tuppurainen 1998).

\section{Magnesium}

Magnesium is the fourth most abundant ellement in the body, about $25 \mathrm{~g}$ in total (Eastwood 1997). Normally, 34\% of total body magnesium is intracellular, $1 \%$ is extracellular and about $65 \%$ is located in bone (Rude and Olerich 1996; Ferment and Touitou 1988). Complexed with ATP, magnesium takes part in many enzyme reactions such as cAMP formation, phosphorylations, and in protein and nucleic acid synthesis (Eastwood 1997).
Magnesium intake is said to be marginal in the entire population (Durlach 1997) but deficiency is seldomly seen. For healthy adult men and women, recommended intakes (Standing Committee on the Scientific Evaluation of Dietary Reference Intakes 1997) are 420 and $320 \mathrm{mg}$ per day respectively. Magnesium is present in most foods, in particular those of vegetable origin containing chlorophyll (Eastwood 1997). High concentrations are found in whole seeds. Relatively poor sources are fish, meat, millk and commonly eaten fruits with the exception of bananas (National Research Councill. 1989). The tolerable upper limit for magnesium from non food sources, i.e. additional magensium for adults is $350 \mathrm{mg}$ (Standing Committee on the Scientific Evaluation of Dietary Reference Intakes 1997).

Intestinal absorption and the role of magnesium in bone metabolism The intestinal absorption, active as well as passive, varies from 25 to $75 \%$ on trigh and low magnesium diets respectively (Eastwood 1997). With increasing age, magnesium absorption decreases. In people older than 70 years of age it is about $70 \%$ of what it was at the age of 30 . This may lead to disturbances in bone. kidney, and hormone metabolism. Aside from a reduced absorption, magnesium may also be lost as a result of urinary leakage (organ function and use of diuretics), diseases and/or their treatments (Durlach 1997).

Five functions are suggested for magnesium in bone metabolism, affecting remodeling, strength and preservation (Kenney 1994; Shils 1980; Driessens and Verbeeck 1988). First, magnesium, which appears to be located on the crystalline surface of bone, destabilizes hydroxyapatite crystals and prevents hydroxyapatite crystall formation. A limitation of hydroxyapatite crystal size increases bone strength (Eaton-Evans 1994; Carpenter 
1992; Sojka 1995). Secondly, magnesium seems to be necessary to maintain the $\mathrm{pH}$ of extra-cellular fluid (ECF) somewhat higher than the $\mathrm{pH}$ of blood to prevent a direct influence of low blood $\mathrm{pH}$ on bone. Patients with osteoporosis showed a decreased ECF pH (Driessens and Verbeeck 1988). Uncontrolled hydrogen ion excretion (via $\mathrm{Na}^{+}-\mathrm{H}^{+}$exchange carriers) by osteoclasts, or insufficiently working potassium pumps of osteocytes may disturb this ECF barrier (Favus 1993; Schaafsma 1987). A higher $\mathrm{pH}$ of ECF also might inhibit the resorption activity of osteoclasts (Morrison and Arnett 1998). Third, magnesium stimulates calcitonin, which inhibits osteoclasts (Ferment and Touitou 1988). Fourthly, magnesium deficiency, intracellular depletion in particular, was found to correlate with low serum PTH levels which may result in symptomatic hypocalcemia (Ausman 1999; Rude and Olerich 1996; Ferment and Touitou 1988). Under these conditions, hydroxyapatite crystals may grow larger (Sojka 1995), active bone resorption is impaired, and calcitrial synthesis may be decreased. The $1 \alpha$-hydroxylation of calcidiol is a magnesium-dependent and PTH stimulated reaction (Traba 1985). Finally, in vitro proliferation of osteoblastlike cells was directly related to magnesium concentrations in the medium (Rude and Olerich 1996). Hypomagnesemia in rats resulted in a decreased trabecular bone volume, decreased osteocalcin levels, and a decreased mineral content of the newly formed metaphysis (Carpenter 1992).

\section{Effects of magnesium}

\section{supplementation.}

Higher intakes of dietary magnesium were associated with a higher BMD in elderly men and women in a community-based study (Tucker 1999) and in Japanese elderly living in Hawail (Yano 1995). In two studies with postmenopausal women, however, no associations were found between daily intakes of about $250 \mathrm{mg}$ of dietary magnesium and BMD (Freudenheim 1986; Angus 1988). Two more recent published studies with postmenopausal women suggest an effect of magnesium on BMD after two years of supplementation, but with hinger daily intakes of magnesium. In five patients with gluten-sensitive enteropathy, BMD of the femoral neck and total proximal femur increased significantly after an intake of about $500 \mathrm{mg}$ of magnesium per day for 2 years. The increase in lumbar spine BMD was not significant. In 14 women it was shown that serum PTH, possible involved in the effect on BMD, rose only in magnesium depleted subjects and not in subjects with an adequate magnesium status. Low serum PTH may result in hypocalcemia and as a consequence may negatively affect bone metabolism. Magnesium status was assessed by determination of serum magnesium, red blood cell and lymphocyte free magnesium, and total iymphocyte magnesium. Unfortunately this study was not placebo-controlled (Rude and Olerich 1996). In an open, controlled Israelían study with postmenopausal women $(n=31)$, BMD of the ultra-distal radius of the forearm was significantly increased after 2 year supplementation with $250 \mathrm{mg}$ magnesium per day. Total daily magnesium intake was about $500 \mathrm{mg}$. In the untreated controls, mean bone density significantly decreased (Stendig-Lindberg 1993). High intakes of magnesium in combination with low dietary calcium, however, were found to be a risk factor for hip fracture. The reason for this is not clear but an impairment of calcium absorption and stimulation of calcium excretion has been proposed (Michaëlsson 1995).

\section{Strontium}

Strontium is the most abundant trace element in seawater (up to $8 \mathrm{mg} / \mathrm{L}$ ) and as a consequence, levels in seafood may be 
as high as $25 \mathrm{mg} / \mathrm{kg}$ (Cabrera 1999). The body store is about $350 \mathrm{mg}$ of which $99 \%$ is present in bones (Eastwood 1997). The radioactive as well as the stable form of strontium have been found in cow's milk. The potentially dangerous radioactive strontium concentrations (Wiechen Von and Tait 1994) reflect environmental contamination (e.g. above ground nuclear tests) (Florou 1996). Stable strontium concentrations in full cream milk have been found to range from 180 to $2,800 \mu \mathrm{g}$ per liter (Wiechen Von and Tait 1994). Other dietary sources are meat, poultry, wheat bran and the peel of root vegetables. The content in drinking water varies from 20 to $60 \mu \mathrm{g}$ per liter, also higher values have been reported. Daily intakes are estimated to be about 1-3 mg (Shiraishi 1994; Eastwood 1997). Although the LD50 of stable strontium chloride for mice was about $5,000 \mathrm{mg} / \mathrm{kg}$ of body weight (Ghosh 1990), much lower amounts (about $76 \mathrm{mg}$ per day) were found to have deleterious effects on bone in rats (Morohashi 1994).

\section{Absorption and action in bone}

The absorption of strontium is discriminated in favor of calcium (Blakely 1989; Sugihira and Suzuki 1991), as is the uptake in bone mineral (Neufeld and Boskey 1994). In animal studies, this discrimination develops with age (Sugihira and Suzuki 1991). In adults, only $20-40 \%$ of the ingested strontium passes through the intestinal wall. From the absorbed amount about $99 \%$ is stored in bone mineral (Blakely 1989). Clearance of strontium seems to be very rapid (Boivin 1996). In animal models, positive effects on trabecular and cortical bone have been found (Reginster 1997), and a positive correlation was found between bone strength and strontium content (Okayama 1991). Strontium easily exchanges calcium on the surface (i.e. adhesion) of hydroxyapatite crystals in old and new bone, and into (i.e. substitution) the crystals of new bone (Boivin 1996; Neufeld and Boskey 1994). The physiological effects of adhesion or substitution however are different. In vitro, adhesion (up to about $25 \%$ of calcium) inhibited the dissolution of calcium hydroxyapatite and increased bending strength. In contrast, substitution (strontium substituting $10 \%$ of calcium) resulted in a faster dissolution in water, a reduced bending strength (Okayama 1991), and slowed down hydroxyapatite deposition (Christoffersen 1997). High intakes of strontium may also block the biosynthesis of calcidiol into calcitriol and, hence, decrease the active intestinal calcium absorption (Cabrera 1999). In monkeys, a short-term treatment with a high dosage of strontium (up to $128 \mathrm{mg} / \mathrm{kg} /$ day) during 13 weeks did not cause disturbances in bone apposition and calcification (Boivin 1996). In animals and in vitro a positive, direct influence of strontium on osteoblastic cells was found (Canalis 1996; Grynpas and Marie 1990; Marie 1985). A stimulated bone formiation may cause a transitory slight decrease in serum calcium levels (Morohashi 1994; Grynpas 1996). In culture and in young growing animals, strontium increased levels of complexed acidic phospholipids (CPLX) which appear to play a role in initiating mineralization (Neufeld and Boskey 1994; Favus 1993). In vitro however, the strontium increased CPLX abolished calcium incorporation. This may be a result of decreased matrix vesicle degradation, which is necessary for mineralization (Cabrera 1999). Matrix vesicles disrupt because of inside developing apatite crystals (Seifert and Watkins 1997). High intakes of strontium may prevent this because of increased non-collagenous proteins of which several prevent hydroxyapatite precipitation (Cabrera 1999) and/or because incorporation of strontium into the initial hydroxyapatite crystals impairs further proliferation (Neufeld and Boskey 1994). 
Effects of strontium supplementation In the fifties, strontium lactate was already used to treat osteoporosis in daily doses representing $1,700 \mathrm{mg}$ of strontium for periods ranging from 3 months to 3 years (McCaslin and Janes 1959). A two-year trial with postmenopausal, osteoporotic women supplemented with about $340 \mathrm{mg}$ of strontium per day (in the form of S12911) resulted in a significant increase in lumbar spine BMD and reduced the number of new vertebral fractures (Reginster 1997). Although strontium may cause false positive BMD increases because of a higher atomic number than calcium (Christoffersen 1997), an increased BMD of the lumbar spine was also found after adjustment for bone strontium content in early postmenopausal women with a daily intake of $170 \mathrm{mg}$ of strontium (S12911) and $500 \mathrm{mg}$ of calcium for two years. The placebo group showed a decreased BMD (Reginster 1998b). In pain treatment, e.g. caused by bone metastases and osteoporosis, not only radioactive strontium but also stable strontium has been shown to be successful (Morohashi 1994; McCaslin and Janes 1959; Robinson 1993).

\section{Fluorine}

Fiuorine is an essential trace element required for normal dental and skeletal development (Turner 1993). However, longterm consumption ( $>10$ years) of relatively low amounts of fluorine per day ( $\geq 10 \mathrm{mg}$ ) may lead to skeletal fluorosis. The adequate dally intake for 19 years and older is $3.8 \mathrm{mg}$ and $3.1 \mathrm{mg}$ per day for males and temales, respectively, with a tolerable upper level of $10 \mathrm{mg}$ per day (Standing Committee on the Scientific Evaluation of Dietary Reference intakes 1997). About $99 \%$ of the body fluorine is found in bone and increases with age because of a long residence time (Machlin 1991). At concentrations as high as 10,000 ppm, bone strength decreases by about
$13 \%$ with normal calcium intakes or by as much as $45 \%$ in case of calcium deficiency (Turner 1993). The concentrations of fluorine in soil, water and many foods vary due to soil fertilizers, pollution, and enrichment strategies. A rich source of fluorine is tea (Standing Committee on the Scientific Evaluation of Dietary Reference Intakes 1997). High intakes of tea have been associated with fluorosis (Cao 1996). In patients with renal deficiency, small doses equivalent to 3-10 $\mathrm{mg}$ per liter of drinking water may already impair mineralization (Turner 1996).

\section{Intestinal absorption and action on bone}

Fluorine is passively absorbed from the intestine, lungs and skin. In the intestine, absorption ranges from $90 \%$ in water to 65 $100 \%$ in food and fluoride preparations (Marcus 1996a; Turner 1993; Rao 1995). Absorption is negatively affected by low gastric acid secretion and concurrent administration of calcium (Marcus 1996a) except for sodium mono-fluorphosphate. In air ${ }_{n}$ hydrogen fluoride is the dominant form, which is rapidly absorbed from the respiratory tract (Turner 1993; Rao 1995). In the body, fluorine stimulates the proliferation of preosteoblasts (Turner 1993) which increases the number of osteoblasts (Patel 1996) without affecting bone resorption. A stimulation of osteoblastic activity leads to overfilling of resorption cavities; increasing trabeculae thickness and bone volume (Marcus 1996a). Vitamin D supplementation seems to be necessary to blunt the increase in osteoid thickness, stimulating a proper mineralization. There is no evidence for the formation of new trabeculae (Balena 1998). The action on preosteoblasts is mediated by one or more growth factors such as insulin-like growth factor-1 (IGF-i) and TGFB (Marcus 1996a). It also has been suggested that, due to fluoride treatment, flat lining cells de-differentiate into 
osteoblasts or become replaced by new asteoblasts, bypassing the normal sequence of remodeling (Balena 1998). Theoretically, active fasting serum fluorine level, substantiated by increased BMD in fluoride treated patients, to stimulate osteoblasts ranges from 5 to $15 \mu \mathrm{mol} / \mathrm{L}$ (Marcus 1996a; Turner 1993). Such levels have been recorded at an intake of 26.4 $\mathrm{mg}$ of fluorine per day (Pak 1995).

Proposed cellular mechanisms are based on the $\mathrm{G}$ protein (guanyl nucleotide-binding proteins) hypothesis and the tyrosine phosphatase hypothesis (Caverzasio 1998). In the G protein hypothesis, fluorine activates a heterotrimeric $\mathrm{G}$ protein, probably by interaction with GDP to form a GTP-like molecule. Activation of GTPbinding proteins may stimulate protein kinase $C$ that subsequently leads to cell proliferation (Marcus 1996a; Stryer 1995; Caverzasio 1998). The tyrosine phosphatase hypothesis is based on inhibition of phosphotyrosyl protein phosphatase (PTPP) by fluorine (Figure 2.3) (Marcus 1996a). Due to the inhibition of PTPP, activation of a receptor tyrosinekinase (Alberts 1994) by growth factor binding such as IGF-I or TGF $\beta$ leads to a cascade of phosphorylations, DNA

Figure 2.3: Schematic and simplified scheme of the suggested role of fluorine in the proliferation of pre-osteoblasts after activation of the receptor tyrosine-kinase by growth factor binding.

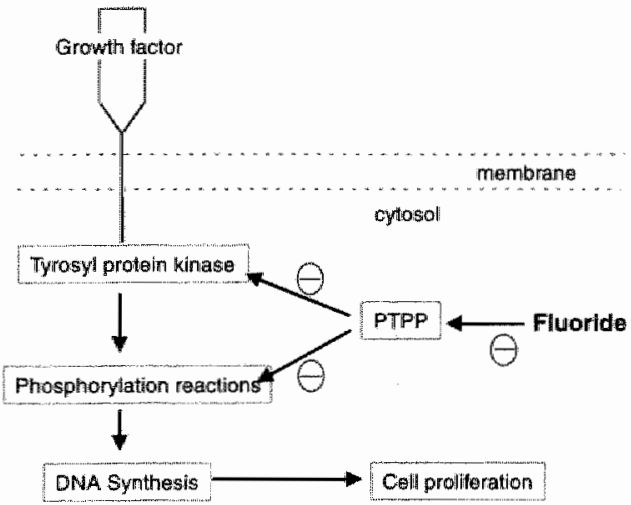

synthesis, and finally to cell proliferation. Evidence for the PTPP-route is the blocking of the mitogenic effect of fluorine by the phyto-oestrogen genistein, found in soybean, which is a tyrosyl kinase inhibitor (Marcus 1996a). Extracellularly, the incorporation of fluorine (substituting hydroxyl ions) in bone, particularly in newly formed trabecular bone, results in the formation of fluoroapatite crystals which are less soluble and larger than the hydroxyapatite crystals (Marcus 1996a; Baud 1977; Duursma 1986). Larger crystals predict an increased compressive strength, but a reduced bending strength, which might explain a reported increase in crystal brittleness (Marcus 1996a).

\section{Effects of fluoride supplementation}

Fluoride in dosages of $50-75 \mathrm{mg}$ sodium fluoride (26.4-33.9 mg of fluorine) per day increased calcium balance (Schaafsma 1987), bone mineralization, and in vitro collagen production (Duursma 1986). Positive effects on BMD are especially seen in the axial skeleton and may last for as long as 6 years (Marcus 1996a). Other sites, e.g. hip and forearm, might be positively or negatively affected depending on concentrations of fluorine and calcium. The latter may become marginal as a result of increased bone formation (Marcus 1996a; Patel 1996; Pak 1995). Effects on fracture prevention are not clear. Treatment with about $40 \mathrm{mg}$ of fluorine per day increased the rate of appendicular fractures and microfractures (Riggs 1990). A fluoridation strategy of drinking water (1 $\mathrm{ppm}$ ) in Germany over a period of 30 years however, was associated with a reduced number of hip fractures in the very old (Lehmann 1998).

A number of studies (Reginster 1998a; Balena 1998a; Meunier 1998a; Patel 1996a; Pak 1995a) have been performed in people with osteoporosis using 20 to about $26 \mathrm{mg}$ of fluorine per day with additional calcium supplementation of 400 and 
$1,000 \mathrm{mg}$. After study periods ranging from 12 to 48 months, increases in lumbar spine $\mathrm{BMD}$ of 10 to $24 \%$ were found: In late postmeno-pausal women with (Ringe 1999) or without (Hansson and Roos 1987) osteoporosis, a lower daily

supplementation of fluorine $(11.2$ and 13.5 mg respectively) combined with $1,000 \mathrm{mg}$ of calcium increased lumbar spine BMD with 12.6 and $17 \%$ during study pertods of 3 years. Three of the before mentioned studies with a duration of 36 or 48 months also reported increases in BMD of the temoral neck (Ringe 1999; Pak 1995), Ward's triangle and trochanter (Ringe 1999), and total hip (Reginster 1998a). Only in the low dose study (Ringe 1999) the increases in BMD of the hip were significantiy different from calcium supplementation alone. Furthermore, all three studies showed a decrease in spinal fracture rate. It has been suggested that the loss of cancelous bone microarchitecture before treatment might explain the low or absence of reduction in fracture risk in other studies (Meunier 1998). No differences were found between continuous and intermittent administration of the same total amount of fluorine. Biopsies indicate that the incidence of osteomalacia was related to fluoride dosage ( 26 and $34 \mathrm{mg}$ of fiuorine) but could at least in part be overcome by additional vitamin $D$ supplementation (Balena 1998).

\section{Boron}

Boron has a function in the maintenance of bone health, especially in the case of deficiencies of vitamin $D_{3}$ magnesium and potassium (Nielsen 1990; Beattie and Peace 1993). When there is no nutritional or metabolic stress, the need for boron seems to be low (Volpe 1993).

A level of about $1 \mathrm{mg}$ per day has been suggested. Intakes of 3 to $4 \mathrm{~g}$ of boron for adults and $1 \mathrm{~g}$ for infants are thought to be toxic (Naghii and Samman 1993). Tissues affected by boron deprivation are the skeleton, kidney and brain (Nielsen 1991). Good sources of boron are fruits

(Moseman 1994), vegetables (Naghii and Samman 1993), nuts (Hunt 1997), and eggs. Particularly rich sources are wine, raisins, dried parsley, and caviar (with boric acid as preservative) (Naghii and Samman 1993). Cow's milk may contain boron in a wide range of $20-1,000 \mathrm{mg} / \mathrm{L}$, which is considered to reflect the amount in the diet (Moseman 1994; Flynn 1992). Daily intakes were calculated to range from 0.3 to $41 \mathrm{mg}$ per day (Naghii and Samman 1993), but perhaps a more realistic reported range is 0.5 to $3.1 \mathrm{mg}$ of boron per day (Blego 1998; Shils 1994).

\section{Intestinal absorption and action on bone and bone tissue}

Boron is rapidly and efficiently absorbed (Shils 1994). Several animal studies (rats, mice and pigs) have shown that boron supplementation ( 3 to $12 \mathrm{mg} / \mathrm{kg}$ diet or per $\mathrm{kg}$ body weight) influenced metabolism and functional properties of bone in combination with calcium and magnesium deficient diets. Different effects were seen on the femur and vertebrae, being often positive for the latter (increased compression load) but negative for the former (thininer femur wall, diminished bone and osteoid mass). A high boron intake (350 $\mathrm{mg}$ per liter of drinking water) reduced osteoblast activity in rats (McCoy 1994; Mertz 1993). Boron supplementation ( $3 \mathrm{mg} /$ day) increased serum concentrations of oestradiol- $17 \beta$ and testosterone in postmenopausal women (Nielsen 1987) possibly by changing the rate or pathway for the catabolism and excretion of these hormones (Beattie and Peace 1993). This effect was especially present in women with a low magnesium status (Nielsen 1987). Some findings suggest that boron enhances (Naghii and Samman 1993) the formation of active or hydroxylated forms of some specific steroid or steroid related hormones (e.g. the 
hydroxylated form of vitamin D) (Flynn 1992). Furthermore, boron may have a regulatory role in maintaining proper cell membrane function (e.g. transmembrane signaling) or stability (Nielsen 1991). It seems that boron supplementation leads to accumulation of boron in bone but not in soft tissue, whereas a high percentage of the absorbed boron is rapidly excreted in urine (Moseman 1994; Beattie and Peace 1993).

\section{Effects of boron supplementation} Boron has been reported to have an antiarthritic effect at intakes of 3 to $10 \mathrm{mg}$ per day, possibly through stimulation of the synthesis of corticosteroids (Naghii and Samman 1993; Newnham 1994). In healthy postmenopausal women, a supplement of $3 \mathrm{mg}$ of boron (total daily intake $3.25 \mathrm{mg}$ ) decreased urinary calcium and magnesium excretion and doubled plasma oestradiol and testosterone concentrations (Nielsen 1987; Nielsen 1990) to levels as found in women on oestrogen replacement therapy (Naghii and Samman 1993). However, these effects could not be confirmed (Beattie and Peace 1993) in another study which differed in some aspects from the former (i.e., lower serum concentrations of oestradiol at the start, an intake of about $300 \mathrm{mg}$ of magnesium per day, and a shorter boron depletion period). The higher intake of magnesium possibly can explain the absence of a reducing effect on calcium excretion. A daily intake of about $300 \mathrm{mg}$ of magnesium combined with boron supplementation was found to increase urinary calcium loss in postmenopausal women at a later date (Hunt 1997). Clinical observations led to the suggestion that boron supplements accelerate the healing of broken bones (Newnham 1994).

\section{Vitamin K}

Compounds with vitamin $\mathrm{K}$ activity contain the 2-methyl-1,4-napthoquinone nucleus with a lipophilic side chain at position 3 (Shils 1994). Three types of vitamin K are known, vitamin $K_{1}$ or phylloquinone, vitamin $\mathrm{K}_{2}$ series or menaquinones (called MK-4 up to MK-13), and menadione (formerly $K_{3}$ ) (Eastwood 1997; Vermeer 1995). The latter may be toxic as it can combine with sulfydryl groups in membranes (Shils 1994). $K_{1}$ and $K_{2}$ have a low toxicity (Machlin 1991). Vitamin $K_{1}$ is present in especially dark, leafy green vegetables ( $40-50 \%$ of total intake (Booth and Suttie 1998)), fruit, and the oils from soybean, canola, cottonseed, and olive (Booth and Centurelli 1999; Shearer 1996). Amounts in dairy products and grains may vary from 2 to $70 \mu \mathrm{g} / \mathrm{kg}$ (Vermeer 1995). Vitamin $\mathrm{K}_{2}$, estimated to contribute 10 to $30 \%$ to daily vitamin K requirement (Shils 1994), is found in fermented dairy (cheese in particularly) and soy products, and is synthesized by the intestinal microflora (Schurgers 1999; Booth and Suttie 1998; Lips 1996). Moderate amounts are found in fish, meat, liver and eggs (Lips 1996;" Vermeer 1995).

The dietary intake of vitamin $\mathrm{K}$ as well as the circulating levels (expressed as a ratio to triglyceride) decrease with age (Booth and Suttle 1998; Vermeer 1995). It is of interest to know that vitamin $\mathrm{K}$ might be an important inhibitor of the aging of the nervous system (Tsaioun 1999). High losses (40-60\% in feces) and low body stores $(50-100 \mu \mathrm{g})$ emphasize the need for a daily supply of vitamin K (Shearer 1996; Shils 1994). Based on markers of bone formation and on BMD, it is suggested that vitamin $\mathrm{K}$ intakes should be much higher than currently recommended $(80 \mu \mathrm{g}$ for men and $65 \mu \mathrm{g}$ for women (Weber 1997)). In The Netherlands, the daily intake of vitamin $K_{1}$ by subjects $55-70$ years of age was found to be already four times higher (about $250 \mu \mathrm{g}$ ) (Schurgers 1999). 
Intestinal absorption and action on bone

Intestinal absorption of vitamin $K_{1}$ along with dietary fat occurs with an efficiency of 40 to $80 \%$ (Olson 1984). Especially supplemented vitamin $K$ has a high absorbability (Vermeer 1997). Vitamin $K_{\text {. }}$ absorption from the natural food matrix is low, its absorption from green vegetables has been found to be $5-15 \%$ (KoivuTikkanen 2000). Vitamin $\mathrm{K}_{2}$ derived from the intestinal microflora possibly is absorbed in the terminal ileum along with the reabsorption of bile salts. Long MKs are poorly absorbed (Shearer 1997; Shearer 1996). After absorption vitamin $K_{1}$ is transported in chylomicrons to target tissues and the liver (Vermeer 1995). The liver and bone marrow clear chylomicrons (and thus vitamin K). Dependent on the genetic variant of the apoE this clearance rate is higher or lower (apoE4>apoE3> apoE2) (Lamon-Fava 1998; Kohlmeier 1996). A part of the vitamin $K_{1}$ might be delivered to extrahepatic tissues via $L D L$ (Lamon-Fava 1998). Liver stores of vitamin $K$ are relatively small and for about $90 \%$ MK-7 to MK-13 (Vermeer 1996; Shearer 1996). The dominant form in bone is vitamin $\mathrm{K}_{1}$ (Kohlmeier 1996).

Vitamin $K$ is an essential co-factor in posttranslational carboxylation, transforming specific glutamate residues (Glu) into $\psi$ carboxyglutamic acid (Gla). Gla residues increase the affinity of proteins for calcium (Ferland 1998). Deficiency or antagonism of vitamin $\mathrm{K}(\mathrm{e}, \mathrm{g}$. by coumarin derivatives (Vermeer 1996), or vitamin $A$ and $E$ in pharmacological doses (Machlin 1991; Shils 1994)) results in undercarboxylation of the specific proteins. Matrix Gla protein, protein $S$, nephrocalcin, and osteocalcin are vitamin $\mathrm{K}$-dependent proteins involved in bone metabolism (Booth 1997). Matrix Gla protein, synthesized in osteoblasts, chandrocytes (Anderson and Garner 1997) and most soft tissues, is stimulated by calcitriol (Vermeer 1995; Booth 1997), and does not react with hydroxyapatite (Shils 1994). This protein appears earlier than osteocalcin possibly preventing calcification of arteries and cartilage (Jie 1996; Booth 1997). Protein $S$, is produced by osteoblasts, hepatocytes, megakaryocytes, and endothelial cells. Based on reported osteopenia and vertebral body compression fractures in case of protein $S$ deficiency, a role in bone metabolism is suggested (Binkley and Suttie 1995; Vermeer 1995). Nephrocalcin probably was involved in a reduction of urinary calcium loss in a group of 'fast calcium losing" postmenopausal women. No effect was seen in 'normal' or 'slow' losers (Binkley and Suttie 1995).

Osteocalcin is the most well known vitamin K-dependent protein in bone metabolism, synthesized by osteoblasts and osteocytes (particularly newly embedded osteocytes). Carboxylated osteocalcin functions as a negative regulator of bone formation (Wolf 1996). It has a high specificity for calcium in hydroxyapatite and inhibits hydroxyapatite formation (Shils 1994). In this way a proper mineral maturation is stimulated (Boskey 1998) without altering bone resorption (Ferland 1998). A small amount of carboxylated osteocalcin is released into the circulation (Sokoll 1997). The Cterminal domain of osteocalcin has chemotactic properties for osteoclast-like cells (Vermeer 1996), possibly only premature osteoclasts (Reichel 1989). The undercarboxylated osteocalcin in serum or its ratio with carboxylated osteocalcin seems to be a sensitive indicator for bone pathology (Knapen 1993: Liu and Peacock 1998) and a predictor of fracture risk (Kohlmeier 1997; Booth 1997).

In postmenopausal women, 1 to 10 years past menopause, undercarboxylated osteocalcin was correlated with lower BMD of Ward's triangle and femoral neck in particular (Knapen 1998). This is in line with the development of more severe 
osteoporosis in ovariectomized, osteocalcin-free mutant mice compared with wild-type mice (Wolf 1996). From a prospective study in women an inverse association between dietary vitamin $\mathrm{K}$ and the risk of hip fractures was observed (Feskanich 1999). The percentage of carboxylated osteocalcin from total osteocalcin was found to range from 70 to $80 \%$ in young, healthy adults (Booth 1999; Jie 1996). In postmenopausal women without and with aortic calcifications this percentage was $59.4 \%$ and $54.6 \%$, respectively (Jie 1996). Other reported anti-osteoporotic vitamin K-activities are the inhibition of interleukin- 6 by vitamin $K_{1}$, $K_{2}$ and menadione in vitro (Reddi 1995), and inhibition of osteoclast formation and stimulation of their apoptosis specifically by MK-4 (Vermeer 1995; Shearer 1997). An inhibitory effect of vitamin $\mathrm{K}_{2}$ on bone resorption might be a result of a suppressed $\mathrm{PGE}_{2}$ synthesis (Shearer 1997).

\section{Effects of vitamin $K$ supplementation} in postmenopausall women with colles fractures, the percentage of carboxylated osteocalcin rose from $56.1 \%$ to $74.8 \%$ after a daily intake of $1 \mathrm{mg}$ of vitamin $\mathrm{K}_{1}$ during two weeks (Douglas 1995). In another group of postmenopausal women, carboxylated osteocalcin was correlated with alkaline bone phosphatase, whereas undercarboxylated osteocalcin was correlated with urinary calcium excretion after 3 months of treatment with $1 \mathrm{mg}$ of vitamin K per day (Knapen 1993).

Treatment of high calcium losers with $1 \mathrm{mg}$ of vitamin $\mathrm{K}_{3}$ per day reduced urinary calcium and hydroxyproline excretion (Vermeer 1995). In young, healthy subjects (20-40 years old) and in older subjects (6080 years old), an increase in the daily intake of vitamin $\mathrm{K}$ during 5 days from 100 to $420 \mu \mathrm{g}$ reduced the undercarboxylated fraction of osteocalcin by about $40 \%$ (Booth 1999; Sokoll 1997).
MK-4, synthesized from menadione or $K_{\text {. }}$ (Shearer 1997), in large doses (45 mg/d) was found to have a significant therapeutic effect on involutional osteoporosis (Orino 1992). The same dosis was effective in vitamin D-and vitamin K-deficient stroke patients who increased BMD $(4.3 \% \pm$ $9.9 \%$ ) of the second metacarpal on hemiplegic sides and showed a smaller loss of BMD on the intact side compared with the untreated group (Sato 1998). The effects of dietary vitamin $\mathrm{K}$ on age-related bone loss, however, were not of the same teno in two studies among older women who used warfarin (a vitamin $K$ antagonist). It has to be remarked however, that no information was avallable about the vitamin-K status of participants (Booth 2000).

\section{Vitamin C}

Vitamin $C$ (ascorbic acid) is a simple sugar and powerful reducing agent synthesized from glucose in many plant and animal tissues but not in man. Enzyme reactions, which require vitamin $\mathrm{C}$, include those involved in the synthesis of hydroxyproline and hydroxylysine, and the amidation of calcitonin (Ausman 1999). Of the fresh fruit and juices, black currant, guavas, Hawthorn berries, acerola, and rose hips are particular rich in vitamin $\mathrm{C}$. Other important sources are leafy, green vegetables (Eastwood 1997). The daily recommended amount of vitamin $C$ is 60 $\mathrm{mg}$ for those older than 50 years of age (National Research Council. 1989), however, this will probably increase to levels of $100-200 \mathrm{mg} /$ day. Although intakes higher than $1 \mathrm{~g}$ of ascorbic acid do not seem to cause toxic symptoms, routine use of such large doses is not recommended (Ausman 1999).

\section{Action on bone metabolism}

Vitamin $C$ is well absorbed, $>80 \%$ at low doses, by passive and active transport mechanisms particularly in the small 
intestine. The body pool has been callulated to be greater than $1.400 \mathrm{mg}$ in healthy male adults, with a turnover rate of 45-60 mg/day (Machlin 1991). Osteoblasts contain a specific saturable, stereoselective (low uptake of D-isoascorbic acid) transport system for vitamin $C$ (Franceschl and Lyer 1992), which is probably $\mathrm{Na}^{+}$ gradient dependent (Franceschi 1995).

The maximum capacity of the $\mathrm{Na}^{+}$ dependent transporter is within the range of normal serum levels of vitamin $C$ of about 10-100 uM (Wolf 1996b). These levels can be achieved with intakes of 40 to $1,000 \mathrm{mg}$ of vitamin C per day (Shils 1994). Therefore, higher dietary intakes would not have much effect on uptake into tissues that produce collagen (Wolf 1996b). It seems that vitamin $C$ increases hydroxylation (by prolyl- and lysylhydroxylases (Eastwood 1997)) of procollagen approximately fiveiold (Franceschi and Lyer 1992). This is an important stimulus for an increased translation and transcription of pro-collagen mRNA. Furthermore, vitamin $C$ stimulates osteoblasts to produce osteocalcin and alkaline phosphatase, and to lay down bone matrix (Franceschi and Lyer 1992; Wolf 1996b).

Bacterial lipopolysaccharides, which activate the complement, have been reported to inhibit vitamin $C$ transport into the osteobllast. This inhibition by complement may, in part, explain the defects in bone repair associated with inflammatory bone diseases such as periodontitis (Franceschi 1995). Urinary excretion of vitamin $\mathrm{C}_{\text {, }}$ as free ascorbic aciid or as oxalate, occurs when the plasma concentration exceeds $70 \mu \mathrm{M} / \mathrm{L}$. A high excretion of oxalate may cause the development of oxalate stones (Eastwood 1997).

\section{Vitamin $C$ and $B M D$}

In healthy premenopausal women the intake of vitamin $C$ was positively correlated with BMD of the lumbar spine, the greatest effects were seen in case of moderate vitamin C intakes (New 1997). In postmenopausal Mexican-American and Caucasian-American women, a positive association was found between dietary vitamin $\mathrm{C}$ and femoral neck BMD ( Hall and Greendale 1998). In the Caucasian women, the association of vitamin $\mathrm{C}$ with BMD was stronger in case diets were higher in calcium (>500 mg/day). This agrees with studies that link vitamin $C$ with a lower risk for hip fracture (Wang 1997). An association between dietary vitamin $C$ (113 $\mathrm{mg} /$ day) and BMD of the hip was not found in another American study (Leveille 1997) with postmenopausal women. However, long term use of vitamin $\mathrm{C}$ supplements (mean total intake $407 \mathrm{mg}$ of vitamin ( per day) in this study was associated with higher BMD of the hip especially in those participants who never used oestrogen preparations and only in women 55-64 years of age. These studies suggest a positive role of vitamin $C$ in the prevention of postmenopausal bone loss in moderate amounts (New 1997) but which are higher than the amounts currently recommended (Levellle 1997).

\section{Discussion}

A high peak bone mass after adolescence provides a profitable starting point at the moment bone mass is lost because of aging and menopause. Following menopause an adequate intake of a number of nutrients will delay or prevent natural bone loss (Table 2.2). The basic element is calcium. Small differences in absorption between several calcium sources do not play an important role. The problem of a lower gastric acid secretion in older women can be overcome by supplementing with liquid calcium citrate (Krishnamra 1992), but also by supplying calcium supplements together with the meal (Heaney 1999). Problems with inhibition of other ingredients in the meal 
are, except for iron, not to be expected.

Frequently ingesting smaller amounts of callium are preferred over a single dosage because efficiency of absorption increases. The effects of calcium supplementation in early postmenopausal women are moderate but nevertheless useful because marginal or low calcium intakes are prevented, and oestrogen and calcitonin therapies are improved (Nieves 1998). In late postmenopausal women and elderly, calcium supplementation to a total daily calcium intake of at least $1,500 \mathrm{mg}$ seems to increase BMD of the spine in particular, and can reduce the number of fractures (Chevalley 1994; Reild 1995; Holbrook 1988).

Fracture reduction is also suggested from vitamin D studies with older women (Heikinheinno 1992; Lips 1996), especially in combination with a sufficient calcium intake (Chapuy 1992). Prevention strategies and long term use indicate that effective additional amounts are in the range of 400 to $8001 \mathrm{IU}$ of vitamin D per day. An effective intake should lead to serum calcidiol levels of about $100 \mathrm{nmol} / \mathrm{L}$ (Vieth 1999). Early postmenopausal women are not very sensitive to vitamin $D$ therapy. A declined set point for bone mass as a result of oestrogen deficiency causes an increased lloss of bone, and as a consequence adequate serum calcium levels, and a decreased need for calcitriol synthesis (Breslau 1994; Marculs 1996a). Only treatment with ready to use vitamin $D$ metabolites seems to be effective alt this stage of life.

The role of magnesium in bone health seems to be underestimated. Based on the five suggested functions, bone strength, preservation and possible formation are stimulated. Effects of magnesium on blood $\mathrm{pH}$ are highest about 4 hours after intake, which makes extra magnesium in the evening most effective because ECF $\mathrm{pH}$ is lowest at night (Driessens 1993). Evidence for an effect of magnesium on BMD in postmenopausal women, however, is scarce since only two studies have been published. Another beneficial effect of magnesium is the inhibition of soft tissue calcification (Driessens and Verbeeck 1988 ), which is suggested to be positive for the cardiovascular system, especially in case of high calcium diets (Shils 1994). Strontium might be a very interesting element with anabolic effects on bone through stimulation of osteoblasts and inhibition of osteoclasts. The effective amounts however are not clear. Although high amounts (e.g. $170 \mathrm{mg}$ per day) showed positive effects on BMD (Reginster 1999), incorporation of strontium into hydroxyapatite crystals, which is a long term effect, may lead to a reduced bending strength, a higher solubility and as a result a possibly higher rate of remodeling. In contrast, strontium adhered to existing hydroxyapatite, which is a short-term effect, increases bone strength and reduces sollubility (Christoffersen 1997; Okayama 1991). The intake of strontium should therefore be low enough to minimize incorporation into newly formed crystals but high enough to have an effect on the surface of existing crystals. That is why in preventive strategies, for the time being, additional amounts of strontium close to the suggested daily intakes of 1-3 mg might be preferred over therapeutic doses of $170 \mathrm{mg}$.

Fluorine intakes, varying from about 14 to $30 \mathrm{mg}$ per day are able to increase BMD of the axial skeleton considerably but effects on fracture reduction are marginal. Effects. on BMD of the hip are much smaller. Due to fluorine incorporation in hydroxyapatite crystals, bending strength might even decrease (Marcus 1996a). Incorporation of fluorine also decreases solubility and by that remodeling.

In time, fluoride concentrations in bone may reach toxic levels. On the one hand it has been shown in vitro (Marcus 1996a) 
Table 2.2: Suggested additional intakes ${ }^{2}$ for postmenopausal women and major actions on bone of calcium, magnesium, strontium, boron, fluoride, and the vitamins $\mathrm{C}, \mathrm{D}$ and $\mathrm{K}$.

\begin{tabular}{|c|c|c|c|}
\hline Component & $\begin{array}{l}\text { Additional daily } \\
\text { intake }\end{array}$ & Action on bone & Action through \\
\hline Calcium & $400-800 \mathrm{mg}$ & Reduction of bone turnover & Lowering of PTH \\
\hline Magnesium & $100 \cdot 200 \mathrm{mg}$ & $\begin{array}{l}\text { Bore strength } \\
\text { Bone preserwation } \\
\text { Reduction bone resorption } \\
\text { Stimulation bone formation } \\
\text { Reduction of bone turnover }\end{array}$ & $\begin{array}{l}\text { Limited HA } \mathrm{A}^{\mathrm{B}} \text {-crystal size } \\
\text { Higher pH ECF } \\
\text { Stimulation calcitonin } \\
\text { Proliferation osteoblasts } \\
\text { Synthesis of calcitriol, decreased } \\
\text { PTH secretion }\end{array}$ \\
\hline Strontium & $1-3 \mathrm{mg}$ & $\begin{array}{l}\text { Bone preservation } \\
\text { Stimulation bone formation } \\
\text { Pain reduction }\end{array}$ & $\begin{array}{l}\text { Decreased solubility of HA-crystals } \\
\text { Stimulation of osteoblasts }\end{array}$ \\
\hline Boron & up to $3 \mathrm{mg}$ & $\begin{array}{l}\text { Reduction bone resorption } \\
\text { and turnover } \\
\text { Anti-arthritic effect }\end{array}$ & $\begin{array}{l}\text { Stimulation gonadal hormones } \\
\text { Synthesis of corticosteroids }\end{array}$ \\
\hline Fluorine & $2-4 \mathrm{mg}$ & $\begin{array}{l}\text { Bone preservation } \\
\text { Stimulation bone formation }\end{array}$ & $\begin{array}{l}\text { Decreased solubility of HA-crystals } \\
\text { Proliferation of pre-osteoblasts. } \\
\text { differentiation of flat lining cells }\end{array}$ \\
\hline \multirow[t]{4}{*}{ Vitamin D } & $200-400 \mathrm{IU}$ & $\begin{array}{l}\text { Reduction bone turnover } \\
\text { Stimulation bone formation }\end{array}$ & $\begin{array}{l}\text { Lowering of PTH } \\
\text { Stimulation mature osteoblasts, }\end{array}$ \\
\hline & & Stimulation bone resorption & $\begin{array}{l}\text { Formation of osteoclasts, anchoring } \\
\text { of osteoclasts }\end{array}$ \\
\hline & & $\begin{array}{l}\text { Calcium absorption/ } \\
\text { reabsorption }\end{array}$ & Regulation of calcium binding proteins \\
\hline & & Stimulation of skeletal muscle & Cellular calcium transport \\
\hline Vitamin $\mathrm{K}$ & $80 \mu g$ & $\begin{array}{l}\text { Stimulation bone formation } \\
\text { Bone preservation } \\
\text { Reduction bone tumover }\end{array}$ & $\begin{array}{l}\text { Carboxylation of osteocalcin } \\
\text { mhibition of interleukin-6 } \\
\text { Carboxylation of nephrocalcin }\end{array}$ \\
\hline Vitamin $\mathrm{C}$ & up to $100 \mathrm{mg}$ & Stimulation bone formation & $\begin{array}{l}\text { Collagen synthesis, stimulation of } \\
\text { osteocalcin and bone alkaline } \\
\text { phosphatase }\end{array}$ \\
\hline
\end{tabular}

\footnotetext{
"Sugcested additonal intakes in relation to postinenopausal bone motabolism. th is assumed thal intakes from romal nutrition are in line with of close to reconmendeticints or wstimatad satte intakes, of the US FDA or DAI (Standing Comminee on the Scientitic Evaluation of

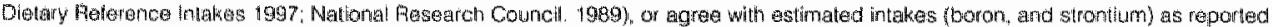
trots hoathy populations. WHydroxyapatitie (HA)
}

that high concentrations of fluorine are necessary for the stimulation of osteoblasts, probably $>26 \mathrm{mg}$ of fluorine per day (Pak 1995). On the other hand, especially low intakes of fluorine were associated with a decreased number of hip fractures in elderly (Lehmann 1998) and late postmenopausal women (Ringe 1999). This and because the anion is bone seeking and has a long residence time are in favor of a chronic supply of low amounts of fluoride e.g. by a regular consumption of 
tea and other fluoricle-rich food ingredients. In all cases of increased fluoride consumption, sufficient intakes of calcium and vitamin $D$ are necessary to support a proper mineralization (Marcus 1996a; Turner 1993).

The role of boron in bone metabolism is especially pronounced in case of magnesilum deficiency. Best effects are seen in patients with arthritis. For these people the suggested boron requirement of about $1 \mathrm{mg}$ per day (Volpe 1993) seems to be too low (Newnham 1994). In postmenopausal women, the preservation of oestrogens (Beattie and Peace 1993) is a positive aspect. The proper dosage of boron however is far from clear (McCoy 1994) but $3 \mathrm{mg}$ of boron per day already suggests positive effects on bone (Naghii and Samman 1993), which is within an achievable dietary range.

Although a number of studies indicate positive effects of vitamin $\mathrm{K}$ on bone health (Tamattani 1998; Binkley and Suttie 1995; Kohimeier 1997), no established causal relationship between vitamin $\mathrm{K}$ deficiency and reduced BMD or increased fracture rate has been found sofar (Binkley and Suttie 1995). Based on the percentage of carboxylated osteocalcin from total osteocalcin, daily vitamin $K$ intakes should be higher in postmenopausal women than currently recommended. Treatment with additional vitamin $\mathrm{K}$ increased carboxylated osteocalcin (Douglas 1995) and increased osteoblast activity (Knapen 1993). This fits within the well-kmown role of osteocalcin as a marker of bone formation. However, it has been suggested that osteocalcin especially plays a role in the 'after bone formation' period in the coupling of formation and resorption (Wolf 1996). This might also explain why osteocalcin has been found to increase in a late stage of fluoride therapy (Patel 1996). Perhaps other vitamin K-dependent proteins, matrix Gla protein and nephrocalcin in particular, deserve more attention.
Vitamin $C$ seems to play a role in bone formation by stimulating osteoblasts (synthesis of alkaline phosphatase and procollagen) and possibly by inthibition of osteoclasts through stimulating the amidation of calcitonin. This is in line with reported positive associations between vitamin $C$ intake and BMD of lumbar spine and hip (Leveille 1997; Wang 1997; New 1997). Based on the capacity of osteoblasts to take up vitamin $C_{\text {, dietary }}$ amounts higher than $1,000 \mathrm{mg}$ are not necessary, but amounts considerably higher than the current recommendations might be beneficial.

Based on the above, it can be concluded that the aforementioned nutrients play a positive role in the delay of natural bone lass (Table 2.2), although for boron this might only be true when magnesium is deficient. It also can be stated that for the afore-mentioned nutrients, a considerable increase (dependent on the component $30-100 \%$ ) of recommended amounts (National Research Council. 1989) or" adequate intakes (Standing Committee on the Scientific Evaluation of Dietary Reference Intakes 1997), or about doubling of the estimated normal intakes, may be very beneficial. Pharmacological amounts, although therapeutically effective, do not seem to be necessary in preventive strategies. Complete foods or supplements are preferred over the supplementation of single nutrients because of the complexity of natural bone loss, the diversity in dietary habitats, and nutrient-nutrient interactions.

Prevention or treatment with nutrients is most effective in late postmenopausal women and elderly. Despite only moderate effects in the early postmenopausal stage, additional supplementation at least overcomes the extra bone loss as a result of malinutrition. 
,
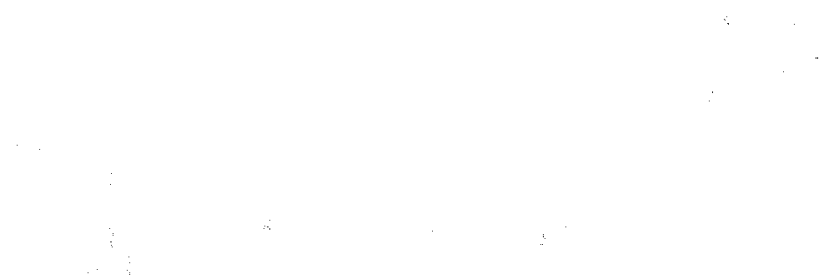

$\therefore$

.

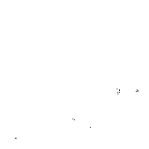

. 


\title{
Mineral, amino acid and hormonal composition of chicken eggshell powder to evaluate its use in human nutrition
}
A. Schaafsma", I. Pakan ${ }^{2}$, G.J.H. Hofstede ${ }^{3}$, E. van der Veer ${ }^{3}$ P.J.F. de Vries"
" Department of Research \& Development Leeuwarden, Friesland Coberco Dairy Foods, Leeuwarden, The Netherlands
2 Department of Surgery, Medical Center Leeuwarden, Leeuwarden "The Netherlands
${ }_{3}$ Pathology and Laboratory Medicine, University Hospital, Groningen, The Netherlands

\section{Submitted}

\begin{abstract}
Chicken eggshell powder (ESP) might be an attractive calcium-source for human nutrition. To study its nutritional value, we analyzed minerals, amino acids and hormones in commercially available Slovakian ESP. The mineral composition was compared with three Dutch ESP samples, which differed in feed and housing, a Japanese ESP, refined calicium carbonate and an oystershell supplement. ESP contains high levels of calcilum (mean \pm $\mathrm{SD} / \mathrm{g}$ ES: $401 \pm 7.2 \mathrm{mg})$ and strontium $(372 \pm 161 \mu \mathrm{g})$ when compared with recommended or estimated daily intakes for man 51-70 years of age. Levels of potentially toxic lead, aluminum, cadmium and mercury were very low as were the levels of vanadium, boron, iron, zinc, phosphorus, magnesium, nitrogen, fluorine, selenium, copper, and chromium. Large differences in the levels of fluorine, selenium, copper, chromium and strontium in the Dutch and Slovakian ESP indicate a strong influence of feed and environment. The small protein fraction of ESP contains high levels of glycine and arginine. Furthermore small amounts of TGF $\beta,(0.75-7.28 \mathrm{ng} / \mathrm{g}$ ESP), calcitonin (10-25 $\mathrm{ng} / \mathrm{g}$ ESP) and progesterone (0.30-0.33 ng/g ESP) were detected. Oestradiol- $17 \beta$ and calcitriol were below the detection limit of the methods used. Compared with ESP, refined calcium carbonate was found to contain increased levels of cadmium whereas the oystershell supplement showed increased levels of aluminum and cadmium. Therefore, ESP seems to have a beneficial composition with about $39 \%$ of elemental calcium, relevant amounts of strontium and low levels of aluminum, lead, cadmium and mercury, and may be used as a calcium-source in human nutrition.
\end{abstract}

Keywords: eggshell, minerals, hormones, amino acids, human nutrition

\section{Introduction}

Severall calcium sources are available for food fortification (Faine 1995). Calcium carbonate is the most widelly used calcium salt with $40 \%$ of well absorbable calcium. This calcium salt can be formullated from calcium hydroxide or chalk in the laboratory, but can also be derived from fossilized or fresh shells (e.gl. chicken eggshell and oyster shell) (Kărkkäinen 1997). Natural calcium sources are of interest, as they do not only contain 
calcium but also other elements (e.g). strontium and fuorine) which may have a positive effect on bone metabolism (Reginster 1999). The safety of natural calcium supplements, however, has been questioned because they may contain relevant amounts of potential toxic elements like lead, aluminum, cadmium and mercury (Whiting 1994).

Chicken eggshells, which serve a first purpose in protection and nutrition of the embryo enclosed (Solomon 1994), have been used by humans for a long period as a food additive but on a very modest scale. Prof. Lichtenstein (1948) already talked about a large store of calcium, which was thrown away instead of being used for human nutrition. in 1953 it was shown that chicken eggshell powder (ESP) had antirachitic effects in rats (Bölönyi and Orsós 1954). In vitro ESP stimulated the growth of chicken embryo cartilage cells (Rovensky 1994). In 1991, demembranized ESP was studied (Makal and Chudacek 1991) in elderly with osteoporosis, which resulted in decreased pain and increased bone mineral density (BMD). In 1995 comparable results were obtained from a Dutch pilot study with osteoporotic subjects (Schaafsma and Pakan 1999). In piglets, the apparent absorbability of calcium from ESP was found to be at least as good as from purified calcium carbonate (Schaafsma and Beelen 1999).

Because hormone-like activity has been suggested to be present in ESP

(Stanciková 1996; Rovensky 1994), this might play a role in the effects on BMD and pain as mentioned before. Transforming growth factor $-\beta_{1}\left(T G F \beta_{1}\right)$ is thought to play a role in the regulation of BMD (Grainger 1999). Calcitonin inhibits osteoclasts and reduces pain in subjects with a high bone turnover (Rong 1996; Overgaard 1992; Aurbach 1988). Based on the amino acid sequence, it has been suggested that chicken calcitonin might be one of the most potent calcitonins, also in mammalian systems (Deftos 1993). Of the steroid hormones, both progesterone and oestrogen reduce bone resorption in postmenopausal women whereas progesterone allso may stimulate bone formation (Oursler 1996). Calcitriol, which is the most active vitamin D-hormone, reduces serum parathyroid hormone and as a consequence bone turnover and bone loss (Aurbach 1988).

The main goal of this study was to get insight in the amounts, and variability in amounts, of elements in ESP and the relevance of these amounts compared with recommended, estimated or acceptable daily intakes. Additionally, three samples of Dutch ESP were analyzed to get an impression about the influence of housing and feed on mineral composition of eggshell. Finally, the presence of a number of hormones in ESP was studied.

\section{Material and methods}

\section{Study Design}

Twelve samples from different batches of Slovakian ESP (Biomin H, Cifer, Slovakia) were analyzed for several elements. It can be supposed that the eggs were derived from chickens with only small differences in feed and housing. Mean values and mean \pm 2 SD-intervals of the Slovakian ESP were compared with purified, food grade calcium carbonate (Scora S.A., Caffiers, France), oyster shell tablets (OTC Pharma BV, Gorichem, The Netherlands), a Japanese ESP (Furikake Tamago Calcium, Toyo Keiran, Tokyo, Japan), and with the recommended (Standing Committee on the Scientific Evaluation of Dietary Reference Intakes 1997; National Research Council. 1989) or acceptable daily intakes (Dokkum van 1985) for adults (51-70 y). Only a small number of ESP samples were studied for the influence of feed and housing of chickens on eggshell mineral composition $(n=3)$, amino acid patterns of the protein fraction $(n=4$, Dutch and Slovakian ESP) 
and the presence of hormones $\langle n=4-10$, Slovakian ESP).

\section{Materials and Methods}

Slovakian ESP was prepared from batteryeggs by a patented process (Reid 1993).

The final powder does not include the two inner-membranes of the eggshell.

Dutch ESP-samples were prepared in the laboratory, two inner-membranes not included, from brown consumption, freerange, 'four-cereal' eggs (ES1: Eiveko, Veen, The Netherlands) and 'Grass' eggs (ES2: Noordster BV, Wormerveer, The Netherlands), and from brown consumption, battery- eggs (ES3: Nieuwe Weme, Leeuwarden, The Netherlands). "Four cereal" chickens are fed with a mix of four cereals (Viergranenmeel, ACM, Meppel, The Netherlands) and are kept inside (with outside light) on a litter of sand and grounded wood. 'Grass' egg chickens can walk outside (enjoy fresh air and sun), are able to eat grass and green vegetables and receive an additional feed consisting of cereals and leguminous plants (Legmeel Grashennen, ACM). Dutch battery chickens received standard feed for laying hens (Legmeel A, B, and C, ACM).

\section{Mineral determination.}

Total nitrogen, ammonia (Kjeldahl, VAP-6, Gerhardt, Bonn 1, Germany), calcium, magnesium, iron, zinc (flame AAS, Perkin Elmer GmbH, Uleberlingen, Germany), phosphorus (spectrophotometrically, Shimadzu-Benelux, 's Hertogenbosch, The Netherlands), copper, lead, aluminum, cadmium (graphite furnace AAS, Perkin Elmer) and mercury (FIAS, Perkin Elmer) were analyzed by the Research and Development department of Friesland Coberco Dairy Foods. Chromium, vanadium (graphite furnace AAS 430, Perkin EImer), boron (ICP-MS, Elan 5000, Perkin Elmer), fluorine (gaschromatographically (Fresen 1968)), selenium (fluorimetrically, RF-1501, Shimadzu), strontium (flame AAS, Perkin Elmer) and silicon (ICP-AES, ARL 3410 with mini torch, Thermo Optek, Breda, The Netherlands) were analyzed by TNO Nutrition (Zeist, The Netherlands).

Amino acids and hormones.

Amino acid patterns were determined directly in ESP with a Hewlett Packard 1090 Aminoquant by Eurosequence B.V. Groningen, the Netherlands, after vaporphase hydrolysis (standard hydrolysis condition: $5.7 \mathrm{~N} \mathrm{HCL}$ for $2 \mathrm{~h}$ at $166^{\circ} \mathrm{C}$ ) of protein samples (Schuster 1988). With this method tryptophane is destroyed, the detection of cysteine is not reliable due to instability, and asparagine and glutamine are deaminated into aspartic acid and glutamic acid. A precision error up to $10 \%$ is normal for amino acid analyses.

TGF $\beta$, was determined with Predicta TGF $\beta_{1}$ (ELISA, Genzym Corporation, Cambridge, MA, USA) by VURCH (Research Institute of Rheumatic Diseases, Piestany, Slovakia). For this analysis, a $12 \%$ ESP in phosphate buffered saline $(\mathrm{pH} 7.2)$ was prepared and stirred at $4^{\circ} \mathrm{C}$ for $24 \mathrm{~h}$, followed by centrifugation $\left(10,000 \mathrm{rpm}, 4^{\circ} \mathrm{C}\right)$. The samples were activated as described for plasma samples (by acidifying with $\mathrm{HCL}$ for $1 \mathrm{~h}$ ) prior to analysis of TGFB.

Calcitonin was determined in the watersoluble protein fraction of ESP, which was prepared according to the method of Hincke et al (1992), by the Universital Hospital of Groningen (Groningen, The Netherlands). A competitive enzyme immunoassay (EIAH 6003, Peninsul Lab. Inc., Belmont, CA, USA), developed for the detection of salmon calcitonin, was used with a standard curve of chicken calcitonin. Progesterone and oestradiol-17 $\beta$ were determined by TNO Nutrition (Zeist, the Netherlands) after organic solvent extraction and cleaning-up via Solid Phase Extraction (SPE $1 \mathrm{ml}$ columns $100 \mathrm{mg}$. Varian, Houten, The Netherlands). 
Progesterone was analyzed with a commercially available RIA kit (Laboratoire d'Hormonology, Marloie, Belgium), whereas oestradiol- $17 \beta$ was analyzed with a RIA-kit from TNO Nutrition.

Calcitriol was determined with a receptor assay from TNO Nutrition. A calcitriolcontaining fraction was received following a warm saponification of ESP, organic solvent extraction and a washing procedure. Finally, the calcitriol was isolated from possible related components with SP-HPLC. The method is described in detail in TNO's internal standard operating procedure (SOP nr DPHA/KRC/039).

\section{Data evaluation}

Twelve samples of Slovakian ESP were considered to have a composition minimally influenced by feed of the chickens. Variability for each element was calculated as mean $\pm 2 \mathrm{SD}$. The mineral compositions of the Dutch ESP (ES1-3) were regarded to be different from the Slovakian ESP when they were out of this range. Dutch samples were presumed to be different from each other in case the detected value of an element of one sample was outside a calculated interval (detected value $\pm 2 \mathrm{SD}$ ) of another sample. The SD used in the calculations derived from the reference group or, when not available, was a standard estimate of variance of $10 \%$ of the detected value (Standing Committee on the Scientific Evaluation of Dietary Reference Intakes 1997).

\section{Results}

Mineral composition (Table 3.1)

The major elements in Slovakian ESP are calcium and magnesium. Compared with recommended or estimated daily intakes, however, calcium and strontium are the most important elements (Table 3.3, Figure 3.1). High variability was found in the

Table 3.1: Mineral composition of Slovakian and Dutch ESP

\begin{tabular}{lccccc}
\hline Component & & Slovakian & ES1 & ES2 & ES3 \\
\hline Nitrogen & $\mathrm{mg} / \mathrm{g}$ & $3.96(0.24)$ & 4.01 & 3.90 & 4.02 \\
Ammonia & $\mathrm{mg} / \mathrm{g}$ & $0.38(0.11)$ & 0.65 & 0.66 & 0.68 \\
Calcium & $\mathrm{mg} / \mathrm{g}$ & $401(7.21)$ & 385 & 393 & 387 \\
Magnesium & $\mathrm{mg} / \mathrm{g}$ & $4.50(0.50)$ & 3.6 & 3.6 & 3.5 \\
Phosphorus (total) & $\mathrm{mg} / \mathrm{g}$ & $0.99(0.21)$ & 1.50 & 0.20 & 1.90 \\
Strontium & $\mu \mathrm{g} / \mathrm{g}$ & $372(161)$ & 380 & 880 & 320 \\
Zinc & $\mu \mathrm{g} / \mathrm{g}$ & $5.13(0.53)$ & 5.0 & 5.0 & 4.0 \\
Iron & $\mu \mathrm{g} / \mathrm{g}$ & $22.4(1.08)$ & 23.0 & 23.0 & 22.5 \\
Copper & $\mu \mathrm{g} / \mathrm{g}$ & $7.7(1.37)^{*}$ & 10.0 & 13.0 & 7.5 \\
Boron & $\mu \mathrm{g} / \mathrm{g}$ & $\leq 0.5^{*}$ & 0.5 & 0.5 & 0.8 \\
Chromium & $\mu \mathrm{g} / \mathrm{g}$ & $0.12(0.05)^{*}$ & 0.20 & 0.40 & 0.25 \\
Fluorine & $\mu \mathrm{g} / \mathrm{g}$ & $3.75(1.04)^{*}$ & 6.0 & 5.5 & 3.0 \\
Selenium & $\mathrm{ng} / \mathrm{g}$ & $23.5(5.0)^{*}$ & 45 & 50 & 53 \\
Vannadium & $\mu \mathrm{g} / \mathrm{g}$ & $<0.5^{*}$ & $<0.5$ & $<0.5$ & $<0.5$ \\
Lead & $\mu \mathrm{g} / \mathrm{g}$ & $<0.5$ & 1.10 & 1.30 & 0.53 \\
Aluminum & $\mu \mathrm{g} / \mathrm{g}$ & $<5$ & $2.0^{1}$ & $2.0^{\prime}$ & $2.0^{*}$ \\
Cadmium & $\mathrm{ng} / \mathrm{g}$ & $<50$ & $18.0^{\prime}$ & $24.0^{1}$ & $3.0^{1}$ \\
Mercury & $\mu \mathrm{g} / \mathrm{g}$ & $<0.2$ & $<0.2$ & $<0.2$ & $<0.2$ \\
\hline
\end{tabular}

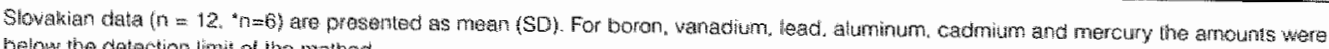
betow the detection limit of the method.

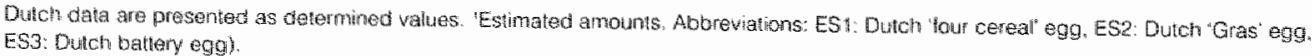


amounts of phosphorus, selenium, fluorine, chromium and strontium. The amounts of lead, aluminum, cadmium, mercury, boron and vanadium were below the detection limit of the methods used. Of the Dutch ESP, increased levels of fluorine, copper, lead and cadmium were found in both freerange ESP (ES1 and ES2). The level of strontium was relatively high in 'grass' ESP (ES2). Dutch ESP contained more selenium than Slovakian ESP. No differences may be expected between the levels of the other elements.

\section{Amino acids and hormones}

No differences were found between the amino acid patterns of Slovakian and Dutch ESP. The ESP protein fraction is rich in glycine (mean $79 \mathrm{mg} / \mathrm{g}$ protein) and arginine (mean $108 \mathrm{mg} / \mathrm{g}$ protein) but absolute amounts are rather low because of the low protein content (mean 1.8\%) of ESP. The mean amino acid composition of Dutch and Slovakian ESP is presented in Table 3.2.

Of the hormones analyzed, small amounts of TGF $\beta_{1}(0.75-7.28 \mathrm{ng} / \mathrm{g} \mathrm{ESP} n=10)$, calcitonin (10-25 ng/g ESP, $n=4)$ and progesterone (0.30-0.33 ng/g ESP, $n=4)$ were detected. Oestradiol-17 $\beta$ and calcitriol $(n=4)$ could not be detected. The absolute values found for calcitonin have to be handled with caution because of a low recovery $(38 \%)$ of a spiked sample.

Furthermore some calcitonin may be lost during centrifugation as about $25 \%$ of the spiked amount was recovered in the pellet. Temperature during sample handling did not influence the amount of calcitonin.

\section{Comparison with other calcium supplements}

Slovakian ESP and Japanese ESP appear to have a comparable mineral composition with exception of magnesium (Table 3.3). The high content in the Japanese sample however might be due to enrichment of the powder. Compared with purified calcium carbonate, ESP contains an equal amount of calcium , more strontium, selenium and magnesium but less fluorine.

The oyster shell tablet studied contains higher amounts of magnesium (in part derived from enrichment), strontium, itron, luorine and boron than ESP. The calcium content in oyster shell was $29.5 \%$ compared with $39-40 \%$ in the other preparations. ESP showed lower levels of vanadium, chromium, lead, aluminum and cadmium than oyster shell and purified calcium carbonate.

Table 3.2: Amino acid pattern of eggshell protein.

\begin{tabular}{lr}
\hline Amino acid & ESP \\
\hline Aspartic acid & 4 \\
Glutamic acid & 198 \\
Serine & 65 \\
Histidine & 54 \\
Glycine & 79 \\
Threonine & 55 \\
Alanine & 55 \\
Arginine & 108 \\
Tyrosine & 28 \\
Valine & 84 \\
Methionine & 32 \\
Phenylalanine & 29 \\
Isoleucine & 43 \\
Leucine & 73 \\
Lysine & 39 \\
Proline & 57 \\
Protein \% & 1.8
\end{tabular}

Dala are paesented as mean values hng/o of prolen in Cystoina aysime and typlophan ware not determinad. Vatues of aspartit acid and glutamic acid ere possibily not valid becausa of movernentg of retention limes

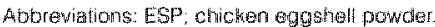


Table 3.3: Mineral compositions of Slovakian eggshell powder and three commercially available calcium preparations.

\begin{tabular}{|c|c|c|c|c|c|c|}
\hline Component & & $\begin{array}{l}\text { Slowakian egg- } \\
\text { shell }\end{array}$ & Calcipural24 & Oyster shell ${ }^{3}$ & $\begin{array}{c}\text { Japanese eggshell } \\
\text { powder" }\end{array}$ & $\begin{array}{l}\text { RDA. DAl } \\
\text { or } A D \|^{*}\end{array}$ \\
\hline Calcium & mg/g & $386-415$ & 397 & 295 & 393 & $1,200 \mathrm{mg}^{*}$ \\
\hline Magnesium & $\mathrm{mg} / \mathrm{g}$ & $3.5-5.5$ & $<0.03$ & 78.8 & 28 & $320-420 \mathrm{mg}^{*}$ \\
\hline Phosphorus & $\mathrm{mg} / \mathrm{g}$ & $0.6-1.4$ & 0 & 0.15 & 0.1 & $700 \mathrm{mg}^{\mathrm{m}}$ \\
\hline Strontium & $\mathrm{mg} / \mathrm{g}$ & $0.050-0.693$ & 0.230 & 0.910 & 0.410 & $1-3 \mathrm{mg}^{5}$ \\
\hline Zine & $\mathrm{mg} / \mathrm{g}$ & $0.004-0.006$ & $<0.001$ & 0.005 & 0.004 & $12-15 \mathrm{mg}$ \\
\hline Mron & $\mathrm{mg} / \mathrm{g}$ & $0.020-0.025$ & 0.036 & 0.42 & 0.027 & $10-15 \mathrm{mg}$ \\
\hline Copper & $\mathrm{mg} / \mathrm{g}$ & $0.005-0.010$ & 0.008 & 0.007 & 0.009 & $1.5-3.0 \mathrm{mg}$ \\
\hline Boron & $\mu g / g$ & $\leq 0.5$ & 0.5 & 9 & nd & $500-1000 \mu g$ \\
\hline Chromium & $\mu \mathrm{g} / \mathrm{g}$ & $0.03-0.20$ & 1.1 & 1.0 & nd & $50-200 \mu g$ \\
\hline Fuorine & $\mathrm{mg} / \mathrm{g}$ & $0.002-0.006$ & 0.025 & 0.070 & nd & $3.1-3.8 \mathrm{mg}^{*}$ \\
\hline Selenium & $\mu g / g$ & $0.014-0.034$ & 0.008 & 0.145 & nd & $55-70 \mu \mathrm{g}$ \\
\hline Vanadium & $\mu \mathrm{g} / \mathrm{g}$ & $<0.5$ & 0.5 & 1 & nd & $<10 \mu g$ \\
\hline Lead & $\mu g / g$ & $<0.5$ & 0,99 & 0.72 & $<0.5$ & $430 \mu g^{* *}$ \\
\hline Aluminum & $\mathrm{mg} / \mathrm{g}$ & $<0.005$ & 0.007 & 4.4 & $<0.005$ & $70 \mathrm{mg}^{* *}$ \\
\hline Cadmium & $\mu g / g$ & $<0.050$ & 0.657 & 0.062 & $<0.050$ & $60 \mu g^{* *}$ \\
\hline Mercury & $\mu \mathrm{g} / \mathrm{g}$ & $<0.2$ & $<0.2$ & $<0.2$ & $<0.2$ & $29 \mu g^{* *}$ \\
\hline
\end{tabular}

Dela are plesonted as mean 2 SD (see Table 3.1)

Food grade, puritied calcium carbontata (Scora. S.A, Catfiers, Firance)

Oyster calcium (Vilasan; OTC Phame BV, Gorinchem, The Netherlands). Angredients; oysler calcum (280 mg Ca/tablet of 900 mg), wharain

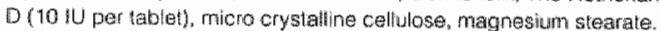

* Japanese eggshell powder (Furkake Tamago Calcism, Toyo Keiran, Tokyo, Japan)

Estimated daly intake (Eastwood 1987)

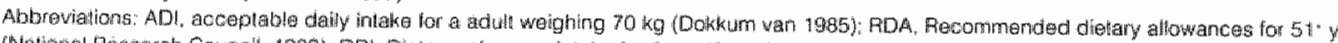

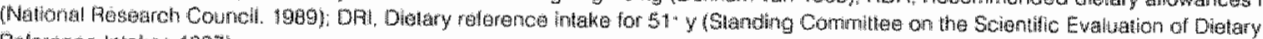

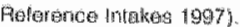

\section{Discussion}

Slovakian ESP, prepared from demembranized chicken eggshells, has a high calcium content (Table 3.1) which is regulated within narrow limits. Although the amounts of strontium showed a wide range, they may contribute considerably to the normal daily intake (Table 3.3) and as a consequence may have a positive influence on bone metabolism in the longterm. The levels of other elements are low especially when compared with recommended or adequate dietary intakes (Table 3.3, Figure 3.1).
Figure 3.1: Percent contribution to recommended or estimated daily intakes. when calcium from eggshell powder supplies $100 \%$.

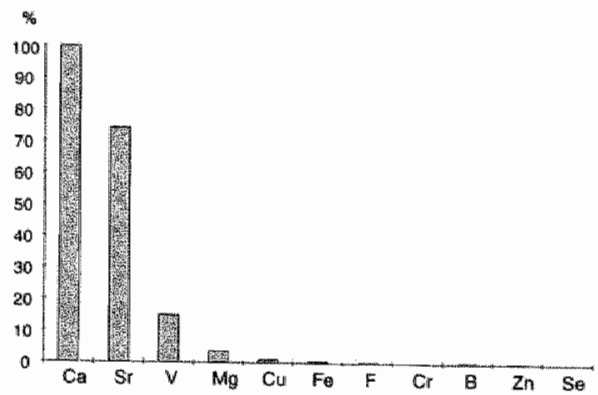

Pecommended and ostimated daily intakes are mentioned in Tabte 3.3 
Low llevels of lead, aluminum, cadmium and mercury may be an advantage of ESP over other natural $\mathrm{Ca}$ sources. For some of the elements (strontium, copper,

chromium, fluorine, selenium, lead, cadimium) a strong influence of feed and housing may be expected. Based on the absolute, low amounts of protein and low levels of calcitonin, TGF 1 and progesterone no specific role seems to be likely. All together, chicken ESP prepared from eggs of chickens on controlled feed and adequately housed, is of interest for human nutrition especially as a source of calcium and strontium.

The amounts of calcium and magnesium were found to be within rather narrow limits. This is a consequence of limited concentrations in the feed. Both elements affect egg production and shell strength (Atteh and Leenson 1983). High as well as low levels of calcium have an adverse effect on egg production. Magnesium is important for egg weight and shell thickness but high levels combined with low levels of calcium increase shell deformity (Nadi 1984; Atteh and Leenson 1983). This means that chicken ESP can be considered to have a rather stable amount of calcium. About 39\% is the maximum amount of calcium possible when calcium is present as calcium carbonate (calcite crystals) and when about $2 \%$ of the eggshell consists of organic matrix (Cortivo 1982). With regard to calcium content, ESP is equal to purified calcium carbonate, which is widely used ajo because of its high calcium content (Kärkkäinen 1997). A piglet study (Schaafsma and Beelen 1999) showed that calcium from ESP was as good absorbed as from purified calcium carbonate, or even better when both calcium sources were given in combination with soya protein. ESP therefore is a rich source of highly bioavailable calcium.

Levels of strontium in the eggshell seem to be directly related to the dietary levels
(Weber 1973). Although high intakes of strontium decrease shell thickness and egg production, reduce fertility and increase embryonic mortality, a content up to 1,500 $2,000 \mu \mathrm{g}$ strontium/g of eggshell is not associated with these negative effects. In other words, the amounts as determined in this study can importantly be improved. In humans, strontium is suggested to have anabolic effects on bone (Reginster 1999). The effective amounts are debated.

Treatment with a pharmacological dosage of $170 \mathrm{mg}$ per day increased BMD (Reginster 1999). However, high intakes of strontium may lead to incorporation into hydroxyapatite crystals, which may result in a reduced bending strength in the long term (Christoffersen 1997). In contrast, adhesion of strontium to hydroxyapatite crystals increases bending strength (Okayama 1991). In long term strategies to prevent natural bone loss, chronic loading with low amounts of strontium therefore may be preferred (Okayama 1991). Normal daily intakes of strontium are estimated to be 1-3 mg (Eastwood 1997), which means that ESP can importantly contribute to a higher" intake of this bone-seeking element. Fluorine has positive effects on bone metabolism whereas this is suggested for copper and selenium (Heaney 1996b; Reginster 1999b; Seifert and Watkins 1997b). Theilr amounts in ESP are probably strongly influenced by the diet (Romanoff and Romanoff 1949) which is also suggested by the differences we found between Dutch and Slovakian ESP. However, as the detected amounts are much lower than the advised amounts (Table 3), concentrations in ESP should increase with a factor $100-1000$ for a relevant contribution. This seems quite impossible.

Low levels of lead, aluminum, cadmium and mercury are an advantage to chicken ESP as natural calcium sources have been questioned because they may be polluted with these elements (Whiting 1994; Faine 
1995). In the purified calcium carbonate powder and oyster shell tablet (Table 3) the amounts of lead, aluminum and cadmium were higher than in Slovakian ESP. As indicated by the Dutch 'grass' ESP in particular, amounts of lead and cadmium probably reflect the amounts in the environment and feed. This means that levels can be controlled as is shown by the low amounts found in battery-eggs.

Although the "high" amounts of aluminum in oyster shell and cadmium in purified calcium carbonate were much lower than the acceptable daily intakes they may ask for a well-considered use. Recently the negative effects of increased environmental cadmium on bone metabolism were reported (Staessen 1999).

The role of amino acids from eggshell protein in bone metabolism is nihil since the absolute amounts per g of ESP are very low. Probably this is also true for the hormones calcitonin, TGF $\beta 1$ and progesterone. Therefore, it is likely that neither amino acids nor the detected hormones from ESP play a role in the increased BMD and reduced pain as reported from small scale studies (Schaafsma and Pakan 1999; Makai and Chudacek 1991).

ESP with its high percentage of calcium, relevant amounts of strontium and controlled low levels of lead, cadmium and aluminum seems to be a useful ingredient for human calcium enrichment strategies. Increases in BMD and reduction of pain as reported from two small studies in subjects with osteoporosis support this application (Schaafsma and Pakan 1999; Makai and Chudacek 1991). Levels of microelements such as strontium, fluorine and selenium in eggshell can be improved and controlled via the feed of the chickens. A large store of wasted calcium (Prof. Lichtenstein, 1948) therefore may be a tailor-made calcium source for postmenopausal women and elderly in particular.

\section{Acknowledgments}

We would like to thank all the co-workers of the several laboratories involved in this study. Furthermore, we would like to thank F.A.J. Muskiet, Ph.D. (University Hospital Groningen) for his critical comment on the manuscript. 


\title{
Eggshell powder, a comparable or better source of calcium than purified calcium carbonate: piglet studies
}

A. Schaafsma ${ }^{1}$ and G.M. Beelen ${ }^{2}$

' Department of Research \& Development Leeuwarden, Friesland Coberco Dairy Foods, Leeuwarden, The Netherlands;

2 TNO Nutrition and Food Research, Department ILOB, Wageningen, The Netherlands

Journal of the Science of Food and Agriculture 1999;79:1596-1600

\begin{abstract}
Powdered chicken eggshells might be an interesting and widely available source of calcium. In two studies using piglets we determined the digestibility of calcium from different diets. The first study compared casein based diets with $\mathrm{CaCO}_{3}$ (CasCC) or eggshell powder (CasES). The second study compared soya protein isolate-based diets with $\mathrm{CaCO}_{3}$ (SoyCC) or eggshell powder (SoyES). Diets were fed to groups of 6 piglets. Faeces were collected quantitatively. No adverse effects of eggshell powder were observed with regard to magnesium and crude fat digestibility. Calcium from eggshell powder was more digestible than calcium from purified $\mathrm{CaCO}_{3}$. In the first study, digestibility coefficients for calcium were 66.9 (SD 7.9)\% for CasCC and 71.3 (SD 3.8)\% for CasES. In the second study, these coefficients were 46.7 (SD 8.6)\% for SoyCC, and 65.9 (SD 3.7)\% for SoyES, a significant difference. Our conclusion is that eggshell powder is, in the case of casein based diets, as good a source of calcium as $\mathrm{CaCO}_{3}$ and, in the case of soya protein based diets, better than $\mathrm{CaCO}_{3}$ for growing piglets. As the piglet model is considered to be representative for humans, chicken eggshell powder is also a promising source of calcium for human nutrition.
\end{abstract}

Keywords: eggshell powder, calcium, digestibility, soya protein, casein.

\section{Introduction}

The proposed higher recommendations of calcium intakes, in particular for postmenopausal women, require calcium preparations (Levenson and Bockman 1994) which are well absorbed in the intestine (Mason 1993). Apparent absorption is one way to study this and is defined as the difference between nutrient intake and faecal excretion. One should remember, however, that this method underestimates the true absorption of calcium as no correction is made for endogenous excretion of calcium into faeces (Krishnamra 1992; Mason 1993). Calcium salts can be supplied as tablets, as part of mineral and vitamin supplements or as an ingredient in food. In the latter case, combinations with dairy and soya products may be advantageous.

Dairy products are known for the high bioavailability of their calcium (Recke von der 1996; Mortensen and Charles 1996). Lactose and small amounts of casein phosphopeptides (casein tryptic digestion products) are thought to enhance the 
passive paracellular calcium absorption (Kitts 1992; Brink 1992; Nagasawa 1991; Mason 1993). Calcium from soya beans seems to be well absorbed despite the presence of phytate and oxalate (Messina 1995) which have traditionally been associated with a low calcium availlability (Bronner 1988). In cases of similar calcium and magnesium concentrations however; the absorption of both minerals from cow's milk was significantly higher than from a soya beverage (Brink 1992). It has been suggested that the soya fibre, rather than pure phytate, impairs calcium and magnesium absorption (Krishnamra 1992). Soya foods are of special interest as they contain relatively high quantities of isoflavones, which have weak oestrogenic effects. They are thought to be responsible for the lower incidence of osteoporosis in Asian populations and vegetarians (Knight and Eden 1996).

$\mathrm{CaCO}_{3}$ is the calcium salt most widely used as a nutritionall supplement because of its high (approx. 40\%) elemental calcium content (Krishnamra 1992). Eggshell powder is a traditional, but still relatively unknown, source of callcium. Information about the bioavailability of calcium in eggshell powder comes from a study using rats (Takada 1990). This study suggests a higher calcium retention rate from eggshell powder and purified $\mathrm{CaCO}_{3}$, than from $\mathrm{Ca}$ lactate, Ca citrate, Ca phosphate or calcium from cattle bone. A subsequent study (Greger 1987), however, did not support the apparent superiority of $\mathrm{CaCO}_{3}$ over Ca lactate, nor were there important differences with regard to calcium from milk or oyster shells. No differences were observed between $\mathrm{CaCO}_{3}$ and osseinocomplex in effects on femoral bone mineral density in vitamin D repleted elderly (Chevalley 1994). With regard to bone density of postmenopausall women, $\mathrm{Ca}$ citrate malate has been reported to be superior to $\mathrm{CaCO}_{3}$ (Dawson-Hughes 1990). Based on the above mentioned studies, small differences seem to be present among the several callcium sources. These differences may, however be the resull of the circumstances under which the studies were conducted. As $\mathrm{CaCO}_{3}$ is used in many studies it can be considered as a generally accepted reference calcium source in digestibility studies.

The main object of this study was to examine the bioavailability of calcium from eggshell powder compared with purified $\mathrm{CaCO}_{3}$ by studying the apparent digestibilities in pigllets. In addition, we studied the influence of casein and soya protein on this calcium bioavailability. As magnesium and crude fat digestibility might be affected due to competition and complex formation (e.g. calcium soaps) (Carnielli 1995; Guilloteau 1986), their digestibility coefficients were determined also.

\section{Material and methods}

Study design

In two separate studies, differing in the source of protein in the diet (casein and soya protein), four test diets were studied using individually housed piglets. In each of the two studies, healthy piglets were divided into groups of 6 animals each based on liveweight, after a period of 6 days to allow for acclimatisation to the metabolic cages. During a pre-test period of 10 days, they were familiarised with the experimental diets and the stoma bags attached to the anus. A test period of 7 days was then initiated. The animals were weighed at the beginning and end of the pre-test period and at the end of the test period. The piglets were fed twice per day and feed intake was recorded per feeding. Weight gain and feed conversion efficiency were calculated based on these figures. Health, appetite, and faeces colour and consistency were monitored. The total amount of faeces per pig was measured during the 7 day test period $(7 \times 24 \mathrm{~h})$. Faeces were collected separately from 
urine in plastic stoma bags. The bags were emptied at least once daily, wet faeces were weighed and stored at $-20^{\circ} \mathrm{C}$ for further analysis. Prior to analysis, the faeces was freeze-dried, ground, homogenised and sampled. The samples were analysed for the quantity of calcium and magnesium (AAS according to NEN 3349) (Dutch Standardization Institute 1984), and crude fat (method of Berntrop, ISO 6492) (International Organization of Standardization 1999). The quantity of calcium, magnesium and crude fat in the collected wet faeces was calculated from the analysed content in the freeze dried samples multiplied by a factor derived from the quotient of the weights of freeze dried and wet samples. The digestibility coefficients of calcium, magnesium and crude fat were calculated according to their quantity in the diets, the wet faeces, the feed intake per pig and the quantity of faeces produced per pig.

\section{Animals and housing}

The experiment was conducted using commercially bred castrated male piglets [Yorkshire x (Dutch Landrace x Finnish Landrace)]. The piglets were weaned at an age of about 4 weeks. Between weaning and the start of the study they were fed a commercial piglet diet "Babybigge-korrel", Rijnvallei, The Netherlands). In the first study (casein-based diet), the age and mean weight after the acclimatisation period were 5 weeks and 10.1 (SD 0.4) kg. At the end of the study, the age and weight of the piglets were 8 weeks and 14.5 (SD $0.5) \mathrm{kg}$. In the second study (soya proteinbased diet), the initial and final ages of the piglets were the same as in the first study. Their weight after the acclimatisation period and their final weight were 11.0 (SD $0.2) \mathrm{kg}$ and 15.5 (SD 0.5) kg, respectively. The metabolic cages with Tendernova floors (Tenderfoot, Eindhoven, The Netherlands) with synthetic coating were located in a room in which the temperature $\left(24^{\circ} \mathrm{C}\right)$, relative humidity $(40-45 \%)$ and lighting (daylight, and fluorescent lighting from 8.00 a.m. to $5.00 \mathrm{p} \mathrm{m}$.) all were controlled.

\section{Diets}

All the pigs were fed a commercial diet during the acclimatisation period ('Babybigge-korrel', Rijnvallei, The Netherlands). During the pre-test period, $25 \%$ of the commercial diet was replaced each day by $25 \%$ of the experimental diet until by day 4 of the pre-test period, all the pigs were fed completely with one of the experimental diets which continued throughout the test period.

The experimental diets were prepared at the feed mixing department of TNO-ILOB (Wageningen, The Netherlands). The four test diets differed in protein and calcium source but not in the absolute quantity of both ingredients. The composition of the diets is shown in Table 4.1. In the first study, the diets contained cow's milk derived casein ( $90 \%$ protein) as protein source in combination with purified $\mathrm{CaCO}_{3}$ (purity >98\%; Boom BV, Meppel, The Netherlands) or chicken eggshell powder (Biomin a.s., Cifer, Slovak Republic), coded CasCC and CasES respectively. In the second study, soya protein isolate (ProFam S788: $90 \%$ protein, ADM, Rotterdam, The Netherlands) was used as protein source in combination with purified $\mathrm{CaCO}_{3}$ or chicken eggshell powder, coded SoyCC and SoyES respectively. Of the total amount of calcium present in the feed, $92 \%$ derived from the specific calcium source which means that $8 \%$ came from other dietary ingredients.

The diets were low in calcium to create a situation of maximum absorption. Feeding took place at $8.00 \mathrm{a} . \mathrm{m}$. and $5.00 \mathrm{p.m}$. at a level based on body weight. The animals received an amount of feed corresponding to $2.2 \times$ maintenance each day. The experimental diets were not pelleted but were fed as a slurry (water : feed ratio of 
Table 4.1: Composition of the experimental diets $(\mathrm{g} / \mathrm{kg})$ during the test period.

\begin{tabular}{|c|c|c|c|c|c|}
\hline \multirow{2}{*}{\multicolumn{2}{|c|}{ Ingredient }} & \multicolumn{4}{|c|}{ Experimental diets } \\
\hline & & Cascc $^{*}$ & CasEs & SoyCc ${ }^{*}$ & SoyES: \\
\hline \multicolumn{2}{|l|}{$\mathrm{CaCO}_{4}$} & 10 & & 10 & \\
\hline \multicolumn{2}{|c|}{ Eggshell powder } & & 10 & & 10 \\
\hline \multicolumn{2}{|l|}{ Casein } & 100 & 100 & & \\
\hline \multicolumn{2}{|c|}{ Soya protein-isolate } & & & 100 & 100 \\
\hline \multicolumn{2}{|l|}{ Barley } & 150 & 150 & 150 & 150 \\
\hline \multicolumn{2}{|l|}{ Corn } & 606.5 & 606.5 & 606.5 & 606.5 \\
\hline \multicolumn{2}{|c|}{ Cornglutenmeal } & 80 & 80 & 80 & 80 \\
\hline \multicolumn{2}{|l|}{ Fal: } & 20 & 20 & 20 & 20 \\
\hline \multicolumn{2}{|l|}{ Premix } & 10 & 10 & 10 & 10 \\
\hline \multicolumn{2}{|l|}{ Salt } & 2 & 2 & 2 & 2 \\
\hline \multicolumn{2}{|c|}{$\mathrm{NaH}_{2} \mathrm{PO}_{4}, 2 \mathrm{H}_{2} \mathrm{O}$} & 5 & 5 & 5 & 5 \\
\hline \multicolumn{2}{|l|}{$\mathrm{MgO}$} & 1 & 1 & 1 & 1 \\
\hline \multicolumn{2}{|l|}{$\mathrm{KHCO}_{3}$} & 10 & 10 & 10 & 10 \\
\hline \multicolumn{2}{|c|}{ L-lysine HCl } & 2 & 2 & 2 & 2 \\
\hline \multicolumn{2}{|c|}{ Luthreonine } & 0.5 & 0.5 & 1.8 & 1.8 \\
\hline \multicolumn{2}{|c|}{ L-tryptophan } & 0.5 & 0.5 & 0.7 & 0.7 \\
\hline \multicolumn{4}{|c|}{ DL-methionine } & 1 & 1 \\
\hline \multirow[t]{3}{*}{ Anialyses: } & $\mathrm{Ca}$ & 4.8 & 4.8 & 4.2 & 4.2 \\
\hline & $\mathrm{Mg}$ & 1.5 & 1.5 & 1.5 & 1.5 \\
\hline & Crude fat & 49 & 49 & 50 & 50 \\
\hline
\end{tabular}

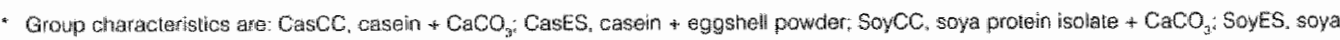
prolein isclate + eggstiell powder

1 Composition of the fat miktund: coconut far 10\%, tallow $35 \%$, lard $35 \%$. soya oil $20 \%$

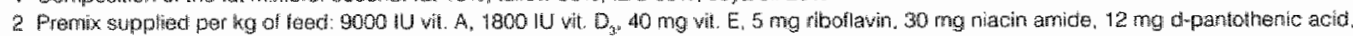

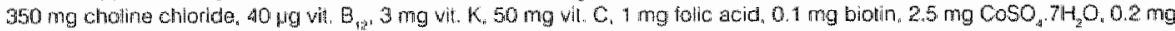

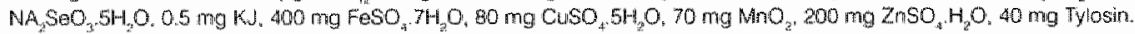

$2.5: 1)$. No extra water was provided as is normal in the case of slurry feeding.

\section{Statistical analysis}

The data sets of the two studies were analysed separately. The independentsamples t-test (two-sided) was used to determine whether the means of CasCC and CasES, and SoyCC and SoyES differed significantly $(p<0.05)$ or not. Levene's Test for Equality of Variances (one-way analysis of variance) was used to see whether the variances of the groups differed. In case of assumed equal variances ( $F$ statistic, significance $>0.05$ ) the pooled-variance independent-samples t-test was used. In case of no equal variances ( $F$ statistic, significance $<0.05$ ) the separate-variance t-test was used. As the effect of the protein source was studied in two separate studies a statistical comparison was invalid, however, suggestions are made in cases of possibly important differences. The statistical package used was SPSS 7.0 for Windows (SPSS, Inc., Chicago).

\section{Results}

Health, appetite, faeces observations, crude fat digestibility, weight gain and feed conversion efficiency

Both experiments progressed well with respect to the health and appetite of the animals. Only one animal in the diet group 
SoyES developed persistent diarhoea at the beginning of the test period. This animal was therefore taken out of the trial. The colour and consistency of faeces from the other piglets were normal. The faecal production was significantly higher in SoyCC compared with SoyES (Table 4.2). No significant differences were observed in weight gain, feed conversion efficiency, and crude fat digestibility (Table 4.2). No feed refusals were observed.

\section{Apparent digestibility of calcium and magnesium.}

In the study with soya protein isolate as protein source, calcium was significantly (Table 4.2) better digested from eggshell powder than from purified $\mathrm{CaCO}_{3}$. In the study with casein as protein source, no significant differences were observed between the two calcium sources.

Athough measured in separate studies, the digestibility coefficients of the casein fed groups were higher than of comparable soy protein ted groups 1 CasCC versus SoyCC, and CasES versus SoyES). in both studies, no significant differences were found in magnesium digestibillies between eggshell powder and purified $\mathrm{CaCO}_{3}$ enriched diets (Table 2). The lowest digestibility coefticient for magnesium was found in the SoyCC group.

\section{Discussion}

Ca plays a key role in the treatment and prevention of bone demineralization.

A widely used calcium source for product enrichment is purified $\mathrm{CaCO}_{3}$ with a high calcium content (about $40 \%$ ) and low production costs. Chicken eggshell powder, with a calcium content of about $38 \%$, is a promising but little known source of Ca for human nutrition. The use of chicken eggshell powder might be beneficial, as it has been suggested that it could increase bone mineral density and reduce pain in patients with osteoporosis (Makai and Chudacek 1991). From a nutritional point of

Table 4.2: Apparent faecal digestibility coefficients (\%) of Ca, Mg. and crude lat during a test period of 7 days in piglets fed four different diets, tested in two separate studies.

\begin{tabular}{|c|c|c|c|c|}
\hline \multirow[t]{2}{*}{ Parameter } & \multicolumn{2}{|c|}{ Study 1} & \multicolumn{2}{|c|}{ Sudy? } \\
\hline & $\begin{array}{c}\text { CascC } \\
(n=6)\end{array}$ & $\begin{array}{c}\text { CasES } \\
(n=6)\end{array}$ & $\begin{array}{l}\text { SoyCC } \\
(n=6)\end{array}$ & $\begin{array}{c}\text { SoyES } \\
(n=5)\end{array}$ \\
\hline $\mathrm{Ca}$ & $\begin{array}{c}66.9 \pm 7.9 \\
(55.9-74.8)\end{array}$ & $\begin{array}{c}71.3 \pm 3.8 \\
(64.4-75.5)\end{array}$ & $\begin{array}{c}46.7 \pm 8.6 \\
(36.3-60.3)\end{array}$ & $\begin{array}{c}65.9 \pm 3.7 \\
(60.9-69.7)\end{array}$ \\
\hline$M g$ & $\begin{array}{c}34.0 \pm 4.6 \\
(27.0-38.2)\end{array}$ & $\begin{array}{c}36.3 \pm 4.0 \\
(29.4-41.0)\end{array}$ & $\begin{array}{c}23.6 \pm 5.9 \\
(15.7-32.4)\end{array}$ & $\begin{array}{c}26.5 \pm 9.7 \\
(16.8-42.1)\end{array}$ \\
\hline Crude fat & $\begin{array}{c}77.8 \pm 2.1 \\
(73.6-79.6)\end{array}$ & $\begin{array}{c}78.3 \pm 1.4 \\
(76.7-80.4)\end{array}$ & $\begin{array}{c}74.4 \pm 1.8 \\
(72.1-76.1)\end{array}$ & $\begin{array}{c}78.2 \pm 2.6 \\
(75.8-82.0)\end{array}$ \\
\hline Faeces $(\mathrm{g} / \mathrm{d})$ & $111 \pm 16$ & $116 \pm 10$ & $153 \pm 7.4 \Delta$ & $117 \pm 16$ \\
\hline Weight gain $(\mathrm{kg})$ & $4.4 \pm 0.5$ & $4.5 \pm 0.5$ & $4.4 \pm 0.5$ & $4.7 \pm 0.4$ \\
\hline Feed inlake $(\mathrm{kg})$ & $6.6 \pm 0.12$ & $6.6 \pm 0.10$ & $6.94 \pm 0.13$ & $6.98 \pm 0.11$ \\
\hline FCE & $1.50 \pm 0.07$ & $1.50 \pm 0.04$ & $1.59 \pm 0.15$ & $1.49 \pm 0.11$ \\
\hline
\end{tabular}

All values are expressed as group means $\pm \mathrm{SD}$ and (range). Weight gain, feed intake and feed comersion efficiency (FCE: $\mathrm{kg}$ feed/kg weight gain) were calculated over the pre-test and test period. Faeces are presented as mean (wet) amounts during the test period.

Statistical differences (independent samples t-test) between SoyES and SoyCC: " $p<0.01, \Delta p \leq 0.001$

Group characteristics are: CasCC, casein $+\mathrm{CaCO}_{3}$. CasES, casein + chicken eggshell powder, SoyCC soya protein isolate $+\mathrm{CaCO}_{3}$, SoyES, soya protein isolate + chicken eggshell powder. 
view, more information was necessary about the availability of calcium from eggshell powder for intestinal uptake. Due to great similarities in gastrointestinal anatomy, physiology and metabolism (e.g. relative activities of major digestive enzymes, $\mathrm{pH}$ values in the several intestinal compartments, active calcium uptake) between the growing pig and the human adult, the piglet model seems to predict effects in humans (Tumbleson 1986; Moughan 1994; Bronner 1988). However, with regard to calcium digestibility the piglet studies do only indicate how eggshell powder will act in the human intestine compared to $\mathrm{CaCO}_{3}$. The apparent digestibility coefficients as measured are not indicative for absorption percentages in humans. In humans as well as in pigs, overall absorption of calcium is influenced by factors such as age, calcium status, calcium intake, and diet composition (Wilkin 1999). A low intake of callcium combined with youth, as in our studies, will increase $\mathrm{Ca}$ absorption to maximum levels. Human neonates, too, show $50-80 \%$ absorption of $\mathrm{Ca}$ from human milk (Wharton 1987). Reports based on isotope techniques indicate that normal subjects (Hansen 1996; Bronner 1988) absorbed (only) about $25 \%$ of $\mathrm{Ca}$ from $\mathrm{CaCO}$.

The higher calcium digestibility from casein based diets (comparing the first study with the second study) may be a result of interaction with casein phosphopeptides which are thought to increase Ca solubility in the small intestine (Nagasawa 1991). Solubilizing properties of casein phosphopeptides were strongly expressed in combination with soya protein in rats (Kitts 1992). This aside, soya products may contain calcium absorption inhibiting components (Yuan and Kitts 1994; Lo 1980; Brink 1992; Mason 1993). Although the soya protein and casein based diets were studied in separate studies "which might account in part of the differences in calcium digestibility), it is of interest to note that calcium digestibility from SoyES and CasCC was approximately the same. This suggests that eggshell powder has casein phosphopeptide'-like properties. Calciumligands (carbohydrate-protein complexes) with basic characteristics have been isolated from eggshell (Krampitz 1977). Digestibility coefficients for magnesium and crude fat were calculated because their absorption may be inhibited by calcium and soya protein (Greger 1981; Carnielli 1995; Guilloteau 1986). In both of our studies, the digestibility of magnesium was slightly, but not significantly improved by the addition of eggshell powder. Like calcium, magnesium digestibility was lower from the soy protein isolate-based diets than from the caseinbased diets. Crude fat digestibility was not affected by the addition of eggshell powder but was slightly lower in the SoyCC group. This group also showed a significantly thigher faecal production and slightly higher feed conversion efficiency suggesting a less efficient utilisation of feed. This too, supports the idea that eggshell powder has solubilizing properties preventing formation of indigestible complexes.

Based on the results of these studies, it can be concluded that chicken eggshell powder is a good source of calcium for growing piglets, and most probably also for humans, with no adverse effects on the digestibility of magnesium and crude fat. Because of the high digestibility coefficient of calcium from chicken eggshell powder in combination with soya protein, it is not only a very interesting source of calcium for dairy products but also for soya foods.

\section{Acknowledgments}

The authors would like to thank W.H.M. Saris, MD., Ph.D. (University Maastricht), F.A.J. Muskiet, Ph.D. (University Hospital Groningen), J. Huisman, Ph.D. (ILOB-TNO Wageningen), and P.J.F. de Vries, Ph.D. (Friesland Coberco Dairy Foods) for their critical comments on the manuscript. 


\section{Short term effects of a chicken eggshell powder enriched dairy-based product on bone mineral density in persons with osteoporosis or osteopenia; a pilot study}

A. Schaafsma ${ }^{1}$ and I. Pakan ${ }^{2}$

Department of Research \& Development Leeuwarden, Friesland Coberco Dairy Foods, Leeuwarden, The Netherlands

2 Department of Surgery, Medical Center Leeuwarden, Leeuwarden, The Netherlands

Bratislava Medical Journal 1999;15(2):157

Abstract

Based on the high calcium content, chicken eggshells are an interesting source of calcium. We studied the short-term effects on bone mineral density (BMD) of the lumbar spine and hip in 9 women and one man (mean age \pm SD, 63.9 \pm 8.1 years) with osteoporosis or osteopenia. Also the effects on pain and general well being were monitored. Ten women (62.5 \pm 5.0 years) from a population study on BMD served as a control group. During a study period of 4-8 months, the intervention group consumed twice daily a dairy-based supplement, which resulted in a daily intake of, among others, $3.0 \mathrm{~g}$ of eggshell powder, $400 \mathrm{IU}$ of vitamin $\mathrm{D}_{3}$ and $400 \mathrm{mg}$ of magnesium. BMD of the lumbar spine (anteroposterior (AP) and lateral (LA) position) and hip were measured by dual-energy $X$-ray absorptiometry. After the intervention period, BMDs of the lumbar spine, total proximal femur and trochanter were significantly ( $p<0.05$ ) increased with (median) $4.4 \%$ : (range) 1.7 to $10.4 \%$ (lumbar spine AP), $5.7 \%:-1.3$ to $15.9 \%$ (lumbar spine LA), $2.2 \%:-1.9$ to $9.4 \%$ (total proximal femur), $1.8 \%:-1.8$ to $9.0 \%$ (trochanter). Within a period of 4 months, an important reduction in pain was reported and as a consequence an improvement in general well being. In the control group, BMDs of the lumbar spine AP and of the femoral neck significantly decreased over a period of 8 months with $-0.7 \%(-1.3$ to $0.2 \%)$ and $-0.9 \%(-2.4$ to $-0.1 \%$ ) respectively. Six women of the intervention group continued to use the supplement on their own free will and without any check on compliance, up to 24 months. They consumed the supplement only once daily except for the last three months when they were asked to take the double dosage again. After 24 months BMDs did not differ from baseline. This study shows that eggshell powder is a good source of bioavailable calcium. Furthermore, this pilot study indicates that the chicken eggshell powder enriched dairybased supplement increases BMD of subjects with a low bone mass in the short term and as a consequence delays bone demineralization for a longer period.

Keywords: calcium, bone mineral density, eggshell powder, magnesium, osteoporosis, pailn, vitamin $D_{3}$ 


\section{Introduction}

Calcium is a very important building block of bone and often seen as key element in bone mineralization and antidemineralization strategies (Devine 1997, Dawson-Hughes 1996; Compston 1995). Dairy products, which are known as the major source of calcium, are only 'recently", about 10,000 years ago introduced in the human diet (Nelson 1996). Before that time, the stone-age adult consumed a high amount of calcium form other sources (Eaton 1996; Barger-Lux and Heaney 1994), possibly including eggshell.

To support increased requirements or to overcome low intakes, several calcium sources are available for food enrichment. In postmenopausal women and elderly, a number of calcium sources, such as purified calcium carbonate (DawsonHughes 1990; Chevalley 1994; Reid 1993), calcium citrate (Dawson-Hughes 1995), osseino-mineral complex (Chevalley 1994), oyster shell electrolysate (Fujita 1990), calcium lactate gluconate (Thamsborg 1996; Prince 1995; Reid 1995; Reid 1993), and milk-calcium (Reid 1995; Nelson 1991) have been studied for their effects on BMD. In general the effects were comparable, causing a small, sometimes transient increase in BMD or an inhibition of bone loss. Chicken eggshell powder, not commonly used as calcium source for humans, might have a higher impact on $B M D$ as has been suggested by a Slovakian study with osteoporotic patients (Makai and Chudacek 1991). The major component of eggshell powder is calcium carbonate (about $98 \%$ of weight) whereas other minerals which are of interest in bone metabolism such as strontium and fluoride, are present in small amounts. Furthermore, Slovakian researchers have suggested that eggshell powder contains bioactive substances (not published). Combinations of calcium with vitamin D (Devine 1997; Dawson-Hughes 1995; Nelson 1991; Meunier 1994; Chevalley 1994; Reid 1993) and magnesium (Abraham 1991) enhance calcium effects on BMD of postmenopausal women in case their intakes are limited.

This pilot study aimed to study the shortterm effects of an eggshell powder enriched dairy-based supplement also containing other minerals and vitamins including vitamin $D_{3}$ and magnesium on BMD of the lumbar spine and hip, and on pain and general well being.

\section{Subjects, material and methods Subjects}

Ten persons ( 1 man and 9 postmenopausal women, $51-82$ years of age) with radiological and dual-energy $X$-ray absorptiometrical (DEXA) confirmed osteoporosis (T-score $<-2.5 \mathrm{SD}$ ) or osteopenia $(-1<T$-score $>-2.5)$ entered the study. Characteristics of the subjects are given in Table 5.1. Beside the low bone mass they were apparently healthy based on a medical check. Ten apparently healthy women (55-73 years of age) from a former BMD population study, served as a control group. These controls were not studied at the same time as the intervention group, but they came from the same region and were measured with the same equipment at the same hospital. No one of both groups used additional calcium or vitamin D supplements or was on medication, which are known to influence bone metabolism. All persons gave their written consent. The Medical Ethical Commission of the Medical Centre Leeuwarden approved the study.

\section{Study design}

During the study period, varying from 4-8 months (mean 6.9 months) the intervention group consumed twice daily a dairy-based supplement (Table 5.2). BMD was measured at the start and at the end of this period. Blood and $24 \mathrm{~h}$ urine were collected at baseline, halfway and at the end of the study. Compliance to product intake was 
Table 5.1: Baseline characteristics

\begin{tabular}{lcc}
\hline & $\begin{array}{c}\text { Intervention } \\
\text { group }\end{array}$ & $\begin{array}{c}\text { Control } \\
\text { group }\end{array}$ \\
\hline Number of participants & 10 & 10 \\
- women & 9 & 10 \\
- men & 1 & \\
Age (years $\pm \mathrm{SD})$ & $63.9 \pm 8.1$ & $62.5 \pm 5.0$ \\
Body weight (kg) & $74.1 \pm 10.1$ & $73.0 \pm 9.7$ \\
Body height (cm) & $167.4 \pm 8.4$ & $166.5 \pm 5.5$ \\
BMl (kg/m²) & $26.4 \pm 2.7$ & $26.4 \pm 4.0$ \\
Diagnose osteoporosis & 10 & 10 \\
- anteroposterior & 5 & 5 \\
- lateral & 5 & 5 \\
\hline
\end{tabular}

Data are presented as mean $\pm \mathrm{sD}$. The interwention group received an eggshell powder enriched dairy based supplement in combination with minerals and witamins. The control group did not consume any supplement.

Bati: body mass index.

checked based on the request for new product. After this official study period, 6 women of the supplemented group used the supplement up to 24 months.

During this additional period compliance to product intake was not recorded. Based on a questionnaire it can be assumed that they used only one supplement daily and not on a regular basis. From month 21-24 they consumed the supplement twice daily again. No restrictions were made for the daily diet. Based on a frequency list of dairy products (Appendix 5.1) at baseline and at the end of the study, total calcium intake during the intervention period was estimated at 2,200 $\mathrm{mg}$ per day. The calcium intake of the control group was calculated to be $1,150 \mathrm{mg}$ per day. BMD of the control group was measured with an interval of 22 to 36 months. For a comparison with the results of the intervention group, data of the control group were interpolated to an interval of 8 months.

\section{Material and methods}

The same person measured body height and weight with calibrated equipment during every visit. Outcomes were used to calculate the body mass index (BMI) ( $\mathrm{kg}$ ) $\left.m^{2}\right)$.

BMD of the lumbar spine (L2-L4) in lateral (LA) and anteroposterior position (AP) and the hip (total proximal femur, femoral neck, trochanter, intertrochanter and Ward"s triangle) were assessed by DEXA on a QDR 2000 (Hologic Inc. "Waltman, MA, USA). The coefficients of variation for BMD measurements were 1.0\%. Non-fasting blood samples were analysed for calcium, phosphate and gamma glutamyl transferase (YGT) (Hitachi 717 Chemistry Analyser, Boehringer Mannheim, Germany), and total alkaline phosphatase (colorimetric, according to the recommendations of the International Federation of Clinical Chemistry (IFCC)).

The volume of 24-hi urine was measured and samples were analysed for creatinine and calcium (Hitachi 717 Chemistry Analyser) and for hydroxyproline (colorimetric, Hypronosticon, Organon Teknica Nederland B.V., Boxtel, The Netherlands).

\section{Statistical analysis}

Data were analysed using SPSS 7.0 (SPSS Inc., Chicago, USA). Although BMDs were normally distributed according to the Shapiro-Wilk's test for normality, non-parametric tests (Mann-Whitney U-test and Wilcoxon signed-rank test) were preferred because of the small sample size. Although the intervention group and the control group were not studied at the same time we did compare the changes (second measurement minus first measurement) in BMDs of both groups.

\section{Results}

\section{Anthropometric measurements}

In both groups no significant changes were noted in body height, body weight or BMI. 
Table 5.2: Composition of the dairy-based supplement.

\begin{tabular}{|c|c|c|c|}
\hline Nutrient & Umit & per $400 \mathrm{mi}$ & US RDA: \\
\hline Milk protein & $g$ & 16.4 & 50 \\
\hline Milk fat & 9 & 10.4 & $73^{3}$ \\
\hline Carbohydrates & $\mathrm{g}$ & 42 & $238^{4}$ \\
\hline Energy & kJ (kcal) & $428(340)$ & $7,980(1,900)$ \\
\hline Calcium total & $\mathrm{mg}$ & 1800 & 800 \\
\hline from eggshiell & $\mathrm{mg}$ & 1200 & \\
\hline from milk & mg & 600 & \\
\hline Phosphorus & $\mathrm{mgi}$ & 520 & 800 \\
\hline Sodium & $\mathrm{mg}$ & 236 & $500^{5}$ \\
\hline Potassium & $\mathrm{mg}$ & 756 & $2.000^{5}$ \\
\hline Magnesium & $\mathrm{mg}$ & 400 & 280 \\
\hline Iron & $\mathrm{mg}$ & 3 & 10 \\
\hline Vitamin A & $\mu g-\mathrm{RE}$ & 600 & 800 \\
\hline Beta carotene & $\mathrm{mg}$ & 2.0 & \\
\hline Vitamin $\mathrm{D}_{3}$ & IU & 400 & 200 \\
\hline Vitamin $E$ & $m g \alpha-T E$ & 20 & 8 \\
\hline Vitamin $B_{6}$ & $\mathrm{mg}$ & 4.0 & 1,6 \\
\hline Vitamin $\mathrm{B}_{12}$ & $\mu g$ & 4.0 & 2.0 \\
\hline Vitamin $\mathrm{C}$ & $\mathrm{mg}$ & 120 & 60 \\
\hline
\end{tabular}

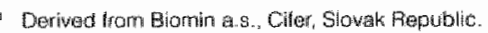

- USA Recommended Dielary Allowances (1989) tor women 51 wears and older.

$325 \%$ of tolal energy

$450 \%$ ol tolat erwergy.

- Estrmaled salle and acequate daily indakes.

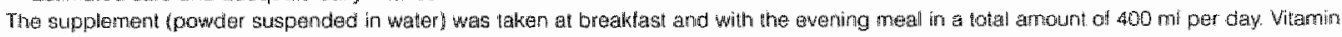

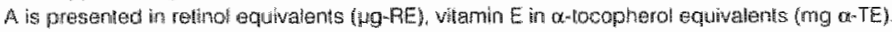

\section{$B M D$}

During the intervention period of $4-8$ months, mean BMDs of the lumbar spine (AP and LA position), total proximal femur and trochanter increased significantly (Table 5.3). Individually changes in spinal BMD in AP and LA position are shown in Figure 5.1.

The control group showed a significant decrease in BMD of the lumbar spine in AP position and femoral neck over a period of 8 months. One woman had a marked increase in BMD of the total proximal femur. This increase of $1.7 \%$ over 8 months coincided with a high calcium intake of $1,510 \mathrm{mg}$ per day. At baseline, mean BMDs of the total proximal femur, trochanter and intertrochanter were higher in the control group. After 8 months these differences disappeared. Comparing the changes in BMDs, the increases in the intervention group of the lumbar spine, femoral neck and total proximal femur were significantly different from the losses in the control group (Table 5.3). 
Table 5.3: Bone mineral densities at baseline and their percent changes after 4-8 months intervention group) and 8 months (control group).

\begin{tabular}{|c|c|c|c|c|}
\hline Measured site & & Intervention group & Control group & $\begin{array}{c}\text { p-value intervention } \\
\text { ws control }\end{array}$ \\
\hline \multirow[t]{2}{*}{ Lumbar spine AP: } & Baseline & $\begin{array}{c}0.824 \pm 0.152 \\
(0.518-1.082)\end{array}$ & $\begin{array}{c}0.858 \pm 0.086 \\
(0.707-0.977)\end{array}$ & 0.436 \\
\hline & Change (\%) & $4.4(1.7-10.4)^{\text {k* }}$ & $-0.8(-1.3-0.1)^{*}$ & $\leq 0.001$ \\
\hline \multirow[t]{2}{*}{ Lumbar spine LA } & Baseline & $\begin{array}{c}0.536 \pm 0.095 \\
(0.373-0.652)\end{array}$ & $\begin{array}{c}0.577 \pm 0.069 \\
(0.504-0.703)\end{array}$ & 0.326 \\
\hline & Change $(\%)$ & $5.7(-1.3-15.9)^{* *}$ & $-1.4(-5.6-3.6)$ & 0.001 \\
\hline \multirow[t]{2}{*}{ Femoral neck } & Baseline & $\begin{array}{c}0.612 \pm 0.125 \\
(0.452-0.914)\end{array}$ & $\begin{array}{c}0.696 \pm 0.110 \\
(0.513-0.888)\end{array}$ & 0.082 \\
\hline & Change (\%) & $0.8(-7.8-8.2)$ & $-0.5(-2.6 *-0.1)^{* *}$ & 0.009 \\
\hline \multirow[t]{2}{*}{ Total prox. femur } & Baseline & $\begin{array}{c}0.720 \pm 0.139 \\
(0.484-1.021)\end{array}$ & $\begin{array}{c}0.829 \pm 0.125 \\
(0.608-1.032)\end{array}$ & 0.031 \\
\hline & Change (\%) & $2.2-1.9 \cdot 9.4 j^{*}$ & $0.1(-2.5-1.7)$ & 0.017 \\
\hline \multirow[t]{2}{*}{ Trochanter } & Baseline & $\begin{array}{c}0.553 \pm 0.102 \\
(0.400-750)\end{array}$ & $\begin{array}{l}0.645 \pm 0.097 \\
(0.472-0.781)\end{array}$ & 0.041 \\
\hline & Change $(\%)$ & $1.8(-1.8-9.0)^{*}$ & $-0.1(-1.8-0.6)$ & 0.086 \\
\hline \multirow[t]{2}{*}{ Intertrochanter } & Baseline & $\begin{array}{c}0.824 \pm 0.171 \\
(0.550-1,180)\end{array}$ & $\begin{array}{l}0.965 \pm 0.154 \\
(0.717-1.231)\end{array}$ & 0.043 \\
\hline & Change $(\%)$ & $4.9(-4.9-12.1)$ & $-0.2(-2.4-4.0)$ & 0.086 \\
\hline \multirow[t]{2}{*}{ Ward's triangle } & Baseline & $\begin{array}{c}0.452 \pm 0.150 \\
(0.310-0.760)\end{array}$ & $\begin{array}{r}0.551 \pm 0.190 \\
(0.361-0.965)\end{array}$ & 0.288 \\
\hline & Change $(\%)$ & $0.0(-8.9-8.9)$ & $-0.3(-7.6-5.5)$ & 0.683 \\
\hline
\end{tabular}

Data are expressed as mean \pm SO (and range) in $\mathrm{g} / \mathrm{cm}^{2}$, and as median percent changs (and range) from basetine. For group oharacteristics sae Tabile 5.1, wor supplement composition see Table 5.2.

" Lumbar spine in anteroposterior position.

- Lumbar spire in lateral position.

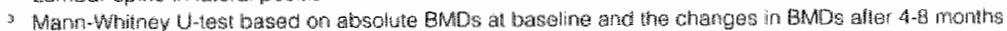

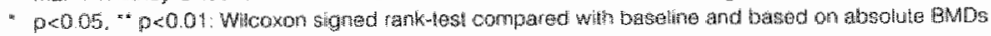

In the small group of 6 women, BMDs after 24 months (Figure 5.2) did not differ from baseline. The control groups lost bone at the lumbar spine AP $(p=0.007)$ and femoral neck ( $p=0.005$ ) over the same time interval. The increase in BMD of the lumbar spine AP at 24 months in the intervention group was still significantly different from the decrease as found in the control group. 
Figure 5.1: Individual changes in lumbar spine BMD of the intervention group in AP (panel A) and $L A$ position (panel $B$ ), after $4-8$ months. Panel $C$ (AP) and D (LA) show the results of the control group over an interpolated period of 8 months.
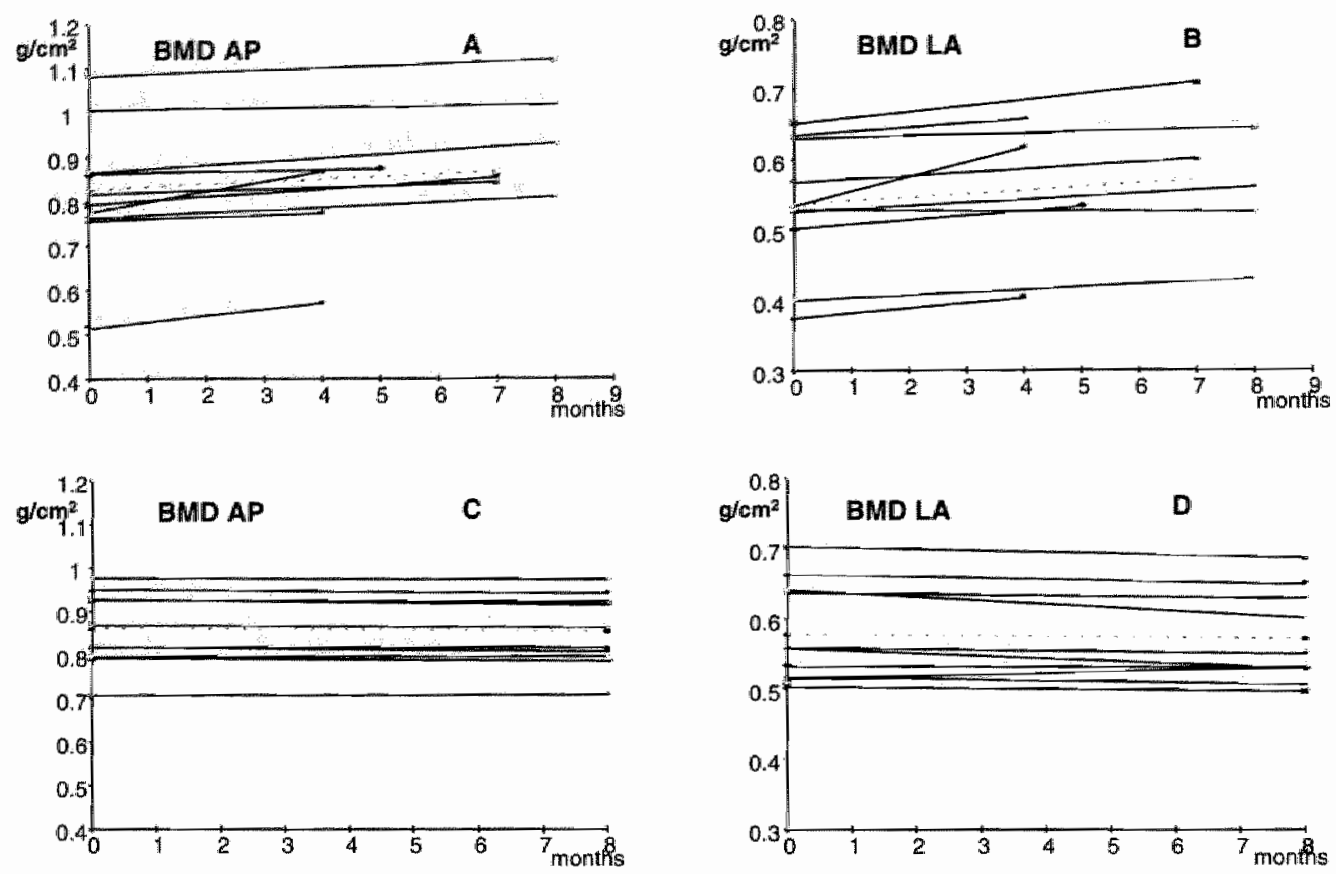

BMO is expressed as g/Gn'as measured by OEXA, Mean BMDs presented as dasthed lines. For a descripton of both oroups and ine

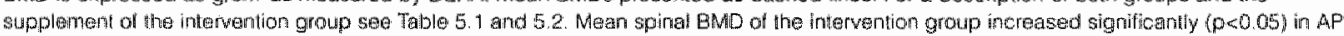
and LA posilion. The control group showed atgnticant decrease of spinal BivD in Ap posilton.

\section{Biochemical measurements}

Mean baseline concentrations ( \pm SD) of serum calcium $(2.36 \pm 0.06 \mathrm{mmol} / \mathrm{l})$ and total alkaline phosphatase $(52.2 \pm 11.3 \mathrm{U} / \mathrm{/})$ did not change during the intervention period.

\section{Figure 5.2:}

Mean courses of BMD in postmenopausal women $(n=6)$ during an intervention period of 24 months with an eggshell powder enriched dairy-based supplement.

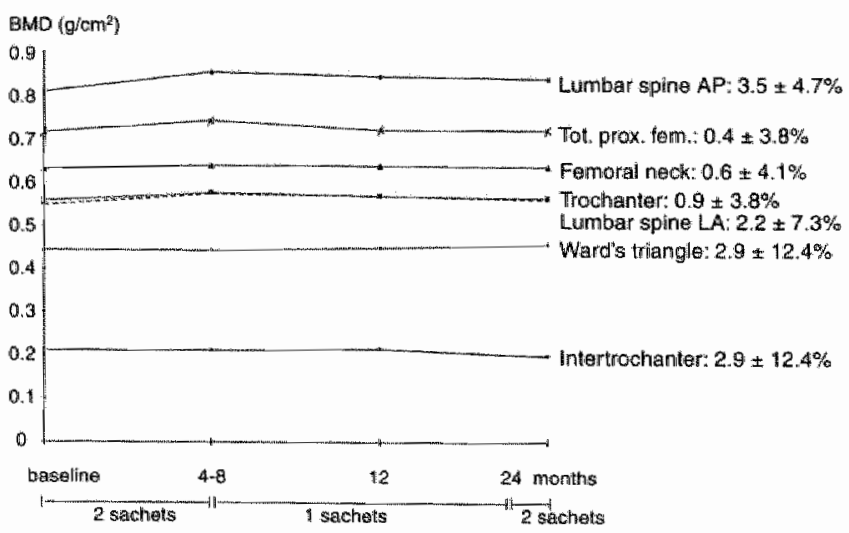

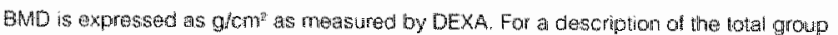
see Table 5. 1. kn supplement composition see Table 5.2. Pefcent changes ir BMD and

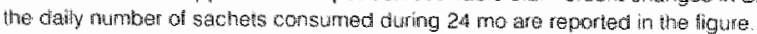


In 24-h urine no significant differences could be detected between start and end excretions of hydroxyproline ( $150 \pm 67.5$ $\mu$ mol/24 $h$, median and range: $156: 61-272$ ) and calcium $(5.5 \pm 3.6 \mathrm{mmol} / 24 \mathrm{~h}$, median and range: $5.6: 1.2-12.0$ ), or their ratios with creatinine.

\section{Discussion}

In this pilot study the effects of an eggshell powder, magnesium and vitamin $D_{3}$ enriched dairy-based product were studied on BMD of the lumbar spine and hip in 10 subjects with spinal osteoporosis or osteopenia. Ten postmenopausal women on a normal diet who participated in a population study in the same region served as a control group. After a study period of 4-8 months, the intervention group significantly increased BMD of the lumbar spine in $\mathrm{AP}(+4.4 \%)$ and LA position $(+5.7 \%)$, total proximal femur $(2.2 \%)$ and trochanter (1.8\%) (Table 5.3). The control group showed a decreased BMD of the lumbar spine in AP position ( $-0.7 \%)$ and femoral neck $(-0.9 \%)$ over a comparable, interpolated period.

The total daily intake of $2,200 \mathrm{mg}$ of calcium by the intervention group is comparable with the amount of about $2,000 \mathrm{mg}$ of calcium per day in the study of Prince et al (1995). In our study the increases in BMD of the lumbar spine are higher compared with the increases over the first 6 months in the study of Prince. The difference might be explained by a lower bone mass of our subjects and/or the supplementation of magnesium (preservation of calcium in bone, calcitriol synthesis) (Abraham 1991; Driessens and Verbeeck 1988), vitamin $D_{3}$ (calcium absorption) (Dawson-Hughes 1995; Nelson 1991; Chevalley 1994) and/or chicken eggshell powder (Makai and Chudacek 1991). Apart from being a source of calcium, chicken eggshell powder contains small amounts of micro-elements, such as strontium and fluoride which may have an additional effect on bone metabolism over purified calcium (Reginster 1999). Although this study lasted for only 4-8 months, calcium supplementation studies up to 4 years indicate that the first year, with an important contribution during the first 6 months, is indicative for longer-term effects (Devine 1997; Reid 1995). Our BMD measurements in 6 women after 2 years suggest a strongly delayed bone loss despite the reduced intake of supplement and suggested lower compliance to product intake.

The intervention and control group were not studied at the same time, but we found it acceptable to compare both groups as the women were recruited from the same region just two years before our study started, and were measured with the same equipment in the same hospital. The control group tended to have higher BMDs at all measured sites (significant for total proximal femur, trochanter and intertrochanter) at baseline. Therefore no statistical differences were found between both groups after 4-8 months despite significant improvements of BMDs in the intervention group. When comparing the changes in BMDs, the intervention group showed a significant increase at the lumbar spine, femoral neck and total proximal femur (Table 5.3).

The high calcium intake by the intervention group did not disturb serum calcium levels nor did it cause an increase in urinary calcium. In theory, an increased calcium excretion of $2.4 \mathrm{mmol}$ per $24 \mathrm{~h}$ might have been expected because of the extra calcium intake and the sodium content of the test product (Table 5.2) (Lemann 1993; Devine 1995). Perhaps the rather high, mean calcium excretion of $5.5 \mathrm{mmol} / 24 \mathrm{~h}$ at baseline masked the expected increase. In other words, a decreased calcium excretion because of an inhibited bone resorption was compensated by an increased excretion as a result of a higher calcium intake. Another study with 
postmenopausal women (Nelson 1991) also reported no increase in urinary calcium after an additional daily calcium intake of $800 \mathrm{mg}$ (total daily calcium intake of $1,500 \mathrm{mg}$ ).

A positive side effect of the test product, probably an effect of eggshell powder, was a reduction in pain and improvement of general well being as reported by the participants. Although these effects are based on a non-validated questionnaire (Appendix 5.2), they confirm what others (Makal and Chudacek 1991) have reported.

In conclusion, this study show that caicium from eggshell powder was available to the body and, in combination with other minerals and vitamins, including vitamin $D_{3}$ and magnesium, increases BMD in the short-term. Therefore, eggshell powder might be an interesting source of calcium for men and women with involutional osteoporosis or osteopenia. The markedly higher gain in BMD of the lumbar spine in particular, compared with other calcium studies over the same length of study period (Devine 1997; Fujita 1990;

Thamsborg 1996; Prince 1995), might point to an effect over the remodelling transient. A placebo or reference product controlled study is warranted to confirm the reported results and to substantiate the role of eggshell powder in healthy postmenopausal women.

Preliminary resuits of this pilot study were published as "Letter to the Editor" (Appendix 5.3).

\section{Acknowledgments}

The authors like to thank the participants for their enthusiastic participation. We are very grateful to Drs. $\mathrm{H}$. Riedstra and $\mathrm{H}$. Storm, Ph.D. (Foundation Clinical Chemical Laboratory Leeuwarden) and their coworkers for the measurements of $B M D$ and biochemical parameters. Finally we would like to thank W.H.M. Saris, M.D., Ph.D. (University Maastricht), F.A.J. Muskiet, Ph.D. (Universital Hospital Groningen) and P.J.F. de Vries, Ph.D. (Friesland Coberco Dairy Foods) for their critical comments on the manuscript. 


\section{Appendix 5.1: Food frequency questionnaire}

\begin{tabular}{|c|c|c|c|c|c|c|c|c|c|}
\hline & \multirow{2}{*}{\multicolumn{2}{|c|}{ 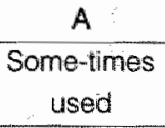 }} & \multicolumn{6}{|c|}{ B } & \multirow{3}{*}{ 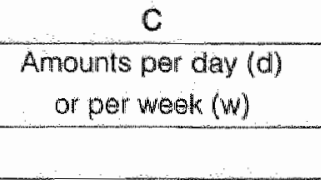 } \\
\hline & & & \multicolumn{3}{|c|}{$\begin{array}{c}\text { Consumption } \\
\text { per day }\end{array}$} & \multicolumn{3}{|c|}{$\begin{array}{c}\text { Corisumption } \\
\text { per week }\end{array}$} & \\
\hline & No & Yes & $1 \times$ & $2-3 x$ & $4+$ & $1 x$ & $2-4 x$ & $5-7 x$ & \\
\hline Coffee: & & & & & & & & & $\ldots$ cups/d/w \\
\hline black & & & & & & & & & \\
\hline with milk & & & & & & & & & \\
\hline no caffeine & & & & & & & & & \\
\hline Added salt & & & & & & & & & $\ldots$ tea-spoons/d \\
\hline $\begin{array}{l}\text { Salty chips, } \\
\text { peanuts, etc }\end{array}$ & & & & & & & & & $\ldots$ grams $/ d / w$ \\
\hline Cheese (on bread) & & & & & & & & & $\ldots$ slices/d/w \\
\hline $\begin{array}{l}\text { Yogurt " curds or } \\
\text { custard }\end{array}$ & & & & & & & & & $\ldots$ dishes/d/w \\
\hline Milk or buttermilk & & & & & & & & & .... cups/d/w \\
\hline Meat & & & & & & & & & $\ldots$ grams/d/w \\
\hline Fish & & & & & & & & & $\ldots$ plece/d/w \\
\hline Fish oill & & & & & & & & & $\ldots$ capsules/d/w \\
\hline Liver & & & & & & & & & $\ldots$ grams/d/w \\
\hline Chinese cabbage & & & & & & & & & $\ldots$ vegetable-spoon/d/w \\
\hline Kale & & & & & & & & & .... vegetable-spoon/d/w \\
\hline Spinach & & & & & & & & & .... vegetable-spoon/d/w \\
\hline Garden-cress & & & & & & & & & $\ldots$ table-spoons $/ d / w$ \\
\hline Eggs & & & & & & & & & $\ldots$ pieceld/w \\
\hline $\begin{array}{l}\text { Dietary fiber (bran, } \\
\text { unpolished rice, } \\
\text { soya) }\end{array}$ & & & & & & & & & $\begin{array}{l}\ldots \text { table-spoons/d/w } \\
\ldots \text { table-spoons/d/w }\end{array}$ \\
\hline Wholemeal bread & & & & & & & & & $\ldots$ slices $/ d / W$ \\
\hline Ginseng & & & & & & & & & $\begin{array}{l}\text {.... measuring glass } \\
( \pm 20 \mathrm{ml})\end{array}$ \\
\hline $\begin{array}{l}\text { Margarine or low } \\
\text { fat margarime }\end{array}$ & & & & & & & & & $\begin{array}{l}\text {... slices of bread, toast, } \\
\text { etc. }\end{array}$ \\
\hline Butter & & & & & & & & & $\begin{array}{l}\text { slices of bread, toast, } \\
\text { elc. }\end{array}$ \\
\hline $\begin{array}{l}\text { Vitamin andior } \\
\text { mineral } \\
\text { supplements }\end{array}$ & & & & & & & & & $\begin{array}{l}\text {.... pills or capsules/diw } \\
\text { Name: ............. }\end{array}$ \\
\hline
\end{tabular}




\section{Appendix 5.1 (continued)}

\section{Elucidation}

To get an impression about the normal daily intake of calcium in particular and possible changes during the study period, participants had to complete the questionnaire at baseline and after 6 and 12 months. $A$ ' $x$ ' marked the proper: answers for the categories $A$ and $B$.

Category $A$ indicates whether the product is never used, or sometimes but less than once per week. Category $B$ indicates the frequency of intake per day, and/or per week. Category $\mathrm{C}$ gives an impression about amounts and volumes but is also a check on the information given in category B.

\section{Estimated consumed amounts and calcium content}

To estimate the daily calcium intake, it was supposed that dairy products supply 70 -
$75 \%$ of this intake (FitzGerald 1998; Dutch National Food Consumption Survey 1998). Amounts of calcium as used in the calculation are presented in the table below.

Other information obtained from the food frequency questionnaire gave us the ability to check on abnormal intakes of certain food components e.g. fish and liver (rich in vitamin D) and Ginseng (a source of phytooestrogens).

This food frequency questionnaire is an extended form of the one described by the US National Osteoporosis Foundation which was developed to estimate daily dietary calcium intake (National Osteoporosis Foundation. Osteoporosis Clinical Updates 1999;1I(1);3)

\begin{tabular}{lcc}
\hline & Amount per consumption & Calcium content \\
\hline Cheese & 20 gram/slice of bread & $180 \mathrm{mg}$ \\
Yogurt, curd or custard & $200 \mathrm{gram} / \mathrm{dish}$ & $250 \mathrm{mg}$ \\
Milk or buttermilk & 200 gram/cup & $240 \mathrm{mg}$ \\
\hline
\end{tabular}




\section{Appendix 5.2: Questionnaire for pain score and general well-being}

\section{Use and evaluation of the questionnaire}

At baseline and at 2-monthly intervals, participants were interviewed according to the questionnaire and answers are circled. Mean values per category were calculated and compared with the answers as given at other moments. General well being is established by combining the four categories.

\begin{tabular}{lcccc}
\hline \multicolumn{1}{c}{ Questions concerning tiredness } & Not at all Sometimes & Pather & Often \\
\hline 1 Do you feel tired? & 1 & 2 & 3 & 4 \\
2 Do you feel spiritless? & 1 & 2 & 3 & 4 \\
3 Do you feel queer? & 1 & 2 & 3 & 4 \\
4 Do you need to rest? & 1 & 2 & 3 & 4 \\
\hline
\end{tabular}

\begin{tabular}{|c|c|c|c|c|c|}
\hline & Questions concerning pain & Not at all & Sometimes & Rather & Severely/often \\
\hline 5 & Do you lhave pain in back or bones? & 1 & 2 & 3 & 4 \\
\hline 6 & Is pain more severe after exertion? & 1 & 2 & 3 & 4 \\
\hline 7 & Does pain disturb your sleep? & 1 & 2 & 3 & 4 \\
\hline 8 & Do you use painikillers? & 1 & 2 & 3 & 4 \\
\hline
\end{tabular}

Questions concerning mobility

9 Do you have difficulty with walking in the house?

10 Do you have difficulty with a small walk outside?

11 Do you have difficulty with walking the stairs?

12 Do you have difficulty with rising, ducking or bending? 1

13 Do you difficulty with dressing?

14. Do you have difficulty with washing yourself?

15. Do you have difficulty with doing your job?
Not at all Sometimes Rather Severely/otten

\begin{tabular}{llll}
1 & 2 & 3 & 4 \\
1 & 2 & 3 & 4 \\
1 & 2 & 3 & 4 \\
1 & 2 & 3 & 4 \\
1 & 2 & 3 & 4 \\
1 & 2 & 3 & 4 \\
1 & 2 & 3 & 4 \\
\hline
\end{tabular}

\begin{tabular}{llccc}
\hline Questions concerning gastrointestinal complaints & Not at all & Sometimes & Rather & Severely \\
\hline 16 Do you have stomach ache? & 1 & 2 & 3 & 4 \\
17 Do you have a bumptious feeling? & 1 & 2 & 3 & 4 \\
18 Do you have a sick feeling? & 1 & 2 & 3 & 4 \\
19 Do you have a loss of appetite? & 1 & 2 & 3 & 4 \\
20 Do you have thin stools? & 1 & 2 & 3 & 4 \\
\hline
\end{tabular}




\title{
Appendix 5.3
}

\section{Effect of a chicken eggshell powder enriched dairy product on bone mineral density in persons with osteoporosis or osteopenia.}

A. Schaafsma' and I. Pakan²

\author{
'Department of Research \& Development Leeuwarden, FRIESLAND Dairy Foods, \\ Leeuwarden "the Netherlands; \\ ${ }^{2}$ Department of Surgery, Medical Center Leeuwarden, Leeuwarden, the Netherlands
}

\section{Letter to the Editor, Nutrition 1999;15(2)157}

A Slovakian study (Makail and Chudacek 1991) found a positive effect from the addition of $6 \mathrm{~g}$ of chicken eggshell powder per day on bone mineral density (BMD) of the lumbar spine in elderly patients with osteoporosis. Furthermore, an important decrease in pain was reported. These effects make chicken eggshell powder an interesting source of calcium for human nutrition to support the prevention and treatment of osteoporosis. However, the amount of eggshell powder as tested (containing about $2,300 \mathrm{mg}$ of calcium) is too high to be consumed daily in addition to the normal diet. That is why we studied the effects of $3 \mathrm{~g}$ of eggshell powder per day combined with magnesium and vitamin $D_{3}$. Nine women and one man, 63.9 $\pm 8.1 \mathrm{y}$ old (mean age $\pm \mathrm{SD}$ ) with osteoporosis (T-score $<-2.5$ ) of the lumbar spine in anteroposterior (AP) or laterall (LA) position, were included in a pilot study. During a study period of $4-8 \mathrm{mo}$, they consumed a dairy product enriched with $1.5 \mathrm{~g}$ of chicken eggshell powder, $200 \mathrm{IU}$ of vitamin $\mathrm{D}_{3}$ and $200 \mathrm{mg}$ of magnesium twice per day, replacing an equal volume of milk. Total calcium intake during the intervention period was estimated at $2,200 \mathrm{mg}$ per day. None of the subjects used additional calcium or vitamin $D$ supplements or medicines, which are known to influence bone metabolism, or suffered from fractures of the spine or hip. BMD of the lumbar spine and hip were measured by dual energy $x$-ray absorptiometry (QDR 2000, Hologic Inc., Waltham, MA, USA). After the intervention period, mean increases in BMD of the lumbar spine in AP (median $4.1 \%$, range $1.5-11.0 \%)$ and $L A(6.5 \%,-1.3-15.9 \%)$ position, and of the total proximal femur $(1.9 \%,-2.3-9.5 \%)$ were significant $(p<0.05$, t-test). Although BMD of the femoral neck improved $(0.9 \%,-5.3-7.8 \%)$, the difference with the baseline value was not significant. A positive side effect of the test product, possibly an effect of eggshell powder, was a reduction in pain and improvement of general well being. Although these effects are based on non-validated questionnaires, it confirms what has been reported by Makai and Chudacek (Makai and Chudacek 1991). In a population study in the same region (BMD measured with the same equipment) it was found that comparable women with a normal diet (approx. 1,150 mg calcium per day) lost bone during the same period at all measured sites. Although it is known from literature that increasing calcium intake from dairy products with (Nelson 1991) or without (Prince 1995) additional vitamin D, and calcium from oyster shell might increase BMD of the lumbar spine in postmenopausal women (mean increases $0.5-2.4 \%$ ), the increases as found in our study are much higher.

Based on our experiment, eggshell powder might be an interesting source of bioavailable calcium for human nutrition, postmenopausal women in particular. A placebo or reference product controlled study, lasting for at least $12 \mathrm{mo}$, is warranted to confirm the reported results and to substantiate the role of chicken eggshell powder. 


\section{Supplementation of healthy, Dutch} postmenopausal women with minerals and vitamins; positive effects of enriched chicken eggshell powder on bone mineral density of the femoral neck

A. Schaafsma', J.J. van Doormaal', F.A.J. Muskiet', G.J.H. Hofstede ${ }^{2}$, I. Pakan ${ }^{3}$, E. van der Veertit

"Department of Research \& Development Leeuwarden, Friesland Coberco Dairy Foods " Leeuwarden. The Netherlands

2 Groningen University Hospital, Groningen, The Netherlands

* Medical Centre Leeuwarden, Leeuwarden, The Netherlands

\section{Submitted}

\section{Abstract}

The objective of this study was to evaluate the effects of chicken eggshell powder as a calcium source and purified calcium carbonate, in combination with minerals and vitamins including magnesium, vitamin $D_{3}$ and vitamin $K_{1}$, on bone mineral density (BMD) of the lumbar spine and hip. For this we designed a randomized, double blind, placebo-controlled study during 12 months. Healthy Caucasian women $(n=85)$ were recruited by telephone calls. They were at least 5 years postmenopausal, 50-70 years of age and had a lumbar spine T-score $>-2.5$. Their habitual daily calcium intake was $1,295 \mathrm{mg}(95 \% \mathrm{Cl}: 1,194$ to 1,396). The women were randomly allocated to: eggshell powder enriched $(A ; n=24)$, purified calcium carbonate enriched $(B ; n=22)$, or placebo $(C ; n=27)$. BMD was measured after 0,6 and 12 months as were the biochemical markers bone-specific alkaline phosphatase, amino-terminal propeptide extension of type I collagen, deoxypyridinoline, calcitonin, intact-parathyroid hormone, calcidiol, and urinary calcium/ creatinine ratio. After 12 months of supplementation, mean BMD of the femoral neck in group A was increased $(p=0.014)$ with $1.75 \%(95 \% \mathrm{Cl}: 0.18$ to 3.32$)$ versus a decrease of $-0.60 \%(-1.92$ to 0.72$)$ in group $C$. This increase coincided with significant decreases in markers of bone resorption and formation.

This study indicates that healthy postmenopausal women, with a baseline calcium intake according to recommendations, increase BMD of the hip within 12 months following supplementation with $\mathrm{a} / \mathrm{o}$ calcium, magnesium, vitamin $\mathrm{D}_{3}$ and vitamin $\mathrm{K}_{1}$. Chicken eggshell powder proved to be a good source of calcium.

Keywords: biochemical markers of bone turnover, bone mineral density, calcium carbonate, eggshell powder, postmenopausal women. 


\section{Introduction}

Age related decrease in bone mass and loss of bone architecture contribute to bone fragility and increased fracture risk.

Consequently, nutritional prevention strategles aiming to reduce the risk of fragility fractures should start as soon as possible. For postmenopausal women this might be at about 10 years past menopause because bone loss during the preceding postmenopausal period is often not a result of nutrient deficiency.

Supplementation during the early postmenopausal period with nutrients such as calcium, is thought to have only small effects (Heaney 1996b).

At least four nutrients are recognized as important in primary prevention strategies and should be present in nutritional supplements: calcium, magnesium, vitamin $\mathrm{D}$ and vitamin $\mathrm{K}$. Magnesium is thought to prevent calcium leakage from bone by regulating the $\mathrm{pH}$ of extracellular fluid. Furthermore, it is necessary for the synthesis of calcitriol (Driessens and Verbeeck 1988). Vitamin $K$ is an essential co-factor in post-translation carboxylation of osteocalcin, which is important for proper minerallization of new bone (Sokoll 1997). Several studies have shown positive effects of additional calcium and/or vitamin $\mathrm{D}$ on BMD of the lumbar spine and hip.

These effects are associated with decreased risk of fracture (Kanis 1999; Dawson-Hughes 1997; Riggs 1998; Prince 1995). The amounts of calcium and vitamin

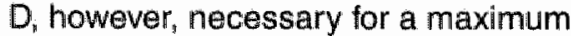
effect are debated (Vieth 1999; DawsonHughes 1998; McKane 1996). The calcium source used may influence the final effect on BMD. Chicken eggshell powder is a rather unknown calcium source with about $39 \%(w / w)$ of elemental calcium with a bioavailability as high as from calcium carbonate (Schaafsma and Beelen 1999). The main difference between eggshell powder and purified calcium carbonate is the presence of small amounts of strontium (about $350 \mu \mathrm{g} / \mathrm{g}$ ) in eggshell powder. Strontium is thought to stimulate bone formation (Reginster 1998b). In small studies, eggshell powder showed positive effects on BMD of the lumbar spine and hip in postmenopausal women with osteoporosis (Schaafsma and Pakan 1999; Makai and Chudacek 1991).

Suitable surrogate parameters to measure effects of nutritional intervention in a healthy population are BMD for bone strength (Kanis 1999), deoxypyridinoline (D-Pyr) for bone resorption (Delmas 1991), and bone specific alkaline phosphatase (bALP) and the amino-terminal propeptide extension of type I collagen (P1NP) (Cabrera 1998) for bone formation. Carboxylated osteocalcin (\%carbOC), expressed as a percentage from total osteocalcin, is a marker of bone mineralization and vitamin $\mathrm{K}$ status (Boskey 1998). Parathyroid hormone (PTH) and calcitonin are regulators of bone remodeling (Aurbach 1988). Serum levels of calcidiol $[25(\mathrm{OH}) \mathrm{D}]$ which is the precursor of calcitriol reflect vitamin Dstatus. Calcitriol has various functions in bone metabolism among others as an inhibitor of parathyroid hormone (PTH) secretion (McKenna and Freaney 1998).

This paper describes a double blind, placebo controlled, randomized study with healthy Caucasian postmenopausal women. The aim of this study was to investigate the effects of two different calcium sources, chicken eggshell powder and purified calcium carbonate, on BMD of the lumbar spine and hip. Both calcium sources were given in combination with other minerals and vitamins, including magnesium and the vitamins $D_{3}$ and $K_{1}$. Apart from the comparison of the two calcium sources, the effect of each calcium-enriched supplement was compared with no change (baseline) and no intervention ( $p$ lacebo). 
Table 6.1: Baseline characteristics.

\begin{tabular}{|c|c|c|c|}
\hline & A & 8 & $\mathrm{C}$ \\
\hline Age $(y)$ & $60.5^{7} \pm 3.6$ & $59.5^{2} \pm 3.8$ & $63.5 \pm 4.0$ \\
\hline Postmenopausal age (y) & $9.9^{2} \pm 4.0$ & $12.1 \pm 6.4$ & $44.3+4.6$ \\
\hline Weight (kg) & $71.4 \pm 9.0$ & $75.5 \pm 10.4$ & $76.9 \pm 11.9$ \\
\hline Height $(\mathrm{cm})$ & $164.2 \pm 5.4$ & $164.5 \pm 5.7$ & $1639 \pm 6.1$ \\
\hline $\mathrm{BM}\left(\mathrm{kg} / \mathrm{m}^{2}\right)$ & $26.5 \pm 3.2$ & $28.1 \pm 4.8$ & $28.7 \pm 4.4$ \\
\hline \multicolumn{4}{|l|}{ Lumbar spine (AP) } \\
\hline T-score & $-0.97 \pm 0.96$ & $-0.73 \neq 0.89$ & $-0.72+1.17$ \\
\hline Z-score & $0.51 \pm 1.00$ & $0.68 \pm 0.87$ & $0.98 \pm 4.16$ \\
\hline \multicolumn{4}{|l|}{ Femoral neck } \\
\hline T-score & $-1.54 \pm 0.95$ & $-1.53 \pm 0.95$ & $-1.06 \pm 1.12$ \\
\hline Z-score & $0.26 \pm 1.04$ & $0.05 \pm 0.78$ & $0.86 \pm 1.07$ \\
\hline \multicolumn{4}{|l|}{ Total proximal femur } \\
\hline T-score & $-0.92 \pm 0.83$ & $.0 .77 \pm 1.01$ & $-0.49 \pm 1.00$ \\
\hline Z-score & $0.20 \pm 0.86$ & $0.29 \pm 1.03$ & $0.81 \pm 0.92$ \\
\hline
\end{tabular}

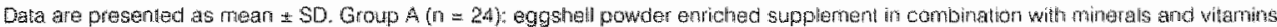

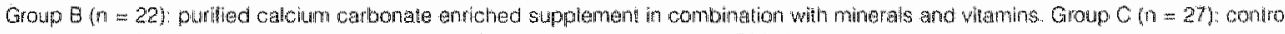
producl containing $2.5 \mathrm{~g}$ skimmed milk powder. AP: anteroposterior position. Ekh: body mass index

" $p \leq 0.05$ compared with group $C$. " $P \leq 0.01$ compared will group $C$

\section{Subjects, material and methods} Subjects

Apparently healthy Caucasian postmenopausal women $(n=85)$ were recruited by telephone calls in co-operation with three general practitioners in the village of Eelde in The Netherlands. They were included in this study after informed consent was obtained. The women were at least 5 years postmenopausal and between 50 and 70 years of age. Baseline characteristics are given in Table 6.1. They did not use medication or vitamin and/or mineral preparations known to interfere with bone metabolism, and they were asked to abstain from artificial sun bathing during the study period. Excluded were women with acute and chronic illnesses, as were the women with a lumbar spine T-score $<-2.5$ measured with dual energy $X$-ray absorptiometry (DEXA). Also were excluded those women who had evident arthrosis of the lumbar spine or hip as suggested by DEXA and confirmed by $X$-ray photography. During the study 12 women dropped out because of the need for medical treatments, not related to the intervention. The Medical Ethical Committee of the University Hospital of Groningen approved the study.

\section{Supplements and diet}

Women were randomly allocated to one of three intervention groups. The three supplements used (Table 6.2) were chicken eggshell powder (Biomin a.s., Cifer, Slovak Republic) combined with magnesium, vitamin $\mathrm{D}_{3}$, vitamin $\mathrm{K}_{1}$ and a standard mixture of minerals and vitamins (supplement A), or purified calcium carbonate (Calcipural GP, Scora S.A., Caffiers, France) combined with the same amounts of minerals and vitamins as $A$ (supplement B), or a placebo product containing $2.5 \mathrm{~g}$ of skimmed millk powder (supplement $\mathrm{C}$ ). The subjects were instructed to take the supplements twice daily, suspended in water yogurt or milk. Compliance, expressed as the percentage of sachets taken, was assessed on the basis of emptied sachet counts and written checklists. 
A minimum compliance of $75 \%$ was necessary for evaluation of results. The intake of calcium was recorded at three occasions during the study period by means of a food frequency questionnaire. The aim was to classify calcium intake as low ( $<800 \mathrm{mg} / \mathrm{day}$ ), median ( 800 $1,000 \mathrm{mg} /$ day) or high ( $>1,000 \mathrm{mg} /$ day).

\section{Material and methods}

Evening weight and height were measured by standardized methods, and body mass index (BMl) was calculated $\left(\mathrm{kg} / \mathrm{m}^{2}\right)$. BMD of the lumbar spine (L1-L4) in anteroposterior position (AP) and of the hip (total proximal femur, femoral neck, trochanter, intertrochanter $r_{n}$ and Ward's triangle) was assessed by DEXA on a Hologic QDR 1000 (Hologic inc., Waltman, MA, USA). The coefficient of variation was $1 \%$ for the spine and $1.6 \%$ for the hip. Those measurements were done at the start and after 6 and 12 months of intervention. Blood samples were obtained between 7:00 - 9:00 p.m., at baseline and after 6 and 12 months. Serum was stored at $-20^{\circ} \mathrm{C}$ within one hour. Second morning urine samples were collected prior to food intake and stored in a freezer until analysis. For standard monitoring, serum albumin, total calcium, phosphate, creatinine, gamma glutamyl transferase $(\gamma \mathrm{GT})$, alanine amino transferase (ALAT) and aspartate amino transferase (ASAT) were measured (Mega automated analyser, Merck, Darmstadt, Germany or Vitros, Johnson \& Johnson Diagnostic, Rochester, NY, USA). Bone formation was studied by assessment of P1NP (RIA, Orion Diagnostica, Espoo, Finland), b-ALP (Immuno assay, Metra Biosystems, Mountain View, CA, USA), and total osteocalcin (OCtot) and undercarboxylated osteocalcin before and after extraction with hydroxyapatite,

Table 6.2: Compositions of the supplements per sachet.

\begin{tabular}{|c|c|c|c|c|c|}
\hline Nutrient & Unit & $\mathrm{A}_{\mathrm{A}}$ & $\mathrm{B}$ & $\mathrm{C}$ & US RDA \\
\hline Energy & $k J(k c a l)$ & $3.4(0.8)$ & $3.4(0.8)$ & $34(8)$ & $7,980(1,900)$ \\
\hline Protein & $g$ & 0.2 & 0.2 & 0.7 & 50 \\
\hline Calcium & & & & & 1,200 \\
\hline from eggshell & $\mathrm{mg}$ & 500 & & & \\
\hline purified $\mathrm{CaCO}_{3}$ & $\mathrm{mg}$ & & 500 & & \\
\hline from millk & $\mathrm{mg}$ & & & 25 & \\
\hline Magnesilum & $\mathrm{mg}$ & 175 & 175 & 2.8 & 320 \\
\hline Zine & $\mathrm{mg}$ & 5 & 5 & 0.08 & 12 \\
\hline Sillican & $\mu \mathrm{g}$ & 1000 & 1000 & \pm 70 & " \\
\hline Vitamin $A$ & $N 0-\mathrm{RE}$ & 160 & 160 & 3 & 800 \\
\hline Vitamin $D_{3}$ & $\mu g$ & 5 & 5 & 0.005 & 10 \\
\hline Vitamin $E$ & mg $\alpha T E$ & 5 & 5 & 0.007 & 8 \\
\hline Whamin $K_{i}$ & $\mu g$ & 40 & 40 & 0.23 & 65 \\
\hline Vitamin $\mathrm{C}$ & $\mathrm{mg}$ & 30 & 30 & 0.12 & 60 \\
\hline Thiamine & $\mu g$ & 700 & 700 & 4.6 & 1,000 \\
\hline Ribotlavin & $\mu g$ & 800 & 800 & 35 & 1,200 \\
\hline Vitamin $\mathrm{B}_{0}$ & $\mu g$ & 1000 & 1000 & 9.2 & 1,600 \\
\hline Vitamin $\mathrm{B}_{12}$ & $\mu g$ & 0.5 & 0.5 & 0.09 & 2.0 \\
\hline
\end{tabular}

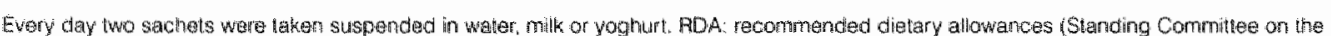

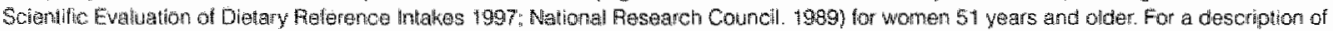
the groups A, B and C stable G.

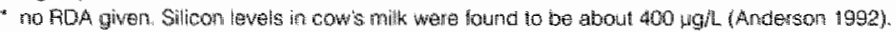

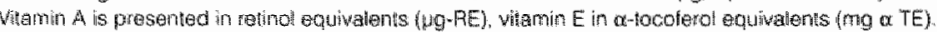


respectively (IRMA, Medgenix-H-Ost, Fleurus, Belgium). The \%carbOC is calculated as the difference between undercarboxylated osteocalicin and OCtot. Calcitonin (RIA, Nichols Institute, San Juan Capistrano, CA, USA), intact-PTH (IRMA, Nichols Institute) and 25(OH)D [competitive protein binding assay (Chen 1990)] were determined because they are important (pro-) hormones in bone metabolism.

Urine was analysed for calcium, phosphate, creatinine (Mega, Merck or Vitros, Johnson \& Johnson) and for D-Pyr (HPLC, (Beardsworth 1990)). The urinary excretion of D-Pyr and calcium was corrected for urinary creatinine.

Premenopausal D-Pyr reference value (University Hospital Groningen) was 11.7 umol/mol creatinine (95\% Cl: 6.8-23.1). DPyr and urinary calcium (u-Ca/Cr) excretion are markers of bone resorption.

\section{Statistics}

Allocation to the different intervention groups was based on computer-generated random numbers. Data were analyzed using SPSS 7.0 (SPSS Inc., Chicago, USA). Because at least some of the parameters were found to have nonparametric distributions according to the Kolmogorov-Smirnov normality test, all parameters were evaluated with nonparametric, two tailed statistical tests.

Differences between the groups were studied with the Kruskal-Wallis test combined with the Mann Whitney U-test. Differences identified by repeated measurements within the groups were investigated with the Wilcoxon Signed-rank test. Associations between baseline values of parameters and their changes after 12 months were studied (Spearman Rank test) taking groups $A$ and $B$ together. Differences were considered significant when $p \leq 0.05$. Changes in parameters were calculated as percentage change from baseline.

\section{Results}

Age, compliance, calcium intake and rowtine parameters.

Although the women were recruited from the same population and randomly allocated to one of the three groups, women in groups $\mathrm{A}$ and $\mathrm{B}$ were significantly younger than those in group $C$. Furthermore, group A had a significantly lower postmenopausal age compared with group $\mathrm{C}$ (Table 6.1). The percentage of women with a postmenopausial age less than 10 years in groups $A, B$ and $C$ was 58,45 and $15 \%$, respectively. Mean compliance with intervention in groups A, B and $\mathrm{C}$ was $97 \%$ (range: $90.8-100$ ), 98.4\% (93.4-100) and 97\% (82.4-100), respectively. The calculated calcium intake of the participants in this study was unexpectedlly high (mean 1,294 $\pm 421 \mathrm{mg}$ per day) when compared with the mean Dutch (Dutch National Food Consumption Survey 1998) daily calcium intake $(995 \mathrm{mg}$ ) by $50-65$ years old women. Habitual calcium intake did not differ between the groups at baseline and did not change during the study. No significant differences were found in body weight, height, and BMI between the groups at baseline (Table 6.1) nor were changes observed during the study. Serum concentrations of calcium, phosphate, creatinine, albumin and the enzymes YGT, ALAT and ASAT did not change during the study either (data not showni).

\section{$B M D$}

Despite the (small) age differences between the groups, BMD baseline values were not significantly different (Table 6.3). After 12 months of intervention, BMD of femoral neck and of Ward's triangle had increased significantly in group $A$ compared with baseline. No significant changes were seen in BMDs at other sites nor in groups $B$ and $C$. No differences were found between groups $A$ and $B$. The increase in BMD of the femoral neck in 
Tabie 6.3. Bone mineral densities at basehne and thei percent changes ater 12 months of intervention.

\begin{tabular}{|c|c|c|c|c|}
\hline BMD & & A & 8 & $\mathrm{C}$ \\
\hline \multirow[t]{2}{*}{ Lumbar spine } & basemine & $0.936 \pm 0.105$ & $0.960 \pm 0.099$ & $0.968=0.129$ \\
\hline & change $(\%)$ & $0.10 \pm 2.14$ & $0.52=207$ & $0.13=231$ \\
\hline \multirow[t]{2}{*}{ Femoral neok } & baseline & $0741 \pm 0.095$ & $0.741=0.095$ & $0.792=0.114$ \\
\hline & change $(\%)$ & $1.757 \pm 3.91$ & $1.16 \pm 5.09$ & $-0.60 \pm 3.50$ \\
\hline \multirow[t]{2}{*}{ Total prox fornur } & baselne & $0.864 \pm 0.099$ & $0.883=0.121$ & $0.917 \pm 0.120$ \\
\hline & change $(\%)$ & $023=3.59$ & $023 \pm 3.57$ & $-0.14 \pm 4.34$ \\
\hline \multirow[t]{2}{*}{ Troohander } & braselne & $0.649 \pm 0.073$ & $0.671 \pm 0.092$ & $0.696 \pm 0.091$ \\
\hline & change $(\%)$ & $-0.34+3.00$ & $-0.46 \pm 5.24$ & $0.57 \pm 6.47$ \\
\hline \multirow[t]{2}{*}{ Interirochanter } & baselne & $1.016 \pm 0.126$ & $1.038 \pm 0.156$ & $1.073 \div 0.159$ \\
\hline & change $(\%)$ & $0.20 \pm 3.94$ & $0.29 \pm 4.53$ & $-0.28 \pm 4.85$ \\
\hline \multirow[t]{2}{*}{ Ward's triangle } & baseline & $0.592 \pm 0.138$ & $0.539 \pm 0.125$ & $0.609 \pm 0.129$ \\
\hline & charge $(\%)$ & $3.38^{5} \pm 5.07$ & $4.08 \pm 10.76$ & $-0.50 \pm 6.24$ \\
\hline
\end{tabular}

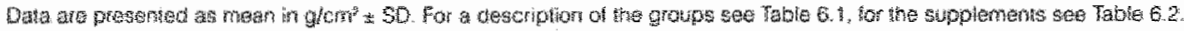

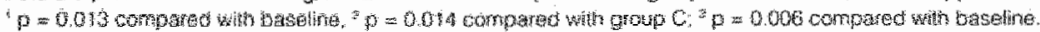

group A was significantly different from the decrease in group $\mathrm{C}$.

Ellects of baseline BMDs on BMD changes after 12 months were studied for the combined groups $A$ and $B$, since these groups only differed in calctum source. Low baseline BMDs in group A \& B were associated $(p<0.01)$ with targer increases or smaller losses ater 12 months in case of the intertrochanter $(x=-0.45)$, total proximal fermur $(r=-0.39)$, and the Ward's mangle $1 \mathrm{r}=0.41$. In contrast. spine buto increased more or decreased Wess when baselne Bum was higher $t=0.39, p<0.01)$. No signimant correlations were found for he temoral neck and trochanter.

\section{Biochewical makters}

Baseine values of biochemical makers and changes (fol afer 2 months are reported in Table 6.4. Ony one woman in group $C$ had a marginal (25-40 moll (Vien 19991 ) 25 (OH) level a beselne. All tree groups had hcreased heir serum $25(\mathrm{OH}) \mathrm{D}$ levels signmwany after 12 months of interwention. Durng the winter months, the mean 25/OHD level in group c decreased with $26 \% 1067$ mollt.
In both supplemented groups, serum levels of PHN and PTH decreased significanty compared with baseline. The percent changes in P N NP and PTH were also difterent trom the percent changes in group C. No differences were found in levels of OCtot. The \%carbOC increased during the study in group B. A significant decrease in $D$-Pyr excretion was found in group $A$. This group also had the highest baseline excretion of D-Pyr. Group C showed a small but significant increase n b-A compared wh baselne and compared why groups $A$ and $B$. No ditherences were bund beween groups and 8 in changes and absolute levels of biochembal parameters at 12 months.

Ony a 6 months, the decrease in D-Py was significanty $1 p=0.04$ greater 1 in group A compared wh group B ldata not shown). When groups A and B were conbined, all baseline values of blochemibal makers were significanty and negatively correlated $(-0.33<x<-0.80)$ with the changes ater 6 (except for calcitonin) and 12 months of supplementation. For he parameters P N D, D-Py and PTH his means that decteases were stronger in case baselne values were higher (Figure 6.1). 
No correlation was found between baseline PTH and baseline 25(OH)D, nor between their changes after 12 months of study. However, in group B alone, larger increases in 25(OH)D during the studly were associated with larger decreases in PTH $(r=-0.42, p \leq 0.05)$.

Only two significant correlations were found between BMD and biochemical parameters in the combined groups $A$ and $B$. Firstly, the increase in femoral neck BMD was associated with a decrease in D-Pyr excretion $(r=-0.32, p<0.05)$. Secondly, BMD of the trochanter showed a higher increase or a smaller decrease when serum PTH decreased more $(r=-0.34$, $p<0.05)$. These correlations were especially an effect of group B.

\section{Discussion}

We investigated the effects of daily supplements with different calcium sources (chicken eggshell powder: group $A, n=24$; purified calcium carbonate: group $B, n=22$ ) but equal amounts of vitamin $D_{3}$, vitamin $K_{4}$, magnesium and other vitamins and minerals (Table 6.2), in healthy postmenopausal women 50-70 years of age (Table 6.1) during one year. Untreated postmenopausal women (group $C, n=27$ ) served as controls. The major finding at the study end was an increased BMD of the femoral neck in group $A$ compared with group $C$. Compared with baseline, group $A$ exhibited an increase of BMD in the Ward's triangle and femoral neck (Table 6.3). Changes in $B M D$ were not different between groups $A$ and $B$. Both groups

Table 6.4: Biochemicall parameters at baseline and percent changes from baseline after 12 months of intervention.

\begin{tabular}{|c|c|c|c|c|c|c|}
\hline Parameter & & A. & $B$ & $\mathrm{C}$ & $\begin{array}{l}\text { p-value } \\
\text { A vs. } \mathrm{C}\end{array}$ & $\begin{array}{l}\text { p-value } \\
\text { Bus. C }\end{array}$ \\
\hline \multirow[t]{2}{*}{ b-ALP (U/L) } & baseline & $16.2 \pm 4.5$ & $17.4 \pm 6.4-$ & $14.8 \pm 3.8^{3}$ & & \\
\hline & change $(\%)$ & $2.2 \pm 12.5$ & $2.8 \pm 21.6$ & $9.9 \pm 13.31$ & 0.015 & 0.012 \\
\hline \multirow[t]{2}{*}{ PYNP ( $\mu g / L)$} & baseline & $45.9 \pm 14.3$ & $47.2 \pm 20.5$ & $37.0 \pm 13.3$ & & \\
\hline & change $(\%)$ & $-17.6 \pm 23.2^{2}$ & $-18.2 \pm 19.5^{3}$ & $-7.0 \pm 21.03$ & 0.029 & 0.015 \\
\hline \multirow[t]{2}{*}{ Calcitonin (ng/L) } & baselline & $8.1 \pm 3.5$ & $8.0 \pm 2.6$ & $6.4 \pm 2.5$ & & \\
\hline & change $(\%)$ & $8.7 \pm 37.4$ & $-4.0 \pm 17.7$ & $8.4 \pm 25.5$ & & \\
\hline \multirow[t]{2}{*}{ intact-PTH (pmol/L) } & baseline & $5.5 \pm 1.3$ & $5.8 \pm 1.9$ & $5.4 \pm 1.7$ & & \\
\hline & change (\%) & $-15.4 \pm 26.6^{1}$ & $-19.5 \pm 42.6$ & $6.5 \pm 35.3$ & 0.019 & 0.010 \\
\hline \multirow[t]{2}{*}{$25(\mathrm{OH}) \mathrm{D}(\mathrm{nmol} / \mathrm{L})$} & baselline & $97.1 \pm 24.1$ & $83.1 \pm 22.4$ & $91.0 \pm 36.5$ & & \\
\hline & change $(\%)$ & $25.1 \pm 29.8^{3}$ & $43.8 \pm 27.3^{3}$ & $11.1 \pm 22.7^{1}$ & & $\leq 0.001$ \\
\hline \multirow[t]{2}{*}{ D-Pyr ( $\mu \mathrm{mol} / \mathrm{mol} \mathrm{Cr})$} & baseline & $15.0 \pm 4.3$ & $126 \pm 3.2$ & $12.2 \pm 3.8$ & 0.023 & \\
\hline & change $(\%)$ & $-14.9 \pm 25.1^{2}$ & $-2.4 \pm 26.9$ & $\$ .6 \pm 23.6$ & 0.041 & \\
\hline \multirow[t]{2}{*}{$\%$ carboc $(\%)$} & baseline & $67.3 \pm 9.0$ & $67.1 \pm 7.4$ & $66.4 \pm 10.2$ & & \\
\hline & change $(\%)$ & $5.0 \pm 1.3$ & $6.9 \pm 14.3 !$ & $-1.8 \pm 15.8$ & & 0.014 \\
\hline \multirow[t]{2}{*}{ OCtot $(\mu g, \mathrm{~L})$} & baseline & $13.9 \pm 5.2$ & $13.9 \pm 4.1$ & $12.4 \pm 4.47$ & & \\
\hline & chainge $(\%)$ & $-1.7 \pm 26.7$ & $-2.4 \pm 24.8$ & $0.4 \pm 17$ & & \\
\hline \multirow[t]{2}{*}{$\mathrm{u}-\mathrm{Ca} / \mathrm{Cr}(\mathrm{mol} / \mathrm{mol})$} & baselline & $0.44 \pm 0.31$ & $0.42 \pm 0.18$ & $0.37 \pm 0.237$ & & \\
\hline & change (\%) & $10.9 \pm 70.9$ & $23.4 \pm 74.5$ & $-0.2 \pm 56$ & & \\
\hline
\end{tabular}


exhibited changes in serum markers of bone resorption (D-Pyr), bone formation (P1NP) and the 25(OH)D-PTH axis (Table 4), all together suggesting a reduction of bone turnover. Since both an increase of $B M D$ and a reduction of bone turnover (Lauritzen 1996; Kanis 1999) are considered to increase bone strength and reduce fracture risk (Dawson-Hughes 1998; Compston 1995), we conclude that the supplements used in groups $A$ and $B$ are likely to be effective. It must be pointed out that BMD changes did not reach significance in group $B$, which might be due to somewhat smaller subject numbers. Negative correlations between baseline BMDs of the hip and changes after 12 months indicate a higher responsiveness of women with low baseline BMDs to additional minerals and vitamins.

Biochemical parameters of bone turnover also showed such negative correlations between baseline and changes after 12 months (Figure 6.1). These associations suggest that especially women with high bone turnover and/or lower baseline BMDs of the hip benefited from the supplementation. The encountered positive correlation between baseline BMD of the lumbar spine and change after 12 months can possibly be explained by a higher transient remodelling effect (Heaney 1996b). It is possible that a higher BMD accounts for a larger surface area of trabecular bone and consequently more resorption cavities to fill.

Although increases in BMD of the femoral neck and Ward's triangle in group $A$ suggest an increased femoral strength we did not observe effects on BMD of the trochanter. This might be of importance, since the strength of the femoral neck seems rather predicted by an increase in BMD of the trochanter than by that of the femoral neck itself (Cheng 1997). Our results are in line with those of Reid (1995), who also found no changes in trochanter $\mathrm{BMD}$, during one year supplementation of women 10 years past menopause with $1,000 \mathrm{mg}$ of calcium dally. A slight increase from baseline was however noticed after 4 years of supplementation. It is therefore possible that prolonged use of the present supplements may also have favorable effects on trochanter BMD.

Both the Ward's triangle and lumbar spine are mostly composed of trabecular bone, whereas the femoral neck contains more cortical bone (Wood and Fleet 1998).

Trabecular bone often responds better to calcium supplementation than cortical bone (Kanis 1999), and it is therefore not clear why we merely observed increases in $\mathrm{BMD}$ of the Wards triangle and femoral neck and not of the lumbar spine. The relatively low postmenopausal age of the present study population might be a factor in this respect. It is known that oestrogen deficiency during the first 5-10 years past menopause results primarily in a loss of trabecular bone and this loss is poorly responsive to nutritional intervention (Compston 1995; Ohta 1996). Studies (Dawson-Hughes 1990; Nelson 1991) with 3-13 years postmenopausal women support this statement but also show that the effect of oestrogen deficiency on trabecular bone might even persist longer than 10 years past menopause. Fifty-eight percent of group $A$ and $45 \%$ of group $B$ had postmenopausal ages below 10 years. This interpretation does not, however, provide us with an explanation for the observed increase of Ward's triangle BMD. It is also possible that the increase of femoral neck BMD, but not the lumbar spine, is caused by an increased intake of magnesium and/or a decreased serum level of PTH. Magnesium supplementation of postmenopausal women with $500 \mathrm{mg}$ magnesium daily for 2 years gave rise to an increase of especially the BMD of the femoral neck (Rude and Olerich 1996). A high PTH level in postmenopausal women is caused by oestrogen deficiency, low 
vitamin D status andor low calcium intake and is regarded to decrease especially BMD of cortical bone (McKenna and Freaney 1998; Compston 1995). In this respect it is important to note that serum $25(\mathrm{OH}) \mathrm{D}$ levels in the supplemented groups reached values above $100 \mathrm{mmol} /$, which are regarded to cause the lowest achievable PTH levels at a given calcium intake (McKenna and Freaney 1998).

Furthermore, the decrease of PTH may partially be due to the increased calcium intake (up to $2,300 \mathrm{mg}$ per day), since a daily intake of over $2,000 \mathrm{mg}$ of calcium by elderly women was found to reduce PTH to premenopausal values (McKane 1996).

Directly past menopause, bone turnover increases with an excess of bone resorption (Allolio 1999) reflected in a higher urinary D-Pyr excretion. The older women in the placebo group therefore probably lost less bone than to be expected in the younger women in group $B$ and group $A$ in particularly. In agreement with their lower postmenopausal age, higher D-Fyr levels in growp A at baseline. compared with group $\mathrm{C}$ (Table 6.4 ), llkaly indicate a ligher bone turnover. At the same time, the lower levels of biochemical markers in group $\mathrm{C}$ may be explained by a gradual decrease of oestrogen deliciency. related bone turnover with advancing postmenopausal age (Ohta 1996). The urinary D-Pyr excretion in group $\mathrm{A}$ decreased within 6 months to levels as found in groups $\mathrm{B}$ and $\mathrm{C}$, which were close to premenopausal reference value as used by the University Hospital of Groningen. Both groups $A$ and $B$ showed a decrease of P1NP levels, which is a marker of bone formation and therefore of bone turnover. Taken together these data suggest that the supplements taken by groups A and B, reduce bone turnover. Recently it has been reported that short-term changes in biochemical markers can predict long-term changes in BMD (Ravn 1999). The supplements are therefore likely to change the balance of bone resorption and bone formation towards the latter especially.

Figure 6.1: Correlations between levels at baseline of D-Pyr, P1NP and PTH and their percent changes after 12 months of intervention.

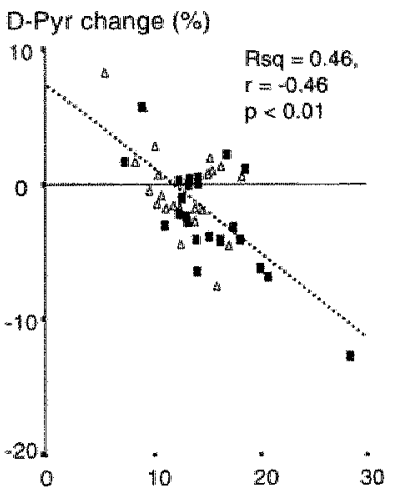

D-Pyr (nmold) at bassaline
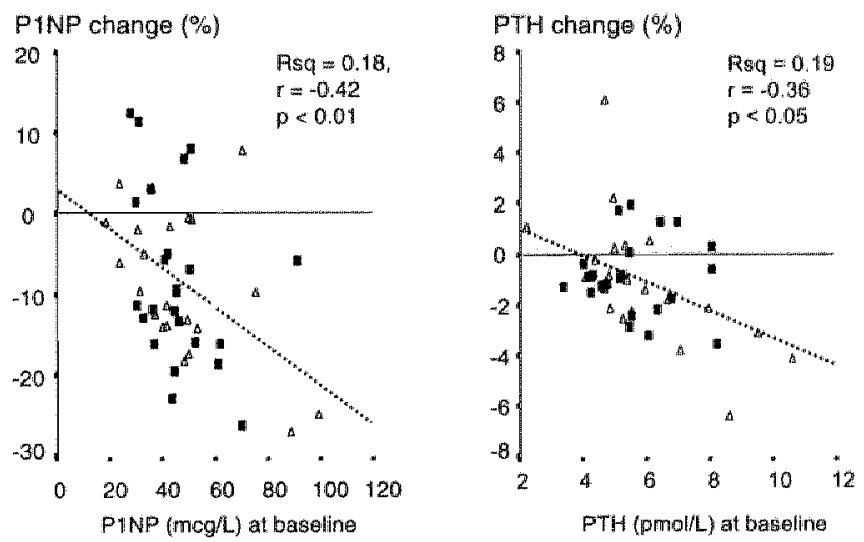

Supplements $\triangle B \quad \mathbf{D A}_{\mathrm{A}}$

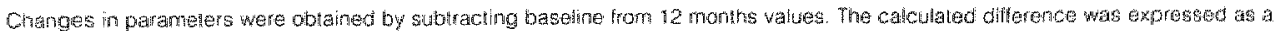

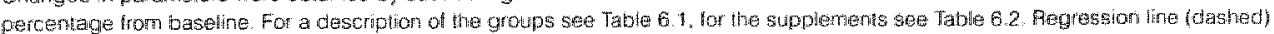

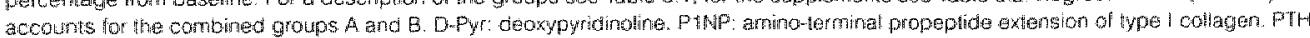
parathyrad houmone. 
when baseline turnover is high. This is shown particularly in group $\mathrm{A}$ with increases in BMD at certain sites. We conclude that in healthy women, close to 10 years past menopause, supplementation with minerals and vitamins increases BMD of the femoral neck and Wards triangle. In theory the effects may at least be attributed to calcium, magnesium, vitamin D or any combination. Favorable effects on BMD are supported by decreases in parameters of bone tumover. This study also suggests, based on changes from baseline and compared with placebo, that eggshell powder may be preferred over purified calcium carbonate as a source of calcium. This, however, warrants further research with higher statistical power.

\section{Acknowledgments}

We would like to thank all the women who participated in this study and Alice Rodenburg for her outstanding technical and organising assistance. Furthermore, we appreciated the co-operation of the general practitioners A.G. Swart, S. Wiarda and P. Sikkens. The latter we also like to thank for placing his practice at our disposal during sampling. We are grateful to D.A. Piers, M.D., Ph.D.n. J.J. Pratt, Ph.D., and their co-workers for the measurements of BMD and several biochemical parameters. Finally, we would like to thank J. Burema, Ph.D. (Wageningen University) for his statistical advice, and W.H.M. Saris, M.D., Ph.D. (University Maastricht) and P.J.F. de Vries, Ph.D. (Friesland Coberco Dairy Foods) for their critical comments on the manuscript. 


\section{Effects of an eggshell powder enriched dairy-based supplement on bone mineral density of postmenopausal women with low bone mass}

A. Schaafsma", I. Pakan², I. Riedstra ${ }^{3}$, H. Storm ${ }^{3}$, G.J.H. Hofstede ${ }^{4}$, F.A.J. Muskiet ${ }^{4}$, E. van der Veer.

Department of Research \& Development Leeuwarden, Friesland Coberco Dairy Foods, Leeuwarden, The Netherlands

2. Medical Centre Leeuwarden, Leeuwarden, The Netherlands

* Foundation Clinical Chemical Laboratory, Leeuwarden, The Netherlands

"Pathollogy and Laboratory Medicine, University Hospital, Groningen "The Netherlands

\section{Submitted}

\section{Abstract}

In an open, controlled, randomized trial the effects are studied of a chicken eggshell powder enriched dairy-based supplement, also containing other minerals and vitamins, on bone mineral density (BMD) of the lumbar spine and hip in postmenopausal women with low bone mass. Apparently healthy Caucasian women, at least five years postmenopausal and with a T-score $\leq-1 \mathrm{SD}$ of the lumbar spine in anteroposterior position, were recruited by general practitioners and clinicians. The women were randomly allocated to the eggshell powder enriched supplement that also contained $350 \mathrm{IU}$ vitamin $\mathrm{D}_{3}$ and $80 \mathrm{\mu g}$ vitamin $\mathrm{K}_{1}$ (group $E S ; n=22$ ) or a combination of $1,000 \mathrm{mg}$ calcium and $400 \mathrm{IU}$ vitamin $\mathrm{D}_{3}$ (group $\mathrm{Ca}$ / $D ; n=23)$. Their estimated mean daily calcium intake at baseline was $1,180 \mathrm{mg}(95 \% \mathrm{Cl}$ : $1,061-1,299)$. BMD, bone-specific alkaline phosphatase, amino-terminal propeptide extension of type I collagen (P1NP), carboxylated osteocalcin (\%carboc),

deoxypyridinoline (D-Pyr), intact-parathyroid hormone, calcidiol and urinary catcium were measured after 0,6 and 12 months. Women who received $E S$ exhibited after 12 months increases in $\mathrm{BMD}$ of the trochanter (mean: $1.58 \% ; 95 \% \mathrm{Cl}: 0.46-2.70$ ) and Ward's triangle $(3.73 \% ; 1.68-5.78)$. No significant changes in BMD were found at the other measured sites, not in the $\mathrm{Ca} / \mathrm{D}$ group. Decreases were found for the bone resorption marker $\mathrm{D} \cdot \mathrm{Pyr}$ after 6 ( $E S$ and $\mathrm{Ca} / \mathrm{D}$ ) and 12 months (Ca/D), and for the bone formation marker $P 1 \mathrm{NP}$ after 6 and 12 months ( $E S$ and $C a / D$ ). Serum \%carbOC increased in both groups, suggesting not only an effect of vitamin $K_{1}$ but also of calcium and vitamin $D_{3}$. The daily intake of $400 \mathrm{lU}$ of vitamin $\mathrm{D}_{\mathrm{s}}$ improved calcidiol status but could not prevent a dip during wintermonths. Both interventions showed to be beneficial for postmenopausal women within 12 months. Most encouraging are the increases in BMD in the women with the eggshell powder enriched dairy based supplement.

Keywords: bone markers, bone mineral density, eggshell powder, osteopenia, osteoporosis, postmenopausal women. 


\section{Introduction}

Osteoporosis is characterized by low bone mass, loss ofl bone architecture and increased susceptibility to fracture.

Antiresorptive therapies with oestrogens or bisphosphonates are effective, but usually reserved for patients or high-risk populations. Nutritional intervention by supplementation might be an effective strategy to prevent loss of bone architecture and to preserve bone strength in the general population.

Several nutrients may be important in osteoporosis prevention. Additional calcium and/or vitamin $D$ have shown to reduce the loss of bone mineral density (BMD) of the lumbar spine and hip, an effect associated with a decreased fracture risk (DawsonHughes 1998). The optimal daily dosages of calcium and vitamin $\mathrm{D}$ are debated and range from 1,200 to over $2,000 \mathrm{mg}$ for calcium and from 400 to over $800 \mathrm{lU}$ for vitamin D (Vieth 1999; Chapuy 1992; Dawson-Hughes 1998). Both calcium and vitamin $D$ reduce serum parathyroid hormone (PTH) levels. This is important as age-related hyperparathyroidism increases bone turnover and as a result bone loss (Chapuy 1992). An adequate magnesium status is necessary for the conversion of calcidiol $[25(\mathrm{OH}) \mathrm{D}]$ into the most active vitamin D metabolite calcitriol $\left[1,25(\mathrm{OH})_{2} \mathrm{D}\right]$. Magnesium may also prevent calcium leakage from bone by its regulating effect on extracellular fluid pH (Driessens and Verbeeck 1988). Vitamin $K$ is an essential co-factor in post-translational carboxylation of osteocalcin. The carboxylated osteocalcin might be important for a proper mineralization of new bone (Vermeer 1996) and may decrease bone loss during oestrogen deficiency as shown in an osteocalcin-free mutant mouse model (Wolf 1996). The micronutrient strontium is of interest as it may have an anabolic effect on bone (Reginster 1999). Strontium is one of several elements found in chicken eggshell powder (on average $380 \mu \mathrm{g} / \mathrm{g}$ ).
The major element in chicken eggshell powder is a highly bioavailable (Schaafsma and Beelen 1999) form of calcium (39\% of weight). Positive effects of eggshell powder on BMD of the lumbar spine and hip have been reported in postmenopausal women with osteoporosis (Makail and Chudacek 1991; Schaatsma and Pakan 1999).

Fracture prevention is the ultimate hard clinical end point of intervention studies but its usage requires both large study populations and long observation periods. More easily studied surrogate endpoints for fracture risk prediction are (Lindsay 1999; Vermeer 1996; Kanis 1999) BMD for bone strength, deoxypyridinoline (D-Pyr) for bone resorption, and bone specific alkaline phosphatase (b-ALP) and the aminoterminal propeptide extension of type I collagen (P1NP) for bone formation. Carboxylated osteocalcin (\%carbOC), expressed as a percentage of total osteocalcin (OCtot), is a marker of bone mineralization and vitamin K status. Serum $\mathrm{PTH}$ is a regulator of bone remodeling and serum $25(\mathrm{OH})$ D reflects vitamin D-status. We studied in apparently healthy postmenopausal women the effects of a dairy-based supplement on BMD of the lumbar spine and hip and on biochemical markers of bone turnover. The women had low bone mass and the study period was one year. The supplement contained chicken eggshell powder and a stuandard mixture of vitamins and minerals, including vitamin $\mathrm{D}_{3}$, vitamin $\mathrm{K}_{1}$ and magnesium (ES group). The control group took calcium and vitamin $\mathrm{D}_{3}$ tablets (Ca/D-group). Effects within and between groups were monitored.

\section{Subjects, materials and methods Subjects}

Apparently healthy Caucasian women $(n=53)$ were recruited in co-operation with three general practitioners in the village of Oenkerk in the Netherlands and by clinicians in the Medical Centre of 
Table 7.1: Baseline characteristics

\begin{tabular}{|c|c|c|}
\hline Characteristic & $\begin{array}{l}\text { ES group } \\
(n=22)\end{array}$ & $\begin{array}{l}\text { Ca/D group } \\
(n=23)\end{array}$ \\
\hline Age (y) & $63.0 \pm 6.7$ & $61.8 \pm 4.7$ \\
\hline $\begin{array}{l}\text { Postmenopausal } \\
\text { age }(y)\end{array}$ & $13.9 \pm 7.0$ & $12.7 \pm 5.4$ \\
\hline Weight (kg) & $70.9 \pm 7.7$ & $70.9 \pm 13.3$ \\
\hline Helight (cm) & $165.6 \pm 5.2$ & $166.1 \pm 6.3$ \\
\hline BMI $\left(\mathrm{kg} / \mathrm{m}^{2}\right)$ & $25.9 \pm 3.0$ & $25.7 \pm 4.4$ \\
\hline $\begin{array}{l}\text { Dietary calcium } \\
\text { (mg/day) }\end{array}$ & $1,115 \pm 385$ & $1.272 \pm 392$ \\
\hline Osteoporosis $(n=)$ & 10 & 11 \\
\hline Osteopenia $(n=)$ & 10 & 11 \\
\hline Normal $^{3}(n=)$ & 2 & 1 \\
\hline \multicolumn{3}{|l|}{ T-score } \\
\hline lumbar spine (AP) & $-2.14 \pm 0.8$ & $-2.40 \pm 1.05$ \\
\hline fiemoral neck & $-2.36 \pm 0.9$ & $-2.40 \pm 1.05$ \\
\hline total prox femur & $-1.43 \pm 0.89$ & $-1.35 \pm 0.92$ \\
\hline \multicolumn{3}{|l|}{$Z$-score } \\
\hline lumbar spine (AP) & $-2.40 \pm 1.05$ & $-2.40 \pm 1.05$ \\
\hline femoral neck & $-2.40 \pm 1.05$ & $-0.22 \pm 1.07$ \\
\hline total prox femur & $-2.40 \pm 1.05$ & $-0.15 \pm 0.93$ \\
\hline
\end{tabular}

Data are presented as mean $\$$ SD. ES group: eggshell powden enriched milk based suppiement in combination with minerals and vtemins. Ca/D group: combination of wo tablets containing calciurn carbonale, calcium lacto-gluconale and vitamin $D$ (see Tabie 2).

"T score lumber spine AP $\leq-2.5$. "T-Scare lumbar spine A, so -2.5 and $\leq \sim, 0$, Tascole lumbar spine AF $>-1,0$

Leewwarden. The women were al least 55 years of age and at least 5 years past menopause. Twenty-tour of them had osteopenta (-2.5 < T-Score <- 1 ) and 26 had csieoporosis (T-score $5-25)$ of the lumbar spine in anteroposterior (AP) position as measured by dual energy $X$-ray absorptiometry (DEXA). Three women wh T-score of -0.950 were also included becatse of he smal number of women per group. None of them used medication or wamin andor mineral preparations known lo interere with bone metabolism. They wore askeo lo remain from artificial sum bathing during the study period. Women wh acute and chronic messes or with mallormations and evident arthrosis of the umbar spine and hip las suggested by
DEXA and confirmed by X-ray photography) were excluded. Eight women dropped out during the study, 7 because of medical treatments not related to the intervention and 1 because of poorcompliance (69\% during the last 9 months) with the study protocol. Baseline characteristics of the finally evaluated women $(n=45)$ are given in Table 7.1 . Informed consent was obtained from all the women and the Medical Ethical Committee of the Medical Centre Leeuwarden approved the study protocol.

\section{Supplements and dietary calcium intake}

Women were randomly allocated to an eggshell powder enriched dairy-based supplement (ES group), or a combination of $1,000 \mathrm{mg}$ of calcium (Sandoz fortissimum, Sandoz, Switzerland) and 400 IU of vitamin $D_{s}$ (Devaron, Solvay Pharma B. V., Weesp, The Netherlands) (Ca/D group). For medical ethical reasons, the use of a placebo was not allowed. The participants in the ES group were instructed to take the powdered supplement twice daily, diluted with water, at breakfast and with the evening meal. The vitamin $\mathrm{D}$ tablet of the $\mathrm{Ca} / \mathrm{D}$ group was to bo taken at breakfast and the calcium tablet with the evoning meal. Total dally intakes from these supplements are given in Table 7.2. Complance, expressed as the percentage of sachets or tablets taken, has assessed on the basis of emptied package counts and whiten checkists. A minimum compliance of $75 \%$ was necessary to take part in the whal evaluation. The dietary intake of calcium was ostimated at three occasions during Whe sudy period by means of a $100 d$ mequency questionnaire.

\section{Material and Methods}

Body weight and height were measured at baseline and after 6 and 12 months by standardized methods. Body mass index 
Table 7.2: Daly supply by the ES-supplement and CalD-tablets

\begin{tabular}{|c|c|c|c|c|}
\hline Wutrent & Unit & $E S$ & Calo & US FDAIROI \\
\hline Energy & k theall & $942(224)$ & nithis & $7,980(1,900)$ \\
\hline Mik proten & 9 & 7.2 & & 50 \\
\hline 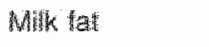 & 9 & 6.6 & & $73^{4}$ \\
\hline Carbohydrates & 9 & 34 & & $238^{5}$ \\
\hline Calcum & $m g$ & $1,310^{\mathrm{s}}$ & $1,000^{2}$ & 1,200 \\
\hline Phosphoris & mg & 161 & & 700 \\
\hline Magnesium & $\mathrm{mg}$ & 355 & & 320 \\
\hline Iron & $m g$ & 5.2 & & 10 \\
\hline Zinc & mo & 5.2 & & 12 \\
\hline Copper & ug & 222 & & $1,500-3,000^{\circ}$ \\
\hline Sodtum & $m g$ & 80 & 400 & $500^{7}$ \\
\hline Potzestum & $m g$ & 276 & & $2,000^{7}$ \\
\hline Chonide & mg & 138 & & $750^{?}$ \\
\hline p-catotene & HgRE & 336 & & see vitamin $A$ \\
\hline Wtamin $A$ & UGRE & 123 & & 800 \\
\hline Vtamin $0_{3}$ & $\lg (0 u)$ & $8.8(352)$ & $10(400)$ & $10(400)$ \\
\hline Vhamin E & $\operatorname{mg} a-1 E$ & 10 & & 8 \\
\hline Vitamin $k$ & LG & 80 & & 65 \\
\hline Vitamin $\mathrm{C}$ & $\mathrm{mg}$ & 61 & & 60 \\
\hline Thiamin & mg & 10 & & 9.0 \\
\hline Aboftavin & $\mathrm{mg}$ & 1.2 & & 1.2 \\
\hline Vitarnin $\mathrm{B}_{6}$ & $\mathrm{mg}$ & 1.6 & & 1.6 \\
\hline Vitemin $\mathrm{B}_{12}$ & 189 & 2.0 & & 2.0 \\
\hline
\end{tabular}

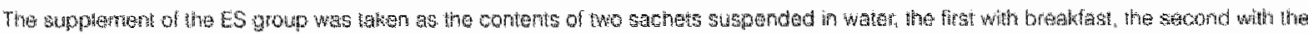

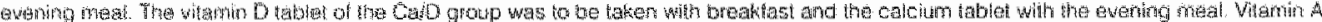

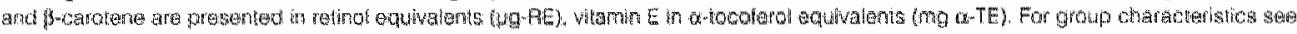
Thible 7

1270 mo dratived lrom aggathat powder.

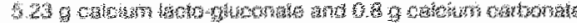

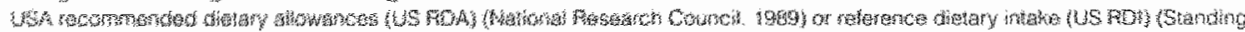
Com

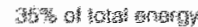

Sols

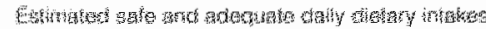

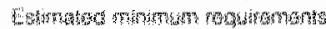

(BN) was chlouled using weight and height $\left(\mathrm{kg} / \mathrm{cm}^{\mathrm{g}}\right)$.

Bone minerat density (BMD) of the umbar spine (L2-L4) in AP position and of the hip (wotal roximal temu, temoral neck, trochanter intertrochanter and Ward's trianghe) was assessed at baseline, after 6 and 12 months by DEXA on a ODP 2000 (Hologic Inc., Watman, MA, USA). The coefficient of variation (CV) was $1 \%$ for the lumbar spine and the hp region. BMD data obtained one year prior to the start of the present sudy, obtained with the same DEXA cquipment, were avalable from 10 women (5 from each group). Non-tasting blood samples were obtained at baseline and after 6 and 12 months. Samples were collected at about the same time during the day to avoid circadian Thythms. Serum was stored at $-20^{\circ} \mathrm{C}$ within one hour. Second moming urine samples were collected prior to food intake and stored at $-20^{\circ} \mathrm{C}$ until analysis. Serum total calcium, phosphate, creatinine, gamma 
glutamyl tranferase ( $\mathrm{GTT}$ ) and serum total protein were measured on a Hitachi 717 Chemistry Analyzer (Roche/Boehringer Mannheim, Germany). Serum thyroid stimulating hormone (TSH) was determined using a microparticle enzyme immunoassay (IMx, Abbott Laboratories, Abbot Park, IL, USA).

Serum amino-terminal propeptide of type-1 procollagen (PINP) was measured with the RIA kit of Orion Diagnostica (Espoo, Finland). Intra- and inter-assay CV were $8.4 \%$ and $9.0 \%$, respectively. Serum bone alkaline phosphatase (b-ALP) was measured with the immuno assay of Metrabiosystems (Mountain View, CA, USA). Intra- and inter-assay CV were $4.9 \%$ and $5.5 \%$, respectively. Serum total osteocalcin (OCtot) and undercarboxylated osteocalcin were measured before and after extraction with hydroxyapatite, respectively, using the IRMA of Medgenix-H-Ost (Fleurus, Belgium). Intra- and inter-assay $\mathrm{CV}$ for OCtot were $3.1 \%$ and $6.4 \%$, respectively, whereas for undercarboxylated osteocalcin both $\mathrm{CV}$ were $8.4 \%$. The percentage carboxylated osteocalcin (\%carbOC) was calculated from the difference of undercarboxylated osteocalcin and OCtot. Serum 25/OH)D was determined with the RlA kit of lncstar (Sorin, Biomedica, Stillwater MN, USA). Intra- and inter-assay CV were $6.0 \%$ and $12-15 \%$, respectively. Because the amount of available serum was limited, intact-PTH was measured in $50 \%$ of the samples by the IRMA of Nichols Institute (San Juan Capistrano, $\mathrm{CA}_{9}$ USA). Intra- and inter-assay CV were less than $4.0 \%$ and $6.0 \%$, respectively. Urine was analyzed for calcium and creatinine with a Hitachi 71 Chemistry Analyzer and for deoxypyridinoline (D-Pyr) by HPLC (Beardsworth 1990)). CV within and between 3 -week runs were 9.4 to $11.6 \%$ and 11.8 to $14.8 \%$, respectively. The urinary excretion of D-Pyr and calcium was corrected for urinary creatinine.

\section{Statistics}

To minimize the between-group differences in T-scores we used a stratified randomization. The participants were assorted according to the baseline Tscores of their lumbar spines in AP position. Their subsequent random allocation to the ES or Ca/D groups took place per subject-couple, starting with the lowest T-score. Data were analyzed using SPSS 7.0 (SPSS Inc., Chicago, USA). Nonparametric two tailed statistical tests were used since at least some of the parameters exhibited nonparametric distributions according to the KolmogorovSmirnov normality test. Between-group differences were studied with the Mann Whitney U-test, and within-group differences were analyzed with the Wilcoxon signed-rank test. Within-group correliations were studied with the Spearman Rank test. They comprised comparisons between baseline values of BMD or clinical chemical parameters and their changes after 12 months. Correlations between baseline values of all participants were also tested with the Spearman Rank test. Differences were considered significant when $p \leq 0.05$.

\section{Results}

Compliance and general parameters Mean compliance with intervention was $96 \%$ (range: $89-100$ ) in the ES group and $98 \%(95-100)$ in the Ca/D group. There were no between-group differences in baseline characteristics as presented in Table 7.1, nor after 12 months (data not shown). Body weight of the ES group was increased $(p=0.001)$ after 12 months with an average of $1.9 \mathrm{~kg}(-3-7)$, corresponding with a BMl increase of $0.69 \mathrm{~kg} / \mathrm{m}^{2}(0.51$ $0.64)$. Standard clinical tests (serum total calcium, phosphate, creatinine, $\gamma \mathrm{GT}$, total protein and TSH) were within the reference ranges for all evalluated participants at baseline and after 12 months (data not shown). These parameters also exhibited 
no between group differences al baseline nor at the study end. Total serum calcium of the ES group increased $(p=0.032)$

during the first 6 months from $2.38 \pm 0.08$ to $2.43 \pm 0.08 \mathrm{mmol} / \mathrm{L}$ and was $2.42 \pm 0.08$ mmol/L after 12 months:

\section{$B M D$, biochemical parameters and} correlations for the ES and $C a / D$ groups

\section{$B M D$}

There were no between-group differences in BMD (in $\mathrm{g} / \mathrm{cm}^{2}$ ) at baseline (Table 7.3) or after 12 months (data not shown). There was also no difference in percent change in BMD after 12 months.

Compared with baseline, the ES group showed increased BMD of the trochanter and Ward's triangle after 12 months (Figure 7.1). For the Ward's triangle it should be noted that results were not necessarily obtained from the same spot since the computer of the DEXA equipment searches for the area with the lowest BMD. Baseline BMD of the Ward's triangle in the $\mathrm{Ca} / \mathrm{D}$ group was correlated $(r=-0.42$, $p<0.05)$ with the BMD change after 12 months. A low baseline BMD resulted in a larger BMD increase $(n=14)$ or a smaller loss $(n=9)$.

\section{Biochemical parameters}

Baseline values of biochemical markers and their percent change after 12 months are reported in Table 7.4. Relevant data after 6 months are reported in the text. At baseline, $23 \%$ of the subjects in the ES group and $26 \%$ in the CarD group had marginal serum $25(\mathrm{OH}) \mathrm{D}$ levels (25-40 $\mathrm{nmol} / \mathrm{L}$ (Vieth 1999)). After 6 months of supplementation, mean \pm SD levels had increased $(p<0.001)$ to $81.5 \pm 25.9$ and $84.4 \pm 32.6 \mathrm{nmol} / \mathrm{L}$ in the ES and $\mathrm{Ca} / \mathrm{D}$ groups, respectively. The lowest level was $43 \mathrm{nmol} / \mathrm{L}$. At the study-end, levels were $53.7 \pm 22.6$ and $64.0 \pm 16.6 \mathrm{nmol} / \mathrm{L}$, respectively, and $23 \%$ of the women in the ES group and $4 \%$ in the $\mathrm{Ca} / \mathrm{D}$ group had marginal $25(\mathrm{OH}) \mathrm{D}$ levels. An influence of season may be expected as samples at 6 months were collected in May and August, whereas those collected at study end were from November and February. PTH was analyzed in $50 \%$ of the samples. The outcome (not shown) indicated a

Table 7.3: Bone mineral densities at baseline and their percent changes after 12 months.

\begin{tabular}{llcc}
\hline BMD & & ES group & CalD group \\
\hline Lumbar spine (AP) & baseline & $0.84 .4 \pm 0.088$ & $0.814 \pm 0.114$ \\
& change $(\%)$ & $1.30 \pm 3.44$ & $1.35 \pm 3.56$ \\
Femoral neck & baseline & $0.659 \pm 0.091$ & $0.695 \pm 0.111$ \\
& change $(\%)$ & $1.37 \pm 3.49$ & $0.00 \pm 3.02$ \\
Total prox fernut & baseline & $0.803 \pm 0.107$ & $0.813 \pm 0.110$ \\
& change (\%) & $1.87 \pm 5.73$ & $0.12 \pm 1.72$ \\
Trochanter & baseline & $0.633 \pm 0.067$ & $0.613 \pm 0.082$ \\
& changie $(\%)$ & $1.58 \pm 2.69$ & $0.00 \pm 3.26$ \\
Intertrochanter & baseline & $0.942 \pm 0.158$ & $0.965 \pm 0.142$ \\
& change $(\%)$ & $1.49 \pm 5.94$ & $-0.10 \pm 2.49$ \\
Ward's triangle & baseline & $0.509 \pm 0.098$ & $0.529 \pm 0.132$ \\
& change $(\%)$ & $3.73^{2} \pm 4.91$ & $2.84 \pm 6.99$ \\
\hline
\end{tabular}

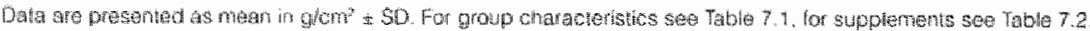


significant decrease $(p=0.002)$ during the first 6 months and a subsequent stabilization till the study end. There were no between-group differences in PTH.

Figure 7.1: Percent changes ( $\pm \mathrm{SD}$ ) in $\mathrm{BMD}$ for women who received the eggshel powder enriched dairy-based supplement

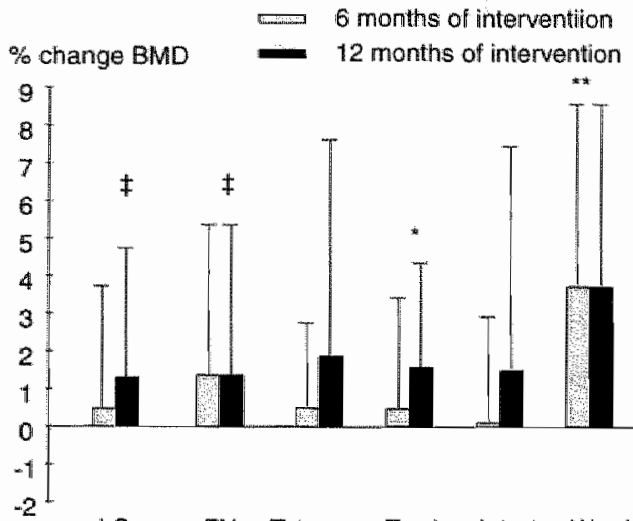

LS

FN Tot prox Troch Intertir Ward

Abbrewalions: LS, lumbar spine in antoposterior position; FM femonal meck Ton prox:, total proxismal temur; Troch, trochanter; interti, intertochanter: Warc. Ward's 1rangle

" $p=0.014$ and " $p=0.003$ boln compared whth baselime \& $p$ a 085 compared with beselinie

A significant $(p<0.001)$ decrease in D-Pyr excretion was found in the ES group $(-20.7$ $\pm 21.2 \%)$ and $\mathrm{Ca} / \mathrm{D}$ group $(-26.0 \pm 29.8 \%)$ after 6 months. After 12 months the decrease was only significant in group $\mathrm{Ca} / \mathrm{D}$. Study end D-Pyr levels were $12.5 \pm 3.6$ and $11.5 \pm 3.0 \mu \mathrm{mol} / \mathrm{mol}$ creatinine for the ES and Ca/D groups, respectively. These levels are close to the premenopausal DPyr reference value of $11.7 \mu \mathrm{mol} / \mathrm{mol}(95 \%$ Cl: 6.8-23.1) as used by the University Hospital of Groningen. The more reduced bone resorption in the $\mathrm{Ca} / \mathrm{D}$ group contrasts with the increased urinary calcium excretion after $6(p=0.002)$ and 12 months.

Serum P1NP levels after 6 and 12 months were decreased in the ES and $\mathrm{Ca} D$ groups, whereas the \%carboc level had increased after $6(p \leq 0.001)$ and 12 months in the ES group, and after 12 months in the Ca/D group.

Baseline values of D-Pyr, PINP and $\%$ carbOC were correlated with their changes after 6 and 12 months $(r>-0.45$, $p<0.05$ ) (Table 7.5). This implies that high baseline values of D-Pyr and P1NP are associated with stronger reductions, and that low baseline values of $\%$ carbOC are associated with stronger increases after 12 months.

A number of correlations were found between biochemical parameters. D-Pyr and P1NP $(r>0.40, p<0.05)$ were correlated at baseline and after 6 months in the ES and Ca/D groups, and also in the $C a / D$ group $(r=0.63, p<0.005)$ after 12 months. P1NP and b-ALP were correlated $(r>0.44, p<0.05)$ at baseline and after 6 months in the $E S$ and $\mathrm{Ca} / \mathrm{D}$ groups, and in the ES group ( $r=0.58$, $p=0.005$ ) also after 12 months. D-Pyr was correlated with b-ALP at baseline $(r>0.56$, $p<0.01)$. This means that higher levels of D-Pyr (bone resorption) were associated with higher levels of P1NP and b-ALP (both bone formation markers) at baseline (elevated bone turnover). Decreased levels of D-Pyr, after intervention, were associated with decreased levels of P1NP atter 6 ( $E S$ and $\mathrm{Ca} / \mathrm{D}$ ) and 12 months (Ca/D) suggesting a reduced bone turnover.

Correlations between changes in BMD and biochemical parameters

BMD increase of the trochanter in the ES group was correlated $(r>0.44, p<0.05)$ with b-ALP, D-Pyr and PINP at baseline. and with OCtot after 12 months.

In the $\mathrm{Ca} / \mathrm{D}$ group, small increases or decreases in BMD of the femoral neck were correlated $(r>-0.44, p<0.05)$ with baseline P1NP, and with changes in serum $25(\mathrm{OH}) \mathrm{D}$ and urinary calcium after 6 months. For the trochanter this implies that higher levels of markers of bone turnover at baseline are associated with a large 
Table 7.4: Blochemical parameters at baseline and their percent changes after 12 months

\begin{tabular}{|c|c|c|c|c|}
\hline Pairameter & & ES group & $\mathrm{Ca} / \mathrm{D}$ group & puvalueES vs. Ca/D \\
\hline \multirow[t]{2}{*}{ D.ALP (UNL) } & baseline & $14.2 \pm 4.6$ & $17.0 \pm 5.6$ & \\
\hline & change $(\%)$ & $-5.6 \pm 24.3$ & $-11.1 \pm 19.5$ & \\
\hline \multirow[t]{2}{*}{ PINP (HgL) } & baseline & $40.8 \pm 126$ & $47.6 \pm 19.6$ & \\
\hline & change $(\%)$ & $-30.7^{2} \pm 25.2$ & $-34 \cdot t^{2} \pm 21.1$ & \\
\hline \multirow[t]{2}{*}{$25(0 \mathrm{HDD}$ (nmol/L) } & baseline & $49.0 \pm 14.2$ & $50.0 \pm 15.9$ & \\
\hline & change $(\%)$ & $9.7 \pm 38.7$ & $28.1^{2} \pm 40.4$ & $p=0.008$ \\
\hline \multirow[t]{2}{*}{ D-Pyr (umol/mol $\mathrm{Cr}$ ) } & baseline & $13.9 \pm 3.8$ & $14.6 \pm 4.6$ & \\
\hline & change $(\%)$ & $-10.3 \pm 24.7$ & $-21.6^{4} \pm 33.6$ & \\
\hline \multirow[t]{2}{*}{$\%$ carboc $(\%)$} & baseline & $55.3 \pm 10.6$ & $56.1 \pm 8.2$ & \\
\hline & change $(\%)$ & $24.8^{2} \pm 20.6$ & $18.9^{2}=16.1$ & \\
\hline \multirow[t]{2}{*}{ OCtot $\left(\mu \mathrm{g} / \mathrm{L}_{-}\right)$} & baseline & $12.8 \pm 4.0$ & $11.9 \pm 4.1$ & \\
\hline & change (\%) & $-8.5 \pm 24.7$ & $-4.1 \pm 336$ & \\
\hline \multirow[t]{2}{*}{ una/Cr (mol/mol) } & baseline & $0.41 \pm 0.25$ & $0.51 \pm 0.36$ & \\
\hline & change (\%) & $14.6 \pm 60.7$ & $37.3^{4} \pm 66.7$ & $p=0,012$ \\
\hline
\end{tabular}

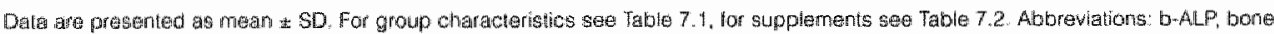

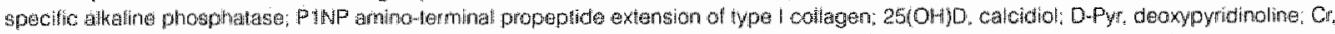

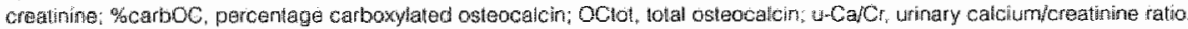

'p e 0.05 compared with baseline.

${ }^{2} \mathrm{p}<0.001$ compered with baseline

increase in BMD. Furthermore, larger increases in BMD of the trochanter were associated with higher levels of osteocalcin after 12 months. With regard to BMD of the femoral neck in the $\mathrm{Ca} / \mathrm{D}$ group, changes in BMD were less when baseline P1NP was higher (this in contrast with the ES group), or when increases in serum 25(OH)D or urinary calcium were larger after 6 months of supplementation.
$B M D$, biochemical parameters and correlations for the combined ES and $C a / D$ groups

Both supplements increased the intake of calcium and vitamin $D$ and showed similar but not significant increases in BMD of the lumbar spine. Therefore we were curious about the effects when data of the ES and $\mathrm{Ca} / \mathrm{D}$ groups were combined (data not shown). When combined, BMD of the

Table 7.5: Correlations between biochemical parameters at baseline and their absolute changes atter 6 and 12 months

\begin{tabular}{llllllll}
\hline Baseline & D-Pyr & U-Ca/Cr & PINP & b-ALP & OClot & \%carbOC & $25(\mathrm{OH}) \mathrm{D}$ \\
\hline Group ES & & & & & & & \\
6 mo & $-0.62^{* *}$ & -0.17 & $-0.52^{*}$ & $-0.48^{*}$ & $-0.75^{* *}$ & $-0.65^{* *}$ & -0.10 \\
$12 \mathrm{mo}$ & $-0.57^{* * *}$ & $-0.44^{*}$ & $-0.52^{*}$ & -0.19 & $-0.78^{* *}$ & $-0.46^{*}$ & -0.42 \\
Group Ca/D & & & & & & & \\
6 mo & $-0.70^{* *}$ & -0.20 & -0.36 & $-0.48^{*}$ & -0.33 & $-0.55^{*}$ & $-0.48^{*}$ \\
$12 \mathrm{mo}$ & $-0.80^{\text {** }}$ & -0.38 & $-0.64^{* *}$ & $-0.67^{* *}$ & -0.26 & -0.11 & $-0.64^{* *}$ \\
\hline
\end{tabular}


lumbar spine increased significantly (1.4\% $\pm 3.5 \%, p=0.023$ ). This is an important improvement because from 10 women it was known that BMD of the lumbar spine in the preceding year decreased with $-1.5 \pm$ $1.7 \%(p<0.05)$. The combined ES and $\mathrm{Ca} / \mathrm{D}$ groups also increased BMD of trochanter and Ward's triangle with $0.8 \pm 3.1 \%(p=0.039)$ and $3.4 \pm 6.1 \%$ $(p=0.001)$, respectively.

Of the biochemical parameters, increases were found for $25(\mathrm{OH}) \mathrm{D}(19.2 \%, \mathrm{p}=$ $0.009)$, \%carboc $(20.4 \%, p<0.001)$ and $u-\mathrm{Ca} / \mathrm{Cr}(26.9 \%, \mathrm{p}=0.010)$, and decreases were found for D-Pyr $(-15.8 \%, p=0.002)$, b-ALP $(-8.6 \%, p=0.029)$ and PINP $(-2.6 \%, p<0.001)$.

Only the change in BMD of the femoral neck after 12 months was correlated with the level of $25(\mathrm{OH}) \mathrm{D}$ at the start $(r=0.30$, $p=0.047$ ).

\section{Discussion}

A one year supplementation with an eggshell powder enriched dairy-based supplement ( $E S$ group, $n=22$ ) resulted in significant BMD increases of the trochanter and Ward's triangle in postmenopausal women with low bone mass (Table 7.3). BMD at the other measured sites was preserved. A reference group $(\mathrm{Ca} / \mathrm{D}, \mathrm{n}=$ 23). who received a combination of calcium and vitamin $D_{3}$, did not exhibit significant BMD changes. No significant differences were found in BMD between the two groups at the study end. Since in both groups levels of biochemical markers (Table 4) of bone resorption (D-Pyr) and bone formation (P1NP) decreased, a reduced bone turnover can be suggested to be the underlying mechanism of action. A concomitant decrease of serum PTH level, as established for subset of samples, supports this thought. The combined ES and $\mathrm{Ca} / \mathrm{D}$ groups showed increases in BMD of the lumbar spine, trochanter and Ward's triangle, decreases of markers of bone turnover, and increases of the
$\%$ carboc and 25(OH)D. Both an increase in BMD and a reduction in bone unover are considered to mcrease bone strength and to reduce fracture risk (DawsonHughes 1998). Therefore, both interventions proved beneficial whth a slight preference for the eggshell powder enriched dairy based supplement because of significant increases in BMD. A less favorable effect might be the encountered increase of body weight in this group. Reduction of the energy content of the tested supplement from slightly lower than that of full cream milk to that of a lowenergy product seems indicated for the studied population.

The increase in trochanter BMD in the ES group seems to indicate an increased femoral neck strength (Cheng 1997). The increase in BMD of the temoral neck itself $(1.4 \%, p=0.07)$ just falled to reach significance. It has been reported (Cummings 1993) that an increase in BMD of approximately $1 \%$ reduces fracture risk with $6-8 \%$ at the particular skeletal site. Supplementation with calcium (800-1,000 mg/day) has shown to be beneficial for BMD of the hip during study periods of 18 to 48 months. These studies also showed that effects during the first year were indicative for the final results (DawsonHughes 1998; Kanis 1999; Devine 1997). The data of our one-year study therefore seem to predict a reduction of fracture rate when consumption of the supplement is continued.

Recently it has been reported (Lindsay 1999; Ravn 1999) that changes in biochemical markers of bone turnover during the first 6 months can be used 10 predict long-term effects on bone mass. The magnifude of change depends on the baseline values of the parameters. The correlation coefficients in Table 7.5 indicate that high baseline levels of D-Pyr and P1NP are associated with larger decreases after 6 and 12 months. These associations suggest that especially women with an 
elevated bone turnover at baseline benefit from supplementation. Both the ES and Ca/D groups showed decreases in D-Pyr excretion and serum P INP within 6 months. In the combination of $E S$ and $\mathrm{Ca} / \mathrm{D}$ groups also b-ALP decreased significantly during the first 6 months. These effects not only support the change in BMD but also predict long-term positive effects on bone. A higher urinary calcium excretion after an overnight fast is assumed to reflect a higher bone resorption (Peacock 1988).

The decreased urinary excretion of D-Pyr in the $\mathrm{Ca} / \mathrm{D}$-group is therefore not in harmony with the increased urinary calcium excretion. The calcium excretion is also significantly higher compared with the ES-group. Although a role of \%carbOC in reducing calcium excretion has been suggested (Weber 1997) we did not find a significant association.

The additional intake of 350 IU (ES group) and $400 \| \mathrm{U}\left(\mathrm{Ca} / \mathrm{D}\right.$ group) of vitamin $\mathrm{D}_{3}$ per day considerably increased serum 25(OH)D levels in both groups during the first 6 months ("summer' period). However, a decline during the "winter' months, at the study end, was not prevented. It was remarkable that at the study end the mean serum level in the $\mathrm{Ca} / \mathrm{D}$ group was significantly higher than in the ES-group since the difference in daily supplemented vitamin $\mathrm{D}_{3}$ was only $50 \mathrm{IU}$. The winter-dip in serum $25(\mathrm{OH}) \mathrm{D}$ is known to be associated with increased bone loss (Storm 1998).

Our study supports the review of Vieth (1999) who reports that a daily vitamin D intake of $400 \mathrm{IU}$ may not be sufficient for women with limited sun exposure and that more than 800 IU per day may be necessary to reach adequate serum $25(\mathrm{OH}) \mathrm{D}$ levels ( $100 \mathrm{nmol} / \mathrm{L}$ ). In a study with elderly, an intake of 800 IU of vitamin $D$ per day was associated with a decreased number of fractures (Chapuy 1992).

Carboxylated osteocalcin is necessary for proper mineralization of new bone.
The carboxylation of osteocalcin is vitamin $K$ dependent (Vermeer 1996).

A population-based study showed that less than $60 \%$ of total osteocalcin is carboxylated in postmenopausal women, whereas this is $70-80 \%$ in young healthy adults (Jie 1996). The mean baseline $\%$ carbOC in our study was about $56 \%$. During the first 6 months of the study, the increase in \%carbOC in the ES group $(15.8 \%)$ was higher than in the $\mathrm{Ca} / \mathrm{D}$ group $(8.3 \%)$. This is probably an effect of vitamin $K$ in the ES supplement. The betweengroup difference, however, was reduced to $5.9 \%$ at the study end. It suggests that the supplemental calcium and vitamin $D$ in the $\mathrm{Ca} / \mathrm{D}$ group has stimulated osteocalcin carboxylation.

We conclude that both interventions are likely to be beneficial for postmenopausal women. Most encouraging are the effects on BMD in the ES group, since these women significantly increased BMD of their trochanter and Ward's triangle. Increases in BMD of the lumbar spine and femoral neck may take place but did not reach significance. Decreased parameters of bone turnover support the increases in BMD and predict long-term effects. This study also suggests that $400 \mathrm{IU}$ of vitamin D per day may not be sufficient for those women to prevent seasonal fluctuation in serum $25(\mathrm{OH}) \mathrm{D}$ levels and to reach the lowest achievable serum PTH levels. The eggshell powder, but also the added magnesium, vitamin $D_{3}$ and vitamin $K_{3}$, may have contributed to the favorable effects of the ES supplement. Eggshell powder not only supplies highly absorbable callcium but also the microelement strontium, which is thought to stimulate bone formation. Eggshell powder enriched dairy-based products are easily introduced in the diet and therefore may be used on a large scale to prevent or reduce age-related bone loss. 


\section{Acknowledgments}

We would like to thank all the women who participated in this study and Haydée

Schaafsma for her enthusiastic organizing assistance. Furthermore we appreciated the co-operation of the general practitioners E.P.P. Wijthoff, P.B. de Boer and M.S. Reitsma. We are very grateful to the co-workers of the clinical laboratory and the department of bone densitometry for the measurements of biochemical parameters and BMD. Finally, we would like to thank J. Burrema, Ph.D. (Wageningen University) for his statistical advice, and W.H.M. Saris, MD., Ph.D. (University Maastrichty and P.J.F. de Vries, Ph.D. (Friesland Coberco Dairy Foods) for their critical comments on the manuscript. 



\title{
Vitamin $D_{3}$ and vitamin $K_{1}$ supple-
} mentation of Dutch postmenopausal women with normal and low bone mineral densities: effects on serum 25-hydroxyvitamin $D$ and carboxylated osteocalcin
A. Schaafsma , F.A.J. Muskiet ${ }^{2}$, H. Storm", G.J.H. Hofstede ${ }^{2}$, I. Pakan', E. Van der Veer ${ }^{2}$
1 Department of Research \& Development Leeuwarden, Friesland Coberco Dairy Foods, Leeuwarden, The Netherlands
2 Pathology \& Laboratory Medicine, University Hospital, Groningen, The Netherlands
3 Foundation Clinical Chemical Laboratory, Leeuwarden, The Netherlands
4 Surgery, Medical Centre Leeuwarden, Leeuwarden, The Netherlands

\section{European Journal of Clinical Nutrition (in press)}

\begin{abstract}
Current recommendations for vitamins $\mathrm{D}$ and $\mathrm{K}$ might not be sufficient to support maximum bone health in postmenopausal women. Therefore we studied whether the vitamin $\mathrm{D}$ and $\mathrm{K}$ status of about 60 years old postmenopausal Dutch women could be improved through daily supplementation. Postmenopausal women with normal (T-score $>-1 ; n=96$ ) and low ( $T$-score $\leq-1 ; n=45$ ) bone mineral density (BMD) of the lumbar spine, received 350-400 IU vitamin $D_{3}, 80 \mu g$ vitamin $K_{1}$, vitamins $K_{1}+D_{3}$, or placebo during one year. Serum 25 hydroxyvitamin D [25(OH)D] and percent carboxylated osteo-calcin (\%carbOC) were measured at baseline and after 3,6 and 12 months. Baseline \%carbOC of the entire study population was positively correlated with BMD of the lumbar spine and femoral neck. Correspondingly, women with low BMD had lower \%carbOC at baseline than women with normal BMD but this difference disappeared after one year of supplementation ( $69 \pm 11$ vs $72 \pm 6 \%$, respectively). One year supplementation with vitamin $D_{3}$ showed maximum increases in $25(\mathrm{OH}) \mathrm{D}$ of $33 \pm 29 \%$ and $68 \pm 58 \%$ in women with normal and low BMD, respectively. During winter, however, a $29 \%$ decline in $25(\mathrm{OH}) \mathrm{D}$ was not prevented in women with low BMD. It is concluded that daily supplementation of Dutch postmenopausal women with $>400 \mathrm{lU}$ vitamin $\mathrm{D}_{3}$ is indicated to prevent a winter decline in $25(\mathrm{OH}) \mathrm{D}$ and to control serum parathyroid hormone levels. Daily supple-mentation with $80 \mu \mathrm{g}$ vitamin $\mathrm{K}_{\text {, }}$ seems to be necessary to reach premenopausal \%carbOC levels, although a stimulatory effect of calcium and/or vitamin D cannot be excluded. Higher levels of \%carbOC are considered to be beneficial for bone mineralization and preservation.
\end{abstract}

Keywords: Postmenopausal women, vitamin D, vitamin K, 25-hydroxyvitamin D. carboxylated osteocalcin, recommendation. 


\section{Introduction}

Vitamins $D$ and $K$ play essential roles in bone metabolism. Calcitriol, the most active vitamin $D$ metabolite, augments active intestinal calcium uptake and reduces serum levels of parathyroid hormone (PTH). Elevated PTH levels are unfavorable since they stimulate bone resorption, bone remodeling and finally. bone loss (Hollick 1998). At latitudes $40^{\circ}$ north and south of the equator, sunlight exposure is unable to sustain vitamin $D_{3}$ photosynthesis in the skin during the winter months. Consequently, circulating 25hydroxyvitamin D [25(OH)D], which is a reliable marker of vitamin D-status $s_{4}$ is lower in winter than in summer (Romagnoli 1999; Meunier 1999; Shearer 1997; Utiger 1998). Vitamin $K$ is a co-factor for $\gamma$-glutamylcarboxylase, which catalyzes the posttranslational carboxylation of specific glutamate residues into $\gamma$-carboxyglutamic acid (Gla) in proteins involved in blood coagulation and bone metabolism.

Osteocalcin is the most intensively studied Gla-protein of bone metabolism. In its carboxylated form, osteocalcin exhibits strong calcium binding properties and is necessary for proper mineralization of new bone (Shearer 1997; Boskey 1998).

The percentage carboxylated osteocalcin (\%carbOC), as calculated from total asteocalcin, was found to be less than $60 \%$ in osteoporotic postmenopausal women as compared to $70-80 \%$ in young, healthy adults (Douglas 1995; Jie 1996). Both the percentages carboxylated prothrombin and $\%$ carbOC are functional parameters of vitamin $\mathrm{K}$ status, but the latter seems to be more sensitive (Shearer 1997; Sokoll and

Sadowski 1996)

To reach adequate $25(\mathrm{OH}) \mathrm{D}$ levels in summer and especially in winter, the Dutch Food Nutrition Council (1992) recommends daily intakes of 100-200 IU (2.5-5 $\mu \mathrm{g})$ of vitamin $\mathrm{D}$ for women 65 years and older. The recommendation is $0-100$ IU for the younger postmenopausal women, since they are considered to spend sufficient time outdoors. A recent survey shows that women 50 years and older consume daily 3.3-3.6 $\mu \mathrm{g}$ of vitamin $\mathrm{D}$ which means that the recommendation is reached (Dutch National Food Consumption Survey 1988). Optimum vitamin D status, however, has recently been subject to renewed discussion (Vieth 1999; Dawson-Hughes 1998; McKenna and Freaney 1998) and was suggested to be $>100 \mathrm{nmol} 25(\mathrm{OH}) \mathrm{D} /$ $\mathrm{L}$ (Meunier 1999). For vitamin $\mathrm{K}$, the US RDA (National Research Council. 1989) amounts to $65 \mu \mathrm{g}$ for 50 years old women, based on the maintenance of plasma carboxylated prothrombin concentrations in the normal range. The daily intake of vitamin $K_{1}$, which is the major form of nutritional vitamin $\mathrm{K}$ and the dominant form in bone, is estimated to be $250 \mu \mathrm{g}$ for 50 years and older Dutch women (Schurgers 1999; Kohlmeier 1996).

This study aimed to investigate whether the vittamin $D$ and $K$ status of about 60 years old postmenopausal Dutch women can be improved. For this we selected two groups with documented normal and low bone mineral density (BMD), respectively, and supplemented them with vitamin $D_{3}$, vitamin $K_{1}$, vitamins $K_{1}+D_{3}$, or placebo during one year. Serum 25(OH)D and \%carbOC served as parameters of vitamin $D$ and $K$ status, respectively.

\section{Subjects, material and methods Subjects}

The subjects reported in this paper were apparently healthy Caucasian postmenopausal women. They participated in two different studies on the effect of calcilum, vitamin $D_{3}$ and vitamin $K_{j}$ supplementation in women with normal $(n=96)$ or low $(n=$ 45) BMD of the lumbar spine. Women with normal and low BMD had lumbar spine Tscores of $>-1$ and $<-1 S D$, respectively, as measured with dual-energy $X$-ray absorptiometry (QDR 2000 and 1000, Hologic Inc, Waltman, MA, USA). 
The women were at least 5 years postmenopausal and between 50 and 77 years of age. Their baseline characteristics are given in Table 8.1. They did not use medication or vitamin and/or mineral preparations known to interfere with bone metabolism, and they were asked to abstain from artificial sun bathing during the study period. Excluded were women with acute and chronic illnesses. All women gave their free and informed consent. The Medical Ethical Committees of the University Hospital of Groningen and the Medical Centre Leeuwarden approved the studies.

\section{Supplements and diet}

Women with normal BMD were, in a double blind study, randomly allocated to daily supplements that provided $400 \mathrm{IU}$ vitamin $D_{3}$ and $80 \mu \mathrm{g}$ vitamin $K_{1}$ (group $A$ ).
$80 \mu \mathrm{g}$ vitamin $K_{4}$ only (group $\mathrm{B}$ ), or $2.5 \mathrm{~g}$ of skimmed milk powder (placebo). Women with low BMD were, in an open study, randomly allocated to a daily supplement that provided $350 \mathrm{IU}$ vitamin $\mathrm{D}_{3}$ and $80 \mu \mathrm{g}$ $\mathrm{K}_{\mathrm{y}}$ (group $\mathrm{C}$ ) or to a commercially available 400 IU vitamin $D_{3}$ tablet (Devaron, Solvay Pharma B.V., Weesp. The Netherlands) (group D). All women, except for the ones who were assigned to placebo, received about $1,000 \mathrm{mg}$ of additional calcium, which increased total daily calcium intake to 2,200-2,300 mg. All supplements also contained other minerals and vitamins, such as magnesium, zinc, B-vitamins and vitamin C (data not shown). Compliance, expressed as percentage sachets or tablets taken, was assessed on the basis of emptied package counts and written checklists.

Table 8.1: Baseline characteristics

\begin{tabular}{|c|c|c|c|c|c|}
\hline & \multicolumn{3}{|c|}{ Normal BMD } & \multicolumn{2}{|c|}{ LOW BMD } \\
\hline & $\begin{array}{c}A \\
n=46\end{array}$ & $\begin{array}{c}B \\
n=23\end{array}$ & $\begin{array}{c}\text { Placebo } \\
n=27\end{array}$ & $\begin{array}{c}C \\
n=22 \\
\end{array}$ & $\begin{array}{c}D \\
n=23\end{array}$ \\
\hline Age $(y)$ & $60.0 \pm 3.7$ & $59.5 \pm 3.8$ & $63.5 \pm 4.0$ & $63.0 \pm 6.7$ & $61.8 \pm 4.7$ \\
\hline Postmenopausal age (y) & $11.0^{*} \pm 5.4$ & $12.1 \pm 6.4$ & $14.3 \pm 4.6$ & $13.9 \pm 7.0$ & $12.7 \pm 5.4$ \\
\hline Weight (kg) & $73.4 \pm 9.8$ & $75.5 \pm 10.4$ & $76.9 \pm 11.9$ & $70.9+7.7$ & $70.9 \pm 13.3$ \\
\hline Height $(\mathrm{cm})$ & $164.4 \pm 5.9$ & $164.5 \pm 5.7$ & $163.9 \pm 6.1$ & $165.6 \pm 5.2$ & $166.1 \pm 6.3$ \\
\hline $\mathrm{BMI}\left(\mathrm{kg} / \mathrm{m}^{2}\right)$ & $273 \pm 3.9$ & $28.1 \pm 4.8$ & $28.7 \pm 4.4$ & $25.9=3.0$ & $25.7 \pm 4.4$ \\
\hline Osteocalcin total $(\mu \mathrm{g} / \mathrm{L})$ & $139 \pm 4.6$ & $11.9 \pm 4.1$ & $12.4 \pm 4.4$ & $12.8 \pm 4.0$ & $11.9 \pm 4.1$ \\
\hline \multicolumn{6}{|l|}{ Lumbar spine (AP) } \\
\hline T-score & $-0.85 \pm 0.93$ & $-0.73 \pm 0.89$ & $-0.72 \pm 1.17$ & $-2.14^{\dagger} \pm 0.81$ & $-2.40^{1} \pm 1.05$ \\
\hline Z-score & $0.59 \pm 0.94$ & $0.68 \pm 0.87$ & $0.98 \pm 1.16$ & $-0.47^{1} \pm 0.96$ & $40.77^{1} \pm 1.06$ \\
\hline \multicolumn{6}{|l|}{ Femoral neck } \\
\hline T-score & $-1.54 \pm 0.94$ & $-1.53 \pm 0.95$ & $-1.06 \pm 1.12$ & $-2.36^{\dagger} \pm 0.91$ & $-1.99 \pm 1.11$ \\
\hline Z-score & $0.11 \pm 0.91$ & $0.05 \pm 0.78$ & $0.86 \pm 1.07$ & $-0.54^{8} \pm 0.94$ & $-0.22^{1} \pm 1.07$ \\
\hline \multicolumn{6}{|l|}{ Total proximal femur } \\
\hline T-score & $-0.85 \pm 0.91$ & $-0.77 \pm 1.01$ & $-0.49 \pm 1.00$ & $-1.43^{1} \pm 0.89$ & $-1.35^{4} \pm 0.92$ \\
\hline Z-score & $0.24 \pm 0.93$ & $0.29 \pm 1.03$ & $0.81 \pm 0.92$ & $-0.10^{*} \pm 0.97$ & $-0.15 \pm 0.93$ \\
\hline $25(\mathrm{OH}) \mathrm{D}(\mathrm{nmol} / \mathrm{L})$ & $90.4 \pm 24.5$ & $90.5 \pm 24 \ldots 2$ & $91.0 \pm 36.5$ & $49.0 \pm 14.2$ & $50.0 \pm 15.9$ \\
\hline \%carboc (\%) & $67.2 \pm 8.2$ & $67.5 \pm 7.2$ & $66.4 \pm 10.2$ & $55.3 \pm 10.6$ & $56.1^{1 *} \pm 8.2$ \\
\hline
\end{tabular}




\section{Material and Methods}

Blood samples were collected at baseline and after 3,6 and 12 months. Serum was stored at $.20^{\circ} \mathrm{C}$ within one hour. All samples were taken at fixed clock times during the day to avoid circadian thythms. Blood samples from the women with normal BMD were taken in the periods of September-December (baseline), December-March (3 mo), March-June /6 mo) and September-December (12 mo).

Those from the women with low BMD were collected during the periods of NovemberFebruary (baseline), March-May ( 3 mo). May-August ( 6 mo) and NovemberFebruary (12 mo).

Serum total osteocalcin and undercarboxylated osteocalcin were measured in the Groningen University Hospital before and after extraction with hydroxyapatite, respectively, using the IRMA of MedgenixH-Ost (Fleurus, Belgium). The \%carbOC was calculated from the difference of undercarboxylated osteocalcin and total osteocalcin. Serum 25(OH)D of the women with normal BMD was determined with a competitive protein binding assay developed in the Groningen University Hospital. This analysis is preceded by solid phase extraction (Chen 1990). Serum 25(OH)D of women with low BMD were measured at baseline and at 6 and 12 months by the laboratory of the Leeuwarden Hospital, that uses the kit of Inostar (Sorin, Biomedica, Stillwater, MN, USA) (Hollis 1993).

\section{Statistics and data analysis}

Between-group differences in baseline characteristics were studied with ANOVA, followed by a Bonferroni-corrected posthoc test. Within-group and between-group differences in \%carbOC and 25(OH)D were studied with nonparametric, two tailed statistical tests (Wilcoxon signed-rank test and the Mann Whitney U-test which was preceded by Kruskal-Wallis test when necessary) since the Kolmogorov-Smirnov test indicated non-Gaussian distribution of both parameters. We did not evaluate $25(\mathrm{OH}) \mathrm{O}$ differences of patients with normal and low BMD. The results of these groups derived from different $25(\mathrm{OH}) \mathrm{O}$ analytical methods, and a recent evaluation of these methods by Lips et al (1999) showed substantial differences in their outcomes: Relations between paxameters were investigated with the Spearman Rank test. Differences were considered significant at $p \leq 0.05$. All analyses were done with SPSS 7.0 (SPSS Inc., Chicago, USA).

\section{Results}

Baseline

Women with normal BMD (group

$A+B+$ placebo, $n=96$ ) and low $B M D$ (group $C+D, n=45$ ) differed clearly in BMD as derived from their T-scores $(p \leq 0.001)$ and $Z$-scores $(p<0.005)$ measured at the various sites (Table 8.1). Women with normal $B M D$ had higher body weight $(p=$ $0.01)$, higher $B M I(p=0.02)$ and higher $\%$ carboc ( $p \leq 0.001)$, compared with women with low BMD. Athough women with normal BMD had significantly higher $25(\mathrm{OH}) \mathrm{D}$ at baseline compared with counterparts with low $B M D$, this may be caused by the use of different $25(\mathrm{OH}) \mathrm{D}$ analytical methods. At baseline and only for the entire population, \%carboc was positively correlated with BMD of the lumbar spine $(r=0.32, p<0.005)$ and femoral neck $(r=0.25, p<0.005)$. This association indicates that low levels of $\%$ carbOC accompany low BMD.

\section{Effects of vitamin $D$, supplementation} Women with normal BMD.

Women with normal BMD who received vitamin $D_{3}$ supplementation (group $A$ ) had higher $25(\mathrm{OH}) \mathrm{D}$ after 3 months $(\mathrm{p} \leq 0.001)$, 6 months $(p \leq 0.001)$ and 12 months $(p=0.001)$ (Figure 8.1; left upper panel) compared with their counterparts who received no vitamin $D_{3}$ supplementation 
Figure 8.1: Percent change of $25(\mathrm{OH})$ and course of \%carboc in postmenopausal women with normal and low BMD following daily supplementation with $350-400 \mathrm{lU}$ witamin $\mathrm{D}_{3,} 80 \mathrm{\mu g}$ vitamin $\mathrm{K}_{\mathrm{n}^{2}}$ or placebo.
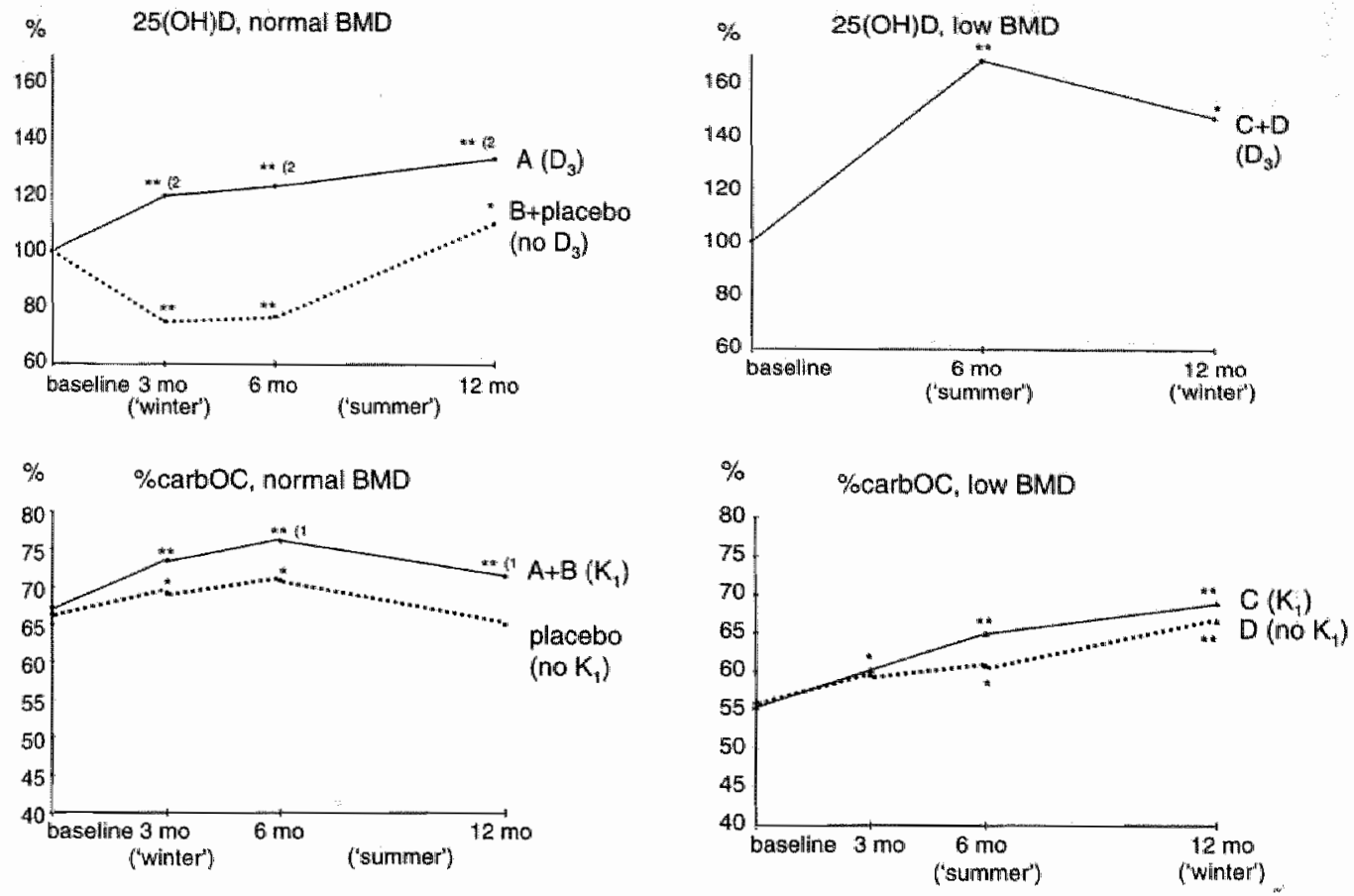

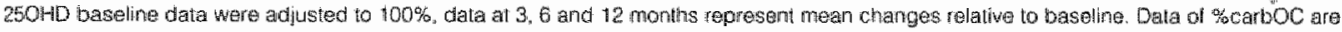
presented as mean absotute parcentages. For group characteristics see Tablte 8.1.

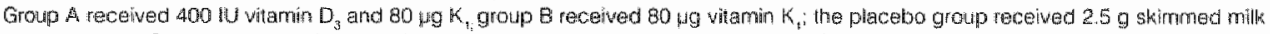

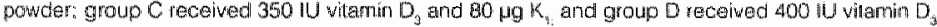

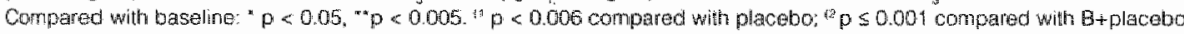

(group B+placebo), 25(OH)D concentrations after 3,6 and 12 months were $108 \pm 25 \mathrm{nmol} / \mathrm{L}, 111 \pm 23 \mathrm{nmo} / \mathrm{L}$ and $121 \pm 27 \mathrm{nmol} / \mathrm{L}$ for group $\mathrm{A}_{\text {s }}$ and $68 \pm 31$ $\mathrm{nmol} / \mathrm{L}, 69 \pm 31 \mathrm{nmo} / \mathrm{L}$ and $100 \pm 31 \mathrm{nmol} / \mathrm{L}$ for group B+placebo. All measured values were within the physiologic range $(\leq 220$ nmol/L) (Vieth 1999). Group A also had higher $25(\mathrm{OH}) \mathrm{D}$ after 3,6 and 12 months, compared with baseline $(p<0.005)$, which can especially be attributed to an effect of the first 3 months $(p \leq 0.001)$. There was a modest 25(OH)D increase from 3-12 months $(p=0.004)$. 25(OH)D concentrations of group $\mathrm{B}+$ placebo decreased during the first 3 months $(p \leq 0.001)$ and subsequently increased from 6-12 months $(\mathrm{p} \leq 0.001)$. The $25(\mathrm{OH}) \mathrm{D}$ concentration of group B+placebo was after 12 months significantly above baseline $(p=0.009)$. The lower concentration after 3 months in group $B+$ placebo coincided with sampling in December-June, whereas the higher concentration after 12 months coincided with sampling in June-December.

\section{Women with low BMD}

Women with low BMD (groups $C+D$ ) showed an initial increase of 25(OH)D from $0-6$ months $(p \leq 0.001)$ and a subsequent decrease from 6-12 months ( $p \leq 0.001$ ) (Figure 8.1; right upper panel). According to the 125 -labeled radioimmunoassay, $25(\mathrm{OH}) \mathrm{D}$ concentrations were $83 \pm 29$ and $59 \pm 20 \mathrm{nmol} / \mathrm{L}$ after 6 and 12 months, respecively. At 12 months, 25(OH)D was 
$46.7 \pm 48.0 \%$ above baseline $(p=0.009)$. The 25(OH)D increase at 6 months and decrease at 12 months (compared with 6 months), coincided with blood samples taken in May-August and NovemberFebruary, respectively.

\section{Effects of vitamin $K$, supplementation} Women with normal $B M D$

Women with normal BMD who received vitamin $K_{1}$ (group $A+B$ ) had higher $\%$ carbOC after 6 months $(p=0.009)$ and 12 months $(p=0.001)$ compared with their counterparts who received placebo (Figure 8.1; lower left panel). Group $A+B$ had higher \%carbOC after 3,6 and 12 months, compared with baseline $(p \leq 0.001)$. Increases of \%carbOC from 0-3 months and 3-6 months, and the decrease from $6-12$ months were significant $(p \leq 0.001)$. After 12 months the level of \%carbOC was $72.6 \pm 6 \%$. The \%carbOC level increased in the placebo group during the first 6 months $(p=0.001)$, which was especially an effect of the first 3 months $(p=0.031)$.

The \%carbOC subsequently decreased from 6-12 months $(p=0.005)$ to reach levels comparable with baseline at 12 month, $65.1 \pm 8.9 \%$. The higher levels at 6 months coincided with samples taken in December-June, whereas the lower levels at 12 months were found in samples collected in June-December.

\section{Women with low BMD}

Women with low BMD who received vitamin $\mathrm{K}_{1}$ (group $\mathrm{C}$ ) did not differ from women who did not receive vitamin $\mathrm{K}_{\text {, }}$ (group D) after 3, 6 and 12 months (Figure 8.1; lower right panel). The \%carbOC of group $C$ was higher at 3,6 and 12 months, compared with baseline $(p=0.025, \leq 0.001$ and $\leq 0.001$, respectively). Also the increases from 3-6 and 3-12 months were significant $(p=0.05)$. In group $D_{n}$ the $\%$ carbOC after 6 and 12 months were higher than baseline $(p \leq 0.001$ and 0.006 , respectively). In this group, the increases from $3-12$ and 6-12 months were significant $(p=0.03$ and $\leq 0.001$, respectively). After 12 months, \%carbOC levels were $69.0 \pm 11.4 \%$ and $66.7 \pm 11.5 \%$

Figure 8.2: Classification of postmenopausal women according to their vitamin $\mathrm{K}$ status at baseline and after 12 months of supplementation with $80 \mu g$ witamin $K_{1}$, or placebo.

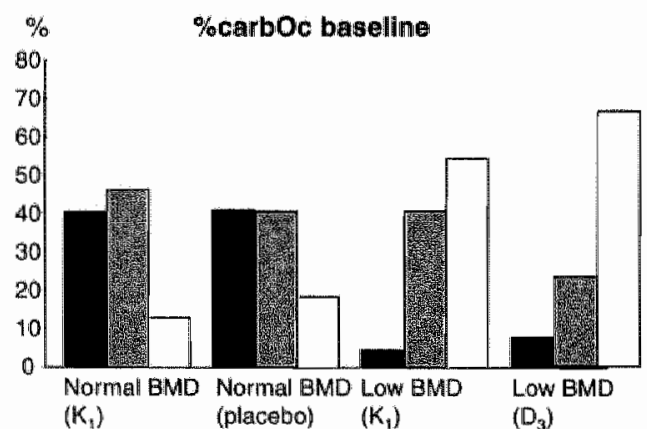

Optimal: $>70 \%$ from total osteocalcin

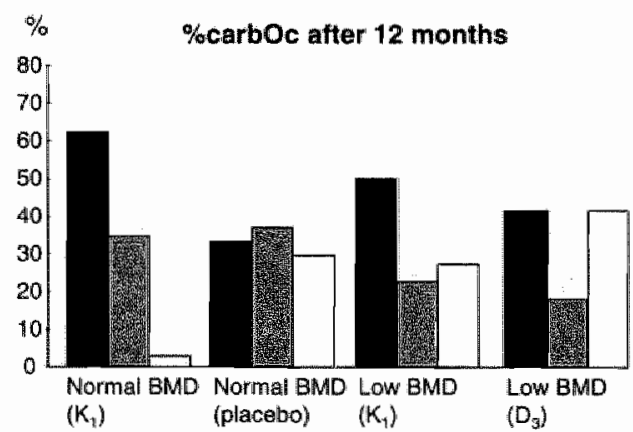

Suboptimal: $60-70 \%$ Low: $<60 \%$

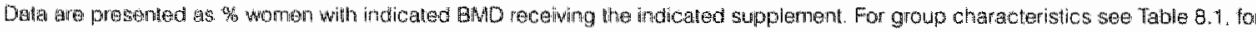

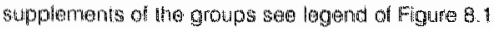

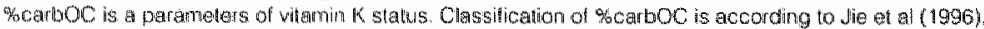

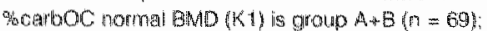

acarboc normal BMD (placebo) is the placebo group (n=27)

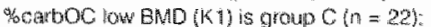

acarbOC bu BND $(03)$ is group $\mathrm{D}(\mathrm{n}=23)$. 
for groups $\mathrm{C}$ and $\mathrm{D}$ respectively. Both groups showed increases of the percentage women who had optimal \%carbOc after 12 months at the expense of suboptimal and low \%carboc (Figure 8.2).

\section{Women with normal BMD versus women} with low $B M D$

Vitamin $K_{1}$ supplemented women with normal BMD (group A+B; Figure 8.1 bottom left panel) did not only have higher $\%$ carbOC at baseline compared with vitamin $\mathrm{K}_{1}$ supplemented counterparts with low BMD (group C, Figure 8.1 bottom right panel), but they also had higher levels at 3 and 6 months ( $p \leq 0.001)$.

\section{Discussion}

This study shows that Dutch postmenopausal women with low lumbar spine BMD (T-score $\leq-1$ ) have lower" $\%$ carbOC, than postmenopausal women with normal BMD (T-score > -1) (Table 8.1). This lower \%carbOC was corrected after supplementation with $80 \mu \mathrm{g}$ vitamin $\mathrm{K}_{1}$ (Figure 8.1). The \%carbOC increase in women with low BMD and possibly also with normal BMD may, however, not be merely attributable to vitamin $\mathrm{K}$, but also to vitamin $D_{3}$ and/or calcium. Vitamin $D_{3}$ supplementation (350-400 IU) improved vitamin D-status in both groups of women with normal and low BMD, but was unable to prevent a decline of $25(\mathrm{OH}) \mathrm{D}$ during the winter months in women with low BMD. With the objective to minimize bone loss and to stimulate proper mineralization of new bone, we conclude that a large proportion of apparently healthy Dutch postmenopausal women, in particular those with low BMD, might need additional daily intakes of at least $400 \mathrm{IU}$ vitamin $\mathrm{D}_{3}$ and $80 \mu \mathrm{g}$ of vitamin $\mathrm{K}_{1}$, in combination with sufficient calcium.

Low 25(OH)D concentrations may imply suboptimal mineralization of newly formed bone and increased bone resorption secondary to increased PTH secretion.
Suboptimal $25(\mathrm{OH}) \mathrm{D}$ concentrations may not be able to give rise to maximum PTH suppression (Vieth 1999; McKenna and Freaney 1998). Supplementation with 350$400 \mathrm{IU}$ vitamin $\mathrm{D}_{3}$ markedly improved 25(OH)D concentrations of women with normal and low BMD (Figure 8.1). In women with low BMD, however, this dose was not sufficient to hold the higher $25(\mathrm{OH}) \mathrm{D}$ concentrations as achieved during summer months. In NovemberFebruary, 25(OH)D levels decreased with $29 \%$. A comparable winter decrease was found in women with normal BMD who received placebo. Since no differences are expected in vitamin $D$ metabolism between the women with low and normal BMD, a lower vitamin $D$-status at baseline can only explain the lower response to vitamin $D$ supplementation by women with low BMD. Prevention of a 25(OH)D dip in winter is important, since BMD of the femoral neck shows the same seasonal variation as 25(OH)D (Dawson-Hughes 1995). Others have shown that a $25(\mathrm{OH}) \mathrm{D}$ decline during winter can be prevented with 700-800 IU vitamin $D_{3}$ per day (Dawson-Hughes 1997; Dawson-Hughes 1995). These higher intakes were found to be associated with lower fracture risk (Meunier 1994; DawsonHughes 1997). Taken together, our study shows that a daily vitamin $\mathrm{D}_{3}$ supplementation with $400 \mathrm{IU}$ is sufficient for healthy postmenopausal women with normal BMD, which is in line with the recent US recommended adequate intake (Standing Committee on the Scientific Evaluation of Dietary Reference Intakes 1997). Postmenopausal women with low $B M D$, however, need higher intakes possibly to correct for a lower habitual vitamin $\mathrm{D}$ consumption. Therefore, an additional intake of 700-800 IU vitamin D may be considered for all postmenopausal women, notably because of the favorable results obtained by Dawson-Hughes (Dawson-Hughes 1997 and 1995). Such an intake is considered to be sale (Vieth 1999; 
Sparks 1994) and far below the vitamin D tolerable upper intake level of 2,000 IU (Standing Committee on the Sclentific Evaluation of Dietary Reference Intakes 1997).

Baseline \%carboc of the whole group was positively correlated with BMD of the lumbar spine and femoral neck. This finding agrees with the inverse correlation between undercarboxylated osteocalcin and $B M D$ as reported by others, who suggested to use high undercarboxylated osteocalcin (i.e. low \%carboc) as an indicator of hip fracture risk (Szulc 1994; Szulc 1996). The \%carbOC is involved in proper mineralization of new bone (Shearer 1997; Boskey 1998), and reduced bone loss in ovariectomized mice (Wolf 1996). Levels found in premenopausal women $(70-80 \%)$ may in this respect be regarded as optimal (Douglas 1995; Jie 1996). Using this criterion we found that in our study $93 \%$ of the women with low BMD and $55 \%$ of the women with normal BMD had suboptimal levels at baseline (Figure 8.2). The mean \%carbOC of the women with low BMD is comparable with levels reported for patients with osteoporosis ( $59 \%$ ) (Jie 1996). Women $(n=6)$ treated with coumarins, which biock the vitamin $\mathrm{K}$ cycle, had a mean \%carbOC level of $40.2 \%(95 \% \mathrm{Cl}: 34-48 \%)$ as established with our method (pers. comm.). On the basis of a previous study conducted in The Netherlands, it can be assumed that baseline vitamin $K_{1}$ intake by our women amounts to about $250 \mu \mathrm{g}$ per day (Schurgers 1999). This intake is considerably higher than the current US recommendation (National Research Council. 1989) $(65 \mu \mathrm{g} /$ day) which is based on the less sensitive hepatic vitamin-K dependent proteins (Booth 1999). Daily supplementation with $80 \mu \mathrm{g}$ vitamin $K_{\text {, was }}$ nevertheless found to cause sizable increases of the \%carbOC towards levels encountered in premenopausal women (Figure 8.2). Somewhat to our sulprise we found that \%carbOC in women with low BMD did not only increase upon vitamin $K_{\text {. }}$ supplementation, but also after daily supplementation with 400 IU vitamin $D_{3}$ and $1,000 \mathrm{mg}$ of calcium as shown by group D (Figure 8.1). A role of vitamin D in osteocalcin carboxylation has previously been suggested by others, although the mechanism is as yet unknown (Shearer 1997; Meunier 1999). Women with normal BMD showed an increased \%carbOC compared with placebo. Since the placebo lacks both vitamin $K_{\text {i }}$ and calcium, a stimulatory effect of calcium on \%carbOC cannot be exciluded. However, as yet this is not supported by any study we know.

An effect of vitamin $D$ is not expected since no difference was found between groups $A$ (with vitamin D) and $B$ (no vitamin D).

Based on these observations, it seems that an estimated daily total intake of about

$330 \mu \mathrm{g}$ vitamin $K_{1}$, and/or higher intakes of calcium and/or vitamin $D_{v}$ are necessary to reach and maintain premenopausal

$\%$ carbOC in all healthy postmenopausal women. Based on these observations, it seems that an estimated daily total intake of about $330 \mu \mathrm{g}$ vitamin $\mathrm{K}_{1}$, and/or higher intakes of calcium and/or vitamin $D$, are necessary to reach and maintain premenopausal \%carbOC in all healthy postmenopausal women. This intake of vitamin $\mathrm{K}_{1}$ is far below the safe maximal daily intake (32.5 mg; (Olson 1994)) and considerably lower than the $1 \mathrm{mg}$ dosage used in the treatment of postmenopausal colles fractures (Douglas 1995).

For patients on anti-coagulant therapy, however, the suggested amount of vitamin $K$ may weaken the therapy. These patients benefit from constant dietary intakes of vitamin $K$ on the level of the US RDA (Booth and Centurelli 1999).

In summary, our study shows that healthy postmenopausal women with low BMD also have low serum \%carbOC when compared with counterparts with normal BMD. Supplementation with $80 \mu \mathrm{g}$ vitamin 
$K_{1}$ is suggested to increase \%carboc to premenopausal values in all women, but an additional effect of vitamin $D$ and/or calcium on \%carbOC cannot be excluded. An increased \%carbOC is a good proxi variable for $B M D$ in postmenopausal women. Supplementation with $350-400 \mathrm{IU}$ vitamin $D_{3}$ for 12 months increased $25(\mathrm{OH}) \mathrm{D}$ in all women, however, it did not prevent a decrease of maximum achieved 25(OH)D concentrations during winter in those with low BMD. Taken together we recommend daily additional intakes of $700-$ $800 \mathrm{IU}$ vitamin $\mathrm{D}$ and $80 \mu \mathrm{g}$ vitamin $K_{4}$ by healthy postmenopausal women to support bone health. These supplements give rise to total dietary intakes that are considerably higher than current US recommendations, but much lower than the assumed safe maximum daily intakes for both of these vitamins (Olson 1994: Standing Committee on the Scientific Evaluation of Dietary Reference Intakes 1997; Vieth 1999). Further research is necessary to elucidate the stimulatory roles of calcium, vitamin $D$ and vitamin $K$ on \%carbOC levels.

\section{Acknowledgment}

We gratefully acknowledge Alice Rodenburg and Haydee Schaafsma, for their assistance in monitoring, and the volunteers who participated in this study. We would like to thank W.H.M. Saris, MD. Ph.D. (University Maastricht) and P.J.F. de Vries, Ph.D. (Friesland Coberco Dairy Foods) for their critical comments on the manuscript. 



\section{General discussion}

\section{Introduction}

Postmenopausal bone loss will sooner or later lead to increased fracture risk. The prevalence of osteoporosis in postmenopausal women (55-84 years of age) was found to be $7 \%$ in a Dutch general practice versus $16.5 \%$ in the Rotterdam (ERGO)study (Versluis 1999). In the United States a prevalence of $21 \%$ is suggested in Caucasian and Asian women, $16 \%$ in Hispanic, and $10 \%$ in African women (Standing Committee on the Scientific Evaluation of Dietary Reference Intakes 1997). Of Caucasian women in the UK (6070 years of age), $24 \%$ proved to have osteoporosis (Ballard 1998). In Eelde (Chapter 6) $16 \%$ of the women (55-70 years) were classified as osteoporotic after measurement of the BMD of the lumbar spine. These figures indicate that an important percentage of apparentiy healthy postmenopausal women have an increased fracture risk already before the age of 70. Important factors in osteoporosis prevention are nutrition, physicall activity, a healthy life-style such as no smoking and avoiding excessive alcohol consumption, and the realization of a high peak bone mass during childhood and adolescence (Krall and Dawson-Hughes 1999; Eddy 1998; Heaney 1996; Anon 1992; Heaney 1987; Cooper and Aihie 1994).

Bone metabolism is very complex and several nutritional components have positive and/or negative effects.

Biochemical changes in cascades of reactions, release of trapped factors, age dependent alterations, and influence of health-status make it difficult to set simple nutritional recommendations for an improved or stabilized bone metabolism. It seems that the complex metabolism is mast benefited by an improvement in a wide-range of nutrients. The nutrients calcium and vitamin $\mathrm{D}$ are well known for their roles in bone metabolism. Human calcium metabolism possibly evolved on high levels of calcium and vitamin $D$ (Vieth 1999; Crawford and Marsh 1989). Nowadays, for a major part of the population the intake of both mutrients is at a much lower level. Levels, which seem to be too low for an optimal bone metabolism. This problem is discerned and recently, recommended intakes for calcium and vitamin D in the USA, for the age-group 51 years and older, already increased (Standing Committee on the Scientific Evaluation of Dietary Reference Intakes 1997). Higher calcium intakes are also necessary for an optimal effect of medical treatment of osteoporosis (Nieves 1998; Kanis 1999). Therefore, an increase in .calcium and vitamin D intakes, especially of the vulnerable group of postmenopausal women, seems to be desirable. This intervention should be inexpensive to be cost effective on a population basis (Torgerson and Kanis 1995). The intake of nutrients with a positive effect on bone metabolism can be improved via enrichment or fortification of existing food items or specific supplements. For lifetime compliance, suitable vehicles are basic food elements, such as dairy products in the Western diet (Dutch National Food Consumption Survey 1998; Standing Committee on the Scientific Evaluation of Dietary Reference Intakes 1997).

\section{Calcium}

Calcium is the basic element in most therapeutic and preventive strategies. The effects of callium alone are, however, still subject of debate. Overall, it is agreed that an increased intake of calcium decreases 
bone turnover, and that effects on BMD are more pronounced in elderly than in early postmenopausal women or middle-aged men. The magnitude of the effect on fracture risk is not clear but certainly present (Kanis 1999). Based on literature and on the study described in Chapter 6 , it may be concluded that a total daily intake of about $1,200 \mathrm{mg}$ of calcium seems to be sufficient for a healthy postmenopausal woman to prevent bone loss from the lumbar spine. However, to prevent also bone loss from the hip, an additional amount of calcium seems to be beneficial.

\section{Chicken eggshell powder: composition and calcium bioavailability}

Several calcium sources are available for fortification of food or supplements, ranging from highly refined to unrefined natural sources. The latter are of interest because they do not only contain calcium but also small amounts of other elements such as strontium, magnesium and fluorine.

As discussed in Chapter 2, increases up to $100 \%$ in the daily intake of these elements may have long-term beneficial effects on bone. A negative aspect of natural sources may be the uncontrolled levels of potentially toxic elements such as lead, cadmium and aluminum (Whiting 1994).

Figure 9.1: Schematic presentation of chicken eggshell and an indication of layers which are used for eggshell powder production

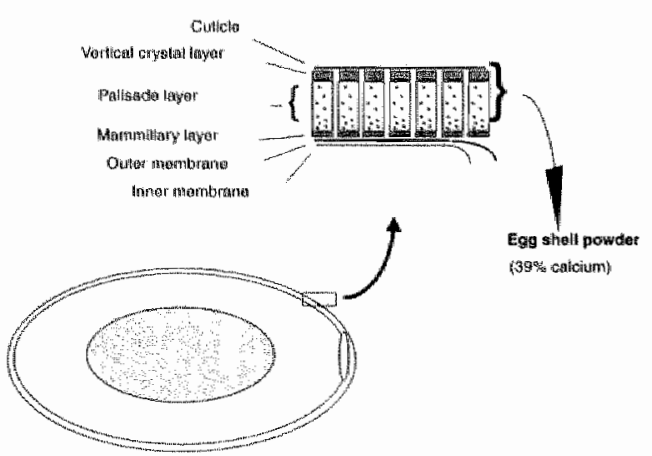

A rather unknown, unrefined source of calcium is chicken eggshell powder, prepared from demembranized eggshelis (Figure 9.1). In two studies (Stanciková 1996; Makai and Chudacek 1991), postmeno-pausal women and patients with osteo-porosis showed increases in BMD or inhibition of bone loss, whereas pain was reported to relief in the patients with osteoporosis. The postmenopausal women were treated for one year with $3 \mathrm{~g}$ of eggshell powder per day, patients with osteoporosis received $6 \mathrm{~g}$ of eggshell powder daily during 2-6 months.

Therefore, the use of chicken eggshell powder in dairy or dairy-based products seems to be an effective combination of calcium and a suitable vehicle with a calcium image. As discussed in Chapter 2, such a product should be fortified with other elements and vitamins, including magnesium, vitamin $D_{3}$ and vitamin $K_{1}$, all known to be beneficial for bone metabolism. Higher intakes of these nutrients not only prevent nutrient deficiency according to current recommendations but also meet suggested higher requirements.

Chicken eggshell powder was found to have only very low levels of lead, cadmium, mercury and aluminum (Chapter 3 ).

Its calcium content is almost as high as in purified calcium carbonate. Such a high calcium content is beneficial and is one of the reasons why calcium carbonate is widely used in food fortification (Kärkkäinen 1997). Furthermore each g of chicken eggshell powder may increase daily strontium intake with $15-40 \%$.

Strontium is thought to have anabolic effects on bone and is used in pharmacological amounts in osteoporosis treatment (Cabrera 1999; Reginster 1999). Chronic loading with increased but still low amounts, may have long term beneficial effects since strontium is a bone-seeking element. Furthermore chronic supply of low amounts of strontium prevent large-scale 
substitution of calcium in hydroxyapatite crystals which is suggested to reduce bending strength (Okayama 1991). The amount of strontium in chicken eggshell powder may increase considerably by increasing the amount in the feed of chickens. Fluorine, which is also anabolic on bone, is only present in very low levels in chicken eggshell powder. These levels probably cannot be increased to relevant levels. Therefore, other products such as tea or tea extracts seem to be more suitable to increase fluorine intake (Cao 1996). Of the hormones analyzed, only very low amounts of calcitonin, transforming growth factor- $\beta_{1}\left(T G F \beta_{i}\right)$ and progesterone were detected. It has to be mentioned however that, within the time frame of this research project, we were not able to optimize the analyses of these hormones. Both the separation of organic material from the mineral matrix and the purification of the organic material need further improvement. Although the before mentioned hormones inhibit bone resorption or stimulate bone formation, the very low amounts detected are not likely to contribute to the reported increases in BMD and relief of pain (Schaafsma and Pakan 1999; Makai and Chudacek 1991). Preliminary in vitro research was done on the effects of eggshell powder on growth of SAOS-2 cells (human osteosarcoma cells with osteoblast-like characteristics). This study was initiated following the reported growth stimulation of eggshell powder on cartilage cells of chicken embryos (Rovensky 1994). Based on cell counts and on determination of protein concentration no positive or negative effects were found. Effects on osteoclasts have not been studied because a suitable cell culture (Gattei 1992) was not available to us at that time.

To measure intestinal calcium absorption, accurate but expensive labelled calcium methods are availlable (Van den Heuvel 1998; Bronner 1988; Hansen 1996).
A good proxi method of human calcium absorption is the apparent digestibility in piglets (Moughan 1994). Although less accurate, the piglet model provides sufficient information since small differences in intestinal absorption do not seem to be important for bodily calcum balance (Marcus 1996a; Bronner and Pansu 1999). The outcome of the study (Chapter 4) shows that chicken eggshell powder can be used quantitatively and qualitatively as an alternative to calcium carbonate. The latter is generally accepted as a calcium source with a high calcium bioavailability. When combined with soy protein, calcium absorption from eggishell powder is less inhibited than from calcium carbonate. This is of interest because many people in the world that do not use dairy products or only in limited amounts, often consume soya or soya-based foods. Also for the Western diet, soya may become more and more important because it contains isoflavones (a group of phytooestrogens) which are thought to have. positive, oestrogen-like effects on bone and other tissues (Anderson and Garner 1997; Cassidy 1994; Knight and Eden 1995; Knight and Eden 1996).

\section{Human studies}

Combination of DEXA and biochenical markers in short-term studies

Changes in BMD of postmenopausal women during one year of intervention with calcium enriched products are expected to be small. Furthermore, a possible increase in BMD in response to a decreased bone resorption may be temporary until a new steady state has been reached in bone turnover (the so-called bone-remodeling transient). On the one hand this implies that these studies should continue for several years before a significant effect of supplementation is found. On the other hand, it has been reported that the effect of calcium supplementation on bone (Devine 1997; Kanis 1999; Dawson-Hughes 1998) 
as found in studies lasting for 18-48 months, were primarity an effect of the first year. DEXA is widely used for the measurement of BMD. This device has a precision (reproducibility of the value upon repeat measurement) and accuracy (ability to reflect the true bone density) error; for the measurement of BMD of spine and hip. of $0.5-2 \%$ and $3-5 \%$, respectively (Kolta 1999; Genant 1989; Eddy 1998). As a consequence of these possible measurement errors, long periods of intervention and large numbers of subjects are necessary to reach sufficient statistical power. Short-term studies with tewer subjects may, however, provide useful information when BMD measurements are combined with biochemical markers of bone metabolism. Recent publications (Garnero 1999; Ravn 1999; Lindsay 1999) report that the response of markers of bone turnover during the first 6 months of treatment were predictive for long term effects (up to two years) on BMD in studies with hormone replacement therapy (HRT) and bisphosphonates. Possibly, the same may be true for nutritional (e.g. calcium/ vitamin D) intervention studies. Therefore, several markers of bone turnover have been used in the intervention studies described in Chapters 5, 6 and 7. Of the bone formation markers (Chapters 6 and 7 ) serum amino terminal propeptide extension of type I collagen (PINP) was found to be the most suitable parameter to study groupwise effects in supplemented healthy postmenopausal women with normal and with low bone mass. Carboxylated asteocalcin (\%carbOC), often used as a marker of bone formation, reflected the

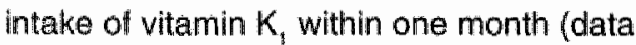
not shown) of supplementation and could differentiate between groups of women with low and normal BMD (Chapter 8). Of the bone resorption markers, urinary deoxypyridinoline (D-Pyr) responded very well and was highly correlated with serum P1NP levels. As also known from literature, serum 25-hydroxyvitamin $\mathrm{D}$ [25(OH)D] concentrations respond strongly to the intake of vitamin $\mathrm{D}$. The absolute concentrations of $25(\mathrm{OH}) \mathrm{D}$ determined, however, depend on the method used (Lips 1999). As long as no standardization has taken place, the best way to compare between group effects is by studying the relative changes. Deviations in outcomes between the several methods also make it difficult to set optimal $25(\mathrm{OH}) \mathrm{D}$ concentrations as suggested by McKenna. (McKenna and Freaney 1998). Finally, insight in serum parathyroid hormone (PTH)-levels may be useful because it is an important regulator of bone turnover and explains the effects on P1NP and D-Pyr as was demonstrated in our study. Other" parameters studied did not or hardly changed during the studies performed, or are known to be too insensitive for research purposes (urinary calcium, hydroxyproline excretion) (Delmas and Garnero 1996).

The ultimate hard clinical endpoint (direct evidence) of intervention studies is fracture prevention. However this does not only require large study populations but also very long observation periods.

The outcome of most intervention studies therefore provides indirect evidence by using the before mentioned combination of BMD and biochemical markers (Lindsay 1999; Kanis 1999; Vermeer 1996).

The human studies described in this thesis also provide indirect evidence.

\section{Effects on BMD}

Three human studies were designed, a short-term (4-8 months) pilot study and two studies lasting for one year. The employed supplements, supplied three gram of chicken eggshell powder per day in combination with vitamins and minerals including magnesium, vitamin $D_{3}$ and vitamin $\mathrm{K}_{y}$. Because of the supplementation the mean daily calcium intake of the women, except for the placebo group, 
Figure 9.2: Percent changes in BMD from baseline after one-year supplementation with eggshell powder enriched supplements, in women with normal (AZG) and low BMD (MCL), or a combination of both (MCL + $A Z G)$.

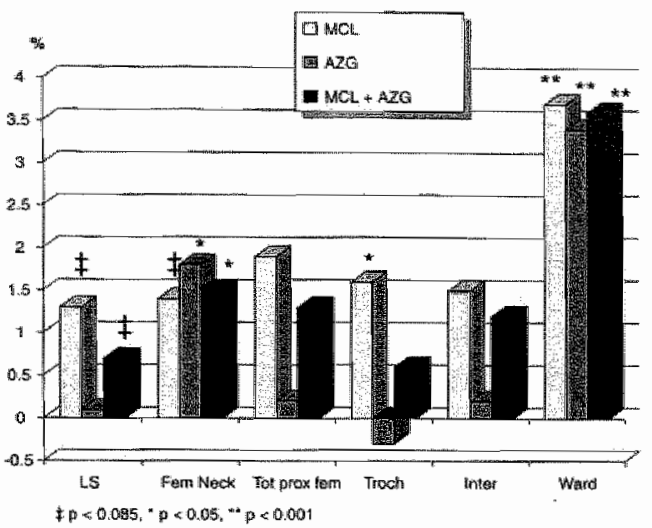

was in the range of $2,200-2,500 \mathrm{mg}$. The pilot study (Chapter 5 ) involved 10 subjects with spinal osteoporosis and only intended to confirm the results of a Slovakian study (Makai and Chudacek 1991) using 3 instead of $6 \mathrm{~g}$ of eggshell powder per day. The BMD results of this study were also used to estimate the sample size for the other two intervention studies. Although $75 \%$ of the participants showed increased $B M D$, the percent of success was set at $60 \%$ for intervention and was estimated to be $20 \%$ for placebo. For $90 \%$-power with $95 \%$ confidence, 24 women should participate (Lemeshow 1990). For both one-year studies, at least 25 apparently healthy postmenopausal women were recruited per group. These studies differed with respect to lumbar spine (AP) BMD of the women. One study (AZG, Chapter 6) was performed with women with normal BMD (T-score $>-1)$. This blinded study was placebo and reference product controlled. The reference product only differed in calcium source with the eggshell powder enriched supplement. The other study (MCL, Chapter 7) included women with osteopenia $(-2.5<\mathrm{T}$-score $<-1)$ or osteoporosis (T-score $\leq-2.5$ ). As a consequence, this study was neither placebo controlled nor blind for medical ethical reasons. Alternatively, women in the reference group received calcium and vitamin $D_{3}$ tablets.

In all three studies, groups with the eggshell powder enriched supplement showed significant increases in BMD at two or three of the measured sites compared with baseline. Effects of supplementation seem to be stronger in women with low initial BMD, as might be expected. Groups taking the reference products or placebo did not show a change in BMD. Figure 9.2, shows the changes in BMD of the eggshell powder supplemented groups of both one-year studies as well as the results of the groups combined. This combination of studies showed increases in BMD of the femoral neck and Ward's triangle, whereas BMD of the lumbar spine showed a tendency to increase. The combined effect might speculate about an effect in the general population of postmenopausal women, although the prevalence of osteoporosis in this combination is $24 \%$ versus $16 \%$ expected. In our opinion the combination of the results is justified because the supplements contained the same amounts of minerals and vitamins, the study protocols were identical, and BMD devices from the same manufacturer are considered to be highly comparable (Kolta 1999).

All together, this combination of studies shows that eggshell powder enriched dairy-based supplements are able to prevent reduction in BMD in postmenopausal women or may even increase BMD of the femoral neck and Ward's triangle in particular.

\section{Effects on biochemical markers}

Biochemical markers of bone formation (P1NP) and bone resorption (D-Pyr) strongly decreased not only in the groups with the eggshell powder enriched 
Table 9.1. Percent changes $\pm \mathrm{SD}$ in biochemical markers of bone formation (P1NP, \%carOC), bone resoiption (D-Pyr) and vitamin $D$-status $[25(\mathrm{OH}) \mathrm{D}]$, atter 6 and 12 months of supplementation with the eggshell powder enriched supplement.

("p<0.05,"p<0.005," "ps0.001."1-2 missing values)

\begin{tabular}{|c|c|c|c|c|c|c|}
\hline & Duration (mo) & $n$ & PINP & Disyr & $25(\mathrm{OH}) \mathrm{D}$ & $\%$ caroc \\
\hline \multirow[t]{2}{*}{$M C L$} & 6 & 22 & $-23.2 \pm 19.7^{* * x}$ & $-20.7 \pm 21.2^{2 * x}$ & $66.3 \pm 48.9^{\text {***i }}$ & $17.6 \pm 20.4^{* x * x}$ \\
\hline & 12 & 22 & $-30.7 \pm 25.2^{* * *}$ & $-10.3 \pm 24.7$ & $9.7 \pm 38.7$ & $24.8 \pm 20.6^{* * * x}$ \\
\hline \multirow[t]{2}{*}{$A Z G$} & 6 & 24 & $-13.6 \pm 25.8^{* x}$ & $-22.7 \pm 23.0^{m+x+1}$ & $19.2 \pm 28.5^{* * *}$ & $9.2 \pm 9.0^{* * * *}$ \\
\hline & 12 & 24 & $-17.6 \pm 23.2^{k}$ & $-149 \pm 15.1^{*}$ & $25.1 \pm 29.8^{* t *}$ & $5.0 \pm 12.3$ \\
\hline \multirow[t]{2}{*}{$M C L+A Z G$} & 6 & $46^{1}$ & $-17.9 \pm 23.5^{\star * *}$ & $-21.8 \pm 22.1^{+* * * * *}$ & $34.0 \pm 36.0^{*-\pi * t}$ & $12.8 \pm 14.6^{\text {tmax }}$ \\
\hline & 12 & $46^{7}$ & $-23.5 \pm 24.4^{* *}$ & $-129 \pm 24.8^{* \cdot k}$ & $20.2 \pm 35.6^{* *}$ & $13.5 \pm 18.0^{* *}$ \\
\hline
\end{tabular}

supplement (Table 9.1), but also in the groups with the reference product (except for D-Pyr in the reference group of $A Z G$ ). These decreases suggest a decrease in bone turnover, or more precisely in collagen metabolism, which is supported by decreases in serum PTH. Although no correlations were found between the changes in BMD after 12 months and changes in biochemical markers after 6 and 12 months, a reduced bone turnover is indicative for an increase bone mineral content (Kanis 1999). Increases in \%carbOC support a proper mineralization and a possible inhibition of postmenopausal bone loss. Serum $25(\mathrm{OH}) \mathrm{D}$ responded to vitamin $\mathrm{D}$ intake.

Figure 9.3: Percent carboxylated osteocalcin ( $\pm \mathrm{SD}$ ) in postmenopausal women with normal (AZG) and low (MCL) BMD after supplementation with $K_{1}$ or placebo.

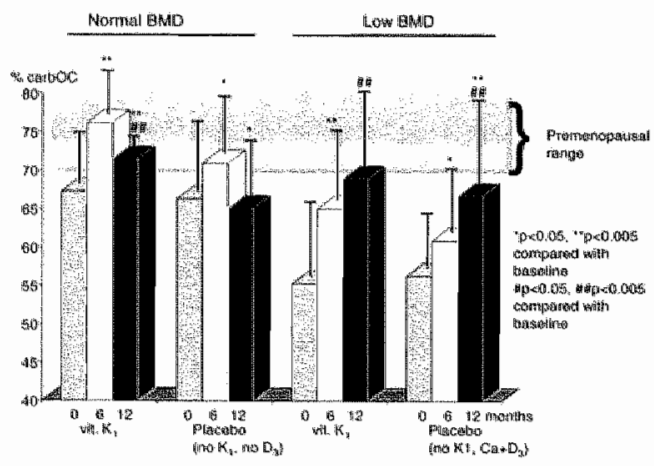

Based on the correlations found between baseline levels and magnitude of decrease after supplementation, for P1NP and D-Pyr, it seems that especially women with a high bone turnover benefit from supplementation. In the pillot study, only the standard biochemical parameters, total alkaline phosphatase in serum, and hydroxyproline and calcium in 24 hours urine collections, were studied. These parameters did not change during the study period.

\section{Response to vitamin $K$}

As discussed in detail in Chapter 8 , $\%$ carbOC levels seem to be lower in women with low BMD compared with women with normal BMD. This is in line with the findings of others (Jie 1996; Douglas 1995). Supplementation with $80 \mu \mathrm{g}$ vitamin $K_{n}$, resulted in significant improvements of \%carbOC-status in all women, as is shown in Figure 9.3. The figure also shows a possible influence of vitamin $\mathrm{D}$ and/or calcium in the carboxylation of osteocalcin since the women with low BMD who received placebo also showed a considerable increase in \%carboc.

Also in the women with normal BMD an effect of calcium cannot be excluded. In young adults, \%carbOC was found to be $70-80 \%$ of total osteocalcin (Douglas 1995 Jie 1996) and this level may be considered 
to be adequate for optimal bone mineralization. In our study, $93 \%$ of the women with low BMD and $59 \%$ of the women with normal BMD were below this range. This is unexpected since the normal dietary intake of vitamin $K_{1}$ in the Netherlands is estimated to be about $250 \mu \mathrm{g}$ per day (Schurgers 1999). This amount is almost four times higher than the US recommendation ( $65 \mu \mathrm{g}$ vitamin $\mathrm{K}$ ) for women 51 years and older (National Research Council. 1989). Because of its role in bone mineralization, and as recently suggested a possible protective role in the aging brain, it might be considered to set up a Dutch vitamin K-recommendation. Based on our results, and in line with the suggestion of Schurgers et al (1999) (375 $\mu \mathrm{g} /$ day), we propose at least $330 \mu \mathrm{g}$ of vitamin $K_{1}$ per day for women 50 years and older. It has to realized ${ }^{\prime}$ however, that this amount of vitamin $\mathrm{K}$ may interfere with anticoagulant therapy. Patients on this therapy benefit form vitamin $K$ intakes that are in line with the current US RDA. Therefore they also may face problems with the fluctuations in the ordinary diet (Booth and Centurelli 1999).

\section{Response to vitamin $D_{3}$}

Supplementation with 350-400 IU vitamin $D_{3}$ per day considerably increased $25(\mathrm{OH}) \mathrm{D}$ concentrations in women with low and normal BMD (Chapter 8). For women with low BMD, however, these amounts of vitamin $\mathrm{D}$ could not prevent a decrease in $25(\mathrm{OH}) \mathrm{D}$ concentration during winter months (Figure 9.4). For a maximum reduction of serum $\mathrm{PTH}$, at least $100 \mathrm{nmol} /$ I 25(OH)D seems to be necessary (Vieth 1999). It is not clear, however, which method provides the most reliable detection of the 25(OH)D concentration (Lips 1999). Therefore, prevention of $25(\mathrm{OH}) \mathrm{D}$ decline during the winter months might be the first objective of vitamin $D$ supplementation. Fine-tuning is possible when PTH course is studied and fluctuations in PTH concentration no longer respond to higher vitamin D-intakes. A recent survey (Dutch National Food Consumption Survey 1998) shows that Dutch women, 50 years and older, consume 130-140 IU vitamin D per day which is sufficient according to the current Dutch recommendation (Dutch Food Nutrition Council 1992). Our studies suggest, however, that the major part of healthy postmenopausal women may have suboptimal vitamin D-status $[<100 \mathrm{nmol}$ $25(\mathrm{OH}) \mathrm{D} / \mathrm{L}]$, based on the method with the highest outcome in $25(\mathrm{OH}) \mathrm{D}$ concentrations. These results suggest that in the standard 'Osteoporosis' of the Dutch College of General Practioners (Elders 1999) the passive attitude towards the use of additional vitamin $D$ in the prevention and treatment of osteoporosis should be revised. These results also plead in favor of a discussion about the restrictive Dutch legislation policy in the matter of supplementation of vitamin D to food. It is at least strange why vitamin $D$ is not allowed to be added to food products for postmenopausal women, whereas vitamin D containing supplements (tablets, capsules, etc) are widely available without limitation. For women with low BMD vitamin $D$ intakes higher than $400 \mathrm{IU}$ may be needed to prevent a $25(\mathrm{OH}) \mathrm{D}$ decline during winter. These findings fit favorably within the major outcome of a comprehensive review by Vieth (1999) concluding that the beneficial daily intake of vitamin $D$ for adults is more likely to be 800-1,000 IU than the new US Daily Reference Intake (Standing Committee on the Scientific Evaluation of Dietary Reference Intakes 1997) of 400 IU for adults 51 through 70 years. 


\section{Conchusions}

Chicken eggshell powder is a suitable source of calcium (and strontium) for human nutrition with a high percentage of elemental calcium and is a good alternative for the traditional purified calcium carbonate in calcium supplementation.

Supplements providing $3 \mathrm{~g}$ of chicken eggshell powder per day, 350-400 IU vitamin $D_{3}, 80 \mu \mathrm{g}$ vitamin $\mathrm{K}_{\mathrm{f}}$ and $350 \mathrm{mg}$ magnesium were able to prevent a decrease or even to cause an increase in BMD of spine and hip during one year supplementation. Based on literature this effect may last for several years and may reduce fracture incidence.

Although no direct associations were found with increments in BMD, the changes in the biochemical parameters P1NP, 25(OH)D, $\%$ carbOC, PTH and urinary D-Pyr indicate that they can be used to monitor group effects induced by supplementation. No conclusion can be drawn about the specific effect of supplementation of eggshell powder on BMD since the supplements also contained other components such as magnesium and the vitamins $\mathrm{D}_{3}$ and $\mathrm{K}_{1}$. However, in comparison with the purified calcium carbonate enriched supplement, the eggshell powder enriched supplement showed significant increases in BMD suggesting an extra effect.

The intakes of vitamin $\mathrm{D}_{3}$ and vitamin $\mathrm{K}_{1}$ were, based on serum 25(OH)D and $\%$ carboc, suboptimal in a major part of the studied postmenopausal women. It may be advised to increase the Dutch vitamin D recommendations for the age group 50 through 70 years to at least $400 \mathrm{lU}$. For women with low BMD, and possibly for elderly in general, even $400 \mathrm{IU}$ vitamin $\mathrm{D}_{3}$ per day may be insufficient to reach optimal levels of 25(OH)D. For these women, additional intakes of 700-800 iU may be advised. A vitamin $\mathrm{K}$ recommendation of at least $330 \mu \mathrm{g}$ per day may be
Figure 9.4. Percent changes in serum $25(\mathrm{OH}) \mathrm{D}$ concentrations $( \pm \mathrm{SD})$ in postmenopausal women with a normal and low BMD in the course of one year supplementation with a/o. vitamin D.

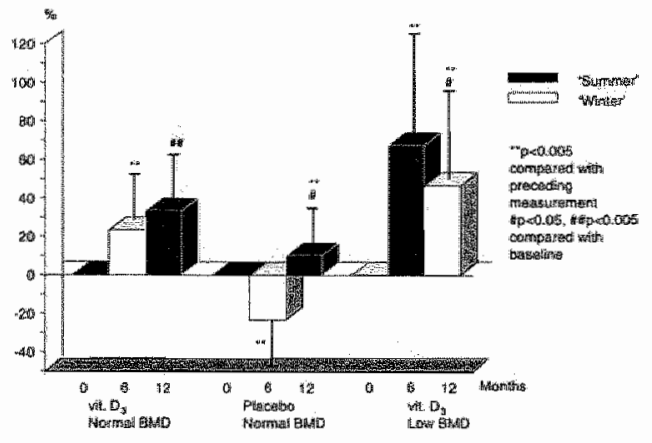

proposed; but a possible stimulatory effect of calcium and vitamin $D$ needs to be clarified.

\section{Relevance for public health}

Fractures undoubtedly imply decreased quality of life and high medical costs. Reduction in fracture incidence is therefore the aim of all strategies. One strategy could be a population-wide prevention of BMD loss (Kanis 1999). For optimal bone strength, preservation of bone microarchitecture is important (Silva and Gibson 1997), which urges an early postmenopausal intervention and stimulation of physical activity. Osteoporosis can be controlled via primary prevention (reducing risk in subjects with no evidence for the disease), secondary prevention (reducing progression in subjects with potentially reversible disease), and tertiary prevention (treatment of the established disease). Three wellknown preparations for this are calcium and vitamin D supplements, HRT and bisphosphonates. Calcium and vitamin $D$ supplements are used during primary and secondary prevention whereas they support other treatment strategies in tertiary prevention (European Community 1998). The observed decrease in fracture incidence is moderate $(\geq 10 \%)$, the 
ingredients are cheap, and no or minimum negative side effects are seen (Melton 1999). Beneficial side effects on blood pressure intestinal protection and muscle strength are suggested (Machlin 1991; Lapre 1993; Miller and Groziak 1997). Supplementation with calcium and vitamin $D$ has to be continued since the effect on bone mass may be lost two years after discontinuation of supplementation (Jonsson 1999). HRT is used in primary, secondary and tertiary prevention, whereas bisphosphonates are especially used during tertiary prevention. Both HRT and bisphosphonates, reduce fracture incidence considerably (25-50\%) but may cause some inconvenience (intake on an empty stomach for bisphosphonates and postmenopausal bleeding for HRT) which reduces compliance. Beneficial side effects of HRT treatment are possibly protective effects in relation to coronary artery disease and perhaps Alzheimer's disease (Eddy 1998). For the time being, HRT and bisphosphonates are restricted to high-risk groups or individuals (European Community 1998) and not meant to be used by the general population. All together, the best preventive strategy to start with for all postmenopausal women (and older men) seems to be via an early intervention with mineral and vitamin supplements, at least containing calcium and vitamin $D$, or preferably via enriched foods to achieve higher compliance. This is in line with recent discussions indicating higher optimal calcium and vitamin D intake (Vieth 1999; Devine 1997; DawsonHughes 1998). The Dutch Health Council is very restrictive and advises calcium and vitamin D intakes up to current Dutch recommendations, $800-1,000 \mathrm{mg}$ calcium for those older than 50 years and 100-200 IU vitamin $D$ for those aged 65 and over. These recommendations, however, date from 1989 and revised recommendations (expected in the year 2000) are possibly higher. Meanwhile, $15-20 \%$ of apparently healthy postmenopausal women have osteoporosis and another $30-50 \%$ have low BMD. Most of them will not be identified as women with an increased fracture risk. The outcome of this thesis suggests that eggshell powder enriched supplements or functional foods, also containing vitamin $D_{3}$, vitamin $K_{4}$ and magnesium, increase BMD and reduce bone turnover in postmenopausal women. These supplements or functional foods can therefore be used in primary, secondary and tertiary prevention of osteoporosis. Since the effect on BMD was not seen with purified calcium carbonate enriched supplements, final effects of eggshell powder enriched supplements on fracture incidence may exceed those suggested for calclum and vitamin D only. This needs, however, confirmatory research whereas additional research is necessary for finetuning and improvement of the functional food (see future research).

\section{Future research}

The studies described in this thesis stimulate ongoing research. At least the following subjects may be of interest:

- Based on the outcome of this thesis, a long-term, randomized and placebo controlled study (4 years) in healthy, late postmenopausal women with a normal calcium intake at baseline $(1,000 \mathrm{mg}$ per day) is warranted. The aim would be to study the effects of $a$ dairy-related functional food, supplying $2.3 \mathrm{~g}$ of eggshell powder, $700 \mathrm{lt}$ of vitamin $D_{3}$, and an as yet to be decided amount of vitamin $\mathrm{K}_{1}$, and $250 \mathrm{mg}$ of magnesium, on BMD of the lumbar spine and hip. Compared with the supplement described in this thesis, some compositional changes have been made. A lower amount of eggshell powder is suggested in order not to exceed the tolerable upper intake level for calcium $(2,500)$ in most $(>90 \%)$ Dutch postmenopausal women. The 
lower amount of magnesium has shown to be effective in postmenopausal women whereas in first instance it was based on the US RDA (1989) for males. The amount of vitamin $D_{3}$ has increased to 70010 . Since this amount of vitamin $\mathrm{D}_{3}$ is not common practise in functional foods, it needs special attention as describe in sub-study 1 . For vitamin $K_{1}$ it seems advisable to study (see sub-study 2) a step-wise increasing amount because avallable information is insufficient to set an optimal amount. Furthermore, information is necessary about the roles of calcium and vitamin $D$ in osteocalcin carboxylation.

BMD should be measured (when possible in duplicate) once per year starting one year before supplementation, preferentially in the same hospital and without change in equipment. Biochemical markers (P1NP, D-Pyr, 25(OH)D, \%carbOC, and PTH) may be studied every 6 months with possibility to detect seasonal influences. Habitual intake of calcium, magnesium, vitamin $\mathrm{D}$ and vitamin $\mathrm{K}_{1}$ should be monitored by food frequency questionnaire at least 2 times per year.

\section{Sub-study 1. Although others support} daily supplementation with 700 IU of vitamin D3 in postmenopausal women, and although the amount is far below the tolerable upper intake level, additional research is warranted. During the long term study as described above the following effects should be monitored: seasonal changes in serum $25(\mathrm{OH}) \mathrm{D}$, the maximum $25(\mathrm{OH}) \mathrm{D}$ concentrations achieved, vitamin $D$ storage in adipose tissue, and effects on serum calcium and serum phosphate. Unacceptable changes in one or more of these parameters are reason to adapt the amount of vitamin $D$ in the functional food.
Sub-study 2. Although in our studies vitamin $\mathrm{K}_{1}$ supplementation probably increased \%carbOC to premenopausal levels we do not know whether this is an optimum effect: During the long term study as described above, the additional amount of vitamin $\mathrm{K}$, could be $80 \mu \mathrm{g}$ per day during the first year, and $160 \mu \mathrm{g}$ per day during the second year. Those escialations continue until a steady-state of \%carbOC is reached. The results of this vitamin $K_{1}$ escalation study, in combination with the habitual vitamin $K_{1}$ intakes, can serve as a guideline for optimal vitamin $K_{f}$.

- Literature suggests that extracts from soya and tea may be of interest for further improvement of the above mentioned dairy-related functional food. More evidence is, however, necessary. Soya is a rich source of isoflavones that seem to mimic the effects of oestrogen in oestrogen depleted women without showing the negative side effects. Tea is a rich source of fluorine that is known to have anabolic effects on bone. It would be of interest to study the combined effect of the eggshell powder enriched functional food, soja extract and tea extract on BMD in late and early postmenopausal women.

As already described in Chapter 2 of this thesis, strontium may have an anabolic effect on bone as suggested by studies supplying $170 \mathrm{mg} /$ day. In theory, a chronic supply of much lower amounts may have long term benefits. When more information will come available about the effects of strontium on bone, and the mechanism behind it, strontium levels in chicken eggshell powder can be adapted via chicken feed and environment without disturbing the physiological function of the eggshell. By applying such an adapted eggshell powder, the functional food can be further improved. 


\section{References}

Abraham. G. A. (1991) The importance of maignesium in the management of primary postmenopausal osteoporosis. J Nultr Med 2:165-178.

Aberts, B., Bray, D., Lewis, J, Ratff, M. Roberts, K. \& Watson, J. D. (1994) Molecular biology of the Cell. Ed.3rd, pp. 1-1294. Garland Publishing. Ino. New York

Allolio, B. (1999) Risk factors for hip fracture not related to bone mass and their therapeutic implications. Osteoporosis Int 9: $s 9-\mathrm{s} 16$.

Aloia, J. F., Vaswani, A, Yeh, d. K., Ross, $P_{n} L_{n}$, Flaster, E. \& Dilmanian, A. (1994) Calcium supplementation with and without hormone replacement therapy to prevent postmenopausal bone loss. Ann Internal Med 120:97103.

Aloia, J. F, Vaswant, A., Yeh, J. K. \& Russo, L. (1996) Differential effects of dietary calcium augrnentation and hormone replacement therapy on bone turnover and serum levels of callitrophic hormones. Osteoporosis Int 6: 5562.

Anderson, J. J. B. \& Garner, S. C. (1997) The effects of phytoestrogens on bone. Nutrition Research 17: 1617-1632:

Anderson, R. R. (1992) Comparison of trace elements in milk of four species. 4 Dairy Scl 75 : 3050-3055.

Angus, R.M., Sambrook, P.N., Pockock, N.A., Eisman, J.A. (1988) Dietary intake and bone mineral density. Mone Miner 4; 265-277.

Anon (1992) Maximizing peak bone mass: calcium supplementation increases bone mineral density in children. Nutr Rev 50: 335-337.

Atteh, J. O.\& Leenson. S. (1983) Influence of increasing dietary calcium and magnesium levels on performance, mineral metabolism, and egg mineral content of laying hens. Poultry Sci 62: 1261-1268.

Aurbach, G. D. (1988) Calcium-regulating hormones: parathyroid hormone and callcitonim. In: Calcium in Human Biology (Nordin, B. E. C. ed.), pp. 43-68. Springer-Verlag, BerlinHeidelberg.

Ausman, L. M. (1999) Criteria and recommendations for vitamin $C$ intake. Nutr Rev 57: 222-224.

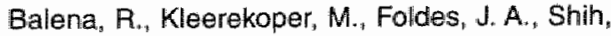
M.-S., Sudhaker Rao, D., Schober, H. C. \& Parfitt, A. M. (1998) Effects of different regiments of sodium fluaride treatment for osteoporosis on the structure, remodeling and mineralization of bone. Osteoporosis Int 8 . 428 435 .

Ballard, P. A., Purdie, D. W. Langton, C. M., Steel, S. A. \& Mussurakis, S. (1998) Prevalence of osteoporosis and related risk factors in UK women in the seventh decade: osteoportosis case finding by clinical referral criteria or predictive model? Osteoporosis int 8: $535-539$.

Barger-Lux, M. J. \& Heaney, R. P. (1994) The role of calcium intake in preventing bone fragillty, hypertension, and certain cancers. Jil Nutr 1,24 : $1406 \mathrm{~s}-1411 \mathrm{~s}$.

Baron, R. (1993) Anatomy of ultrastructure of bone. In: Primer on the Metabolic Bone Diseases and Disorders of Mineral Metabolism (Favus, M. J. ed.). pp. 3-9. Raven Press Nlew York.

Barret-Connor, $E_{n}$, Gore, R.,Browner, W. S. \& Cummings, S. R. (1998) Prevention of osteoporatic hip fracture: global versus highrisk stralteglies. Osteoporosis Int $8: \$ 2-\$ 7$.

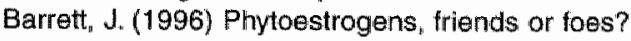
Environm Health Perspectives 104: 478-482.

Baud, C. A., Bang, S. \& Very, J. M. (1977) Minor elements in bone mineral and their effects on its solubility. J Biol Buccialle 5: 195-202.

Beardsworth, C. J., Eyre, D. R. \& Dickson, J. F. (1990) Changes with age in the urinary excretion of |ysyl- and hydroxylysyl pyridinolime two new markers of bone collagen turnover. J Bone Min Fies 5: 671-676.

Beattie, J. H. \& Peace, H. S. (1993) The influence of a low-broron diet and boron supplementation on bone, major mineral and sex steroid metabolism in postmenopausal women. $\mathrm{Br} \mathrm{J}$ Nutr 69: 871-884.

Berard, A., Bravo, G. \& Gauthier, P. (1997) Meta analysis of the effectiveness of physical acitvity for the prevention of bone loss in postmenopausal women. Osteoporosis Int 7:331-337.

Biego, G. H., Joyeux, M., Hartemann, P. \& Debry. G. (1998) Daily intake of essential minerals and metallic micropollutants from foods in France. Scl Total Environ 217: 27-36.

Bikle, D. D. (1994) Role of vitamin D, its metabolites, and analogs in the management of osteoporosis. Osteoporosis 20:759.775.

Bingham, S. A., Atkinson, C., Liggins, لd. Bluck, L. \& Coward, A. (1998) Phyto-日strogens: where are we now? Brít J Nutr $79: 393-406$.

Binkley, N. C. \& Suttie, J. W. (1995) Witamin K nutrition and osleoporosis. $J$ Nutr 125 : 1812 1821.

Biomin a.s. (1995) Pharmaceutical compositions 
on ags shell basis and heir preparation and use. Prtent EP 0347899 B $1-7$.

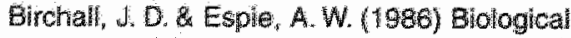
mplications of the intraction (ve silanol groups) of silicon whith metal hons. Conterence Procedings. Chba Foundation Sympostum 121. Whey Chichester 140-159.

Blakely. R. L. (1989) Bone strontum in pregnant and lactating females from archaeological samples. Am I Phys Anthrpol 80: 173-185.

Boivin, G., Delptre, P. Perrat, B. Panczer, G. Boudewle, $W_{*}$, Mauras, $Y_{r}$ Altain, $P$, Tsouderos, Y. Meuner, P. J (1996) Strontum distribution and interaction with bone mineral in monkey liac bone atter strontum sali (S12911) admintstration. Bane Miner Res $11: 1302$ 1311.

Booth. S. L. (1997) Skeletal functions of vitamin Kdependent proteins: not just for clotting anymore. Nutr Rev 55: 282-284.

Booth, S. L. OBrien-Morse, M. E. Dallal, G. E. Davidson. K. W. \& Gundberg, C. M. (1999) Response of witamin $K$ status to different intakes and sources of phylloquinone-rich foods: comparison of younger and older aduls. Ain J Clin Nutt 70: 368-377.

Booth, S. L. (2000) Wartarin use and fracture risk. Nutr Rev 58: 20-22.

Booth, S. L. C Centurelli. A. A. (1999) Vitamin K. a practical guide to the dietary management of patients on Wartarin. Nutt Rev $57: 288-296$.

Booth, S. L. \& Suttie, J.W. (1998) Dletary intake and adequacy of vitamin K. J Nutr 128:785. 788

Boskey, A. L. (1988) Calcifled tissues: chemistry and biochemistry. In: Calcium in Human Biology (Nordin, B. E. C. ed.), pp. $172-186$. Springer-Verlag, Berlin-Heldelberg.

Boskey, A. L., Gadewlata, S., Gundberg, C., Doty, S. B., Ducy, P. Karsenty, G. (1998) Fourier transform infrared microspectroscopic analysis of bones of osteocalcin-deficient mice provides insight into the function of osteocalcin. Bone 23: $187-196$.

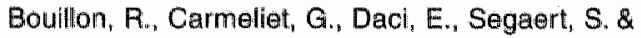
Vorstuyl, A. (1998) Vittamin D metabolism and action. Osteoporosis int 8: $\$ 13-519$.

Bölönyi, F. \& Orsós, S. (1954) Examen de leffet antirachitique die la coquille doeuf sur les dents des rats. Acta Morphologica Academiae Scientiarum Hungarcae 4: 45-49.

Breslau, N. A. (1994) Calcium, estrogen, and progestin in the treatment of osteoporosis. Osteoporosis 20: 691-716.

Brink, E. J., Dekker, P. R. Van Beresteyn, E. C. H. \& Beynem, A. C. (1992) Bioavailability of magnesitum and calcium from cow's milk and soyabean beverage in rats. $\mathrm{Br} J$ Nutr 68: 274-282.
Bronner, F: (1988) Gastrointestinal absorption of calcium. In: Calcium in Human Biology Nordin; B. E. C. ed. . pp. 93-123. Springer-Verlag. London.

Bronmer, F. (1994) Calcium and osteoporosis. Am J Chin Wut 60:831-836.

Bronner, F \& Pansu, D (1999) Wutritional aspecis of calcium absorption i Nut 129:9-12:

Bulstra, S, (1997) Niet hardlopen a.u,b. Nat Techn $65: 64-72$

Burger, E. H. Kein-Nulend, J., Van der Plas, A. \& Naweide, P. . (1995) Function of osteocytes in bone: their role in mechanotransduction. J Nutr 125: 2020s-2023s.

Cabrera, C. D. Henriquez, M. S., Traba, M. L. Vilataña, E. A. \& De La Pledra, C. (1998) Biochemical matkers of bone formation in the study of pastmenopausal osteoporosis Osteoporosis Int 8: $147-151$.

Cabrera, W. E., Schrooten, 4, De Broe, M. E. \& D'Haese, P.C. (1999) Strontium and bone. $\mathrm{s}$ Bone Min Res 14: 661-668.

Calvo, M. S., Eyre, D. R. \& Gundberg, C. M. (1996) Molecular basis and chinical application of biological markers of bone turnover. Endocr Rev 17: 333-368

Canalis, E. Hott, M., Deloffre, P., Tsouderos, Y. \& Marie, P. J (1996) The divalent strontium salt S12911 enhances bone cell replication and bone formation in vitro. Bone 18:517-523

Cao, J., Bai, X., Zhao, Y., Liu, H., Zhou, D. Fang, S. Jia, M. \& Wu, J. (1996) Fluorosis induced by drinking brick tea. Fluoride 29: 139-143.

Carlisle, E. M. (1986) Silicon as an essential trace element in animal nutrition. Conference Proceedings. Ciba Foundation Symposium 121. Wiley Chichester: 123-139.

Carnielli, V. P., Luijendijk, I. H. T., Beek van, R. H. T.

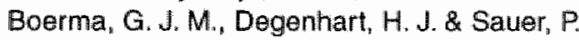
J. J. (1995) Effect of dietary Iriacylglycerol fatty acid positional distribution on plasma lipid classes and theil fatty acid composition in preterm intants. Am J Clin Nutr 62: 776-781.

Carpenter, T. O. Mackowiak, S. J., Troiano, N. \& Gundberg. C. M. (1992) Osteocalcin and its message: relationship to bone histology in magnesium-deprived rats. Am Physiolog Soc E107-E114.

Cassidy, A., Bingham, S. \& Setchell, K. D. R. (1994) Biological effects of a diet of soy proten rich in isoflavones on the menstrual cycle of premenopausal women. Am J Clin Nutr 60: $333-340$.

Caverzasio, J., Palmer, G. \& Bonjour, J.-P. (1998) Fluoride, mode of action. Bone 22: 585-589.

Chapuy, M.. C., Monique, E... A., Duboeuf, F., Brun, J., Crouzet, B., Arnouid, S., Dellmas, P. D. \& Meunier, P. J. (1992) Vitamin D3 and calcium to 
prevent thip fractures in elderly women. N Engl J Med 327: 1637-1642.

Chapuy, M. C. Preziosi, P. Maamer, M., Arnoud, S. Galan, P., Hercberg, S. \& Meunier, P. J. (1997) Prevalence of vitamin $D$ insufficiency in an adult normal population. Osteoporosis unt 7 : $439-443$.

Chen, J.T., Shiraki, M., Hasumi, K., Tanaka, N., Katase, K., Kato, T., Hirai, Y., Nakamura, T. \& Ogata, E. (1997) 1- $\alpha$-Hydroxyvitamin D3 treatment decreases bone turnover andi modu* lates calcium-regulating hormones in early postmenopausal women. Bone 20: 557-562.

Chen, T. C., Turner, A. K. \& Holick, M. F. (1990) Methods for the determination of circulating concentration of 25-hydroxyvitamin D. J Nutr Biochem 1: 315-319.

Cheng, X. G. Lowet "G., Boonen, S., Nicholson, P. H. F., Brys, P. Nijs, J. \& Dequeker, J. (1997) Assessment of the strength of proximal femur in vitro: relationship to femoral bone mineral density and femoral geometry. Bone 20: 213218.

Chevalley, T., Rizzoli, R., Nydegger, $W_{\text {. Slosman, }}$ D., Rapin, C..$H_{\text {, }}$ Michel, J.-P., Vasey, H. \& Bonjour, J.-P. (1994) Effects of calcium supplements on femoral bone mineral density and vertebral fracture rate in vitamin $D$ replete elderly patients. Osteoporosis int 4: 245-252.

Christoffersen, J., Christoffersen, M. R., Kolthoff, N. \& Bäreninoldt, O. (1997) Effects of strontium lons on growth and dissolution of hydroxyapatite and on bone mineral detection. Bone 20: 47-54.

Compston, J. E. (1995) The role of witamin D and calcium supplementation in the prevention of osteoporotic fractures in the elderly. Clin Endocrinol 43: 393-405.

Cooper, C. \& Aihie, A. (1994) Osteoporosis: recent advances in pathogenesis and treatment Ouarterly J Med 87: 203-209.

Cortivo, R., Castellani, I., Martelli, M., Michelotto, G. \& Abatangelo, G. (1982) Chemical characterization of the hen eggshell matrix: isolation of an akali-resistant peptide. J Chrom 237: $127-135$.

Crawford, M. \& Marsh, D. (1989) The Driving Force. Food, evolution and the future, pp. 1-298. Harper \& Row "Publishers. New York.

Cuijpers, S. (1997) Archeologie met de microscoop. Nat Tech 65: 22-29.

Cummings, S. R., Black, D. M. Nevitt, M. C.. Browner, W. Cauley, J. A., Ensrud, K., Genant, H. K., Palermo, L., Scott, $\downarrow$. \& Voigt, T. M. (1993) Bone densily at various sites for prediction of hip fractures. The Study of Osteoporotic Fractures Riesearch Group. Lancet 341: 72-75.
Dambacher, M. A. \& Schacht, E. (1996) Osteoporosis and active vitamin D metabolites, pp. 3-104. EULAR Publishers, Basle.

Dawson-Hughes, B, Dallal, G. E. Krall, E. A. Sadowski, L. Sahyoun, N. Tannenbaum, $S$. (1990) A controlled trial of the effect of calcium supplementation on bone density in postmenopausal women. N Engl J Med 323: 878-883.

Dawson-Hughes, 1 ., Harris, S. S. Krall, E. A Dallal, G. E., Falconer, G. Green, C. (1995) Rates of bone loss in postmenopausal women randomly assigned to one of two dosages of vitamin D. Am J Clin Nutr 61: 1140-1145.

Dawson-Hughes, B. (1996) The role of calcium in the treatment of osteoporosis. In: Osteoporosis (Marcus, R., Feldman, D. \& Kelsey, J. eds.), pp. 1159-1168. Academic Press, San Diego.

Dawson-Hughes, B., Harris, S. S. Krall, E. A. \& Dallal, G. E. (1997) Effect of calcium and vitamin D supplementation on bone density in men and women 65 years of age or older. $N$ Engl J Med 337: 670-676.

Dawson-Hughes, B. (1998) Vitamin D and calcium: reconmended intake for bone health. Osteoporosis Int 8: $\$ 30-534$.

Deftos, L. J. (1993) Calcitonin. In: Primer an the Metabolic Bone Diseases and Disorders of Mineral Metabolism (Favus, M. J. ed.), pp. 7076. Raven Press, New York.

Deimas, P. D. (1991) What do we know about biochemical bone markers? Clin Obst Gynaecol 5: 817-830.

Delmas, P. D. (1997) Hormone replacement therapy in the prevention and treatment of osteoporosis. Osteoporosis Int 7: 53-s7.

Delmas, P. D. \& Garnero, P. (1996) Utility of biochemical markers of bone turnover in osteoporosis. In: Osteoporosis (Marcus, R., Feldman, D. \& Kelsey, J. eds.), pp. 1075-1088. Academic Press inc. San Diego.

DeLuca, H. F. \& Zierold, C. (1998) Mechanisms and functions of vitamin D. Nutr Rev 56: s4-s10.

Dempster, D. W. L Lindsay, R. (1993) Pathogenesis of osteoporosis. Lancet 341: 797-801.

Devine, A. Criddle, R. A. Dick, I. M. Kerr, D. A. \& Prince, R. L. (1995) A longitudinal study of the effect of soditum and calcium intakes on regional bone density in postmenopausal women. Am a Clin Nutr 62: 740-745.

Devine, A., Dick, I, M., Heal, S. J., Criddle, R. A. \& Frince, R. L. (1997) A 4-year follow-up study of the effects of calcium supplementation on bone density in elderly postmenopausal women. Osteoporosis Int 7: $23 \cdot 28$

Devogelear, J. F., Broll, H., Correa-Rolter, R., Cumming, D. C., Nagant de Deuxchailsnes, $C$.. Geusens, P. Hosking, D. \& Jaeger, P. (1996) 


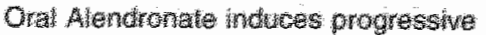
increases in bone hass of the spine, hip and tolal bouly over 3 wears in postmenopausat women whth osteoporosis. Bone 18:141-150.

Dotkum wan, W (1985) Sale dady inteke by a 70 $\mathrm{kg}$ weighing adut. Addftieven en contarninanten. In: Nutrition in Practise Woeding in de Praktikn Wows, R. Claesen. H. Hemus, R. 2 , Kromenberg, C, Go, Van

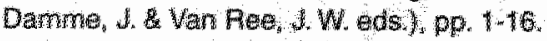
Bohn Scheltema \& Holkema, Utrecht.

Dougles, A. S. Fobins, S. P, Hutchison, D. Porter, F. W. Stewant, A. a Red, D.W. (1995) Carboxylation of asteocatcin in postmenopausal osteoporotic women lothowing vitamin $K$ and $D$ supplenentation.

Bone 17: $15-20$.

Driessens, F. C. M. (1993) Magnesum en verkaking. Nat ${ }^{\prime}$ Techn $61: 324-335$.

Driessens, F. C.M. Verbeeck, A. M. H. (1988) On the prevention and reatment of catcification disorders of otd age. Med Hyp 25: 134-137.

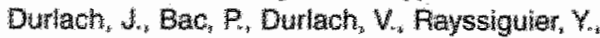
Bara, M. G Gulet-Bara. A. (1997) Magnesium status and ageing: an update. Magnes Res $25-42$.

Dutch Food Mutrition Counch. (1992) Dutch Recommendations, Ed.2nd, pp. 1-293. Voorm hichtingsbuteau woor de Voeding, Den Haag.

Dutch National Food Consumption Survey (1998) Zo eat Nedertand. Resultaten van de Voedselconsumptiepeiling $1997-1998,0.199$ Van Marken Defll Drukkers, Deft.

Dutch Standardization institute (1884)

Determination of calchum, potassium, magnesium, sodum, iron and zinc. Report NEN 3349. Dutch Standardizatioin Institute, Filjswijk

Duursma, S. A., Glerum, J. H. Raymakers, Jl. A. \& Van Dijk، A. (1986) Fluoride bij de behandeling van patienten met osteoporose. Ned Tijdschr Genesskd 130: 1467-1471.

Eastwood, M. (1997) Principles of Human Nutrition, pp. 1-565. Chapman \& Hall, London.

Eaton, S. B., Eaton III. S. B. Konner, M. J. \& Shostalk. M. (1996) An evolutionary perspective enhances understanding of human nutritional requirements. J Nutr 126: 1732-1740.

Eaton, S. B., Eaton III, S. B. \& Konner M. J. (1997) Paleolithic nutrition revisited: a twelve-year retrospective on its nature and implications. Eur J Clin Nutr 51: 207-216.

Eaton-Evans, J. (1994) Osteoporosis and the role of diet. Br J Biamed Sci 51: 358-370.

Eddy, D. M., Johnston, C. C., Cummings, S. R., Dawson-Hughes, B. Lindsay, R., Melton, L. J. \& Slemenda, G.W. (1998) Osteoporosis: review of the evidence for prevention, diagnosis, and

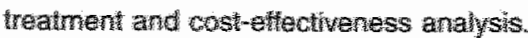
Osteoporosis In 8 : s.

Einhorn, T. A. (1996) The bone organ system. Osteoporosis Marcus, A. Feldman, D. B. Kolsey, d. ads. . po. 322. Academic Press, San Diego.

Elders, P. Keimpena van, J. C. Petri, H. Matser,

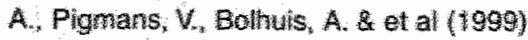
NHG-standard Osteoponose. Husarts Wet 42: $115-128$.

Elders, P J M, Lips, $P_{x}$ Netelenbos, J. $C_{*}$ Van Cinkel, F. C. Khoe, E, Van der Vigh, W. J.F. \& Van der Steht P. F. (1994) Long-tern effect of calcinn supplementation on bone loss in permenopausal women. I Bone Min Res 9 : $963-970$.

Etringer, B, Genant, H. K. Cann, C. E. (1987) Postmenopausal bone hoss is prevented by treatment with low-dosage estrogen with calcium. Ann he hed 108: 40-45.

European Community (1998) Beport on Osteoporosis in the European Community Action tor prevention. European Communites. Brussets: 3-112.

Faine, M. R. (1995) Dietary factors related to preservation of oral and skeletal bone mass in women. J Prosthet Dent 73: 65-72.

Fallon, M. D. (1994) Morphotogy and dynamics of bone: nutititional interactions. In: Modern Nutrition in Heath and Disease (Shils, M. E Olson, A. A \& Stike, M eds), pp, 883-908. Lea \& Febiger, Phtadelohia.

Favus, M. U. (1993) Primer on the Metabolic Bone Diseases and Disorders of Minerat Metabolism, Ed.2nd, pp 4-441. Raven Press New York.

Forland, G. (1998) The vitamin K-dependent proteins: an update. Nutr Rev 56: 223-230

Ferment O. \& Touitou, Y. (1988) Regulation hormonale et interrelations metabolique du magnesium. La Presse Medicale 17: 584-587.

Ferrari, S. L., Rizzoli, R., Slosman, D. O. \& Bonjour, J.-P. (1998) Do dietary calcium and age explain the controvery surrounding the relationship between bone mineral density and vitamin $D$ receptor gene polymorphisms? J Bone Miner Res 13: 363-370.

Feskanich, D., Willett, W. C., Stampfer, M. J.\& Colditz, G. A. (1997) Milk, dietary calcium, and bone fractures in women: a 12-year prospective study. Am J Public Health 87: 992-997.

Feskanich, D., Weber, P., Willett, W. C., Rockett, H., Booth, S. L. \& Colditz, G. A. (1999) Vitamin K intake and hip fractures in women: a prospective study. Am J Clin Nutr 69: 74-79.

Finkelstein, J. S., Klibanski, A., Schaefer, E. H., Hornstein, M. D., Schiff, I. \& Neer, R. M. (1994) Parathyroid hormone for the prevention of bane 
lass induced by estrogen deficiency. W Engl a Med 331: 1618-1623.

FitzGerald, R. J. (1998) Potential uses of caseinophosphopeptides. Int Dairy J 8: $451-457$.

Fleet, J. C. (1999) Vitamin D receptors: not just in the nucleus anymore. Nutr Rev 57:60-64.

Fleisch. H. (1996) Osteoporosis 1996, pp. 3-407. Elsevier Science B.V. Amsterdam.

Florou, $H_{\text {, }}$ Savidou, A. \& Chaioulou, C. (1996) Strontum-90 activity in monthly milk samples from Greece. \Dairy Sci 79: 1679-1682.

Flynn, A. (1992) Minerals and trace elements in millk. Adv Food Nultr Res 36: "209-252.

Franceschi, R. T., Wilson, J. X. \& Dixon, S. J. (1995) Requirement for $\mathrm{Na}+$-dependent ascorbic acid Iransport in osteoblast function. Am Physiol Soc $01430-\mathrm{C} 4339$

Franceschi, R. T. \& Lyer, B. S. (1992) Relationship between collagen synthesis and expression of the osteoblast phenotype in MCT3T3-E1 cells. $J$ Bone Min Res 7: 235-246.

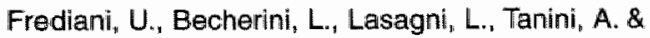
Brandi "M. L. (1996) Catecholamines modulate growth and differentiation of human preosteoclastic cells. Osteoporosis Int 6: 1421.

Fresen, J. A., Cox, F. H. \& Witter, M. J. (1968) The determination of fluoride in biological materials by means of gas chromatography. Pharm Weekblad 103: 909-914.

Freudenheim, J.L. "Johnson, N.E., Smith, E.L. (1986) Relationship between usual nutrient intake and bone-mineral content of women 35-65 years of age: Longitudinal and crosssectional analysis. Am J Clin Nutr 44: 863-876.

Frost, H. M. (1997) Obesity, and bone strength and mass: a tutorial based on insights from a new paradigm. Bone 21: 211-214.

Frost, H. M. (1999) Changing views about 'Osteoporoses' (a 1998 overview).

Osteoporosis Int 10:345-352.

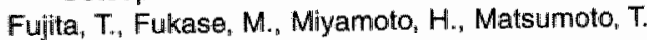
\& Ohue, T. (1990) lncrease of bone mineral density by calcium supplement with oyster shell electrolysate. Bone and Mineral 11:8591.

Garnero, P. Darte, C. \& Delmas, P. D. (1999) A model to monitor the efficacy of alendronate treatment in women with osteoporosis using a biochemical marker of bone turnover. Bone 24 603-609.

Gattei, V., Bernabei, P A. Pinto, A. Bezzini, R." Ringressi, A. Formigli, L., Tanini, A., Attadia, V. 8. Brandi, M. L. (1992) Phorboll ester induced osteoclast-like differentiation of a novell human leukemic cell line (FLG 29.1). J Cell Biol 116: $437-447$

Genant, H. K., Block, J. E., Steiger, P., Gllueer, C.
C. Ettinger, B. Hartis, S. T. (1989)

Appropriate use of bone densitometry. Radiology 170:817-822.

Ghosh, S, Tahuker, G. Sharma, A. (1990) Clastogenic activity of strontium chioride on bone marrow cells in vivo. Biol Tr Elam Res 25: 51.56

Gimbie, J. M. Robinson, C. E. Wu, X. \& Kelly, K. A. (1996) The function of adipocytes in the bone marrow stroma: an update, Bone $19: 421-428$.

Ginty, F, Flynn, A. \& Cashmen, K. D. (1998) The effect of dietary sodium intake on biochemica markers of bone metabolism in young women Br J Nutr 79: $343-350$.

Gomez, S., Rizzo, R., Pozzl-Mucelli, M., Bonucci, E. \& Vittur, F. (1999) Zinc mapping in bone tissues by histochemistry and synchotron radiation-induced $\mathrm{X}$-ray emission: correlation with the distribution of alkaline phosphatase. Bone 25: 33-38.

Grainger, D. U., Percival, J., Chilano, M. \& Spector, T. D. (1999) The role of serum TGF-beta isoforms as potential markers of osteoporosis. Osteoporosis Int 9: 398-404.

Greger, J. L. (1981) Effect of dietery calcium and phosphorus levels on the utilization of calcium. phosphorus, magnesium, manganese and selenium by adulit male. Nutr Res 1: 315-325.

Greger, J. L., Krzykowski, C. E., Khazen, R. R. \& Krashoc, C. L. (1987) Mineral utilisation by rats fed various commercially available calcium supplements or milk. J Nutr 117: 717-724,

Groot, C. G. \& Vermeer, C. (1988) Osteocalcine, signaaleiwit voor botziekten. Nat \& Techn 56 : 326-335.

Grympas, M. D. (1993) Age and disease-related changes in the mineral of bone. Calcif Tissue Int $53: s 57-s 64$.

Gryripas, M. D. Hamilon, E., Cheung, $\mathrm{A}$. Tsouderos, Y., Deloffre, P., Hott, M. \& Marlo, P. J. (1996) Strontium Increases vortebral bone volume in rats at a low dase that does not induce detectable mineralization defect. Bone 18: $253-259$.

Grympas, M. D. \& Marie, P. J. (1990) Elfects of low doses of strontium on bone quality and quantity in rats. Bone $11: 313-319$.

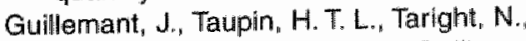
Allemandou, A., Peres, G. \& Guillemant, $S$ (1999) Vitamin D status during puberty in French healthy male adolescents. Osteoporosis Int 10: 222-225.

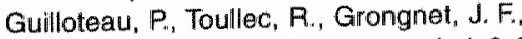

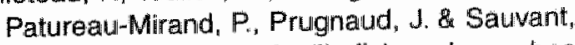
D. (1986) Digestion of milk, fish and soya-bean protein in the preruminant calf flow of digesta. apparent digestibility at the end of the lleum and amino acid composition of lleal digesta. $\mathrm{Br}$ 
Jutr 55: $571-592$

Hall, 3 . L. Grendale, G. A. (1998) The relation of dietary vitamin $\mathrm{C}$ intake to bone mineral density: results from the PEPI study. Calcif Tisave Int 63: $183-189$.

Hansen, C., Werner, E. Erbes, H.-J., Larrat, W. E Kaltwasser, J. P. (1996) Intestnal calclum äbsorption from difterent calctum preparations: influence of anion and solubillty Osteoporosis Int 6.: $386-393$.

Hansson, T. \& Rods, $\bar{B}$. (1987) The effect of fluoride and calcium on spinal bone mineral content: a controlled, prospective ( 3 years) study. Calcif Tissue Int 40: $315-317$.

Harris, S. S. \& Dawson-Hughes, B. (1998) Seasonal changes in plasma $25-$ hydroxyvitamin $D$ concentrations of young American black and white women. Am J Clin Nutr 67: $1232-1236$.

Hasling, $C_{\text {. }}$, Sondergaard, $K_{\text {., }}$ Charles, P. \& Mosekillde, L. (1992) Calcium metabolism in postmenopausal osteoporotic wornen is determined by dietary calcium and coffee intake. J Nutr 122: 1119-1126.

Heaney, R. P. (1987) The role of calcium in prevention and treatment of osteoporosis. Phys Sports Med 15: 83-88.

Heaney, R. P. (1993) Thinking straight about calciumin. N Enğl J Med 328: 503-505.

Heaney, R. P. (1996a) Bone mass, nutrition, and other lifestyle factors. Nutr Rev 54: s3-s10.

Heaney, R. P. (1996b) Nutrition and risk for osteoporosis. In: Osteoporosis (Marcus, R., Feldman, D. Kelsey, J. eds.), pp. 483-509. Academic Press, San Diego.

Heaney, A. P., Dowell, M. S. \& Barger-Lux, M. J. (1899) Absorption of calcium as the carbonate and citrate salts, with some observations on method. Osteoporosis int 9: 19-23.

Heininhemo, R. \$., Inkovalara, J. A., Hariu, E.J., Haavisto, M. V., Kaarota, R. H. Kataje, J. M., Kokko, A. ML. Koho, L. A. \& Rajala, S. A. (1992) Annual injection of vitamin D and fractures of aged bones. Calcit Tissue int 51 : $105=110$.

Hincke, M. T., Bernard, A. Lee, E. R., Tsang, C. P. W. Narbaitz, R. (1992) Soluble protein constituents of the domestic Fowis eggshell. Bit Poultry Sci 33: 505-516.

Hodgskinson, R. Wjeh, C. F., Currey, J. D. \& Langton, C.M. (1997) The ability of uttrasound velocity to predict the stiffnes of cancellous bone in vitro. Bone 21: 183.190.

Holbrook, T. L., Barret-Connor, E. \& Wingard, D. L. (1988) Dietary calcium and risk of hip fracture: 14-year prospective population study. Lancet 1046-1049.

Holick, M. F. (1998) Vitamin D requirements for humans of all ages: new increased requirements for women and men 50 years and older. Osteoporosis Ini 8: \$24-829.

Hollis, B. W, Kamerud, d. Q, Selvaag, S.R., Lorenz, J. D. \& Napoli, U.. L. (1993)

Determination of vitamin $\mathrm{D}$ status by radioimmunoassay with an 12 -labeled tracer. Clin Chem 39: 529.533.

Hruska, K. A. Roinick, F, Huskey, M., Alvarez, U. Cheresh, D. (1995) Engagement of the osteoclast integrin v3 by osteopontin stimulates phosphatidylinositol 3-hydroxyl kinase activity. Endocrinology 136: 2984-2992.

Hui, S. L., Zhou, L., Evans, R., Slemenda, C.W. Peacock, M., Weaver, C. M., McClintock, C. \& Johnston, C. C. (1999) Rates of growth and loss of bone mineral in the spine and femoral neck in white females. Osteoporosis Int 9: 200205.

Hunt, C. D., Herbel, J. L. \& Nielsen, F. H. (1997) Metabolic responses of postmenopausal women to supplemental dietary boron and aluminum during usual and low magnesium intake: boran, calcium, and magnesium absorption and retention and blood mineral concentrations. Am J Clin Nutr 65: 803-813.

International Organization of Standardization (1999) Determination of fat content: animal feeding stuff. Report ISO 6492. International Organization of Standardization, Geneva

Jacques, P. F. Felson, D. T., Tucker, K. L., Mahnken, B., Wilson, P. W. F., Rosenburg, I. H. \& Rush, D. (1997) Plasma 25-hydroxyvitamin D and its determinants in an elderly population sample. Am J Clin Nutr 66: 929-936.

Jie, K. G., Bots, M. L., Vermeer, C., Witteman, J. C. \& Grobbee, D. E. (1996) Vitamin K status and bone mass in women with and without aortic atherosclerosis: a population-based study. Calcif Tissue Int 59: 352-356.

Jomsson, B., Kanis, J. A., Dawson, A., Oden, A. \& Johnell. $O$. (1999) Effect and offset of effect of treatments for hip fracture on health outcomes. Osteoporosis Int 10: 193-199.

Kanis, $\sharp$ A. (1997) Osteoporosis: a view into the next century. Neth J Med 50: 198-203.

Kanis. J.A. (1999) The use of calcium in the management of osteoporosis. Bone 24: 279 290.

Kawaguchi, H., Pibeam, C. C., Harrison, J. R. \& Raisz, L. G. (1995) The role of prostaglandins in the regulation of bone metabolism. Clin Orthop Rel Res 313: 36-46.

Kärkkäinen, M. U. M., Wiersma, J.W. \& LambergAllardt, C. J. E. (1997) Postprandial parathyroid hormone response to four calcium-rich foodstufts. Am J Clin Nutr 65: 1726-1730.

Kenney, M. A. McCoy, H. \& Willams, L. (1994) 
Effects of magnesium deficiency on strength, mass, and composition of rat femur. Calcif Tissue Int 54: 44-49.

Kerstetter, لU. E., O'Brien, K. O. \& Insogna, K. L. (1998) Dietary protein affects intestinal calcium absorption. Am J Clin Nutr 68: 859-865.

Kiel, D. P., Zhang, Y., Hannan, M. T. Anderson, J.

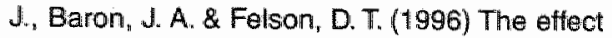
of smoking at different life stages on bone mineral density in ellderly men and women. Osteoporosis Int 6: 240-248.

Kim, Y.-J. \& Liu, R. H. (1999) Selective increase in conjugated linoleic acid in milk fat by crystallization. J Food Sci 64: 792-795.

Kinyamu, H. K. . Gallagher, J. C., Balhorn, K. E., Petranick, K. M. \& Raflerty, K. A. (1997) Serum vitamin D metabolites and calcium absorption in normal young and elderly free-living women and in women living in nursing homes. Am J Clin Nutr 65: 790-797.

Kinyamu, H. K., Gallagher, J. C., Rafferty, K. A. \& Balhorn, K. E. (1998) Dietary calcium and vitamin D intake in elderly women: effect on serum parathyroid hormone and vitamin $D$ metabolites. Am J Clin Nutr 67: 342-348.

Kitts, D. D. Yuan, Y. V., Nagasawa, T. \& Moriyama, Y. (1992) Effect of caseinphosphopeptides and calcium intake on ileal ${ }^{45} \mathrm{Ca}$ dis-appearance and temporal systolic blood pressure in spontaneously hypertensive rats. $\mathrm{Br} J$ Nutr 68 : 765-781.

Kitts, D. D. \& Yuan, Y. V. (1992) Caseinophosphopeptides and calcium bioavailability. Trends in Food Sci Technol 3: 31-35.

Kleerekoper, M. (1995) Extensive personal experience: the clinical evaluation and management of osteoporosis. J Clin Endocrinol Metab 80: 757-763.

Knapen, M. H. J, Jie, K., Hamulyák, K. \& Vermeer, $C_{n}$ (1993) Vitamin K-induced changes in markers for osteoblast activity and urinary calcium loss. Calcif Tissue Int 53: 81-85.

Knapen, M. H. J. Nieuwenhuijzen Kruseman, A. C. Wouters, R. S. M. E. \& Vermeer, C. (1998) Correlation of serum osteocaicin fractions with bone mineral density in women during the first 10 years after menopause. Calcif Tissue Int 63 : 375-379.

Knight, D. C. \& Eden, J. A. (1995) Phytoestrogens, a short review. Maturitas 22: 167-175.

Knight, D. C. \& Eden, J. A. (1996) A review of the clinical effects of phytoestrogens. Obstet Gynecol 87: 897-904.

Knox, T. A., Kassarjian, Z. Dawsorn-Hughes, B., Golner, B. B., Dallal, G. E., Arora, S. \& Russell, R. M. (1991) Calcium absorption in elderly subjects on high- and low-fiber diets: effect of gastric acidity. Am J Clin Nutr 53: 1480-1486.
Kohimelier, M.s Salomon, A., Saupe, J. \& Shearer M. J. (1996) Transport of vitamin $K$ to bone in humans. I Nutr 126: $1192 \mathrm{~s} \times 1196 \mathrm{~s}$.

Kohlmever, M., Saupe, J., Sheareit, M. d., Schaefer. K. \& Asmus, G. (1997) Bone health of adult hemodialysis patients is related to vitamin $K$ status. Kidney Int 51: 1218-1221.

Koiwu-Tikkanen, T. J., Schurgers, L. J, Thijssen, $H$. H. W. \& Vermeer, C. (2000) Intestinal, hepatic, and circulating vitamin $K$ levels at low and high intakes of witamin $K$ in rats. Brit J Nutr 83: 185 190.

Kolta, S., Ravaud, P., Fechtenbaum, J., Dougados, M. \& Foux, C. (1999) Accuracy and precision of 62 bone densitometers using a European spine phantom. Osteoporosis Int 10: 14-19.

Komulainen, M., Tuppurainen, M. T., Kröger, H., Heikkinen, A. M. Puntila, E., Alhava, E., Honkanen, R. \& Saarikoski, S. (1997) Vitamin D and HRT: no benefit additional to that of HRT allone in prevention of bone loss in early postmenopausal women. A 2.5 year randomized placebo-controlled studly. Osteoporasis Int 7: 126-132.

Krall, E. A. \& Dawson-Hughes, B. (1999) Smoking increases bone loss and decreases intestinal calcium absorption. J Bone Miner Res 14: $215-$ 220.

Krampitz, G., Engels, J., Hamm, M, Kriesten, K. \& Cazaux, C. (1977) On the molecular mechanism of the biological calcification. 1 . Ca-Ligands from gastropod shells, egg shells and tuterine fluid of thens. Biomineralisation 5972 .

Krefting, E. R., Frentzel, K., Tebarek, J. \& Höhling, H. J. (1993) Strontium, a tracer to study the transport of calcium in mineralizing tissues by electron probe microanalysis. Scan Microscopy int 7: 203-207.

Krishnamra, N., Saengumnert, W. \& Limiomwongse, L. (1992) Dietary calcium bioavailability and a search for calcium supplement sources for Thal people: a review. J Sci Soc Thalland 18: 73-91.

Kung, A. W. C. Luk, K. D. K., Chu, L. W. \& Chiu, P. K.Y. (1998) Age-related osteoporosis in Chinese: an evaluation of the response of intestinal calcium absorption and calcitropic hormones to dietary calcium deprivation. Am $J$ Clin Nutt 68: 1291-1297.

Lamon-Fava, S. Sadowski. U. A., Davidson, K. W. O'Brien, M. E. McNamara, J.A. \& Schateter, E. J. (1998) Plasma lipoproteins as carriers of phylloquinone (vitamin $K 1$ ) in humans. Am $J$ Clin Nutr 67: 1226-1231.

Lane, N. E., Bauer, D. C., Novit, M. C., Pressman, A. A. \& Cummings, S. R. (1997) Aspirin and nonsteroidal antiinflammatory drug use in 
elderly women: ettects on a marker of bone resorption. Wheumatol 24: 1132-1 136 .

Lapre, J. A., De Vries, H. T. Termont, D. S. M. L. Keibeuker, J. H., De Vries; E. G. E. \& Van der Meer, R. (1993) Mechanism of the protective effects of supplemental dietary calcium on cytolytic activity of focal water. Cancer Res 53 : $248-253$.

Lauritzen, d. B. (1996) Hip fractures: incidence, risk factors, energy absorption, and prevention. Bone 18: $565-\$ 75$.

Lea, C. K., Ebrahim, H., Tennant, S. \& Flanagan, A. M. (1997) Aromatase cytochrome P450 transcripts are detected in fractured human bone but not in normal skeletal tissue. Bone 21: $433-440$.

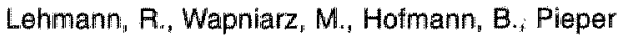
B. Haubitz, 1. \& Allolio, B. (1998) Drinking water fluoridation: bone mineral density and hip fracture incidence. Bane 22: 273-278.

Lemann, J. (1993) Urinary excretion of calcium!, magnesium, and phosphorus. In: Primer on the Metabolic Bone Diseases and Disordiers of Mineral Metabolism (Favus, M. J.edl.), pp. 5054. Raven Press, New York.

Lemeshow, S., Hosmer, D. W., Klar, J. \& Lwanga, S. K. (1990) Adequacy of Sample Size in Health Studies, pp. 1-233. John Wiley \& Sons, Chichester:

Leveille, S. G., LaCroix, A. Z., Koepsell, T. D., Beresford, S. A., Van Belle, G. \& Buchner, D. M. (1997) Dietary vitamin $C$ and bone mineral density in postmenopausal women in Washington State, USA J Epidemiol Community Health 51: 479-485.

Lewenson, D. 1. \& Bockman: A. S. (1994), A review of calcium preparations. Nutr Rev 52: 221-232.

Lian, J. B. Stein, G. S. (1995) Osteoblast biology. In: Osteoporasis (Marcus, R., Feldman, D. Kelsey, J eds.), pp. 23-59. Academic Press, Sient Diego.

Libanati, C. Law, K.-H.\& Baylink, D. (1996) Fluoride therapy for osteoporosis. Im: Osteoporosis (Marcus, R., Foldman, D. \& Kelsey, u eds.), pp. 1259-1277. Academic Press, San Diego.

Liberman, U. A., Weiss, S. Ri, Broll, J., Minne, H. W. Quan, H., Bell, N. H., Rodriguez-Portales, J. \& (1995) Effect of oral Alendronatie on bone mineral density and the incidence of fractures in postmenopausal osteoporosis. N Engl J Med 333: $1437-1443$

Lichterstein, F. (1948) Eierschalien zur peroralen Kalktherapie. Zentralblatt für Gynäkologie 4: 346 \% 348 .

Liebman, M. Chai, W. (1997) Effect of dietary calcium on urinary oxalate excretion after oxalate loads. Am J Clin Nutr 65: 1453-\#459.
Lindsay, D. G. (1999) Diel and ageing: the posssible relation to reactive oxygen species. I Nutr Heath Aging 3: 84-91.

Lindsay, R. (1993) Prevention and treatment of osteoporasis. The Lancet $341: 801-805$.

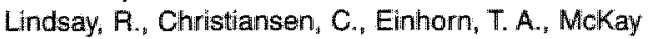
Hart, D, Ljunghall, S. Mautalen, A, Meunier, P. J., Moril, H., Mundy, G. R., Rapado, A. \& Stevenson $J$. (1997) Who are candidates for prevention and treatment for osteoporosis. Consensus Development Statement. European Foundation for Osteoporosis and the National Osteoporosis Foundation. Osteoporosis lnt 7: $1-6$.

Lindsay, R. (1999) Clinical utility of biochemical markers. Osteoporosis Int 9: $129-\$ 32$.

Lips, P. (1996) De toepassing van vitamine D3 en actieve metabolieten ervan bij preventie en behandeling van osteoporose. Ned Tüjdschr Geneeskd 140: 65-68.

Lips, P. Graafmans, W. C., Ooms, M. E., Bezemer, P. D. \& Boutter, L. M. (1996) Vitamin D supplementation and fracture incidence in ellderly persons: a randomized, placebocontrolled clinical trial. Ann Intern Med 124 : 400-406.

Lips, P., Chapuy, M. C., Dawson-Hughes, B., Pols, H. A. P. \& Holick, M. F. (1999) An international comparison of serum 25-hydroxyvitamin D measurements. Osteoporosis Int 9: 394-397.

Litu, G. \& Peacock, M. (\$998) Age-related changes in serum undercarboxylated osteocalcin and its relationships with bone densily, bone quality and hip fracture. Calcif Tissue Int 62: 286-289.

Lloyd, T, Rollings, N., Eggli, D. F, Kieselhorst, K. \& Chinchilli, V. M. (1997) Dietary caffeine intake and bone status of postmenopaustal women. Am J Chin Nutr 65: 1826-1830.

Lo, G. S., Steinke, F. H. \& Hopkins, D. T. (1980) Effect of isolated soybean protein on magnesium bioavailability J Nutr 110: 829-836.

Lord, S. R., Ward, J. A., Williams, P. \& Zivanovic, E. (1996) The effects of a community exercise pragram on fracture risk factors in older women. Osteoporosis int 6: 361-367.

Lukent, B., Higgins, J \& Stoskopf, M. (1992) Menopausal bone loss is partially regulated by dietary intake of witamin D. Calcif Tissue Int 51 : 173-179.

Machlin, L. J. (1991) Handbook of Vitamins, Ed.2nd, pp. 1-595. Marcell Dekker, New York.

Mackerras, D. \& Lumley, T. (1997) First- and second-year effects in trials of calcium supplementation on the loss of bone density in positmenopausal women. Bane 21: 527-533

Makai, F. \& Chudacek. J. (1991) The treatment of osteoporosis with Biomin-H. Arch Gerontol Geriatr 2: 487-490. 
Manten, J. W, Verhaar, H. J. J. \& Duursma, S. A. (1996) Groeihormoon en botmetabolisme. Ned Tijdschr Geneeskd 140: 1064-1068.

Marcus R., Feldman D., Kelsey J. (1996a) Osteoporosis pp. 3-1373. Academic Press. Inc., San Diego.

Marcus, R. (1996) The nature of asteoporosis. In: Osteoporosis (Marcus, R., Feldman, D. \& Kelsey, J. eds.), pp. 647-670. Academic Press, San Diego.

Marie, P. J., Garba, M. T., Hott, M. \& Miravet, L. (1985) Effect of low doses of stable strontium on bone metabolism in rats. Min Electr Met 11 : 5-13.

Martini, L. A. (1999) Magnesium supplementation and bone turnover. Nutr Rev 57: 227-229.

Mason, A. C., Weaver, C. M., Kimmel, S. \& Brown, R. K. (1993) Effect of soybean phytate content on calcium bioavaillability in mature and immature rats. J Agric Food Chem 41: 246-249.

McCarthy, M. (1996) Bones protected by promotion of osteoclasts apoptosis. Lancet 348: 1019

MoCaslin, F. E. \& Janes, M. J. (1959) The effect of strontium lactate in the treatment of osteoporosis. Proc Staff Meet Mayo Clin 95-183.

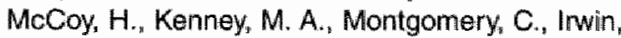
A., Williams, L. \& Orrell, R. (1994) Relation of boron to the composition and mechanical properties of bone. Envir Health Perspect 102: 49-53.

McKane, W. R., Khosla, S., O'Fallon, W. M., Robins, S. P., Burritt, M. F. \& Riggs, B. L. (1996) A high calcium intake reverses the secondary hyperparathyroidism and increased bone resorption of elderly women. J Clin Endocrinol Metab 81: 1699-1703.

McKenna, M. J.\& Freaney, R. (1998) Secondary hyperparathyroidism in the elderly: means to defining hypovitaminosis $D$. Osteoporosis Int 8 : s3-s6.

Mee, A. P., Hoyland, J. A., Braidman, I. P., Freemont, A J., Davies, M. \& Mawer, E. B. (1996) Demonstration of vitamin $D$ receptor transcripts in actively resorbing osteoclasts in bone sections. Bone 18: 295-299.

Melsen, F. \& Mosekilde, L. (1988) Calcified

Tissues: cellular dynamics. In: Calcium in Human Biology (Nordin, B. E. C. ed.), pp. 187208. Springer-Verlag, London.

Melton, J. L. (1999) Cost-effective treatment strategies for osteoporasis. Osteoporosis 9 : s111-s116.

Mertz, W. (1993) Essential trace metals: New definitions based on new paradigms. Nutr Rev 51: 287-295

Messina, M. (1995) Modern uses for an ancient bean: soyfoods and disease. Chemistry \& Industry June: 412-415.
Messina, M. J. (1999) Legumes and soybeans: overview of their nutritional profilles and health effects. Am I Clin Nutr 70: 439s-450s.

Meunier, P. J., Chapuy, M. C. Arlot M. E., Delmas, P. D. \& Duboeut, F. (1994) Can we stop bone loss and prevent hip fractures in the elderly? Osteoporosis Int 4: s71-s76.

Meunier, P. J., Confavreux, E., Tupinon, I. Hardoutin C. \& Delmas, P. O. (1997) Prevention of early postmenopausal bone loss with cyclical etidronate therapy (a double-blind, placebo-controlled study and 1-year follow-up). $\mathrm{J}$ Clin Endocrinol Metab 82: 2784-2791.

Meunier, P. J., Sebert, J.-L., Reginster, J.Y., Briancon, D., Appelboom, T., Netter, P., Loeb, G., Rouillon, A, Barry, S., Evireux, J.-C., Avouac, B. \& Marchandise, X. (1998) Fluoride salts are no better at preventing new vertebral fractures than calcium-vitamin $D$ in postmenopausal osteoporosis. Osteoporosis Int 8: 4-12.

Meunier, P. J. (1999) Calcium, vitamin D and vitamin $\mathrm{K}$ in the prevention of fractures due to asteoporosis. Osteoporosis Int 9: \$48-s52.

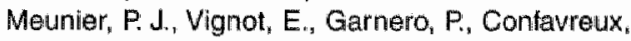
E."Paris, E., Liu-Leage, S., Sarkar, S. Liu, T., Wong, M. \& Draper, M.W. (1999) Treatment of postmenopausal women with osteoporosis or low bone density with Raloxifene. Osteoporosis Int 10: 330-336.

Michaëlsson, K., Holmberg, L., Mallmin, H., Sörenson, S., Wolk, A., Bergström, Ljunghall, S. \& et al. (1995) Diet and hip fracture risk: a case-control study. Int J Epidemol 24: 771-782.

Michaëlsson, $K_{\text {, }}$ Bergström, $R_{\text {, }}$ Holmberg, $L$., Mallmin, H., Wolk, A. \& Ljunghail, S. (1997) A high dietary calcium intake is needed for a positive effect on bone densilty in Swedish postmenopausal women. Osteoporosis Int 7: 155-161.

Miller, D. G. \& Groziak, S. M. (1997) Galcium and blood pressure. Report 322 (Schaatsma, G. ed.) International Dairy Federation, Brusseis 25-28.

Montessori, M. L. M., Scheele, W. H., Nettelenbas, J. C., Kerkhoff, J. F. \& Bakker, K. (1997) The use of Etidronate and calcium versus calcium alone in the treatment of postmenopausal osteopenia: results of three years of treatment Osteoparosis Int 7: $52-58$.

Morohashi, T., Samo, T. \& Yamada, S. (1994) Effects of strontium on calcium metabolism in rats. 1. A distinction between the pharmacological and toxic doses. Jpn J Pharmacol 64: 155-162.

Morrison, M. S. \& Arnett, T. R. (1998) pH effects on osteoclast formation and activation. Abstract. Bone 22: $30 \mathrm{~s}$ 
Mortengen, L. \& Charles, P. (1996) Bioavallability of callew supplements and the effect of wamin D: comparisons between mik; calcium carbonate, and calchum carbonate plus witamin D. Arr J Clin Nutr $63.354-357$.

Moseman. A.F. (1994) Chemical disposition of boron in anmals and humans. Environ Health Perspect $102: 113-117$.

Moughan, P J, Cranwell, P. D, Darragh, A.J. Powan, A. M. (1994) The Domestic Pig as a Model Animal for Studying Digestion in Humans, pp. 389-396. Forschungsingtitut fill die Biologie landwirtschaftlicher Nutztiere, Dummerstort.

Mundy, G. R. (1993) Bone resorbing cells. Un: Primer on the Metabolic Bone Diseases and Disorders of Mineral Metabolism (Favus, M. N. ed. ) pp. 25-31. Raven Press, New York.

Muindy, G. F. (1999) Cellular and molecular regulation of bone turnover. Bone $24: 35 \mathrm{~s}-38 \mathrm{~s}$

Murray, A. E M. \& Ralston, S. H. (1997) Polymorphism of the interleukin-6 gene are associated with bone mineral density. Bone 21: 88-92.

Muck, A. O. \& Lippert, T. H. (1994) Die Bedeutung von Laboruntersuchungen für die Dlagnose der Osteoporose. Med Klin 89:611-618.

Nadi, M. M. E., Rahman, K. M. A. \& Rahman, H. A. (1984) The effect of calcium-magnesium relationship in the nutrition of Fayoumi laying hens on body weight, eggshell quallity and blood composition. Minufiya J Agric 8: 235-255.

Nagasawa, T., Yuan, Y. V. \& Kitts, D. D. (1991) Casein phophopeptides enthance paracellullar calcium absorption but do not alter temporal blood pressure in normotensive rats. Nutr Res 11: $819-830$.

Naghil, M. R. \& Samman, S. (1993) The role of boron in nutrition and metabolism. Prog Food Muti $\mathrm{Sol} 17: 331-349$.

National instatutes of Health Consensus Panel. (1994) Optimal calcium intake. JAMA 272: $1942-1948$.

National Research Council. (1989) Recommended Dietary Allowances, Ed.10th, National Academy Pross, Wasthington, D.C.

Nelson, D. A. (1996) An anthropological perspective on optimizing celcium consumption for the prevention of esteoporosis. Osteoporosis Int 6: 325-328.

Neison, M. E., Fisher, E. C, Dimanian, F, A. Dallal, G. E \& Evans, W. J. (1991) A 1-y walking program and increased dietary calcium in postmenopausal women: effects on bone. Am $\|$ Clin $\mid$ Nutr 53: 1304-1311.

Nelson, M. E., Flatarone, M. A., Morganti, C. M., Trice, I. Girenberg, R. A. \& Evans, W. J. (1994) Effects of high-intensity strength training on muliple risk fectors for osteoporotic hacures. JAMA 272: 1909-1914.

Netelenbos, J. C. \& Lips, P (1996)

Botdichtheidsmeting en de preventie van fracturen: wie komen hiervoor in aanmerking? Ned TJdschr Geneeskd 140: 1061 -1064.

Neufeld, E. B. Boskey, A. L. (1994) Strontium alters the complexed acidic phasphollpid content of minerallizing tissues. Bone 15: 425 . 430.

Nevitt, M. C. (1994) Epidemiology of osteoporosis. Osteoporosis 20: $535-559$

New, S. A., Bolton-Smith, C., Grubb, D. A. \& Reid, D. M. (1997) Nutritional influences on bone mineral density: cross-sectional study in premenopausal women. Am J Cin Nutr 65: 1831.1839

Newrham, R. E. (1994) Essentiality of boron for healthy bones and joints. Environ Health Perspect 102: 83-85.

Nielsen, F. H. (1990) Studies on the relationship between boron and magnesium which possibly affects the formation and maintenance of bones. Mag Tr Elem 9:61-69.

Nielsen, F.H. (1991) Nutritional requirements for boron, silicon, vanadium, nickel and arsenic: current knowledge and speculation. FASEB J 5: $2661-2667$.

Nielsen, F. H. M. Hunt JR. Hunt, C. D. Mullen, L. M. \& Hunt, J. R. (1987) Effect of dietary boron on mineral, estrogen, and testosterone metabolism in postmenopausal women. FASEB J 1: 394-397.

Neves, U. W. Komar, L., Cosman, F. \& Lindsay, R. (1998) Callium potentiates the effect of estrogen and calcitonin on bone mass: review and analysis. Am J Clin Nutr 67: 18-24

Nordin B. E. C. (1988) Galcium in Human Biology, pp. 1-481. Springer-Verlag, London.

Nordin, B. E. C., Need, A. G., Morris, H. A., Horowitz, M. \& Robertson, W. G. (1991) Evidence for a renal calciumi leak in postmenopausal women. $\mathrm{d}$ Clin Endocrinol Metab 72:" $401-407$.

Nordin, B. E. C., Need, A. G., Morris, H. A. \& Horowitz, M. (1993) The nature and significence of the relationship between urinary sodium and urinary calcium in women. $J$ Nutr 123: $1615-1622$

Nordin, B. E. C. (1997) Calicium and osteoporosis. Report 322 (Schaafsma, G. ed.). International Dairy Federation, Brussels 4-10.

Ohta, H., Sugimoto, I., Masuda, A., Komukai "S., Suda, Y., Makita, K.. Takamatsu, K., Horiguchi, F. \& Nozawa, S. (1996) Decreased bone mineral density associated with early menopause progresses for at least ten years: crosssectional comparisons between early and 
normal menopausal women. Bone 18: 227-231.

Okayama, S., Akao, M. Nakamura, S, Shin, $Y_{\text {, }}$ Higashikata, M. \& Aoki, H. (1991) The mechanical properties and solubility of strontium-substitued hydroxyapatite. Bio-Med Mat Eng 1: 11-17.

Olson, R. E. (1984) The function and metabolism of vitamin K. Ann Rev Biochem 4: 281-337.

Olson, R. E. (1994) Vitamin K. In: Modern Nutrition in Health and Disease (Shils, M. E., Olson, J. A. \& Shike, M. eds.), pp. 342-358. Lea \& Febiger, Philadelphia.

Ooms, M. E. (1994) Osteoporosis in elderly women. Thesis. Vrije Universiteit Amsterdam. 3-117.

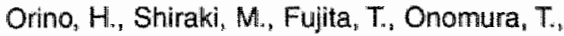
Inove, T. \& Kushida, K. (1992) Clinical evaluation of menatetrenone in the treatment of involutional osteoporosis - A double-blind multi-center comparative study with 1-hydroxy vitamin D3. J Bone Miner Res 7: s122

Oursler, M. J. Kassem, M., Turner, R., Riggs, B. L. \& Spelsberg, T. C. (1996) Regulation of bone cell function by gonadal steroids. In: Osteoporosis (Marcus, R., Feldman, D. \& Kelsey, J. eds.), pp. 237-260. Academic Press, San Diego.

Overgaard, K., Hansen, M. A. Jensen, S. B. \& Christiansen, C. (1992) Effect of calcitonin given intranasally on bone mass and fracture rates in established osteoporosis: a doseresponse study. BMJ 305: 556-561.

Pak, C.Y. C., Sakhaee, K., Adams-Huet, B., Piziak, V., Peterson, R. D. \& Pointdexter, J. R. (1995) Treatment of postmenopausal osteoporosis with slow release sodium fluoridle. Ann Intern Med 123: 401-408.

Patel, S., Chan, J. K. M. \& Hosking, D. J. (1996) Fluoride pharmacokinetics and changes in lumbar spine and hip bone mineral density. Bone 19: 651-655.

Peacack, M. (1988) Renal excretion of calcium. In: Calcium in Human Biology (Nordin, B. E. C. ed.), pp. 125-169. Springer-Verlag, London.

Peacock, M., Turner, C. H., Liu, G., Manatunga, A. K. Timmerman, L. \& Johnston, C. C. (1995) Better discrimination of hip fracture using bone density, geometry and architecture.

Osteoporosis Int 5: 167-173.

Peel N. \& Eastell, R. (1995) Osteoporosis. BMJ 310: $989-992$.

Polley, K. J., Nordin, B. E. C., Baghurst, P. A., Walker, C. Jl \& Chatterton, B. E. (1987) Effect of calcium supplementation on forearm bone mineral content in postmenopausal women: a prospective, sequential controlled trial. \& Nutr 117: 1929-1935.

Prentice, A. (1997) Is nutrition important in osteoporosis? Proc Nutr Soc 56: $357-367$.

Prestwood, K. M. Pennullo, A. M. Kenny, A. M. Pilbeam, C. C. \& Raisz, L. G. (1996) The offect of short course of calcilum and vitamin D on bone turnover in older women. Osteoporosis Int 6: $314-31$.

Prince, R., Devine, A., Dick, I., Criddle, A., Kerr, D., Kent, N., Price, R. Randell, A. (1995) The effects of calcium supplementation (milk powder or tablets) and exercise on bone density in postmenopausal women. J Bone Miner Res 10: 1068-1075.

Puntila, E., Kroger, H., Lakka, T., Honkanen, R. \& Tuppurainen. M. T. (1997) Physical activity in adolescence and bone density in peri- and postmenopausal women: a population-based study. Bone 21: 263-267.

Puzas, J. E. (1993) The Osteoblast. In: Primer on the Metabolic Bone Diseases and Disorders of Mineral Metabolism (Favus, M. J. ed.), pp. 15. 21. Raven Press, New York.

Qu, Q., Perälä-Heape, M., Kapanen, A., Dahilund,

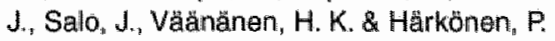
(1998) Estrogen enhances differentiation of osteoblasts in mouse bone marrow culture. Bone 22: 201-209.

Ralston, S. H. \& Grabowski, P. S. (1996) Mechanisms of cytokine induced bone resorption: role of nitric oxidie "cyclic guanosine monophosphate, and prostaglandins. Bone 19: 29-33.

Rao, H. V., Belites, R. P., Whitford, G. M. \& Turner, C. H. (1995) A physiologically based pharmacokinetic model for fluoride uptake by bone. Reg Toxicol Pharmacol 22: 30-42.

Ravn, P., Clemmesen, B., Rills, B. J. \& Christiansen, $\mathrm{G}$. (1996) The effect on bone mass and bone markers of different doses of ibandronate: a new bisphosphonate for prevention and treatment of postmenopausal osteoporosis: a 1-year, randomized, doubleblind, placebo-controlled dose-tinding study. Bone 19: 527-533.

Rawn, P., Clemmesen, B. \& Christiansen, C. (1999) Biochemical markers can predict the response in bone mass during alendronate treatment in early postmenopausal women. Bone 24: 237\% 244

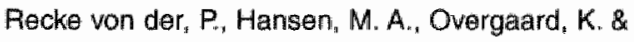
Christiansen, C. (1996) The impact of degenerative conditions in the spine on bone mineral density and fracture risk prediction. Osteoporosis Int 6: 643-649.

Recker, R. R., Saville, P. D. \& Heaney, R. P. (1977) Effect of estrogens and calcium carbonate on bone loss in postmenopausal women. Ann Int Med 87: 649-655.

Reddi, K., Henderson, B., Meghii, S., Wilson, M.n 
Poole, S., Hopper, C. Harris, M. Hodges, $S$. J. (1995) Interleukin 6 production by lipopolysaccharide-stimulated human tibroblasts is potentially inhibited by maphthoquinone (vitamin $K$ ) compounds. Cytokine 7: 287-290.

Reeve, J., Arlot, M, Wootton, Fi, Edouard, $C$., Tellez, M. Hesp, P., Green II $_{\text {I. }}$. R. \& Meuner P. J. (1988) Skeletal blood flow, iliac histomorphometry, and strontium kinetics in osteoporosis; a relationship between blood flow and corrected apposition rate. J Clin Endocrinol Metab 66: 1124-1131.

Reginster, J. Y. (1997) Miscellaneous and experimentall agents. Am J Med Sci 313: 33-40.

Reginster, J.Y., Meurmans, L., Zegels, $B$, Rovati, L. C., Minne, H.W., Giacovelli, G., Taquet, A. N., Setnikar, I., Collette, J. \& Gosset, C. (1998a) The effect of sadium monoiuorophosphate plus calcium on vertebral fracture rate in postmenopausal women with moderate osteoporosis. Ann Intern Med 129: 1-8.

Reginster, J. Y., Roux, C., Jupsin, I., Prowedini, $D_{\text {. }}$ M., Birman, P: \& Tsouderos, Y. (1998b) Strontium Ranelate for the prevention of bone loss of early postmemopause. Abstract. Osteoporosis Int 8: 12

Reginster, J. Y., Halkin, V., Henrotin, Y. \& Gosset, C. (1999) Treatment of osteoporosis: role of boneforming agents. Osteoporosis. Int 3: $\$ 91-\mathrm{s} 96$.

Reichel, H. Koeffler, H. P. \& Norman, A. W. (1989) The role of the vitamin $D$ endocrine system in health and disease. $N$ Engl $J$ Med 320: 980992.

Reichelt, B. Bonneux, L., Van den Bosch, J. M. H. Barendregt, J. J. \& Pols, H. A. P. (1996) veroudering als oorzaak van heupfracturen: een theoretisch rekenmodel. Ned Tijdschr Qeneeskd 140: 1312-1317.

Feid, I. F., Ames, R. W., Evans, M. C., Gamble, G. D. \& Sharpe, S. J. (1993) Effects of calcium supplementation on bone loss in postmenopausal women. N Engl J Med 328: 460-464.

Roid, I. R, Ames, R. W., Evans, M. C., Gamble, G.D. \& Sharpo, S. J. (1995) Long-term effects of calcium supplementation on bone loss and fractures in postmenopaucal women: a randomized controlled trial. Am J Med 98: 331335.

Renner, E. (1994) Dairy calcium, bone metabolism, and prevention of osteoporosis. J Dairy Sci 77 : 3498-3505.

Riggs, B. L., Hodgson, S. F., O'Failon, W. M., Chao, E. Y., Wahner, H. W. Muhs, J. M. \& el al. (1990) Effect of fluoride treatment on the fracture rate in postmenopausal women with osteoporosis. N Eng J Med 322: 802-809.
Riggs, L. B., O'Fallon, M. W., Muhs, J., O'Connor. M. K. Kumar, R. \& Melton, لJ. L. (1998) Longterm effects of calcium supplementation on serum parathyroid hormone level, bone turnover, and bone loss in elderly women. J Bone Miner Res 13: 168-174.

Rilis, B., Thomsen, K. \& Christiansen, C. (1987) Does calcium supplementation prevent postmenopausal bone loss? A double-blind, controlled clinical study. N Engl IJ Med 316: 173-177.

Ringe, J. D., Kipshoven, C., Coster, A. \& Umbach, R. (1999) Therapy of established postmenopausal asteoporosis with monofluorophosphate plus calcium: doserelated effects on bone density and fracture rate. Osteoporosis Int 9: 171-178.

Robey, P. G. \& Boskey A. L. (1995) The bilochemistry of bone. In: Osteoporosis (Marcus, R., Feldman, D. \& Kelsey, J, eds.), pp. 95-183. Academic Press, New York.

Rabinson, R. G., Preston, D. F. Baxter, K. G., Dusing, R. W. \& Spicer, J. A. (1993) Clinical experience with strontium-89 in prostatic and breast cancer patients. Sem Oncology 20: 44= 48.

Rodian, G. A. (1997) Bone mass homeostasis and bisphosphonate action. Bone 20: 1-4.

Romagnoli, E., Caravella, P., Scarnecchia, L., Martinez, P. \& Minisola, S. (1999)

Hypovitaminosis $D$ in an Italian population of healthy subjects and hospitalized patients. $\mathrm{Br} \mathrm{J}$ Nutr 81: 133-137.

Aomanoff, A. L. \& Romanoff, A. ل. (1949) The Avian Egg, p. 358 John Wiley \& Sons, Inc. New York.

Rong, H., Sääf, M., Torring, O., Sjöstedt, U. \& Bucht, E. (1996) Circulating monomer-like calcitonin in osteoporotic patients.

Osteoporosis Int 6: 394-398.

Rosenberg, 1. H. \& Rosenberg, L. E. (1998) The implication of genetic diversity for nutrient requirements: the case of folate. Nutr Rew 56 : $\$ 47-\$ 53$.

Rovensiky, J., Marek, J., Schreiberova $0 . \&$ Stancikova, M. (1994) Somatomadin-type activity of Biomin $\mathrm{H}$. Casopis Lekaru Ceskych 133: $213-214$

Rude, R. K. \& Olerich, M. (1996) Magnesium deficiency: possible role in osteoporosis associatted with gluten-sensitive enteropathyy. Osteoporosis Int 6: 453-461.

Sato, Y., Honda, Y., Kuno, H. \& Oizumi, K. (1998) Menatetrenone ameliorates asteopenia in disuse-affected limbs of vitamin D-and $\mathrm{K}$ deficient stroke patients. Bone 23: 291-296.

Schaatsma, A. \& Beellen, G. M. (1999) Eggshell powder, a comparable or better source of calcium than purified calcium carbonate: piglet 
studies. J Sci Food Agric 79: 1-5.

Schaafsma, A. \& Pakan, 1. (1999) Short-term effects of a chicken egg shell powder enriched dairy-based product on bone mineral density in persons with osteoporosis or osteopenia. Bratis! Lek Listy 100: 651-656.

Schaafsma, G., Van Beresteyn, E. C $\mathrm{C}_{\text {., }}$ Raymakers, J. A. \& Duursma, S. A. (1987) Nutritional aspects of osteoporosis. Wid Rev Nutr Diet 49: 121-159.

SchiessI, H. Frost, M. \& Jee, S. S. (1998) Estrogen and bone muscle strength and mass relationships. Bone 22:1-6.

School of Public Health (1992) Health Letter Associates. University of California, Berkley 2: 2

Schurgers, L. J., Geleijnse, J. M., Grobbee, D. E.» Pols, H. A. P., Hofman, A. Witteman, J. C. M. \& Vermeer, $\mathrm{C}$. (1999) Nutritional intake of vitamins $K_{1}$ (Phylloquinone) and $K_{2}$ (Menaquinone) in The Netherlands. J Nutr Einviron Med 9: 115-122.

Schuster, R. ل. (1988) Determination of amino acids in biological, pharmaceutical, plant and food samples by automated precolumn derivatization and high-performance liquid chromatography. J Chromatog 431: 271-284.

Seeman, E., Tsalamandris, C., Bass, S. \& Pearce, G. (1995) Present and future of osteoporosis therapy. Bone 17:23s-29s.

Seibel, M. J., Cosman, F., Shen, V., Gordon S., Dempster, D. W., Ratcliff, A. \& Limdsay, R. (1993) Urinary hydroxypyridium crosslinks of collagen as markers of bone resorption and estrogen efficacy in postmenopausal osteoporosis. J Bone Min Res 8: 881-889.

Seifert, M. F. \& Watkins, B. A. (1997) Role of dietary lipid and antioxidants in bone metabolism. Nutr Res 17 : 1:209-1228.

Shearer, M. U., Bach, A. \& Kohlmeier, M. (1996) Chemistry, nutritional sources, tissue distribution and metabolism of vitamin $K$ with special reference to bone heallh. J Nutr 126 : $1181 \mathrm{~s}-1186 \mathrm{~s}$.

Shearer, M. J. (1997) The roles of vitamins D and $K$ in bone health and osteoporosis prevention. Proc Nutr Soc 56: $915-937$.

Silhils, M. E. (1980) Magneshum, calcium, and parathyroid hormone interactions. WYAS 165-194.

Sthils, M. E. OHson, N. A. \& Shike, M. (1994) Modern Nutrition in health and disease, Ed.8th, pp. 1-923. Lea \& Febiger, Philadielphia.

Shiraishi, K., Yamamoto, $M_{0}$, Yoshimizu, $K_{*,}$ Igarashi, Y. \& Ueno, K. (1994) Daily intakes of alkaline earth metals in Japanese males. Heath Phys 66: 30-35.

Silva, M. J. \& Gibson, L. J. (1997) Modeling the mechanical behavior of vertebral trabecular bone: effects of age-related changes in microstructure, Bone 21: 191-199.

Sinaki, Mi, Wahner, H. W. Bergstrallh, E.J., Hodgson, S. F Offord, K. P. Squires, R. W. Swee, P. G. Kao, P. C. (1996) Three-year controlled: randomized trial of the effect of dose-specific loading and strengthening exercises on bone mineral density of spine and femuir in nonathietic, physically active women. Bone 19: 233-244.

Sojka J. E. (1995) Magnesium supplementation and osteoporosis. Nutr Rev 53:71-80.

Sokoll, L. J., Booth, S. L., OHBrien, M. E., Davidson, K. W., Tsaloun, K. I. \& Sadowski, J. A. (1997)

Changes in serum osteocalcin, plasma phyloquinone, and urinary -carboxyglutamic acid in response to altered intakes of dietary phylloquinone in human subjects. Am $\mathrm{J} \mathrm{Clin}$ Nutr 65: $779-784$.

Sokolly. L. J. \& Sadowski, J. A. (1996) Compartson of biochemical indexes for assessing vitamin $K$ nutritional status in a healthy adult population. Am J Clin Nutr 63: 566-573.

Solomon, S. E.., Bain, M. M., Cranstoun, S. \& Nascimento, V. (1994) Hens egg shell structure and function. In: Microbiology of the avian egg (Board, R. G. \& Fuller, R. eds.), pp. 1-24. Chapman and Hall, London.

Sparks, N. H. C. (1994) Shell accessory materials structure and function. In: Microbiology of the avian egg (Board, R. G. \& Fuller, F. eds.), pp. 25-42. Chapman and Hall, London.

Spiers, F.W. (1988) Particle dosimetry in bone and the toxicity of bone-seeking radionuclides. Phys Med Biol 33: 395-411.

Staal, A., Bemd wan den, G. J. C. M., Birkenhager, J. C . Pols, H. A. P. \& Leeuwen van, J. P. T. M. (1997) Consequences of vitamin $D$ receptor regulation for the 1,25-ditydroxyvitamin $\mathrm{DB}$. induced 24-hydroxylase activity in asteobles" like cells: initiation of the 24-oxidation pathway. Bone 20: 237-243.

Staessen, 1: A. Roels, H. A. Emelianow, D. Kunetsova, $T$, Thijs, L. Vangronsweld, \&. \& Fagard, R. (1999) Environmental exposure to cadmium, forearm bone density, and risk of fractures: prospective population study. Lancet 353: $1140-1144$.

Stanciková, M., Masaryk, P. Letkovska, A. Roverisky, Ko, Wendlova, \& \& Orvisky, E. (1996) Effect of Biomin $H$ on the biochemical markers of osteoporosis in postmenopausal women. Abstract. Osteoporosis Int 6:267.

Standing Committee on the Scientific Evaluation of Dietary Reference Intakes. (1997) Dietary reference intakes: calcium, phosphorus, magnesium, vitamin D, and fluoride. National Academy Press, Washington, DC.

Stendig-Lindberg, G., Tepper, A. \& Leichter, 1. 
(1993) Trabecular bone density in a two year controlled thial of peroral maginesium in osteoporosis. Magnes Res 6: 155-163.

Storm, D. Estin, R., Smith-Porter E., Musgrave,

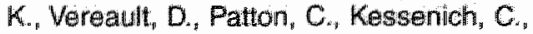
Mohan, S., Chen, T., Hollick, M. F. \& Rosen, C. J. (1998) Calcium supplementation prevents seasonal bone loss and changes in biochemical markers of bone turnover in elderly New England Women: a randomized placebo controlled trial. 1 Clin Endocrinol Metab 83: $3817-3825$.

Stryer, L. (1995) Blochemistry, Ed.4th, pp. 1-1064. W.H. Freeman and Company, New York.

Sugihira: N. \& Suzuki, K. T. (1991) Discrimination between strontium and calcium in suckling rats. Biol Tr Elem Res 29: 1-10.

Szulc, P. Artot, M. Chapuy, M. C., Duboeuf, F., Meunier, P. J. \& Dellmas, P. (1994) Serum undercarboxylated osteocalcin correlates with hip bone mineral density in elderly women. $J$ Bone Miner Res 9: 1591-1595.

Szulc, P., Chapuy, M. C. Meunier, P. J. \& Delmas, P. D. (1996) Serum undercarboxylated osteocalcin is a marker of the risk of hip fracture: a three year follow-up study. Bone 18: $487 \sim 488$.

Takada, Y., Suetake, N., Yahiro, M., Ahiko, K. \& Nakajima, I. (1990) 1. Bioavailability of various dietary calcium compounds. 2. Examination in view of various dietary calcium compounds. Report Snow Brand Milk Products Co, Ltd, Sapporo 75-84.

Tamatani, M., Morimoto, S., Nakajima, M., Fukuo, K., Onishi, T., Kitano, $S_{\text {, }}$ Nilinobu, T. \& Ogihara, T. (1998) Decreased circulating levels of vitamin $K$ and 25-hydroxyvitamin $D$ in osteopenic elderly men. Metabolism 47: $195-199$.

Termine, $J_{1} D_{n}$ (1993) Bone matrix proteins and the mineralization process. In: Primer on the Metabolic Bone Diseases and Disorders of Mineral Motabolism (Favus, M. J. ed.), pp. 2125. Raven Press, New York.

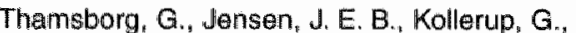
Hauge, E. M., Melsen, F. \& Sorensen, O. H. (1996) Effect of nasal salmon calcitonin on bone remodeling and bone mass in postmenopausal osteoporosis. Bone 18: 207212.

The National Osteoporosis Society. (1995) Exercise \& Physiotherapy in the Prevention and Treatment of Osteoporosis, St. Andrews Press of Wells, Radstock.

Tobias, J. H. \& Compston J. E. (1999) Does estrogen stimulate osteoblast function in postmenopausal women? Bone 24: 121-124.

Torgerson, D. J. \& Kanis, J. A. (1995) Cost- effectiveness of preventing hip fractures in the elderly population using vitamin $D$ and calcium. Q J Med 88: 135-139.

Traba, M. L. De La Piedra, C. Marin, A., Babe, M. \& Riapado, A. (1985) Effect of magnesium on the synthesis and distribution of vitamin $D$ metabolites in serum, bone, intestine and kidney, In: Magnesium deficiency (Halpern, G. \& Durlach, J.edsi), pp. 227-232. Karger, Basel.

Trang, H. M., Cole, D. E. C., Rubin, L. A., Pierratos, A. Silu, S. \& Vieth, R. (1998) Evidence that vitamin D3 increases serum 25-hydroxyvitamin D more efficiently than does vitamin D2. Am J Clin Nutr 68: 854-858.

Tsaioun, K. L. (1999) Vitamin K-dependent proteins in the developing and aging nervous system. Nutr Rev 57: 231-240.

Tucker, K. L., Hannan, M. T., Chen, H., Cupples, L A., Wilson, P. W. F. \& Kiel, D. P. (1999) Potassium, magnesium, and fruits and vegletable intakes are associated with greater bone minerall density in elderly men and women. Am J Clin Nutr 69: 727-736.

Tumbleson, M. E. (1986) Swine in Biomedical Resiearch. Penum Press, New York.

Tuppurainen, M. T., Komulainen, M., Kröger, $H_{\text {. }}$ Honkanen, R., Jurvellin, J. . Puntila, E. Heikkinen, A. M., Alhava, E. \& Saarikoski, S. (1998) Does vitamin $D$ strengthen the increase in femoral neck BMD in osteoporotic women treated with estrogen? Osteoporosis Int 8: 3238.

Turner, C. H., Boivin, G. \& Meunier, P. J. (1993) A mathernatical model for fluoride uptake by the skeleton. Calcif Tissue Int 52: 130-138.

Turner, C. H., Owan, I., Brizendine, E. J., Zhang, W., Wilson, M. E. \& Dunipace, A. J. (1996) High fluoride intakes cause osteomallacia and diminished bone strength in rats with renal deficiency. Bone 19: 595-601.

Utiger, R. D. (1998) The need for more vitamin D. N Eng Ul Med 338: 828-829.

Van den Heuvel, E. G. H. M. (1998) Application of dual stable isotope techniques to measure absorption of calcium, magnesium and iron in man. Thesis. University Maastricht. 7-160.

Vermeer, C., Jie, K.-S. \& Knapen, M. H. J. (1995) Role of vitamin $\mathrm{K}$ in bone metabolism. Annu Rev Nutr 15: 1-22.

Vermeer, C., Gijsbers, B. L. M. G., Cracium, A. M., Groenem-Van Dooren, M. M. C. L. \& Knapen "M. H. J. (1996) Effects of vitamin $K$ on bone mass and bone metabolism. J Nutr 126:1187s$1191 \mathrm{~s}$.

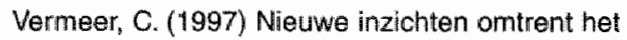
bellang van vitamine $K$ in voeding. Voeding 58 : $11-14$.

Versluis, R. G. J. A., Petri, H., Van de Ven, C. M., 
Scholtes, A. B. J. Papapoulos "S. E. \&

Springer, M. P. (1999) Prevalence of osteoporosis among postmenopausal women in a general pratice. Ned Tijdschr Geneesikd 143: $20-24$

Vieth, R. (1999) Vitamin D supplementation, 25hydroxyvitamin $D$ concentrations and safety. Am J Clin Nutr 69: 842-856.

Visser, J. J. \& Hoekman, K. (1994) Arginine supplementation in the prevention and treatment of osteoporosis. Med Hypotheses 43: 339-342

Volipe, S. L., Taper, L. J. \& Meacham, S. (1993) The relationship between boron and magnesium status and bone mineral density in the human: a review. Magnes Res 6: 291-296.

Wang, M.-C., Villa, M. L., Marcus, R. \& Kelsey, J. L. (1997) Associations of vitamin C, calcium and protein with bone mass in postmenopausal Mexican American women. Osteoporos is Int 7: 533-538.

Weaver, C. M. \& Plawecki, K. L. (1994) Dietary calcium: adequacy of a vegetarian diet. Am $\downarrow$ Clin Nutr 59: 1238s-1241s.

Weber, C.W., Doberenz, A. R. \& Reild, B. L. (1973) Strontium metabolism in mature hens and growing embryos. Poultry Sci 52: 1472-1478.

Weber, P. (1997) Management of asteoporosis: is there a role for vitamin $K$ ? Int J Vitam Nutr Res 67: 350-356.

Welten, D. C., Kemper, H. C. G., Post, G. B. \& Van Staveren, W. A. (1995) A meta-analysis of the effect of calcium intake on bone mass in young and middle aged females and males. J Nutr 125: $2802-2813$.

Wharton, B. A. (1987) Calcium, phosphorus and magnesium. In: Nutrition and Feeding of Preterm Infants (Wharton, B. A. ed.) pp. 117132. Blackwell Scientific Publications, Oxford.

White, C. P., Morrison, N. A., Gardiner, E. M. \& Eisman, J. A. (1994) Vitamin D receptor alleles and bone physiology. I Cell Biochem 56: 307 314.

Whiting, S. J. (1994) Safety of some calcium supplements questioned. Nutr Rev 52: 95-105.

Whiting, S. J. \& Wood, R. J. (1997) Adverse effects of high-calcium diets in humans. Nutr Rev 55 : $1-9$.

Whiting, S.J. \& Lembke, B. (1999) Excess retinal intake may explain the high incidence of osteoporosis in Northern Europe. Nutr Rev 58 : 192-198.

Wiechen Von, A. \& Tait, D. (1994) Stabiles Strontium in Milch and Milchpulver in der Bundesrepublic. Deutschland Milchwissenschaft 49: 603-607.

Wilkin, T. J. (1999) Changing perceptions in osteoporosis. BMJ 318: 862-865.
Wimalawansa, S. J. De Marco, G., Gangula, P. \& Yallampalli; C. (1996) Nitric oxide donor alleviates ovariectomy-induced bone loss. Bone 18: 301-304.

Wimalawansa, S. J., Chapa, M. T., Yallampalli, C., Zhang, R. \& Simmons, D. J. (1997) Prevention of corticosteroid-induced bone loss with nitric oxide donor nitroglycerin in male rats. Bone 21 : 275-280.

Wishart, J. M., Horowitz, M., Need, A. G., Scopacasa, F., Morris, H. A., Clifton, P. M. \& Nordin, B. E. C. (1997) Relations between calcium intake, calcitriol, polymorphisms of the vitamin $D$ receptor gene, and calcium absorption in premenopausal women. Am J Clin Nutr 65: 798-802.

Wolf, G. (1996b) The mechanism of uptake of ascorbic acid into osteoblasts and leukocytes. Nutr Rev 54: 150-152.

Wolf, G. D. (1996) Function of the bone protein osteocalcin: definitive evidence. Nutr Rev 54: 332-333.

Wood, R. J. (1994) Potassium bicarbonate supplementation and calcium metabolism in postmenopausal women: are we barking up the wrong tree? Nutr Rev 52: 278-280.

Wood, R. J. \& Fleet, J. C. (1998) The genetics of osteoporosis: vitamin $\mathrm{D}$ receptor polymorphisms. Annu Rev Nutr 18: 233-258.

Wood, R. J. \& Zheng, J. J. (1997) High dietary calcium intakes reduce zinc absorption and balance in humans. Am J Clin Nutr 65: 18031809.

World Heallth Organization (1994) Assessment of fracture risk and its application to screening for postmenopausal osteoporosis. WHO technical report series 843 . World Health Organization, Geneva

World Health Organization. (1998) Guidelines for preclinical evaluation and clinical trials in osteoporosis, pp. 1-68. World Health Organization, Geneva.

Yano, K., Heilbrun, L.K., Wasnich, R.D., Hankin, J.H., Vogel, J.M. (1985) The relation ship between diet and bone mineral content of multiple skeletal sites in elderly Japanese men and women living in Hawaii. Am J Clin Nutr. 42 : 877-888.

Yuan, Y. V. \& Kitts, D. D. (1994) Calcium absorption and bone utilization in spontaneously hypertensive rats fed on native and heat damaged casein and soya-bean protein. $\mathrm{Br} J$ Nutr 71: 583-603. 


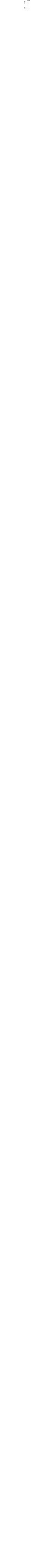




\section{Summary}

Bone remodeling is a process of bone formation and bone resorption, that takes place on bone surfaces. In this way, the skeleton can respond to changing circumstances (mechanical loading, damage, hormones). Bone remodeling is coupled during middle age, i.e. formation takes place following resorption. During the period of bone growth, however, bone formation exceeds bone resorption (bone modeling). During menopause and the next few years, bone resorption and bone turnover increase, because of a strongly decreased production of oestrogens. A considerable amount of bone may be lost. Therefore, establishment of a high peak bone mass during puberty and adolescence (maximum modeling), preservation of bone mass during middle age (balanced remodeling), and inhibition of bone loss at older age (reduced bone turnover and controlled serum PTH) are all of importance in osteoporosis prevention. In Western countries, the prevalence of osteoporosis among postmenopausal women (55-70 years of age) is estimated to be $15-25 \%$. Only women with increased risk, e.g. family history of fractures, will be investigated and treated to decrease fracture risk. Many women, however, will not be aware of their precarious skeletal condition. For this reason "strategies to prevent osteoporosis should be directed towards all postmenopausal women. These strategies also have to start soon after menopause since preservation of bone architecture is important for bone strength. Adlapted nutrition and physical activity may inhibit or even prevent age-related bone loss, as measured by bone mineral density (BMD) of the lumbar spine and hip.

A number of minerals and vitamins are of special interest, as reviewed in detail in Chapter 2. Calcium and vitamin $D$ have shown beneficial effects on BMD and fracture rate, especially at older age and when normal dietary intakes are low. Magnesium may be involved in bone preservation, increased bone strength, and possibly bone formation. Fluorine and probably also strontium stimulate bone formation. Vitamin $K$ is necessary for the post-translational carboxylation of glutamic acid residues of the protein osteocalcin. Carboxylated osteocalcin binds strongly to bone mineral and is probably involved in proper bone mineralization. Vitamin $\mathrm{C}$ is necessary for the synthesis of hydroxyproline and hydroxylysine (both components of collagen), and stimulates osteoblasts to produce osteocalcin, alkaline phosphatase, and type I collagen matrix.. Positive effects of these minerals and vitamins may already be expected in amounts about two times higher as currently recommended or consumed. For calcium supplementation, sources of natural origin, such as chicken eggshell powder (ES), are of interest because they contain more components than calcium only. This thesis deals with the composition of ES, the apparent digestibility of its calcium, and the effects of an ES enriched supplement on BMD of the lumbar spine and hip of postmenopausal women. Analyses of ES (Chapter 3) revealed that especially calcium and strontium are present in relevant amounts, $401 \pm 7 \mathrm{mg} / \mathrm{g}$ and $371 \pm 161 \mu \mathrm{g} / \mathrm{g}$ respectively, compared with recommended or consumed amounts. Other elements in ES, or hormones related to bone metabolism, are not expected to be of importance because of the small amounts detected. Of particular interest was the finding of only low levels of potentially toxic lead, mercury, aluminum and cadmium.

Since ES is primarily a calcium source, 
apparent digestibility of calcium from ES was studied in piglets (Chapter 4). ES was given in combination with casein from cow's milk or soya protein isolate. Purified calcium carbonate, known for its highly bloavailable calcium, was used as reference calcium source. Casein supplies caseinophosphopeptides which may stimulate calcium absorption. From soya protein an inhibitory activity on calcium absorption is reported. However, because of the presence of isoflavones, calcium retention in bone may be stimulated. The piglet studies show that calcium availability from $E S$ is as good as from purified calcium carbonate when combined with casein, and better when combined with soya protein isolate.

With this information, ES enriched dairybased supplements were studied in human. A former and uncontrolled study in osteoporotic patients showed an increased BMD of the lumbar spine and hip after 4 months of dailly supplementation with $6 \mathrm{~g}$ of ES. These patients also reported a strong reduction in pain. With regard to the upper tolerable dailly intake of $2,500 \mathrm{mg}$ of calcium, however, our supplements contained 'only' $3 \mathrm{~g}$ af ES. Furthermore the supplements were enriched with other minerals and vitamins including magnesilum, vitamin $D_{3}$ and vitamin $K_{1}$. A pilot study (Chapter 5$)$, in subjects $(n=10)$ with osteoporosis or osteopenia, showed positive effects of the ES supplement on BMD. After 4-8 months, BMDs of the lumbar spine (anteroposterior), total proximal femur, and trochanter were increased with $4.1 \%, 1.9 \%$, and $1.8 \%$, respectively. Also an important reduction in pain was reported although the questionnaire was not validated. Compared with 10 apparently healthy postmenopausal women, the intervention group showed significant improvements in BMD of the lumbar spine, femoral neck, and total proximal femur. Voluntarily, 6 women used the product for another 16 months, without any check on intake of the supplement, and at onily half the dosage. After this period, BMD of the measured sites was still increased but not significantly different from baseline. This study indicates that the ES enriched supplement may improve BMD of subjects with a low baseline BMD in the short term and may prevent bone demineralization for a longer period. Next, we studied the effects of an ES. enriched supplement on BMD of apparently healthy postmenopausal women with normal (Chapter 6) and low BMD (Chapter 7 ) of the lumbar spine, during a period of 12 months. Apart from BMD we also studied changes in parameters of collagen metabolism and bone turnover [amino-terminal propeptide extension of type I collagen (P1NP), bone specific alkaline phosphatase (b-ALP), intact-parathyroid hormone (intact-PTH), deoxypyridinoline (D-Pyr), and urinary calcium excretion ( $\mathrm{u}-\mathrm{Ca} / \mathrm{Cr})$ )], of vitamin-D status $[25(\mathrm{OH}) \mathrm{D}]$, and of vitamin $\mathrm{K}$-status (carboxylated osteocalcin). The mean estimated habitual, daily calcium intakes were 1,295 (normal BMD) and 1,190 $\mathrm{mg}$ (low BMD) which are higher than currently recommended in the Netherlands (900 $\mathrm{mg}$ ) but lower than the suggested optimal amount $(1,500 \mathrm{mg})$ for postmenopausal women.

In women with normal BMD of the lumbar spine, the ES group $(n=24)$ tended to increase BMD at all measured sites, except for the trochanter. The increase was significant for the femoral neck $(1.8 \%)$ and Ward's triangle $(3.4 \%)$. Women $(n=22)$ taking a supplement containing calcium carbonate instead of ES did not show significant improvements in BMD. In the placebo group ( $n=27$ ), BMD of the lumbar spine and trochanter increased slightly but not to a significant extent, whereas the other measured sites tended to decrease. In women with low BMD of the lumbar spine, the ES group $(n=22)$ tended to increase BMD at all measured sites which 
was significant for the trochanter $(1.6 \%)$ and Ward's triangle $(3.7 \%)$. The reference group ( $n=23$ ), taking $1,000 \mathrm{mg}$ calcium and $400 \mathrm{lU}$ vitamin $\mathrm{D}_{3}$ per day did not show a significant change in BMD at any site, but they tended to increase BMD of the lumbar spine, total proximal femur and Ward's triangle. In both studies there were no significant differences between the ES and reference groups. Only the increase in BMD of femoral neck in ES supplemented women with normal BMD was significantly different from the slight decrease in BMD of women in the placebo group.

Of the biochemical parameters studied, P1NP, D-Pyr, PTH, 25(OH)D and \%carbOC strongly responded to intervention. In all calcium and vitamin $D_{3}$ supplemented groups, levels of P1NP and PTH decreased within the study period of 12 months. Urinary excretion of D-Pyr was significantly decreased in the ES group with normal $B M D$, in the ES group with low $B M D$, and in the reference group with low $B M D$, after 12, 6, and 12 months respectively. No change in D-Pyr concentrations was found in the placebo group and calcium carbonate group of women with normal BMD. Decreases in P1NP, D-Pyr and PTH indicate a decreased bone turnover. Effects of vitamin $D_{3}$ supplementation were reflected in increased serum levels of 25(OH)D. However, a decline in 25(OH)D concentrations during the winter months was not prevented in women with low BMD. Vitamin $\mathrm{K}_{1}$ supplementation probably increased \%carbOC levels. A stimulatory effect of supplemented calcium and/or vitamin $D_{3}$ on carboxylation of osteocalcin, however, cannot be excluded. The $\mathrm{u}-\mathrm{Ca} / \mathrm{Cr}$ ratio increased significantly only in women with low BMD taking the reference product. This suggests a higher absorption or a lower retention of calcium from the reference product.

The above shows that ES contains a high percentage of well absorbable calcium; relevant amounts of strontium, and llow levels of heavy metals. In human studies it was found to be a good alternative for the traditional purified calcium carbonate and for the combination of calcium carbonate and calcium lacto-gluconate. The ES enriched supplements increased BMD of the hip, and possibly also of the spine, in healthy postmenopausal women with a baseline calcium intake of about 1,200 $\mathrm{mg}$. Women taking reference products did not show significant changes in $\mathrm{BMD}$, which implies that ES might have an additional benefit compared with the other calcium sources. The underlying mechanism for effects on BMD might be a decreased bone turnover as indicated by decreases in serum PINP, serum PTH, and urinary DPyr in women supplemented with calcium and vitamin $\mathrm{D}_{3}$. The current USA recommendations for the vitamins $D$ and $K$ do not seem to be adequate for Dutch postmenopausal women. Additional intakes of $>400$ IU per day might be necessary since daily supplementation with 400 IU vitamin $\mathrm{D}_{3}$ could not prevent a decline in serum 25(OH)D during the winter months in women with a low BMD. Based on the carboxylation of osteocalcin, a daily consumption of $330 \mu \mathrm{g}$ vitamin $\mathrm{K}$, may be proposed for postmenopausal women. Taken together, this thesis shows that nutritional intervention, with calcium, magnesium, vitamin $\mathrm{D}_{3}$ and vitamin $\mathrm{K}_{4}$, can be successful in the prevention of age related bone loss. The use of ES, as source of calcium and possibly other components, has probably contributed much to this success. 



\section{Samenvatting}

Botombouw (bot remodellering) is een samenspel van botafbraak en botaanmaak aan het oppervlak van het bot. Door dit proces kan het skelet reageren op veranderende omstandigheden (mechanische belasting, beschadigingen, hormonen). Op middelbare leeftijd is de botombouw normaliter in evenwicht en volgt botaanmaak op botafbraak. Tijdens de groei van het skelet is dit proces niet gekoppeld en overheerst botaanmaak (bot modellering). Bij ouderen en in het bijzonder bij vrouwen na de menopauze, overheerst de botafbraak. Door een sterk verminderde oestrogeenproductie wordt tijdens de menopauze en de eerste jaren daarna de botafbraak gestimuleerd, neemt de botombouwsnelheid toe en kan een aanzienlijk verlies van bot optreden. Bij ouderen kan botafbraak worden gestimuleerd door een stijgende serum spiegel van het parathyroid hormoon (PTH). In de strijd tegen osteoporose zijn dan ook de volgende punten van belang: een maximale botdichtheid tijdens puberteit en adolescentie (maximale modellering), behoud van botmassa op middelbare leeftijd (geballanceerde bot remodellering) en het remmen van botafbraak op oudere leeftijd (verlaagde botombouwsnelheid en het beheersen van de PTH spiegel).

In de Westerse wereld komt osteoporose voor bij $15-25 \%$ van de postmenopauzale vrouwen (55-70 jaar).

Alleen vrouwen met een vermeend hoger risico, b.v. osteoporotische fracturen in de familie, worden onderzocht en eventueel behandeld om het risico op een fractuur te verminderen. Veel vrouwen zijn dan ook niet op de hoogte van hun hachelijke botstatus. Om wille van deze vrouwen, zullen maatregelen ter voorkoming van osteoporose zich moeten richten op alle postmenopauzale vrouwen. Verder zullen deze maatregelen spoedig na de menopauze moeten worden doorgevoerd voor het behoud van bot-achitectuunt hetgeen belangrijk is woor de botsterkte. Gemeten aan de botmineraaldichtheid (BMD) van de lumbale wervelkolom en heup, kunnen aangepaste voeding en lichaamsbeweging leeftijdsgerelateerd botverlies verminderen of zelfs voarkomen. Daarbij zijn een aantal mineralen en vitamines van bijzonder belang (hoofdstuk 2). Calcium en vitamine $D$ verbeteren de BMD en verlagen het risico op fracturen. Dit is met name het geval bij oudere mensen en bij] een lage inneming van beide voedingsstoffen uit de normale voeding. Magnesium is mogelijk betrokken bij het behoud van bot en botaanmaak, en is daarmee van belang voor de botsterkte. Fluor en mogelijk ook strontium stimuleren botaanmaak. Vitamine $\mathrm{K}$ is essentieel voor de carboxylering van glutaminezuurresiduen van het eiwit osteocalcine. Gecarboxyleerd osteocalcine bindt sterk aan het botmineraal en is waarschijnilik betrokken bij een juiste mineralisatie van bot. Vitamine $C$ is nodig voor de synthese van hydroxyproline on hydroxylysine (beide een onderdeel van collageen) en stimuleert osteoblasten tot de produktie van osteocalcine, alkalisch fosfatase en matrix type I collageen. De positieve effecten van deze mineralen en vitamines kunnen al optreden bij hoeveelheden die ongeveer twee keer hoger zijn dan de huidige aanbeveling of consumptie. Natuurlijke calciumbronnen, zoàls kippeneierschalenmeel (ES) zijn interessant omdat ze meer dan alleen calcium verstrekken. Dit proefschrift behandelt de samenstelling van ES, de ogenschijnlijke verteerbaarheid van EScalcium, en de effecten van een met $E S$ 
verrigt supplement op de BMD van umbale wervelkolom en heup van postmenopauzale vrouwen.

Wit onderzoek naar de samenstelling van ES (hoofdstuk 3) blijkt dat met name calcium ( $401 \pm 7 \mathrm{mg} / \mathrm{g}$ ) en strontium $(371 \pm 161 \mu \mathrm{g} / \mathrm{g})$ in relevante hoevee lheden aanwezig zijn. Andere voor bot belangrijke mineralen en hormonen komen slechts in uiterst kleine en wellicht onbelangrike hoeveelheden voor. Dit geldt ook voor het potentieel toxische lood, $k w i k$, aluminium en cadmium, hetgeen van groot belang is. Omdat ES primair als calciumbron zou worden toegepast, is de ogenschijnlijke verteerbaarheid van $E S$ calcium bestudeerd in biggen (hoofdstuk 4). ES werd gegeven in combinatie met koemelk caseinne of soja-eiwit isolaat. Gezuiverd calciumcarbonaat, bekend vanwege de hoge beschikbaarheid van het calcium, diende als referentie calciumbron.

Caseinofosfopeptiden, welke vrijkomen bij de vertering van caseïne, stimuleren mogelijk de calcium absorptie. Hoewel soja-eilwit de calcium absorptie kan remmen, kunnen de aanwezige isoflavonen de calcium retentie in het bot stimuleren. De biggenproeven geven aan dat de beschikbaarheid van calcium uit ES gelijk is aan die van calciumcarbonaat indien caseine als eiwitbron wordt gebruikt. In combinatie met soja-eiwit isolaat is de calcium beschikbaarheid uit $E S$ echter beter.

Op grond van deze informatie zijn ES verrijkte en op zuivel gebaseerde supplementen bestudeerd in humaan onderzoek. In eerder uitgevoerd, niet gecontroleerd, onderzoek met osteoporotische patienten verbeterde de BMD van de lumbale wervelkolom en heup. Tevens verminderde de pijn aanzienlijk bij deze patiënten. Zil consumeerden dagelijkse 6 gram ES gedurende 4 maanden. Om echter de dagelijks aanvaardbare inneming van $2500 \mathrm{mg}$ calcium niet te overschrijden, verstrekten de supplementen in onze onderzoeken "slechts' 3 gram ES per dag. Verder waren de supplementen verrijkt met andere mineralen en vitamines waaronder magnesium, vitamine $D_{3}$ en witamine $K_{\text {. }}$. In een vooronderzoek (hoofdstuk 5) met 10 personen met osteoporose of osteopenie had het $E S$ supplement een positief effect op de BMD. Gedurende 4-8 maanden stegen de BMD's van de lumbale wervelkolom (in buik-rug positie gemeten), totale proximale femur en trochanter met respectievelijk $4,1 \%, 1,9 \%$ en $1,8 \%$. Tevens werd, middels een niet-gevalideerde pijnscore lijst, een belangrijke vermindering van pijn waargenomen. In vergelijking met 10 ogenschijnlijk gezonde postmenopauzale vrouwen, trad in de interventie-group een duidelijke verbetering op in de BMD van de lumbale wervelkolom, de femurhals en de totale proximale femur. Uit eigen beweging zijn 6 vrouwen het supplement blijven gebruiken gedurende nog eens 16 maanden, zij het in een halve dosering en zonder controle op het gebruik. Na deze periode waren de BMD's weliswaar nog hoger maar niet significant verschillend van de waarden bij aanvang van het onderzoek. Dit vooronderzoek duidt dan ook op een mogelijke verbetering van BMD in personen met een lage botmassa op korte termijn en op een mogelijk voorkomen van botontkalking op langere termijn bij gebruik van het ES supplement. Vervolgens is een ES verrijkt supplement gedurende 1 jaar verstrekt aan ogenschilnlijk gezonde postmenopauzale vrouwen met een normale (hoofdstuk 6) en lage BMD (hoofdstuk 7) van de lumbale wervelkoiom. Naast BMD is ook gekeken naar veranderingen in parameters van collageenmetabolisme en botombouw [aminoterminale propeptide-extentie van type I collageen (PINP), bot specifiek alkalisch fosfatase (b-ALP), intact parathyroid hormoon (intact-PTH), deoxypyridinoline (D-Pyr), en calcium uitscheilding in de urine (u-Ca/Cr)], 
vitamine D-status $[25(\mathrm{OH}) \mathrm{D}]$ en vitamine K-status (gecarboxyleerd osteocalcine). De geschatte, gemiddelde calcium inneming uit de normale voeding was 1295 en 1190 $\mathrm{mg} / \mathrm{dag}$ in de groep vrouwen met een respectievelijk normale en lage BMD. Deze innemingen zijn hoger dan de huidige Nederlandse aanbeveling (900 mg) maar lager dan de veronderstelde optimale hoeveelheid calcium voor postmenopauzale vrouwen (1500 $\mathrm{mg}$ ).

In de ES-groep $(n=24)$ met een normale $B M D$ van de wervelkolom, nam de $B M D$ van de femurhals en Ward's triangle significant toe met respectievelijk $1,8 \%$ en $3,4 \%$. De andere BMD's stegen niet significant met uitzondering van de trochanter. In de groep vrouwen met het gezuiverde calcium-carbonaat $(n=22)$, in plaats van ES, werd eveneens een lichte stijging waargenomen in BMD's maar deze waren niet significant. In de placebo groep ( $n=27$ ) nam de BMD van de lumbale wervelkolom en trochanter in geringe mate (niet significant) toe terwijl de andere meetpunten een niet significante daling lieten zijen.

In vrouwen met een lage BMD van de wervelkolom, nam in de ES-groep $(n=22)$ de BMD van de trochanter $(1,6 \%)$ en Ward's triangle $(3,7 \%)$ silgnificant toe. De BMD's van de wervelkolom, femurhals, intertrochanter en de totale proximale femur lieten wel een verbetering zien, maar deze was niet significant. In de referentie groep $(n=23)$, met $1000 \mathrm{mg}$ calcium en 400 IE vitamine $D_{3}$ per dag, trad geen significante verbetering op van de BMD's maar was wel een neiging naar verbeterde BMD's van lumbale wervel-kolom, totale proximale femur en Ward's triangle.

In beide onderzoeken bestonden geen significante verschillen tussen de ES en referentie groepen. Wel was de toename in BMD van de femurhals in ES glesuppleerde vrouwen met een normale BMD significant verschillend van de lichte daling in de placebo groep.
Van de biochemische parameters reageerden PINP, D-Pyr, 25(OH)D en $\%$ carbOC sterk op de interventie: In alle calcium en vitamine D gesuppleerde groepen daalden PINP en PTH binnen de duur van het onderzoek (12 maanden). De uitscheiding van D-Pyr in de urine was significant gedaald in de ES groep met een normale en lage $\mathrm{BMD}$, en in de referentiegroep met een lage $B M D$, na respectievelijk 12, 6 en 12 maanden. In de placebo en calcium-carbonaat-groep met een normale BMD veranderde de uitscheiding van $D-P y r$ niet. Verlaagde gehaltes van P1NP, D-Pyr en PTH duiden op een verlaging van de botombouwsnelheid. Vitamine $D_{3}$ suppletie werd weersplegeld in hogere plasma $25(\mathrm{OH}) \mathrm{D}$ concentraties. Echter, in de vrouwen met een lage BMD kon een daling van $25(\mathrm{OH}) \mathrm{D}$ gedurende de wintermaanden niet worden voorkomen. Vitamine $K_{\mathbb{1}}$ suppletie resulteerde in hogere $\%$ carbOC spiegels. Hierbij kan een stimulerend effect van calcium en vitamine $\mathrm{D}_{3}$ niet worden uitgesloten. De $\mathrm{u}-\mathrm{Ca} / \mathrm{Cr}$ ratio was alleen significant verhoogd in de referentie groep met een lage BMD. Dit is mogelijk een gevolg van een verhoogde calcium absorptie of een verlaagde calcium retentie.

Uit het bovenstaande blijkt dat ES een hoog gehalte aan goed beschikbaar calcium beval, een relevante hoeveellheid strontium en een laag gehalte aan zware metalen. Bij mensen is gebleken dat ES niet alleen een goed alternatief is voor het veel gebruikte gezuiverde calciumcarbonaat, maar ook voor de combinatie van calciumcarbonaat en calciumlactogluconaat. In gezonde postmenopauzale vrouwen, met een calcium inneming uit de normale voeding van ongeveer $1200 \mathrm{mg}$ per dag, steeg de BMD van de heup en mogelijk ook van de lumbale wervels na gebruik van het ES verrijkte supplement. Omdat significante veranderingen in BMD niet werden gezien met de referentieproducten, kan dit betekenen dat ES een 
meerwaarde heeft ten opzichte van de andere calciumbronnen. Een verlaagde botombouwsnelheid in vrouwen gesuppleerd met calcium en vitamine $D_{3}$, ligt mogelijk ten grondslag aan behoud of verbetering van de $B M D$. De huidige Amerikaanse aanbevelingen voor vitamine $D$ en K lijken niet toereikend voor Nederlandse postmenopauzale vrouwen. Om een daling van serum $25(\mathrm{OH}) \mathrm{D}$ gedurende de wintermaanden te voorkomen is een dagelijkse inneming van meer dan 400 IE vitamine $D$ wenselijk.

Op basis van de carboxylering van osteocalcine zou voor vitamine $K_{1}$ een postmenopauzale aanbeveling kunnen geiden van $330 \mu g$ per dag. Alles bij elkaar geeft dit proefschrift aan dat voedingsinterventie met calcium, magnesium, vitamine $D_{3}$ en vitamine $K_{t}$, succesvol kan zijn in het voorkomen van leeftijdsgerelateerd botverlies. Het gebruik van kippeneierschalenmeel, als bron van calcium en mogelijk andere componenten, heeft waarschijnlijk in belangrijke mate aan dit succes bijgedragen. 


\section{Dankwoord}

Een promotieonderzoek doe je gelukkig niet alleen. Vele handen maakten het werk lichter. ledereen die hieraan heeft meegewerkt wil ik dan ook heel hartelijk bedanken. In chronologische volgorde volgen hieronder een aantal details. Het verhaal begint in 1989. Wegens rug-en knieklachten kreeg een collega eierschalenmeel van I. Pakan, chirurg in het Medisch Centrum Leeuwarden. Gelet op de eenvoud van het preparaat en het effect van de behandeling leek dit een el van Columbus. Beste Igor, jou will ik dan ook als eerste bedanken voor het aanleveren van het idee. In de vele gesprekken die we samen hebben gevoerd heb je mij, in je eigen directe bewoordingen, deelgenoot gemaakt van je kennis op dit gebied. Naast een gewelding gleneesheer ben je ook een fantastische vriend en wetenschappelijk collega.

Het promotieonderzoek heb ik uiteindelijk te danken aan de overredingskracht van mijn zeer gewaardeerde vriend en collega Jan de Vries. Tijdens onze gezellige kantooruren en reizen door Nederland bleef jij volhouden dat de uitgezette onderzoekslijn voor een 'functional food' met eierschalenmeel voldeed aan de eisen van promotieonderzoek. Gedurende de onderzoeksperiode was je een plezierig klankbord en een kritisch lezer van de manuscripten. Zonder aarzeling kreeg het promotieonderzoek ook die goedkeuring van het toenmalige Friesland Dairy Foods, bij monde van de heren $G$. Stolk en C. Glas. De huidige vertegenwoordigers van Friesland Coberco Dairy Foods wil ik bedanken voor het geduld en vertrouwen. Toen de financiën waren geregeld zijn Jan en ik op zoek gegaan naar een promotor. Het lot voerde ons naar Maastricht, naar prof.dr W.H.M. Saris. Na amper een uur uitleg volgde een ongeremd 'ja". Dit karakteriseert ook de ongedwongen samenwerking in de daarop volgende jaren. Wim, ik heb die samenwerking zeer gewaardeerd en wil je daar dan ook heel hartelijk voor bedanken. Omdat MaastrichtLeeuwarden een dagtocht is bestond behoefte aan een steunpunt in het noorden. Dr. F.A.J Muskiet was graag bereid als co-promotor op te treden. Frits. niet alleen heb je actiefi deelgenomen aan het begeleiden van onderzoek, je was ook een grote steun bij het schrijven van de artikelen. Ik heb me verbaasd over je werklust als op zondagochtend de telefoon rinkelde en een wetenschappelijke verhandeling volgde. Toen de sleutelposities waren ingevuld konden de onderzoeken van start gaan. Allereerst wil ik dan graag de vrijwilligers bedanken voor hun enthousiaste deelname. Zonder hen was dit boekje niet tot stand gekomen. Daarbij wil ik ook graag wijzen op de plezierige medewerking met de Friese huisartsen J.H.A. Dambrink, W.J. van thet Veer, N.M. Postema, E.P.P. Wijthof, P. de Boer en M.S. Reitsma en de Groningse huisartsen P Sikkens, A.G. Swart en S. Wiarda.

De prikmomenten waren niet alleen wetenschappelijk nuttig maar ook uitermate gezellig. Dit laatste was vooral te danken aan de goede steer waarin één en ander zich afspeelde, een uitvloeisel van de uitstekende contacten die bestonden tussen deelnemers en de onderzoeks assistenten Alice Rodenburg (Groninger onderzoek) en Haydée Schaafsma (Friese onderzoek). Alice, door je persoonlijke contact en een altijd vriendelijk woord, je uitstekende prikkwaliteiten, het invoeren en verzamelen van gegevens is het onderzoek tot een succes geworden.

Monstermateriaal zonder een hoogstaande analyse levert weinig informatie. 
De medewerking van dr. E. van der Veer (AZG), G.J.H. Hotstede (AZG), dr.H. Storm (MCL) en H. Bosma (MCL) is dan ook zeer op prijs gesteld. Eveline, jij hebt altijd zeer kritisch gekeken naiar de uitkomsten van analyses, kwaliteit van de methodes, en uiteindelijk ook naar de interpretatie daarvan in de artikelen. Je bijdrage is dan ook van grote waarde geweest. Gert, zonder jouw analytische kwaliteiten en kritische blik op de gebruikte methodes waren we niet zover gekomen. Huib, jouw wil ik graag bedanken voor het goede werk dat door je afdeling is uitgevoerd, de plezierige samenwerking en je bijdrage aan de verwerking van de informatie. Hilly, iij hebt een belangrijke rol gespeeld in het beheer van monstermateriaal en het inplannen van de analyses. Voor de botdichtheidsmetingen stonden de nucleaire afdelingen van het AZG (dr.D.A. Piers) en MCL (drs. H.G. Riedstra) garant. Ineke, je uitleg over de "DEXA-plaatjes" was zeer waardevol en ik heb daar veel van geleerd. Dr. J.J. van Doormaal was niet alleen betrokken bij de beoordeling van DEXA uitkomsten in het Groninger onderzoek maar hield daarnaast als medicus de algehele gezondheid van de deelnemers in dle gaten. Jaap, ik heb onze samerwerking alis wijzonder plezterig ervaren. Ik heb me alleen verbaasd over je behoefte aan ean vette snack na afloop wan een avondje bloedprikken in Eelde. Uiteindelijk moest een statistisch oordeel worden geveld over de onderzoeksresultaten. De hulp en adviezen van Jan Burema (Universiteit Wageningen) heb ik zeer gewaardeerd. Jan, bedankt!

De chemisch analyses van eierschalenmeel zijn woor een deel uitgevoerd door het facilitair chemisch laboratorium, onderdeel van Research \& Development Leeuwarden. Collega's hartelijk dank voor jullie inspanningen het was als altijd plezierig samenwerken. Verder is een kwalitatief hoogstaande bijdrage geleverd door TNO. Gerard van Beelen wil ik graag bedanken voor de vakkundige wijze waarop de biggenproeven zijn uitgevoerd.

Uiteindelijk stond het hele verhaal op papier. De leescommissie (prof. $d r$.

G. Hornstra, prof. dr. G.J. Dinant, prof. dr. J.G.A.J. Hautvast, dr. C.J. Netelenbos en dr. C. Vermeer) ben ik zeer erkentelijk woor het wotte leeswerk en de plezierige gesprekken die we daarna hebben gevoerd. Na goedkeuring van het manuscript kon worden gewerkt aan de vormgeving van het uiteindelijke proefschrift. De nodige trucs zijn uitgehaald voor het geheel camera-klaar was. Anneke Boringa-Heins heeft hier een sleutelrol in gespeeld. Anneke, je hebt fantastisch werk geleverd!

Verder zijn er nog drie mensen van het eerste uur die ik graag will bedanken. Gerrit Stolk voor de gedrevenheid waarmee hij het project in gang heeft gezet. Ben Heirs (Heirs Associates International S.A., Zwitserland), als extern adviseur betrokken bij het project, voor zijn voortdurend enthousiasme en het vertrouwen in het te ontwikkelen idee. Mede door zijn marketing ideeën is steeds gekeken naar onderzoek met een praktische betekenis. Marianne Stevelink voor het coördinerende werk binnen de projectgroep.

Terisionte is ef dan de "ierrimite. "ik vind net fijn dat mijn ouders dit meemaken, zij hebben mij altijd gestimuleerd in een voortdurende verbreding van mijn kennis. Ook de ondersteuning van mijn zuster, schoon-zusters, zwagers, en uiteraard mijn schoonouders heb ik zeer op prijs gesteld. Voor mijn zuster Rieteke geldt een bijzonder woord van dank omdat zij verantwoordelijk is voor de uiteindelijke vormgeving van de omslag van dit proefschrift. Het is jammer dat mijn broer Hildo niet meer bij deze afronding aanwezig kan zijn. "Last" maar absoluut niet 'least' het eigen gezin, Haydée, mijn lieve echtgenote, nooit heb je één wanklank laten horen over alle vrije tijd die ik heb opgeofferd voor dit onderzoek. De rek 
binnen een goed huwelijk is groot en ik waardeer dat zeer. De komende jaren kom iij op de eerste plaats. Onze kinderen Dedmer, Amber en Wandert zijn intussen zeer succesvol bezig met hun eigen opleidingen en lijken zich niet te storen aan de perikelen van hun vader. Zij zien mijn laptop als een buitenechtelijke relatie hetgeen tot verwarring kan leiden in zinsconstructies als "mijn vader zit met zijn buitenechtelijke relatie op schoot voor de $T V$ en mijn moeder zet koffie". 



\section{Curriculum vitae}

Anne Schaafsma werd geboren op 12 mei 1956 als zoon van een warme bakker in het door Leeuwarden opgeslokte dorp Huizum. Hij behoorde tot de laatste lichting die na de MAVO mocht doorstromen naar hoger beroepsonderwijs. In oktober 1976 behaalde hij het diploma van de Bijzondere Hogere Landbouwschool in Friesland met biochemie en microbiologie als specialisaties. Op dat moment werkte hij al bij de Rijksuniversiteit Groningen als laborant Medische Microbiologie.

Gedurende 1,5 jaar leerde hij daar het kweken en determineren van pathogene bacteriën en strikt anaeroben, bestudeerde hiij de effecten van knoflook- en uiensap op de darmflora van muizen en beheerde en fokte kiemvrije muizen. In de avonduren volgde hij met succes een cursus microfotografie van de Stichting Bedrijfsopleidingen Rijksuniversiteit Groningen. Op 1 februari trad hij als bacteriologisch analist in dienst van de toenmalige Coöperatieve Condensfabriek 'FRIESLAND'. Permanent uitgeleend aan de researchgroep van de Veevoederfabriek 'Sloten' heeft hij zich tot 31 mei 1988 kunnen verdiepen in de bacteriologie van de kalvervoormaag, zowel in vivo als middels fermentatietechnieken. Ter ondersteuning volgde hij aan de Rijksuniversiteit Groningen de theorie van Microbiële Oecologie en Microbiële Fysiologie. Beide vakken werden in 198384 succesvol met een tentamen afgerond. De Teleac-cursus Statistiek werd in 1987 met goed gevolg afgesloten. In die tijd vond ook een verdere verdieping plaats van de techniek om strikt anaerobe bacteriën te kweken en werd een bacteriologisch controlelaboratorium opgezet bij het kalvermelk produktiebedrijf in Sloten (Frl). In 1988 kreeg hij de functie van voedingskundige aangeboden op de afdeling Research Services van CC FRIESLAND. Tot 1994 heeft hij zich voornamelijk bezig gehouden met het formuleren en onderbouwen van prematuren- en klinische enterale voeding. Vanwege het internationale karakter van het bedrijf nam Anne in de periode 198890 deel aan twee cursussen Engels van de Leeuwarden Business School en behaalde in 1990 een certificaat op niveau 4. In 1994 werd hij geplaatst in de werkgroep Selfcare Nutrition van Friesland Frico Domo (het latere FRIESLAND Dairy Foods). Deze nieuwe werkgroep had als taak het ontwikkelen van op zuivel gebaseerde voedingsmiddelen in combinatie met unieke grondstoffen waaraan gezondheidsclaims konden worden verbonden. Het in dit proefschrift beschreven kippeneierschalenmeel is één van die unieke grondstoffen. Het onderzoek, met prot.dr. W.H.M. Saris van de vakgroep Humane Voeding van de Universiteit Maastricht als promotor, duurde van mei 1994 tot en met december 1999. Het bestuderen van de effecten van op zuivel gebaseerde supplementen verrijkt met eierschalenmeel op de botmineraaldichtheid van postmenopauzale vrouwen vond plaats in samenwerking met het Academisch Ziekenhuis Groningen en het Medisch Centrum Leeuwarden. De 20ste eeuw werd afgesloten met deelname aan de cursus Algemene Toxicologie van de Stichting PAON. Vanaf 1 februari houdt Anne zich weer bezig met kindervoeding in afwachting van de invulling van Corporate Research van Friesland Coberco Dairy Foods. Oh ja, nog één wapenfeit vergeten, in 1991 is Anne geslaagd voor zijn zwarte band examen Judo. 


\section{Publications}

Schaafsma A, Pakan I. Short-term effects of a chicken egg shell powder enriched deiry-based products on bone mineral density in persons with osteoporosis or osteopenia. Bratisl Lek Listy 1999:100:651-656

Schaafsma A, Beelen GM. Eggshell powder, a comparable or better source of calcium than purified calcium carbonate: piglet studies. I Sci Food Agric 1999;79:1596-1600.

Schaafsma A, Pakan I. Effect of a chicken egg shell powder enriched dairy product on bone mineral density in persons with osteoporosis or osteopenia. Letter to the Editor. Nutrition 1999;15(2): 157 .

Woltil $H_{\text {v }}$ Van Beusekom $C M$, Okken-Beukens $M$, Schaatsma A, Muskiet FAJ, Okken A.

Development of low-birthweight infants at 19 months of age correlates with early intake and status of long-chain poly-unsaturated fatty acid. Prostaglandins Leukot Essent Fatty Acids 1999;61:235-241.

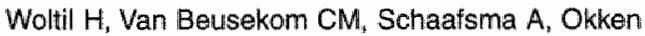
A, Muskiet FAJ. Does supplementation of formula with evening primrose and fish oils augment long chain polyunsaturated fatty acid status of low birthweight infants to that of breast-fed counterparts? Prostaglandins Leukot Essent Fatty Acids 1999;60:199-208.

Woltil HA, Van Beusekom CM, Schaatsma: $A$, Muskiet FAJ, Okken A. Long-chain polyunsaturated fatty acid status and early growth of low birth weight infants. Eur J Pediatr $1998 ; 157: 146-152$

Beukelman CJ, De Vires PJF, Schaafsma A, Quarles van Ufford $H C$, Kuenen $J$, Kroes $B H$, Van der Warm $E$, Van den Berg A JJ, Van Dijk $\mathrm{H}$. Immunomodulating properties of propolis. Pharm Pharmacol Lett 1997;7:75-77.

Beijers RJW, Schaafsma A. Long chain polyunsaturated fatty acid content in Dutch preterm breast milk; differences in the concentrations of docosahexaenoic acid and arachidonic acid due to length of gestation. Early Hum Dev 1996:44:215-223.

Schaafsma A, Siemensma AD. Developments in nutrition for preterm intants. Voeding 1993;54:14-18 (Dutch).

Beijers AJW, Graal vd F, Schaafsma $A$, Siemensma $\mathrm{AD}$. Composition of premalure breast-milk during lactation: constant digestible protein content (as in full term milk). Early Hum Dev 1992;29:351-356.
Siemensma AD, Schaafsma A. Arginine, a conditionally essential amino acid. Voeding 1992;53:263-266 (Dutch)

Glas C, Schaatsma A. An in vivo model to study factors in milk which can reduce the Gramnegative flora in the porte d'entree (abomasum) of milk-fed calwes. Neth Milk Dairy J 1988:42:437-447.

\section{Abstracts}

Van der Veer $E$, Schaafsma $A_{1}$ Hofstede $G_{*}$ Rodenburg A, Muskiel FAJ, Van Doormaal JJ. Ability of biochemical markers of bone formation to reflect changes during one year supplementation of postmenopausal women with calcium and vitamins $K$ and $D$. Calcilf Tissue Int 1999;64:665.

Schaafsma A, Pakan I, Riedstra I, Storm H, Van der Veer E. Eggshell powder as a calcium source in postmenopausal women with excessive demineralization. Osteoporosis Int 1998;8:103.

Woltil HA, Van Beusekom CM. Schaatsma A, Muskiet FAl, Okken A. Docosahexaanzuur status correleert met hersengewioht bij 6 weken oude flesgevoede pasgeborenen met een laag geboortegewicht. Tijdschr Kindergeneeskd 1997;suppl 1:110. 